Revisão taxonômica de Galeocharax Fowler, 1910 (Teleostei: Ostariophysi: Characiformes)

Taxonomic revision of Galeocharax Fowler, 1910 (Teleostei: Ostariophysi: Characiformes) 


\section{Revisão taxonômica de Galeocharax Fowler, 1910 (Teleostei: Ostariophysi: Characiformes)}

\section{Taxonomic revision of Galeocharax Fowler, 1910 (Teleostei: Ostariophysi: Characiformes)}

Dissertação apresentada ao Instituto de Biociências da Universidade de São Paulo, para a obtenção de Título de Mestre em Ciências Biológicas, na Área de Zoologia.

Orientadora: Mônica de Toledo-Piza Ragazzo

São Paulo 
Giovannetti, Victor

Revisão taxonômica de Galeocharax

Fowler, 1910 (Teleostei: Ostariophisy:

Characiformes)

xvii +130 pp.

Dissertação (Mestrado) - Instituto de Biociências da Universidade de São Paulo. Departamento de Zoologia.

\section{Galeocharax 2. Revisão}

taxonômica. 3. Characinae Universidade de

São Paulo. Instituto de Biociências.

Departamento de Zoologia.

Comissão Julgadora:

$\operatorname{Prof}(\mathrm{a}) \cdot \operatorname{Dr}(\mathrm{a})$.

$\operatorname{Prof}(\mathrm{a}) . \operatorname{Dr}(\mathrm{a})$.

Prof(a). Dr.(a). Mônica de Toledo-Piza Ragazzo

Orientador(a) 
Dedicatória

Dedico este trabalho aos meus melhores amigos e maiores apoiadores, Marcio, Marlene, Larissa e Amanda. 
I believe in evidence. I believe in observation, measurement, and reasoning, confirmed by independent observers. I'll believe anything, no matter how wild and ridiculous, if there is evidence for it. The wilder and more ridiculous something is, however, the firmer and more solid the evidence will have to be. 


\section{Agradecimentos}

Sou grato à Professora Dra. Mônica de Toledo-Piza Ragazzo pela orientação, paciência e apoio desde meu ingresso no Laboratório de Ictiologia, sem os quais, sem dúvida nenhuma, não seria possível a realização do presente trabalho assim como meu desenvolvimento como ictiólogo.

Ao Dr. Oswaldo Oyakawa e Michel Donato Gianeti, do Museu de Zoologia pelo empréstimo de material e por me receberem e auxiliarem diversas vezes na seção de peixes.

Às seguintes pessoas por me receberem e proporcionarem o devido auxílio durante as visitas às suas instituições, assim como pelo empréstimo de material: ao Dr. Carlos Lucena, do Museu de Ciencias e Tecnologia da PUCRS; aos Dr. Vinicius Bertaco e Dr. Marco Azevedo da Fundação Zoobotânica do Rio grande do Sul; à Dra. Carolina Doria e Dr ${ }^{\mathrm{a}}$ Andrea Paixão da Universidade Federal de Rondônia; aos Dr. Marcelo Britto e Dr. Paulo Buckup do Museu Nacional; ao Dr. Paulo Lucinda e Everton Oliveira da Universidade Federal do Tocantins; Ao Dr. Hernan Ortega, Junior Chuctaya e Dario Fuster da Universidad Mayor de San Marcos; ao Dr. Homero Sanches do Instituto de Investigaciones de la Amazonía Peruana e à Dra. Carla Pavanelli e Fagner de Souza do Núcleo de Pesquisa em Limnologia Ictiologia e Aquicultura da UEM.

Ao Dr. Mark Sabaj e Kyle Luckenbill da Academy of Natural Science of Drexel University pelo envio de material e de fotografias e radiografias de material tipo.

Ao Dr. Jansen Zuanon e Dra. Lucia Rapp do Instituto Nacional de Pesquisas da Amazônia; à Dra. Sandra Raredon do Smithsonian Institution National Museum of Natural History, ao Dr. Otto Castillo do Museo de Ciencia Naturales de Guanare e à Dra $^{\mathrm{a}}$. Barabara Brown do American museum of Natural History pelo envio de material.

À Dra. Zora Gabsi do Muséum National d'Histoire Naturelle e à Dra. Anja Palandacic do Naturhistorisches Musem Wien pelo envio de fotografias e radiografias de material tipo.

Aos técnicos do Departamento de Zoologia Enio Mattos e Philip Lenktaitis pelo auxílio na produção das micrografias utilizadas neste trabalho.

Aos Professores Dra. Ana Carolina Fonseca Pinto e Dr. Stefano Hagen da Faculdade de Medicina Veterinária da USP além dos técnicos Hugo Idalgo e Reginaldo Silva pelo auxílio nas radigrafias dos exemplares utilizados neste estudo.

Aos meus amigos e colegas do Laboratório de Ictiologia Kleber Mathubara, Carmen Paradeda, André Casas, Andrea Paixão, George Mattox, Caio Isola, Rodrigo Nakagawa, João Pedro Fontenelle, Maíra Ragno, João Paulo Capretz, Thiago Loboda, 
Diego Vaz, Flávia Petean, Carolina Laurini, Renan Moreira, Karla Soares e Sarah Viana pelo agradável ambiente de trabalho e pelas discussões sempre pertinentes.

Aos colegas da Seção de Ictiologia do MZUSP Priscila Camelier, Marina Loeb, Henrique Varella, Ilana Fichberg, Túlio Teixeira, Manoela Marinho e Fernando Dagosta pelo ambiente agradável durante minhas visitas ao museu, auxílio e discussões durante a fase final deste estudo.

Aos professores Dr. Naércio Menezes e Dr. Alessio Datovo e ao Dr. Flávio Lima pelas discussões e críticas construtivas para a realização deste trabalho.

Agradeço à minha família, meu pai, Marcio Roberto Giovannetti, quem considero ser o responsável pelo meu interesse pela ictiologia. Minha mãe, Marlene Aparecida Giovannetti, minha namorada Larissa Andreoni Medeiros e minha irmã Amanda Giovannetti. Obrigado por todo o apoio, suporte e incentivo, não só durante a realização deste trabalho, também no decorrer de toda a minha formação.

À Coordenação de Aperfeiçoamento de Pessoal de Nível Superior, CAPES pela bolsa de mestrado concedida. 


\section{Sumário}

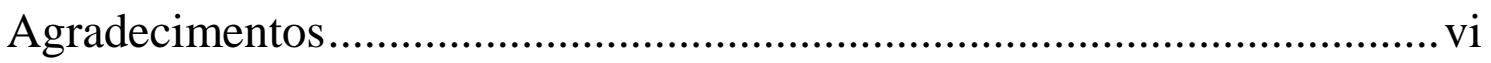

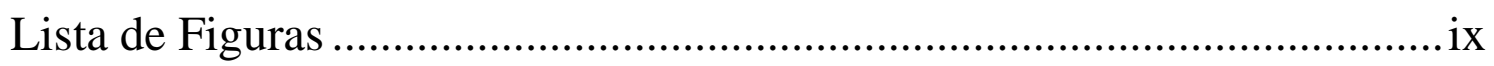

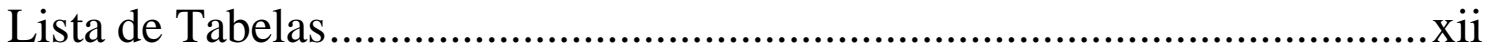

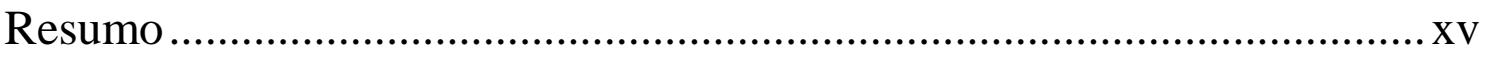

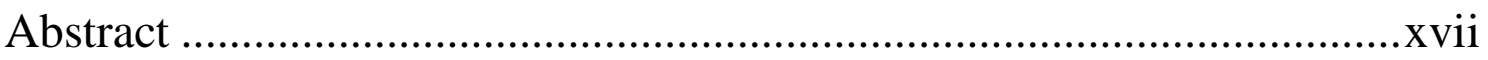

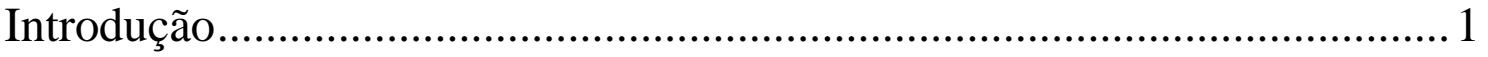

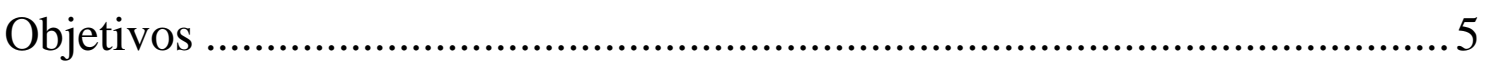

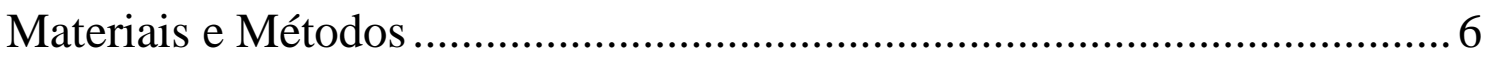

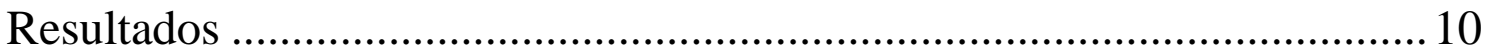

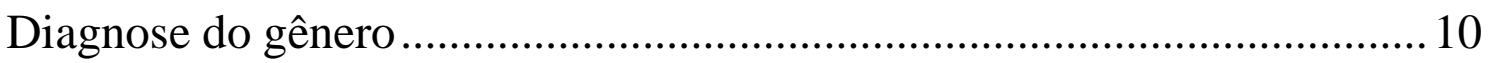

Chave de identificação para as espécies de Galeocharax............................. 10

Galeocharax humeralis (Valenciennes, 1834)........................................... 10

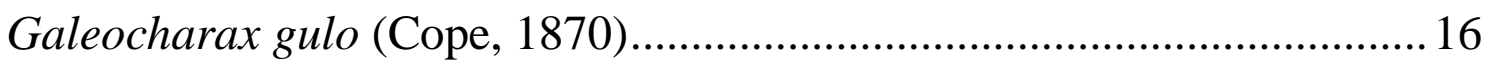

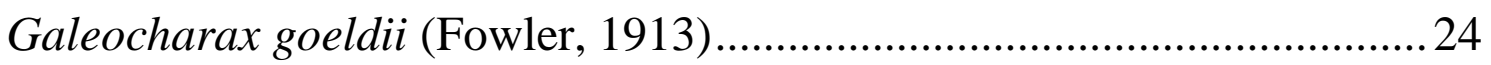

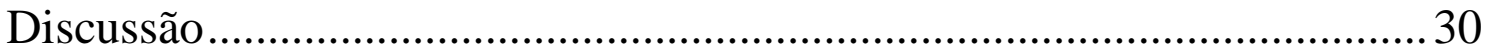

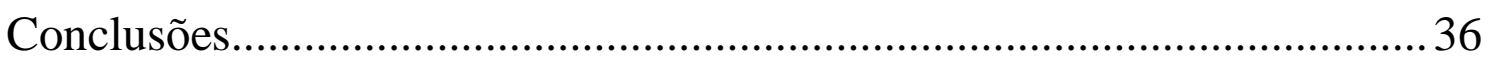

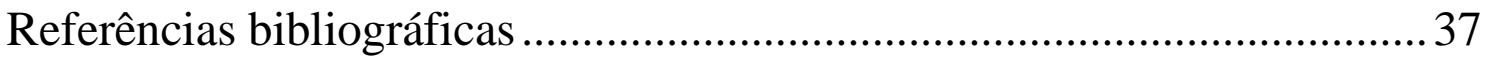

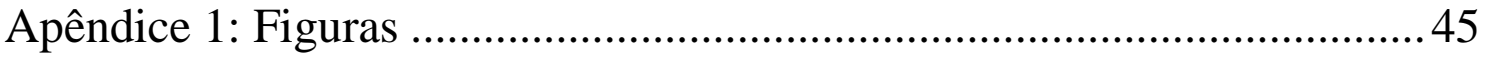

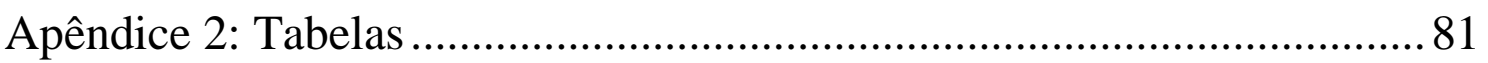

Apêndice 3: Material examinado ………………....................................... 109 


\section{Lista de Figuras}

Figura 1 - Região anterior da cabeça de (A) Cynopotamus xinguano, MZUSP 94196, 97,9 mm CP; (B) Acentrocephalus stigmatus, MZUSP 94216, 85,0mm CP; (C)

Galeocharax gulo MZUSP 62839 127,2 mm CP.

Figura 2 - Série infraorbital de (A) Cynopotamus xinguano, MZUSP 94196, 97,9 mm CP; (B) Acentrocephalus stigmatus, MZUSP 94216, 85,0mm CP; (C) Galeocharax gulo MZUSP 62839 127,2 mm CP.

Figura 3 - Suspensório e serie opercular de (A) Acentrocephalus stigmatus, MZUSP 94216, 85,0 mm CP; (B) Cynopotamus xinguano, MZUSP 94196, 97,9 mm CP; (C) Galeocharax gulo, MZUSP 62839, 127,2 mm CP; (D) Galeocharax goeldii, UFRO-I 5468, 77,9 mm CP; (E) Galeocharax humeralis, MZUSP 19984, 66,0 mm CP; (F) Galeocharax gulo MZUSP 10480, 88,8 mm CP.

Figura 4 - Maxila inferior de (A) Cynopotamus xinguano, MZUSP 94196, 97,9 mm CP; (B) Acentrocephalus stigmatus, MZUSP 94216, 85,0mm CP; (C) Galeocharax gulo, MZUSP 62839 127,2 mm CP.

Figura 5 - Cintura peitoral de (A) Cynopotamus xinguano, MZUSP 94196, 97,9 mm CP, barra de escala 2 mm; (B) Galeocharax gulo, MZUSP 62839 127,2 mm CP, barra de escala $5 \mathrm{~mm}$.

Figura 6 - Mapa da porção central e norte da América do Sul mostrando a distribuição geográfica do gênero Galeocharax.

Figura 7 - Galeocharax humeralis, MZUSP 78865, 124,3 mm CP.

Figura 8 - Galeocharax humeralis, MZUSP 89961, 187,4 mm CP.

Figura 9 - Galeocharax humeralis, MCP 20401, 197,4 mm CP.

Figura 10 - Galeocharax humeralis, MCP 20401, 151,8 mm CP.

Figura 11 - Maxila inferior de (A) Galeocharax humeralis MZUSP 19984, 66,0 mm CP; (B) Galeocharax gulo MZUSP 62839 127,2 mm CP; (C) Galeocharax goeldii UFRO-I5468, 77,9 mm CP.

Figura 12 - Vista lateral da região anterior de (A) Galeocharax humeralis MZUSP 19907, 144,4 mm CP; (B) Galeocharax gulo MZUSP 10440, 115,3 mm CP; (C) Galeocharax goeldii USNM 305367 129,3 mm CP.

Figura 13 - Micrografias de varredura de escama de Galeocharax humeralis, MZUSP 78865, 124,3 mm CP.

Figura 14 - Micrografias de varredura de escama de Galeocharax humeralis, MZUSP 90473, 210,5 mm CP. 
Figura 15 - Vista lateral do pedúnculo e nadadeira caudal de (A) Galeocharax humeralis MZUSP 27684, 140,4 mm CP; (B) Galeocharax gulo MZUSP 29882, 108,3 mm CP; (C) Galeocharax goeldii INPA 24598, 109,7 mm CP.

Figura 16 - Esquema da conformação dos músculos que formam o pseudotimpano de Galeocharax.

Figura 17 - Região anterior da nadadeira caudal de Galeocharax gulo MZUSP 53858, $111,8 \mathrm{~mm} \mathrm{CP}$.

Figura 18 - Micrografias de varredura do segundo raio ramificado da nadadeira anal de um macho de Galeocharax humeralis MZUSP 19907, 111,5 mm CP.

Figura 19 - Micrografias de varredura do primeiro raio ramificado da nadadeira pélvica de um macho de Galeocharax humeralis MZUSP 19907, 111,5 mm CP.

Figura 20 - Vista lateral dos raios anteriores da nadadeira anal de fêmeas de (A) Galeocharax humeralis MZUSP 90473, 210,5 mm CP; (B) Galeocharax gulo MZUSP 10479, 179,7 mm CP.

Figura 21 - Mapa da região central da América do Sul mostrando a distribuição geográfica de Galeocharax humeralis.

Figura 22 - Galeocharax humeralis, holótipo, MNHN 9848 117,6 mm CP.

Figura 23 - Galeocharax gulo, MZUSP 110473, 148,2 mm CP.

Figura 24 - Galeocharax gulo, MZUSP 29882, 108,3 mm CP.

Figura 25 - Galeocharax gulo, MCNG 49082, 102,3 mm CP.

Figura 26 - Galeocharax gulo, USNM 258535, 113,6 mm CP.

Figura 27 - Galeocharax gulo, MCP 36354, 128,6 mm CP.

Figura 28 - Galeocharax gulo, UNT 2689, 88,3 mm CP.

Figura 29 - Galeocharax gulo, MCN 19060, 132,8 mm CP.

Figura 30 - Galeocharax gulo, MZUSP 10558-83, 119,1 mm CP.

Figura 31 - Galeocharax gulo, MNRJ 19834, 224,9 mm CP.

Figura 32- Vista ventro-lateral da nadadeira peitoral de Galeocharax gulo MCNG 54050, 34,0 mm CP.

Figura 33 - Micrografias de varredura de escama de Galeocharax gulo, MUSM 22189, $134,1 \mathrm{~mm} \mathrm{CP}$.

Figura 34 - Micrografias de varredura de escama de Galeocharax gulo, MCP 41380, $134,3 \mathrm{~mm} \mathrm{CP}$.

Figura 35 - Micrografias de varredura de escama de Galeocharax gulo, MZUSP $110473,148,2 \mathrm{~mm} \mathrm{CP}$.

Figura 36 - Micrografias de varredura do segundo raio ramificado da nadadeira anal de um macho de Galeocharax gulo MZUSP 40901, 110,6mm CP. 
Figura 37- Micrografias de varredura do primeiro raio ramificado da nadadeira pélvica de um macho de Galeocharax gulo, MZUSP 40901, 110,6mm CP.

Figura 38 - Gráfico de dispersão dos valores de distância inter-orbital pelo comprimento da cabeça (CC) em exemplares de Galeocharax gulo da bacia dos rios Amazonas e alto rio Paraná.

Figura 39 - Grafico de dispersão dos valores de distância inter-orbital pelo comprimento da cabeça (CC) em exemplares de Galeocharax gulo da bacia dos rios Amazonas, Tocantins Orinoco e alto rio Paraná.

Figura 40 - Gráfico de dispersão dos valores de diâmetro orbital pelo comprimento da cabeça (CC) em exemplares de Galeocharax gulo da bacia do rio Amazonas e da bacia do rio Tocantins.

Figura 41 - Gráfico de dispersão dos valores de diâmetro orbital pelo comprimento da cabeça (CC) em exemplares de Galeocharax gulo da bacia dos rios Amazonas, Tocantins Orinoco e alto rio Paraná.

Figura 42 - Mapa da região central e norte da América do Sul mostrando a distribuição geográfica de Galeocharax gulo. Estrela indica localidade tipo.

Figura 43 - Galeocharax gulo, holótipo, ANSP 8053, 73,9 mm CP.

Figura 44 - Anacyrtus (Cynopotamus) knerii, sintipos, NMW 62660.

Figura 45 - Galeocharax goeldii, INPA 24598, 109,7 mm CP.

Figura 46 - Galeocharax goeldii, MUSM 8790, 143,4 mm CP.

Figura 47 - Galeocharax goeldii, MZUSP 35951, 144,6 mm CP.

Figura 48 - Galeocharax goeldii, USNM 305367, 129,6mm CP.

Figura 49 - Micrografias de varredura de escama de Galeocharax goeldii, MZUSP 92434, 108,0 mm CP.

Figura 50 - Micrografias de varredura de escama de Galeocharax goeldii, UFRO-I 9668, 160,8 mm CP.

Figura 51 - Micrografias de varredura de escama de Galeocharax goeldii, UFRO-I 5468, 77,9 mm CP.

Figura 52 - Vista lateral dos raios anteriores da nadadeira anal (A) e vista dorsal da nadadeira pélvica esquerda (B) em macho de Galeocharax goeldii MUSM 9564, 125,4 $\mathrm{mm} \mathrm{CP}$.

Figura 53 - Mapa da região norte da América do Sul mostrando a distribuição geográfica de Galeocharax goeldii.

Figura 54 - Galeocharax goeldii, holótipo, ANSP 39308, 42,6 mm CP.

Figura 55 - Gráfico de dispersão dos valores de altura do corpo pelo comprimento padrão $(\mathrm{CP})$ em exemplares de Galeocharax gulo das bacias do alto rio Paraná e Amazonas. 
Figura 56 - Gráfico de dispersão dos valores de número de dentes na fileira posterior do detário pelo comprimento padrão (CP) em exemplares de Galeocharax gulo das bacias do alto rio Paraná e Amazonas.

Figura 57 - Vista dorsal da região anterior do suspensório de (A) Cynopotamus xinguano, MZUSP 94196, 97,9 mm CP; (B) Galeocharax gulo, MZUSP 62839 127,2 mm CP; (C) Galeocharax humeralis, MZUSP 19984, 66,0 mm CP (D) Galeocharax goeldii, UFRO-I 5468, 77,9 mm CP; (E) Galeocharax gulo MZUSP 10480, 88,8 mm CP; (F) Galeocharax gulo NUP 3119, 94,4 mm CP.

\section{Lista de Tabelas}

Tabela 1. Frequência de distribuição do número de escamas na linha lateral nas três espécies de Galeocharax reconhecidas no presente estudo.

Tabela 2. Frequência de distribuição do número de escamas acima da linha lateral nas três espécies de Galeocharax reconhecidas no presente estudo.

Tabela 3. Frequência de distribuição do número de escamas abaixo da linha lateral na vertical da origem da nadadeira pélvica nas três espécies de Galeocharax reconhecidas no presente estudo.

Tabela 4. Frequência de distribuição do número de escamas abaixo da linha lateral na vertical da origem da nadadeira anal nas três espécies de Galeocharax reconhecidas no presente estudo.

Tabela 5. Dados morfométricos das três espécies de Galeocharax reconhecidas no presente estudo.

Tabela 6. Frequência de distribuição do número de raios ramificados na nadadeira anal nas três espécies de Galeocharax reconhecidas no presente estudo.

Tabela 7. Frequência de distribuição do número de dentes na fileira externa do prémaxilar nas três espécies de Galeocharax reconhecidas no presente estudo.

Tabela 8. Frequência de distribuição do número de dentes no maxilar nas três espécies de Galeocharax reconhecidas no presente estudo.

Tabela 9. Frequência de distribuição do número de dentes na fileira interna do dentário nas três espécies de Galeocharax reconhecidas no presente estudo.

Tabela 10. Frequência de distribuição do número de escamas ao redor do pedúnculo caudal nas três espécies de Galeocharax reconhecidas no presente estudo.

Tabela 11. Distribuição de ganchos nos raios da nadadeira anal de exemplares de Galeocharax humeralis.

Tabela 12. Distribuição de ganchos nos raios da nadadeira pélvica de exemplares de Galeocharax humeralis. 
Tabela 13. Dados morfométricos dos exemplares machos maduros e fêmeas e machos imaturos de Galeocharax humeralis.

Tabela 14. Dados morfométricos dos exemplares de Galeocharax humeralis das bacias do rio Paraguai e do rio Uruguai.

Tabela 15. Frequência de distribuição do número de dentes na fileira posterior do dentário em Galeocharax gulo, como definido do presente estudo.

Tabela 16. Distribuição de ganchos nos raios da nadadeira anal de exemplares de Galeocharax gulo.

Tabela17. Distribuição de ganchos nos raios da nadadeira pélvica de exemplares de Galeocharax gulo.

Tabela 18. Dados morfométricos dos exemplares machos maduros e fêmeas e machos imaturos de Galeocharax gulo.

Tabela 19. Frequência de distribuição do número de escamas acima da linha lateral em exemplares de Galeocharax gulo, como definido no presente estudo.

Tabela 20. Frequência de distribuição do número de escamas abaixo da linha lateral na vertical da origem da nadadeira pélvica em exemplares de Galeocharax gulo, como definido no presente estudo.

Tabela 21. Frequência de distribuição do número de escamas abaixo da linha lateral na vertical da origem da nadadeira anal em exemplares de Galeocharax gulo, como definido no presente estudo.

Tabela 22. Frequência de distribuição do número de dentes no maxilar em exemplares de Galeocharax gulo, como definido no presente estudo. Grupamentos formados baseando-se na localidade de ocorrência.

Tabela 23. Frequência de distribuição do número de raios ramificados na nadadeira anal em exemplares de Galeocharax gulo, como definido no presente estudo.

Tabela 24. Frequência de distribuição do número total de vértebras em exemplares de Galeocharax gulo, como definido no presente estudo.

Tabela 25. Frequência de distribuição do número de vértebras pré-caudais em exemplares de Galeocharax gulo, como definido no presente estudo.

Tabela 26. Dados morfométricos dos exemplares de Galeocharax gulo das bacias do rio Orinoco e do rio Tocantins.

Tabela 27. Dados morfométricos dos exemplares de Galeocharax gulo das bacias do rio Amazonas e do alto rio Paraná.

Tabela 28. Distribuição de ganchos nos raios da nadadeira anal de exemplares de Galeocharax goeldii.

Tabela 29. Distribuição de ganchos nos raios da nadadeira pélvica de exemplares de Galeocharax goeldii. 
Tabela 30. Dados morfométricos dos exemplares machos maduros e fêmeas e machos imaturos de Galeocharax goeldii.

Tabela 31. Dados morfométricos dos exemplares de Galeocharax goeldii das bacias do rio Madeira e do rio Madre de Dios.

Tabela 32. Frequência de distribuição do número de dentes na fileira posterior do dentário em exemplares de Galeocharax gulo, como definido no presente estudo.

Tabela 33. Frequência de distribuição do número de escamas na linha lateral em exemplares de Galeocharax gulo, como definido no presente estudo.

Tabela 34. Frequência de distribuição do número de escamas ao redor do pedúnculo caudal em exemplares de Galeocharax gulo, como definido no presente estudo. 


\section{Resumo}

Galeocharax Fowler é um gênero de peixes de água doce distribuído por todos os principais sistemas hídricos da América do Sul cisandina, com exceção da bacia do rio São Francisco, do rio Xingu e das drenagens litorâneas do leste. Conhecidos popularmente no território brasileiro como saicanga, peixe-cigarra, peixe-cadela, peixecachorro e dentudo e dentón e dientón alargado em países como Peru e Venezuela. Alcançam até $25 \mathrm{~cm}$ de comprimento, alimentam-se de peixes e invertebrados. Reproduzem-se durante todo o ano, não apresentam cuidado parental ou comportamento migratório.

Quatro espécies têm sido consideradas válidas no gênero: Galeocharax humeralis (Valenciennes, 1834) das bacias do rio Paraguai e baixo rio Paraná; Galeocharax gulo (Cope, 1870), das bacias dos rios Amazonas e Tocantins; Galeocharax knerii (Steindachner, 1878), da bacia do alto rio Paraná e Galeocharax goeldii (Fowler, 1913), da bacia do rio Madeira.

Um estudo prévio sugeriu a existência de uma possível espécie não descrita de Galeocharax da bacia do rio Orinoco. Além disso, o exame preliminar de exemplares recentemente depositados em coleções revelou que a distribuição geográfica do gênero é mais ampla que o registrado até agora e que há sobreposição de características consideradas diagnósticas para algumas espécies do gênero. O presente trabalho teve como objetivo realizar um estudo taxonômico de Galeocharax para determinar quantas e quais espécies podem ser reconhecidas e estimar a distribuição geográfica das mesmas.

Foram examinados 1226 exemplares, dos quais 677 tiveram dados merísticos e morfométricos tomados. Detalhes osteológicos e morfológicos foram examinados por meio de radiografias, imagens de microscopia eletrônica de varredura e dissecções de exemplares diafanizados.

São reconhecidas três espécies: Galeocharax humeralis, Galeocharax goeldii, com registros de distribuição geográfica ampliados para as bacias dos rios Madre de Dios, Beni, Mamoré e Guaporé, e Galeocharax gulo amplamente distribuída pelas bacias dos rios Amazonas, Orinoco, Tocantins e alto Paraná.

O exame de material realizado no presente estudo, incluindo exemplares provenientes de localidades não amostradas em estudos prévios, mostrou que as duas características previamente propostas para diferenciar Galeocharax gulo de Galeocharax knerii: altura do corpo e número de dentes na fileira posterior do dentário apresentam sobreposição quase total de suas amplitudes de variação. Sendo assim Galeocharax knerii foi considerado sinônimo júnior de Galeocharax gulo. 
A morfologia dos ganchos ósseos presentes nas nadadeiras anal e pélvica de machos e na nadadeira anal de algumas fêmeas, assim como a morfologia das escamas espinoides foram ilustradas e detalhadas por meio de microscopia eletrônica de varredura. Uma chave de identificação para as espécies de Galeocharax é apresentada. 


\begin{abstract}
Galeocharax Fowler is a genus of freshwater fishes distributed throughout most South American cis-Andean river systems, except the rio São Francisco and rio Xingu basins and the eastern drainages of Brazil. The species reach up to $25 \mathrm{~cm}$ in length, and feed on fishes and invertebrates. They reproduce throughout the year, and do not seem to show any parental care or migratory behaviour.

Four species have been considered as valid in the genus: Galeocharax humeralis (Valenciennes, 1834), from rio Paraguay and lower rio Paraná basins; Galeocharax gulo (Cope, 1870), from rio Amazonas and rio Tocantins basins; Galeocharax knerii (Steindachner, 1878), from upper rio Paraná basin and Galeocharax goeldii from rio Madeira basin.

A previous study suggested the existence of a possible non described species of Galeocharax from the rio Orinoco basin. In addition, a preliminary examination of recently collected specimens revealed that the genus is more widely distributed than previously registred. In addition the overlap of some diagnostic characteristic for some species was observed. The main objective of the current study was to undertake a taxonomic revision of Galeocharax in order to determine how many species can be considered as valid and to estimate their geographical distributions.
\end{abstract}

A total of 1226 specimens were examined from which 677 had meristic ans morphometric data taken. Osteological and morfological features were examined by in radiographs, scanning eletron microscope images and in dissected cleared and stained specimens.

Three species are recognized as valid: Galeocharax humeralis, Galeocharax goeldii, with records of geographical distibution expanded to the rio Madre de Dios, rio Beni, rio Mamoré and rio Guaporé basins and Galeocharax gulo, which is widespread throughout rio Amazonas, rio Orinoco, rio Tocantins and upper rio Paraná basins.

The examination of specimens performed in the current study, including specimens from localities not sampled previously showed that both characteristics used to differentiate Galeocharax gulo form Galeocharax knerii, (i.e. body depth and number of teeth on the posterior row of the dentary) show almost total overlap of their range of variation. Therefore, Galeocharax knerii is herein considered as a junior synonym of Galeocharax gulo.

The morphology of the bony hooks present in the anal and pelvic fins of mature males and in the anal fin of some females and the morphology of the spinoid scales were illustrated and characterized. An identification key to the species of Galeocharax is presented. 


\section{Introdução}

Galeocharax Fowler é um gênero de peixes de água doce de pequeno a médio porte, que alcançam até $25 \mathrm{~cm}$ de comprimento. São conhecidos popularmente no território brasileiro como saicanga, peixe-cigarra, peixe-cadela, peixe-cachorro e dentudo (Langeani \& Rêgo, 2014; Graça \& Pavanelli, 2007) e dentón e dientón alargado em países como Peru e Venezuela (Taphorn, 1992; Ortega et al, 2012). Os representantes do gênero estão distribuídos por todos os principais sistemas hídricos da América do Sul cisandina, com exceção da bacia do rio São Francisco, do rio Xingu e das drenagens litorâneas do leste e são geralmente encontrados em rios e corpos d'água artificiais.

São peixes carnívoros, alimentam-se de pequenos peixes e invertebrados (Gandini et al, 2012; Ribeiro Neto et al, 1998). Reproduzem-se durante todo o ano, não apresentam cuidado parental ou comportamento migratório (Magalhães et al, 2004). É comum a presença de um crustáceo isopoda parasita (Braga cigarra, Cymothoidae), popularmente conhecido como cigarrinha, na cavidade oral dos representantes do gênero que ocorrem na bacia do alto rio Paraná (Brandão et al, 2013), daí o nome comum peixe-cigarra.

O gênero Galeocharax está inserido na família Characidae, que é a família mais rica em espécies da ordem Characiformes com aproximadamente 165 gêneros e mais de 1000 espécies (Eschmeyer, 2014), das quais mais de 600 ocorrem no território brasileiro (Buckup et al, 2007). É também nessa família que se concentram os principais problemas taxonômicos da ordem, sendo que o aumento do conhecimento da diversidade de espécies da família e de suas distribuições geográficas depende ainda de estudos de revisão taxonômica de muitos gêneros. Dentro da família Characidae, Galeocharax tem sido tradicionalmente incluído na subfamília Characinae, (Lucena \& Menezes, 2003; Mirande, 2010; Mattox \& Toledo-Piza, 2012).

A última revisão do gênero Galeocharax foi realizada por Menezes (1976) que considerou três espécies válidas: Galeocharax humeralis (Valenciennes, 1834) das bacias do rio Paraguai e baixo rio Paraná; Galeocharax gulo (Cope, 1870), das bacias do rio Amazonas, Araguaia e Tocantins e Galeocharax knerii (Steindachner, 1878), da bacia do alto rio Paraná. No mesmo estudo, Galeocharax goeldii (Fowler, 1913), descrita da bacia do rio Madeira, foi considerada sinônimo de G. gulo (Menezes, 1976, Lucena \& Menezes, 2003), porém, mais recentemente, foi reconhecida como válida por Menezes (2007a), após exame de mais exemplares daquela drenagem.

As espécies nominais de Galeocharax foram todas descritas entre 1834 e 1913, e o gênero só foi proposto em 1910 (Fowler, 1910: 790). Antes da descrição do gênero as 
espécies foram alocadas em diversos gêneros distintos como Charax Scopoli, Hydrocyon Cuvier (= Hydrocynus Cuvier), Cynopotamus Valenciennes, Xiphorhamphus Müller \& Troschel (= Acestrorhynchus Eigenmann \& Kennedy), Anacyrtus Günter (= Charax), Eucynopotamus Fowler (= Roeboides) e Cyrtocharax Fowler (= Cynopotamus).

O nome Galeocharax foi proposto a fim de sanar uma confusão nomenclatural protagonizada por Fowler (1901, 1904, 1910) e Eigenmann (1903, 1907, 1910), e que foi posteriormente detalhada por Géry \& Vu-Tân-Tuê (1963a). Eigenmann (1903: 146) propôs o gênero Evermannella para incluir Cynopotamus biserialis Garman (=Roeboides biserialis), porém Fowler (1904: 119) salientou que já havia proposto esse mesmo nome como substituto para o nome Odontostomus (Aulopiformes: Evermannellidae), pré-ocupado em Mollusca (Fowler, 1901: 211) e propôs então o nome Eucynopotamus para substituir o nome proposto por Eigenmann. Eigenmann \& Ogle (1907: 2, 3) propuseram o nome Evermannolus para substituir Evermannella, ignorando o trabalho de Fowler (1904), que já havia resolvido a questão. Posteriormente Eigenmann (1910: 445) fez uso equivocado do nome Eucynopotamus, agrupando Cynopotamus humeralis (= Galeocharax humeralis), C. magdalenae (Steindachner), $C$. gulo (Galeocharax gulo) e C. knerii (Galeocharax knerii), indicando, erroneamente, $C$. gulo como espécie-tipo do gênero. Fowler (1910), em resposta a Eigenmann \& Ogle (1907) e Eigenmann (1910), salienta que Evermannolus é sinônimo objetivo de Eucynopotamus e que o grupo erroneamente delimitado como Eucynopotamus por Eigenmann (1910) passaria a ser reconhecido como Galeocharax, tendo Cynopotamus gulo Cope como espécie tipo. Cabe ressaltar que a proposta de Fowler não foi acompanhada de uma discussão sobre as espécies incluídas nem por uma diagnose de Galeocharax, o que só ocorreu posteriormente.

A grande maioria dos trabalhos subsequentes à proposição de Galeocharax constituem apenas listagens de espécies e não discutiram ou caracterizaram os agrupamentos que incluíam as espécies de Galeocharax. Uma discussão um pouco mais ampla foi feita por Schultz (1944: 295), que ressaltou a existência de problemas no que se dizia respeito à nomenclatura e hipóteses de relações feitas para gêneros relacionados à Charax, especialmente os gêneros Cynopotamus, Cyrtocharax (= Cynopotamus), Gilbertolus e Eucynopotamus (= Roeboides). Naquele trabalho o autor reconheceu um agrupamento que continha três das quatro espécies hoje incluídas em Galeocharax ( $G$. humeralis, G. gulo e G. knerii), porém incluiu todas sob o gênero Cynopotamus (juntamente com $C$. argenteus, espécie tipo do gênero). A diagnose desse gênero foi apresentada em uma chave de identificação e incluía, entre diversas outras, as seguintes características: duas séries de dentes na maxila inferior, dentes caninos nas maxilas 
superior e inferior e "escudo" peitoral não entalhado (i.e. ausência de uma reentrância na margem posterior do cleitro na região anterior à base do primeiro raio da nadadeira peitoral). Estas características são empregadas ainda hoje para diferenciar Galeocharax dos gêneros citados acima.

Mesmo reconhecendo um grupo com espécies hoje incluídas em Galeocharax e baseando-se em características usadas até hoje como diagnósticas para o gênero, Schultz (1944, 1950) não fez menção ao nome Galeocharax, que só foi retomado na literatura por Géry \& Vu-Tân-Tuê (1963 a, b) que o consideram como sinônimo de Acestrocephalus, um sub-gênero de Cynopotamus segundo os autores. Naquele trabalho os autores consideraram como válidas as espécies Galeocharax humeralis, G. gulo e $G$. goeldii referidas respectivamente como: Cynopotamus (Acestrocephalus) humeralis, Cynopotamus (Acestrocephalus) gulo e Cynopotamus (Acestrocephalus) goeldii. Os autores consideraram Galeocharax knerii como sinônimo de Cynopotamus (Acestrocephalus) humeralis e propuseram que o nome Charax goeldii fosse empregado para uma forma amazônica de com número de escamas na linha lateral intermediário entre C. humeralis e C. gulo.

Menezes (1976) reconheceu um agrupamento natural que inclui Cynopotamus, Acestrocephalus e Galeocharax baseando-se na combinação das seguintes características: 1) presença de uma série de ossos circum-orbitais incompleta; 2) número e arranjo dos dentes do pré-maxilar; 3) ausência de rinoesfenóide; 4) estrutura dos rastros branquiais; 5) o tipo de contato entre orbitoesfenóide e paraesfenóide; 6) presença de suprapreopérculo; e 7) presença de escamas ctenóides (i.e. espinóides). O autor diferenciou Galeocharax de Acestrocephalus e Cynopotamus com base em três características exclusivas: 1) a ausência de uma crista óssea no ectopterigóide, em contraste com Acestrocephalus e Cynopotamus, que apresentam uma crista com aspecto de lâmina ao longo da face médio-ventral estendendo-se da margem anterior até dois terços do seu comprimento; 2) formato do osso nasal, que em Galeocharax, apresenta uma projeção laminar óssea que se estende lateralmente à porção tubular do osso, em contraste com a ausência dessa projeção laminar em Acestrocephalus e Cynopotamus; e 3) infraorbital 1 mais largo em sua região mediana e consideravelmente mais longo do que a ossificação em Acestrocephalus e Cynopotamus. Como resultado do maior tamanho, a porção anterior do infraorbital 1 cobre parcialmente a porção posterior do pré-maxilar e a porção ventral do antorbital.

O monofiletismo de Galeocharax foi recentemente corroborado por Mattox \& Toledo-Piza (2012), em um estudo que incluiu as quatro espécies então consideradas válidas do gênero: G. knerii, G. humeralis, G. gulo e G. goeldii. Este táxon formado por estas espécies é suportado, além da presença de uma projeção antero-ventral do 
infraorbital 1 e da presença da expansão lateral do nasal, que já haviam sido propostas por Menezes (1976), pelas seguintes sinapomorfias: 1) presença de escamas cobrindo os lobos da nadadeira caudal, ao menos parcialmente, na parte mediana da nadadeira; e 2) limite da porção ventral do músculo levator arcus palatini estendendo-se até a margem anterior do metapterigoide; e 3) margem anteroventral do cleitro com uma projeção bem desenvolvida direcionada anteriormente. Na análise de Mattox \& Toledo-Piza (2012), a ausência de uma crista óssea na superfície ventral do ectopterigóide em Galeocharax (vs. presença da crista em Cynopotamus e Acestrocephalus), resultou como uma sinapomorfia para o gênero, porém com otimização ambígua. Não obstante, esta característica continua sendo útil para diferenciar Galeocharax de Acestrocephalus e Cynopotamus.

Os gêneros Galeocharax, Acestrocephalus e Cynopotamus têm sido considerados filogeneticamente relacionados, porém o arranjo dos três gêneros dentro deste clado difere entre alguns autores. Dos trabalhos mais recentes o de Lucena (1998), que incluiu apenas G. humeralis e G. knerii, e o de Mattox \& Toledo-Piza (2012), propuseram a relação (Cynopotamus (Galeocharax + Acestrocephalus)). Por outro lado, Mirande (2010), que incluiu apenas G. humeralis em sua análise propôs a relação (Acestrocephalus (Cynopotamus + Galeocharax)). Oliveira et al (2011), em uma análise filogenética de Characidae com base em dados moleculares propuseram que Galeocharax e Acestrocephalus formariam um grupo monofilético e que Cynopotamus não seria um grupo natural, com pelo menos uma espécie mais relacionada a outros gêneros de Characinae. Dentre os trabalhos citados apenas Mattox e Toledo-Piza (2012) incluíram as quatro espécies de Galeocharax então consideradas válidas. Os quatro trabalhos citados também variam no que diz respeito às espécies de Cynopotamus e Acestrocephalus que foram utilizadas.

Posteriormente à última revisão taxonômica dos três gêneros (Menezes, 1976) somente Galeocharax ainda não foi objeto de um estudo taxonômico mais recente. Como resultado de revisões recentes quatro espécies foram adicionadas a Cynopotamus e seis a Acestrocephalus (Menezes, 1987, 2006, 2007 b).

Taphorn (1992:185) sugeriu a ocorrência de uma possível espécie não descrita de Galeocharax na drenagem do rio Apure, bacia do rio Orinoco, Venezuela, contudo devido à sobreposição de alguns caracteres com G. gulo e G. knerii o autor ressaltou a necessidade de uma comparação mais cuidadosa com exemplares da bacia amazônica para confirmar se esses exemplares representariam mesmo uma espécie não descrita.

O número de exemplares de Galeocharax depositados em coleções ictiológicas aumentou consideravelmente nas últimas décadas, revelando que a distribuição do gênero é bem mais ampla que a registrada até o momento. Um estudo taxonômico que 
conte com o exame detalhado do maior número possível de exemplares se faz necessário para determinar quantas e quais espécies podem ser reconhecidas em Galeocharax, rever suas características diagnósticas e estimar suas distribuições geográficas.

\section{Objetivos}

Este trabalho tem como objetivo principal realizar um estudo taxonômico do gênero Galeocharax para determinar quantas e quais espécies podem ser reconhecidas e estimar a distribuição geográfica das mesmas. 


\section{Materiais e Métodos}

Para o presente estudo foram examinados 1226 exemplares depositados em diversas coleções ictiológicas e provenientes de toda área de distribuição do gênero, dos quais 677 tiveram dados merísticos e morfométricos tomados. Os dados morfométricos foram tomados ponto a ponto com o auxílio de um paquímetro digital com precisão de $0,1 \mathrm{~mm}$, sempre que possível no lado esquerdo dos exemplares. Foram tomadas 20 medidas distintas de cada exemplar e que foram expressas no texto e nas tabelas em porcentagens do comprimento padrão $(\% \mathrm{CP})$, exceto às relativas à cabeça que foram expressas em porcentagem do comprimento da cabeça (\% CC).

O sexo de alguns exemplares foi determinado por meio do exame de gônadas e os dados morfométricos de cada sexo foram analisadas separadamente para verificação de possível dimorfismo sexual.

As medidas tomadas no presente trabalho são as seguintes.

- Comprimento padrão: distância entre a extremidade anterior focinho e extremidade posterior da placa hipural.

- Comprimento da cabeça: distância entre a extremidade anterior focinho e a extremidade ventral da concavidade posterior do opérculo.

- Comprimento da cabeça II: distância entre a extremidade anterior do focinho e a extremidade dorsal da concavidade posterior do opérculo.

- Altura do corpo: maior altura do corpo, tomada na vertical que passa pela origem da nadadeira dorsal.

- Comprimento do focinho: distância entre a extremidade anterior do focinho e a margem (óssea) anterior da órbita.

- Diâmetro orbital: distância entre as duas margens (ósseas) da órbita, tomada na linha horizontal.

- Distância interorbital: distância entre as margens superiores das duas órbitas, tomada nas margens dos frontais contralaterais.

- Comprimento da maxila superior: distância entre a extremidade anterior do focinho e a extremidade posterior do osso maxilar.

- Comprimento da nadadeira dorsal: distância entre a origem da nadadeira dorsal e a extremidade do segundo raio não ramificado.

- Comprimento da base da nadadeira dorsal: distância entre as extremidades anterior e posterior da base da nadadeira dorsal.

- Comprimento da nadadeira peitoral: distância entre a origem da nadadeira e a extremidade do raio não ramificado. 
- Comprimento da nadadeira pélvica: distância entre a origem da nadadeira e a extremidade do raio não ramificado.

- Comprimento da nadadeira anal: distância entre a origem da nadadeira e da extremidade do último raio não ramificado.

- Comprimento da base da nadadeira anal: distância entre as extremidades anterior e posterior da base da nadadeira anal.

- Distância pré-peitoral: distância entre a extremidade anterior do focinho e a origem da nadadeira peitoral.

- Distância pré-pélvica: distância entre a extremidade anterior do focinho e a origem da nadadeira pélvica.

- Distância pré-dorsal: distância entre a extremidade anterior do focinho e a origem da nadadeira dorsal.

- Distância pré-anal: distância entre a extremidade anterior do focinho e a origem da nadadeira anal.

- Altura do pedúnculo caudal: menor altura do pedúnculo caudal tomada em uma linha vertical.

- Comprimento do pedúnculo caudal: distância ente a extremidade posterior da nadadeira anal e a extremidade posterior da placa hipural.

Os dados merísticos foram tomados, sempre que possível, do lado esquerdo dos exemplares. Contagens de escamas, raios e dentes foram feitas com o auxílio de estereomicroscópio. O número de raios não ramificados é expresso na forma de algarismos romanos e o de ramificados na forma de algarismos arábicos. Para melhor visualização dos dentes foi aplicada uma solução de azul de metileno em álcool $70 \%$ nos exemplares, esta coloração é temporária e desbota em poucos minutos após o retorno do exemplar ao frasco do qual foi retirado. A contagem das vértebras foi feita em parte dos exemplares, com base em radiografias feitas na seção de radiologia do Hospital Veterinário da Faculdade de Veterinária e Zootecnia da USP (HOVET FMVZ/USP) e examinadas no programa RadiAnt DICOM viewer (32-bit).

As contagens realizadas são as seguintes:

- Número de escamas na linha lateral: número total de escamas perfuradas ao longo da linha longitudinal do corpo.

- Número de escamas acima da linha lateral: número de fileiras horizontais de escamas não perfuradas entre a origem da nadadeira dorsal e a linha lateral.

- Número de escamas abaixo da linha lateral: número de fileiras horizontais de escamas não perfuradas entre a linha lateral e a origem da nadadeira anal. 
- Número de escamas abaixo da linha lateral na vertical que passa pela origem da nadadeira pélvica: número de fileiras horizontais de escamas não perfuradas entre a linha lateral e a origem da nadadeira pélvica.

- Número de escamas ao redor do pedúnculo caudal: número total de fileiras horizontais de escamas ao redor do pedúnculo caudal.

- Número de escamas na bainha da nadadeira anal: número de fileiras de escamas ao longo da base dos raios da nadadeira anal.

- Número de raios da nadadeira dorsal

- Número de raios da nadadeira peitoral

- Número de raios da nadadeira pélvica

- Número de raios da nadadeira anal: o último raio ramificado, dividido em sua base, foi contado como um único raio.

- Número de dentes no osso maxilar

- Número de dentes na fileira externa do dentário

- Número de dentes na fileira interna do dentário: fileira de dentes menores que os demais voltados posteriormente.

- Número de dentes na fileira interna do osso pré-maxilar

- Número de dentes na fileira externa do osso pré-maxilar

- Número total de vértebras: número de vértebras abdominais e caudais.

- Número de vértebras abdominais: incluindo as quatro primeiras vértebras, que constituem o aparelho de Weber, até a última vértebra sem espinho hemal.

- Número de vértebras caudais: incluindo a primeira vértebra que apresenta espinho hemal até o último centro, associado ao esqueleto caudal, que foi contado com um elemento.

A estatística descritiva dos dados merísticos e morfométricos (amplitude de variação, média, moda, desvio padrão, gráficos de dispersão e tabelas de frequência) foi realizada com o auxílio do programa MYSTAT 12.

Os mapas de distribuição do gênero Galeocharax e de suas espécies foram elaborados com o auxílio dos programas Google Earth e Quantum GIS Wroclaw 1.7.0, seguindo o tutorial detalhado no site www.wikipeixes.com.br/tutoriais:mapas

Detalhes da morfologia das escamas e dos ganchos ósseos presentes nos raios das nadadeiras anal e pélvica foram examinados com o auxílio de imagens de microscopia eletrônica de varredura produzidas com microscópio eletrônico Zeiss DSM940.

Exemplares foram diafanizados e corados segundo o protocolo de Taylor \& Van Dyke (1985). 
Exemplares de uma mesma localidade foram inicialmente comparados e caso não fossem detectadas diferenças nas características examinadas, eles eram agrupados. Isso foi feito sucessivamente para localidades próximas e depois para localidades na mesma bacia hidrográfica até que todos os exemplares fossem examinados e agrupamentos preliminares fossem definidos.

A bacia do rio Amazonas, sempre que citada no texto não inclui a bacia do rio Tocantins.

A lista de material examinado está separada por países. Os estados ou departamentos estão sublinhados. Segue o código da instituição e número do lote, número de indivíduos examinados do lote, amplitude de variação do comprimento padrão em milímetros, localidade de coleta, nome dos coletores e data de coleta. Os lotes que não contavam com as coordenadas geográficas da localidade de coleta tiveram essa informação estimada com base na informação disponível.

Abreviaturas institucionais:

AMNH - American Museum of Natural History, Nova Iorque; ANSP - Academy of Natural Sciences of Drexel University, Filadélfia; INPA - Instituto Nacional de Pesquisas Amazônicas, Manaus; MCN - Museu de Ciências Naturais, Fundação Zoobotânica do Rio Grande do Sul, Porto Alegre; MCNG - Museo de Ciencias Naturales de Guanare, Guanare; MCP - Museu de Ciências e Tecnologia, Pontifícia Universidade Católica do Rio Grande do Sul, Porto Alegre; MNRJ - Museu Nacional, Rio de Janeiro; MUSM - Museo de Historia Natural, Universidad Nacional Mayor de San Marcos, Lima; MZUSP - Museu de Zoologia, Universidade de São Paulo; NUP Núcleo de Pesquisas em Limnologia, Ictiologia e Aquicultura, Universidade Estadual de Maringá, Maringá; UFRO-I - Universidade Federal de Rondônia, Porto Velho; UNT Universidade Federal do Tocantins, Porto Nacional; USNM - National Museum of Natural History, Smithsonian Institution, Washington D. C. 


\section{Resultados}

\section{Galeocharax Fowler, 1910}

Galeocharax Fowler, 1910: 790 [espécie tipo Cynopotamus gulo Cope, 1870: 565]; Géry \& Vu-Tân-Tuê, 1963a: 239 [como sinônimo de Acestrocephalus, sub-gênero de Cynopotamus]; Géry, 1972: 27 [como sinônimo de Acestrocephalus, sub-gênero de Cynopotamus]

\section{Diagnose do gênero}

O gênero Galeocharax distingue-se de Cynopotamus e Acestrocephalus por possuir uma projeção óssea lateral no osso nasal (vs. projeção ausente em Cynopotamus e Acestrocephalus, figura 1). Infraorbital 1 alongado anteriormente, alcançando o antorbital e o pré-maxilar (vs. menos alongado e não alcançando o antorbital e o prémaxilar em Acestrocephalus e Cynopotamus, figura 2). Ausência de uma crista óssea na face medial do ectopterigóide (vs. crista presente em Acestrocephalus e Cynopotamus figura 3). Galeocharax se diferencia de Cynopotamus por possuir uma fileira de 6-13 pequenos dentes cônicos posterior aos caninos do dentário (vs. fileira ausente ou apenas um dente próximo à sínfise, figura 4) e por apresentar o cleitro sinuoso (vs. entalhado, figura 5).

\section{Chave de identificação para as espécies de Galeocharax}

1. Escamas na linha lateral $77-87$ Galeocharax gulo.

Escamas na linha lateral 88-105. 2.

2. Pequenos dentes cônicos entre o terceiro e quarto dentes caninos do dentário 13. Galeocharax humeralis.

Pequenos dentes cônicos entre o terceiro e quarto dentes caninos do dentário ausentes Galeocharax goeldii.

Distribuição geográfica do gênero apresentada na figura 6.

\section{Galeocharax humeralis (Valenciennes, 1834)}

Figuras 7-10

Hydrocyon humeralis Valenciennes, 1834: prancha 11, fig 2 [prancha; localidade tipo América meridional (Buenos Aires, Argentina)]; 1847: 9 [texto] 
Xiphorhamphus humeralis; Müller \& Troschel, 1844: 93 [listado; América meridional]; 1845: 18 [listado; América meridional]

Cynopotamus humeralis; Valenciennes, 1849: 320 [descrição]; Kner, 1860: 49 [parte; apenas exemplares de Cuiabá, rio Paraguai]; Garman, 1890: 13 [listado; parte, apenas material de Rosario]; Eigenmann \& Eigenmann, 1891: 58 [listado; parte, apenas La Plata e Rosario]; Schultz, 1950: 67 [diagnose em chave de identificação]; Aramburu, 1953: 299 [descrição; Rosario, Paraná Pavon e San Pedro]; Géry \& VuTân-Tuê, 1963a: 149 [Descrição]

Anacyrtus humeralis; Kner 1860: [parte, apenas exemplares de Cuiabá]; Günther, 1864: 348 [descrição; Buenos Ayres]; Perugia, 1891:649 [listado; Empedrado, Corrientes, Villa Maria, Matto Grosso, rio Paraguay]; Goeldi, 1898: 467 [listado; Paraguay, nome popular]

Cynopotamus knerii; Eigenmann \& Eigenmann, 1891: 58 [listado; parte, apenas Cujaba (Cuiabá) e rio Paraguay]; Eigenmann, McAtee \& Ward, 1907: 143 [listado; Bahia Negra e Corumba]; Fowler, 1945: 158 [listado; parte, apenas La Plata]

Eucynopotamus humeralis; Eigenmann, 1907: 770 [listado]; 1910: 445 [listado; parte apenas La Plata basin]

Eucynopotamus knerii; Eigenmann, 1910: 445 [listado; parte La Plata basin]

Galeocharax humeralis; Fowler, 1910: 790 [listado]; Fowler, 1950: 315 [listado; parte, apenas rio Paraguai]; Menezes, 1976: 41 [sinonímia, descrição, distribuição]; López et al, 1987 [listado]; Sverlij et al, 1998: 15 [rio Uruguay]; Britski et al, 1999: 52 [listado]; Lucena \& Menezes, 2003: 203 [listado, distribuição]; López et al, 2003: 18 [listado]; Filho et al, 2004: 25 [alto rio Uruguai]; Buckup et al, 2007: 35 [listado, distribuição]; Zayas \& Cordiviola, 2007: 178 [conservação, bacia do rio da Prata]; Copatti et al, 2009: 181 [rio Jaguari]

Cynopotamus (Acestrocephalus) humeralis; Géry \& Vu-Tân-Tuê, 1963b: 240 [diagnose em chave de identificação]; Géry, 1977: 306 [listado]

Galeocharax knerii; López et al, 2003: 18 [listado]

Diagnose: Galeocharax humeralis diferencia-se das demais espécies do gênero por ser é a única que apresenta 1 a 3 dentes pequenos situados entre o terceiro e quarto dentes da fileira externa do dentário (figura 10), (vs. dentes ausentes). Diferencia-se de G. gulo pelo número de escamas na linha lateral (90-105 vs. 77-87 em G. gulo, tabela 1) e pela frequência de distribuição das seguintes características: número de escamas acima da linha lateral (17-20, mediana 18 vs. 14-19, mediana 16 em G. gulo, tabela 2); número de escamas abaixo da linha lateral na vertical que passa pela origem da nadadeira pélvica (14-16, mediana 15 vs. 11-16, mediana 13 em G. gulo, tabela 3); 
número de escamas abaixo linha lateral na vertical que passa pela origem da nadadeira anal (16-20, mediana 18 vs. 14-18, mediana 15 em G. gulo, tabela 4).

Descrição. Dados morfométricos de Galeocharax humeralis apresentados na tabela 5. Maior exemplar examinado $251,8 \mathrm{~mm} \mathrm{CP}$. Corpo alongado, comprimido lateralmente e moderadamente alto. Maior altura do corpo na linha vertical que passa pela origem da nadadeira dorsal. Perfil dorsal da cabeça reto a levemente côncavo da ponta do focinho à extremidade posterior do espinho do supraoccipital. Perfil dorsal do corpo levemente convexo da extremidade posterior do espinho do supraoccipital até base do primeiro raio da nadadeira dorsal. Perfil ao longo da base da nadadeira dorsal geralmente reto, levemente convexo em alguns exemplares. Perfil dorsal da base do último raio da nadadeira dorsal até linha vertical que passa pela menor altura do pedúnculo caudal reto. Perfil ventral da cabeça e corpo convexo da extremidade anterior do dentário até base do primeiro raio da nadadeira anal. Perfil ao longo do primeiro raio da nadadeira anal até linha vertical que passa pela menor altura do pedúnculo caudal reto. Perfil da margem posterior do opérculo geralmente convexa, raramente apresentando margem reta ou côncava (figura 12).

Supraneurais 4(2) ou 5(1) orientados obliquamente, extremidade proximal voltada antero-ventralmente, primeiro situado anteriormente ao espinho neural da $5^{\mathrm{a}}$ vértebra, quarto supraneural situado entre os espinhos neurais da $7^{\mathrm{a}}$ e $8^{\mathrm{a}}$ vértebra. Quinto supraneural, quando presente, situado anteriormente ao espinho neural da $9^{\mathrm{a}}$ vértebra, orientado verticalmente. Base do primeiro raio da nadadeira dorsal situada anteriormente à metade do $\mathrm{CP}$, base do último raio posterior à vertical que passa pela origem da nadadeira anal. Radial proximal-medial do primeiro pterigióforo inserido posteriormente ao espinho neural da $9^{\text {a }}$ vértebra. Raios da nadadeira dorsal ii,9. Perfil da margem posterior da nadadeira dorsal geralmente reto, conferindo aspecto triangular à nadadeira estendida, perfil posterior levemente côncavo em alguns exemplares. Base do primeiro raio da nadadeira anal situada aproximadamente na metade do $\mathrm{CP}$, radial proximal-medial do primeiro pterigióforo da nadadeira anal posterior ao espinho hemal da $17^{\mathrm{a}}$ vértebra. Raios da nadadeira anal v (3), 40-48 (tabela 6). Lóbulo anterior da nadadeira anal pouco desenvolvido, perfil da margem distal da nadadeira anal côncavo nos dois terços anteriores; levemente convexo no terço posterior. Nadadeira peitoral i,13 (14), 14 (61), 15 (34) ou 16 (2); raio mais longo alcançando origem da nadadeira pélvica quando nadadeira é deprimida. Perfil da margem posterior da nadadeira peitoral reto, quatro ou cinco últimos raios mais próximos ao corpo mais curtos que os demais, não alcançando projeção do perfil reto criado pelos demais raios. Nadadeira pélvica situada anteriormente à origem da nadadeira dorsal; raios $\mathrm{i}, 7$; raio mais longo alcançando abertura urogenital na maioria dos exemplares, não alcançando origem da 
nadadeira anal. Perfil da margem posterior da nadadeira pélvica levemente convexo, com aspecto de leque quando aberta. Nadadeira caudal furcada, raios do lobo superior i,9, raios do lobo inferior 8,i, raios procorrentes dorsais 14 (1), 15(2) ou 17 (1), raios procorrentes ventrais 13 (3) ou 14 (1); lobo inferior pouco mais longo e alto que superior. Muitos exemplares maiores que $200 \mathrm{~mm}$ de $\mathrm{CP}$ com perfil da margem posterior da nadadeira caudal quase reto. Nadadeira adiposa presente, situada anteriormente à vertical que passa pela base do último raio da nadadeira anal.

Escamas espinoides (figuras 13 e 14) distribuídas por todo corpo com exceção das axilas das nadadeiras pares e região posterior às bases das nadadeiras dorsal e anal, que apresentam escamas cicloides. Escama axilar presente na nadadeira pélvica. Escamas cobrindo aproximadamente um quinto da extensão dos raios mais anteriores da nadadeira anal. Quatro fileiras horizontais de escamas na base dos raios anteriores, número de fileiras horizontais de escamas diminuindo gradualmente posteriormente até uma fileira de escamas nos raios mais posteriores. Bases dos raios da nadadeira caudal cobertas por escamas (figura 15).

Boca terminal, obliquamente orientada em relação ao eixo longitudinal do corpo, maxila superior ligeiramente mais pronunciada anteriormente que inferior. Extremidade posterior do maxilar ultrapassa vertical pela margem posterior da órbita. Infraorbitais 1 a 6 presentes, supraorbital ausente, infraorbital 3 não alcançando pré-opérculo, infraorbital 4 não alcançando pré-opérculo na maioria dos exemplares. Dentes cônicos. Pré-maxilar com duas fileiras de dentes; fileira interna com dois dentes voltados para interior da boca, fileira externa com 7-13 dentes (tabela 7), o mais medial e o mais lateral caninos. Maxilar com 39-57 dentes cônicos distribuídos ao longo de toda margem ventral do osso (tabela 8). Dentário com duas fileiras de dentes. Fileira interna com 7-12 dentes voltados posteriormente (tabela 9). Fileira externa com grupo anterior formado por quatro dentes caninos espaçados entre si, terceiro mais desenvolvido, geralmente primeiro e quarto de tamanho similar, alguns exemplares com quarto de tamanho intermediário entre primeiro e terceiro, segundo sempre menor e mais externo. Terceiro e quarto dentes bem espaçados entre si, espaço ocupado pelo dente canino posterior do pré-maxilar quando boca está fechada. Grupo posterior de dentes da fileira externa do dentário formando uma fileira adjacente ao quarto dente do grupo anterior composta por 17 (1), 21 (1) ou 26 (1) pequenos dentes. Um a três dentes cônicos pequenos entre o terceiro e o quarto dente do grupo anterior da fileira externa do dentário (figura 10).

Linha lateral completa, estendendo-se da escama imediatamente posterior ao supracleitro até a escama situada na base da nadadeira caudal. Tubo de linha lateral presente entre os lobos da nadadeira caudal. Escamas na linha lateral 90-105 (tabela 1), 
com apenas uma bifurcação, ramificação orientada postero-ventralmente; fileiras horizontais de escamas entre a origem da nadadeira dorsal e a linha lateral 17-20, (tabela 2); fileiras horizontais de escamas entre a linha lateral e a origem da nadadeira pélvica 14-16 (tabela 3); fileiras horizontais de escamas entre a linha lateral e a origem da nadadeira anal 16-20 (tabela 4); fileiras horizontais de escamas circundando o pedúnculo caudal 23-27 (tabela 10).

Vértebras totais 40 (1) ou 41(21), vértebras pré-caudais 16, caudais 24 (1) ou 25 (21).

Pseudotímpano presente, limitado antero-ventralmente pelo músculo obliquus superioris, posteriormente pelo músculo obliquus superioris e pela costela associada à sexta vértebra, postero-dorsalmente pelo músculo lateralis superficialis e pelo nervo da linha lateral. Costela associada à quinta vértebra visível anteriormente, não delimita anteriormente hiato muscular (figura 16).

Coloração em álcool. Corpo amarelado, região dorsal mais escura que região ventral devido à presença de cromatóforos no campo posterior das escamas, principalmente próximo à suas margens. Faixa mediana dorsal escura conspícua do espinho do supraoccipital até a base do primeiro raio da nadadeira dorsal, não distinguível na região posterior à nadadeira dorsal.

Crânio mais escuro na região dorsal até, aproximadamente, linha horizontal que passa pela margem dorsal da órbita. Alguns indivíduos com cromatóforos esparsos sobre infraorbitais, principalmente 4, 5 e 6. Margens dos lábios mais pigmentadas no pré-maxilar, maxilar e no dentário principalmente nas bases dos quatro dentes caninos da maxila inferior. Face lateral do maxilar com cromatóforos esparsos desde extremidade anterior até pouco mais da metade do seu comprimento.

Mancha na região umeral de aspecto oval, maior comprimento no sentido vertical. Alguns exemplares com mancha umeral com o aspecto de "meia lua", com as pontas voltadas anteriormente (figura 8).

Uma faixa longitudinal prateada no corpo dorsal à linha lateral, margem ventral da faixa alcançando linha lateral na maioria dos exemplares. Faixa longitudinal estende-se desde margem posterior do supracleitro até margem posterior da placa hipural, mais estreita em suas porções mais anterior e mais posterior, mais larga na região situada na vertical que passa pela base da nadadeira dorsal. Alguns indivíduos com a faixa longitudinal prateada gradualmente mais larga do pedúnculo caudal até margem posterior da placa hipural, estes indivíduos com margem ventral da faixa longitudinal prateada ultrapassando, ventralmente, a linha lateral na região do pedúnculo caudal.

Uma faixa longitudinal escura dorsal à linha lateral estendendo-se da margem posterior do supracleitro até aproximadamente metade do comprimento dos raios da 
nadadeira caudal, estreita na região anterior, gradualmente mais larga posteriormente até região abaixo da base da nadadeira dorsal, gradualmente mais estreita posteriormente deste último ponto até o pedúnculo caudal. Faixa longitudinal escura alarga-se entre região do pedúnculo caudal e margem posterior da placa hipural, afunilando-se posteriormente até ultrapassar escamas que cobrem parte dos raios da nadadeira caudal, formando mancha com formato de losango. Faixa escura não atinge mesma largura que faixa prateada, exceto na região do pedúnculo caudal. Geralmente margens dorsais das faixas se sobrepõem. A faixa escura é mais superficial em relação à faixa parateada.

Exemplares menores (até 126,5 mm CP) apresentam linhas de cromatóforos na região entre pterigióforos da nadadeira anal, dorsalmente essas linhas acompanham linha dos miosseptos da musculatura hipaxial, ventralmente acompanham os raios da nadadeira anal (figura 17).

Nadadeiras peitorais e pélvicas hialinas. Nadadeira dorsal com linhas de cromatóforos ao longo dos raios e cromatóforos esparsos na membrana interradial. Alguns exemplares com nadadeira adiposa com padrão de distribuição de cromatóforos similar ao da região dorsal do corpo.

Dimorfismo sexual: Machos de Galeocharax humeralis apresentam ganchos ósseos nas nadadeiras anal e pélvica. Ganchos da nadadeira anal dispostos nas superfícies laterais do ramo posterior dos raios ramificados, alguns exemplares com ganchos no raio não ramificado mais longo. Geralmente um ou dois, raramente três, ganchos por segmento do raio, orientados dorso posteriormente (figura 18). Ganchos presentes nos 12 até 27 raios anteriores (tabela 11). Ganchos da nadadeira pélvica apenas na face ventral da nadadeira, na superfície posterior do ramo posterior dos raios ramificados. Geralmente um ou dois, raramente três, ganchos por segmento, voltados para base do raio (figura 19). Distribuição dos ganchos varia desde os dois aos seis raios mais laterais (geralmente cinco) (tabela 12).

Algumas fêmeas grandes (MZUSP 90473 210, 5 mm CP) também apresentam ganchos ósseos na nadadeira anal, porém menos desenvolvidos, em menor número e distribuídos em um número menor de raios comparado aos machos (figura 20).

Não foram encontradas diferenças nas amplitudes de variação das proporções corporais (tabela 13).

Variação geográfica: não foram encontradas diferenças nos dados merísticos e morfométricos de exemplares oriundos da bacia do rio Paraguai e da bacia do rio Uruguai. Há sobreposição total nas amplitudes de variação dos caracteres merísticos em quase sua totalidade. Também não foram encontradas diferenças nas amplitudes de variação das proporções corporais (tabela 14). 
Os poucos exemplares do baixo rio Paraná examinados não apresentaram diferenças em relação às populações dos rios Paraguai e Uruguai

Distribuição: Galeocharax humeralis ocorre nas bacias dos rios Paraguai, baixo rio Paraná e rio Uruguai (figura 21).

Observações: Na descrição original de G. humeralis foi indicada como localidade tipo a cidade de Buenos Aires, Argentina. Valenciennes (1849) explicitou que o espécime de G. humeralis, assim como o de Cynopotamus argenteus foram obtidos em um mercado, sendo assim, é mais adequado definir o rio da Prata como a localidade tipo da espécie.

Não foi possível examinar o tipo de G. humeralis (figura 22) durante o presente estudo, porém foi realizada uma comparação com os dados sobre o exemplar tipo presentes na literatura.

Informações sobre o exemplar tipo: Valenciennes (1849) descreve as seguntes características: raios na nadadeira dorsal 11; raios na nadadeira anal 44; escamas na linha lateral 115. Géry \& Vu-Tân-Tuê (1963a) apresentaram uma descrição mais completa que conta com as seguintes características: raios na nadadeira dorsal ii,9; raios na nadadeira anal iv,41; raios na nadadeira peitoral i,14-15; escamas acima da linha lateral 17; escamas na linha lateral 97-98; escamas abaixo da linha lateral 15; dentes pré-maxilares externos 10; dentes pré-maxilares internos 4, dois caninos e dois cônicos; dentes maxilares 43-46; dentes na fileira externa do dentário 4, três caninos e um cônico; dentes na fileira posterior do dentário 23; dentes na fileira interna do dentário 9.

Dentre os dados descritos na literatura apenas o número de escamas na linha lateral relatado por Valenciennes (1849) e o número de escamas abaixo da linha lateral relatado por Géry \& Vu-Tân-Tuê (1963a) não concordaram com as amplitudes de variação observadas no presente estudo.

\section{Galeocharax gulo (Cope, 1870)}

Figuras 23-31

Cynopotamus gulo Cope, 1870:_565 [descrição original; localidade tipo Pebas, Peru]; Eigenmann \& Eigenmann, 1891: 58 [listado]; Fowler, 1906: 459 [descrição]; 1940: 268 [descrição, bacia do rio Ucayali]; Schultz, 1950: 69 [Como sinônimo de Cynopotamus molossus Kner]

Anacyrtus (cynopotamus) knerii Steindachner, 1878: 65 [parte, apenas material de Oriçanga; descrição original; localidade tipo Oriçanga, rio Mogi-guaçu]; Schultz, 1950: 68 [como sinônimo de Cynopotamus humeralis (Valenciennes)]; Aramburu, 
1953: 299 [como sinônimo de Cynopotamus humeralis (Valenciennes)]; Godoy, 1975: 235 [como sinônimo de Cynopotamus humeralis (Valenciennes)]

Anacyrtus knerii; Boulenger, 1887: 282 [listado; Canelos, Equador]; 1898: 426 [listado; rio Juruá]; Eigenmann \& Eigenmann, 1891: 57 [listado; Canelos, Equador]

Cynopotamus knerii; Garman, 1890: 13 [listado; Tabatinga]; Eigenmann \& Eigenmann,

1891: 58 [listado, parte, apenas Iriçanga (= Oriçanga) e Tabatinga]; Eigenmann \& Norris, 1900: 359 [listado; Piracicaba, São Paulo]; Eigenmann \& Allen, 1942: 259 [rio Itaya, Iquitos]; Fowler, 1945: 158 [listado; parte, apenas Iquitos]; 1950: 309 [listado; parte, exceto Bolívia e rio Paraguai]

Cynopotamus humeralis; Kner, 1960: 49 [parte; apenas exemplares de Oriçanga]; Garman, 1890: 13 [listado; parte, apenas material de Saô Paulo (São Paulo) e Goyaz (Goiás)]; Eigenmann \& Eigenmann, 1891: 58 [listado; parte, apenas Sao Paolo (São Paulo) e Goyaz (Goiás)]; Schultz, 1944: 296 [listado]; de Godoy, 1975: 235 [Mogi Guassu, descrição]

Anacyrtus humeralis; Pellegrin, 1899: 157 [rio Apure, Venezuela]

Eucynopotamus gulo; Eigenmann, 1907: 770 [listado]; 1910: 445 [listado]; Eigenmann \& Allen, 1942: 259 [listado]

Eucynopotamus knerii; Eigenmann, 1907: 770 [listado]; 1910: 445 [listado; parte, não de La Plata]

Cynopotamus kneri; Pellegrin, 1909: 150 [listado; Tonnantins (Tocantins)]

Eucynopotamus humeralis; Eigenmann, 1910: 445 [listado; parte, Goyaz (Goiás)]; La Monte, 1935:8 [listado; Purus]

Galeocharax gulo; Fowler, 1910: 790 [listado]; Fowler, 1950: 314 [listado; parte, exceto rio Paraguai]; Menezes, 1976: 43 [sinonímia, descrição, distribuição]; Ortega \& Vari, 1986: 7 [listado]; Lowe-McConnell, 1991: 68 [Rio das Mortes]; Taphorn, 1992: 185 [rio Apure] Silvano et al, 2001:72 [rio Juruá]; Lucena \& Menezes, 2003: 203 [listado, distribuição]; Santos et al, 2004: 57 [Baixo rio Tocantins, diagnose]; Lasso et al, 2004: 120 [Rios Ventuari, Meta, Arauca, Apure e Orinoco]; Mojica et al, 2005: 199 [Rio Amazonas, Letícia, Colômbia]; BogotáGregory \& Maldonado-Ocampo, 2006: 72 [Rio Amazonas, Colômbia]; Galvis et al, 2006: 201 [Letícia, Colômbia]; Ortega et al, 2006: 104 [rio Putumayo, Peru]; Buckup et al, 2007: 35 [listado, distribuição]; Menezes, 2007a [correção ocorrência no rio São Francisco]; Maldonado-Ocampo et al, 2008: 178 [Bacia do rio Amazonas, Colômbia]; Pelicice et al, 2009: 35 [impacto ambiental de barragens]; Freitas et al, 2009:47 [ecologia em reservatório]; Neuberger et al, 2009: 61 [atividade reprodutiva em reservatório]; Monteiro et al, 2009: 82 [variação na dieta 
em reservatório]; Mérona et al, 2010: 196 [listado, baixo Tocantins]; Ortega et al, 2012: 36 [listado]

Galeocharax knerii; Fowler, 1910: 790 [listado]; Menezes, 1976: 45 [sinonímia, descrição, distribuição]; Lucena \& Menezes, 2003: 203 [listado, distribuição]; Milko et al, 2003: 43 [Bacia do rio Paranapanema]; Júlio Jr. et al, 2003: 79 [listado, planície de inundação do alto rio Paraná]; Magalhães et al, 2004 [reprodução em reservatório]; Petry et al, 2005: 5 [listado]; Gomiero \& Braga, 2006: 58 [Bacia do rio Corumbataí]; Shibatta \& Dias, 2006: 57 [listado]; Buckup et al, 2007: 35 [listado, distribuição]; Graça \& Pavanelli, 2007: 90 [planície de inundação do alto rio Paraná]; Langeani et al, 2007: 184 [listado]; Geahl, 2007: 153 [Bacia do rio Tibagi]; Apone et al, 2008: 102 [rio Quilombo]; Brandão et al, 2009: 454 [rio Paranapanema]; Zeinad \& Prado, 2012: 130 [pesca esportiva, distribuição, parte, exceto rio Paraguai]; Gandini et al, 2012: 58 [alimentação, rio Grande]; Langeani \& Rêgo, 2014: 90 [bacia do rio Araguari];

Eucynopstamus gulo; Pearson, 1937: 92 [Tingo de Pauca, Peru]

Cynopotamus (Acestrocephalus) gulo; Géry \& Vu-Tân-Tuê, 1963b: 240 [diagnose em chave de identificação]; Géry, 1972: 29 [diagnose em chave de identificação]; 1977: 306 [listado]

Cynopotamus (Acestrocephalus) knerii; Géry \& Vu-Tân-Tuê, 1963b: 240 [como sinônimo de Cynopotamus humeralis (Valenciennes)]; Géry, 1972: 29 [como sinônimo de Cynopotamus humeralis (Valenciennes)]; 1977: 306 [listado]

Galeocharax aff. gulo; Planquette et al, 1996: 193, 220 [chave de identificação; Oyapock]; Le Bail et al, 2012: 300 [Oyapock]

Galeocharax kneri; Vaz et al, 2000: 70 [listado]

Diagnose: Galeocharax gulo se distingue das demais espécies do gênero por possuir menos escamas na linha lateral (77-87 vs. 90-105 em G. humeralis e 88-97 em G. goeldii, tabela 1). Galeocharax gulo diferencia-se ainda de G. humeralis pela ausência de pequenos dentes cônicos situados entre o terceiro e quarto dente da fileira externa do dentário (figura 11) (vs. 1 a 3 dentes entre o terceiro e o quarto dente da fileira externa do dentário em G. humeralis).

Apesar de haver ampla sobreposição das contagens de escamas nas três espécies a frequência de distribuição dessas contagens varia: número de escamas acima da linha lateral (14-19, mediana 16 vs. 17-20, mediana 18 em G. humeralis e G. goeldii, tabela 2); número de escamas abaixo da linha lateral na vertical que passa pela origem da nadadeira pélvica (11-16, mediana 13 vs. 14-16, mediana 15 em G. humeralis e 15-17 em G. goeldii, mediana 16, tabela 3); e número de escamas abaixo da linha lateral na 
vertical que passa pela origem da nadadeira anal (14-18, mediana 15 vs. 16-20, mediana 18 em G. humeralis e 16-19, mediana 18 em G. goeldii, tabela 4).

Descrição: Dados morfométricos de Galeocharax gulo apresentados na tabela 5. Maior exemplar examinado, 245,2 $\mathrm{mm} \mathrm{CP}$. Corpo alongado, comprimido lateralmente e moderadamente alto. Maior altura do corpo na linha vertical que passa pela origem do primeiro raio da nadadeira dorsal. Perfil dorsal da cabeça levemente côncavo da ponta do focinho à extremidade posterior do espinho do supraoccipital. Perfil dorsal do corpo levemente convexo da extremidade posterior do espinho do supraoccipital até base do primeiro raio da nadadeira dorsal. Perfil ao longo da base da nadadeira dorsal levemente convexo. Perfil ao longo do último raio da nadadeira dorsal até linha vertical que passa pela menor altura do pedúnculo caudal reto. Perfil ventral da cabeça e corpo convexo da extremidade anterior do dentário até base do primeiro raio da nadadeira anal. Perfil ao longo do primeiro raio da nadadeira anal até a linha vertical que passa pela menor altura do pedúnculo caudal reto. Perfil da margem posterior do opérculo geralmente apresentando uma concavidade bem marcada, raramente reto ou convexo (figura 12).

Supraneurais 4 (9) orientados obliquamente, extremidade proximal voltada anteroventralmente, mais anterior situado anteriormente ao espinho neural da $5^{\mathrm{a}}$ vértebra, mais posterior situado entre os espinhos neurais da $7^{\mathrm{a}}$ e $8^{\mathrm{a}}$ vértebras. Base do primeiro raio da nadadeira dorsal situada anteriormente à metade do $\mathrm{CP}$, base do último raio posterior à origem da nadadeira anal. Radial proximal-medial do primeiro pterigióforo inserido posteriormente ao espinho neural da $9^{\text {a }}$ vértebra. Raios da dorsal ii (464) ou iii (3), 8 (2), 9(457), 10 (7) ou 11 (1). Perfil da margem posterior da nadadeira dorsal levemente côncavo na maioria dos exemplares. Base do primeiro raio da nadadeira anal situada aproximadamente na metade do $\mathrm{CP}$, radial proximal-medial do primeiro pterigióforo da nadadeira anal posterior ao espinho hemal da $17^{\mathrm{a}}$ (4) ou $18^{\mathrm{a}}$ (4) vértebra. Raios da anal $\mathrm{v}$ (5),33-46 (442) (tabela 6). Lóbulo anterior da nadadeira anal pouco desenvolvido, perfil da margem distal da nadadeira anal côncavo nos dois terços anteriores, levemente convexo no terço posterior. Nadadeira peitoral i,13 (7), 14 (164), 15 (231) 16 (61) ou 17 (1); raio mais longo alcançando a origem da nadadeira pélvica quando nadadeira é deprimida. Perfil da margem posterior da nadadeira peitoral reto, quatro ou cinco mais próximos ao corpo mais curtos que os demais, não alcançando a projeção do perfil reto formado pelos demais raios. Retenção da forma larval da nadadeira peitoral em exemplares de até $34,0 \mathrm{~mm} \mathrm{CP}$ (figura 32). Nadadeira pélvica situada anteriormente à origem da nadadeira dorsal; raios i,7, raio mais longo geralmente não alcançando a abertura urogenital, nunca alcançando origem da nadadeira anal. Perfil da margem posterior da nadadeira pélvica levemente convexo, nadadeira com aspecto de leque quando aberta. Nadadeira caudal furcada, raios do lobo superior i,9 (5), raios do lobo 
inferior 8,i (5), raios procorrentes dorsais 14 (2), 15 (1) ou 16 (2), raios procorrentes ventrais 12 (1) ou 13(4); lobo inferior mais longo e alto que o superior. Nadadeira adiposa presente situada anteriormente à vertical que passa pela base do último raio da nadadeira anal.

Escamas espinoides (figura 33-35) distribuídas por todo o corpo com exceção das axilas das nadadeiras pares e região posterior às bases das nadadeiras dorsal e anal, que apresentam escamas cicloides. Escama axilar presente na nadadeira pélvica. Escamas cobrindo menos de um quinto da extensão dos raios mais anteriores da nadadeira anal. Duas fileiras horizontais de escamas na base dos raios anteriores, número de fileiras horizontais de escamas diminuindo gradualmente posteriormente até uma ou nenhuma fileira sobre os raios mais posteriores. Base dos raios da nadadeira caudal coberta por escamas (figura 14).

Boca terminal, obliquamente orientada em relação ao eixo longitudinal do corpo, maxila superior ligeiramente mais pronunciada anteriormente que a inferior. Extremidade posterior do maxilar geralmente não ultrapassando vertical que passa pela margem posterior da órbita. Infraorbitais 1 a 6 presentes, supraorbital ausente, infraorbital 3 geralmente não alcançando pré-opérculo. Dentes cônicos. Pré-maxilar com duas fileiras de dentes; fileira interna com dois dentes voltados para o interior da boca, fileira externa com 7-11 dentes (tabela 7), o mais medial e o mais lateral, caninos. Maxilar com 35-55 dentes cônicos (tabela 8) distribuídos ao longo de toda margem ventral do osso. Dentário com duas fileiras de dentes. Fileira interna com 6-10 dentes (tabela 9) voltados posteriormente. Fileira externa com grupo anterior formado por quatro dentes caninos espaçados entre si, terceiro mais desenvolvido, geralmente primeiro e quarto de tamanho similar, alguns exemplares com quarto dente de tamanho intermediário entre primeiro e terceiro, segundo sempre menor e mais externo. Grupo posterior de dentes da fileira externa do dentário formado por uma fileira adjacente ao quarto dente do grupo anterior com 21-34 pequenos dentes cônicos (tabela 15).

Linha lateral completa, estendendo-se da escama imediatamente posterior ao supracleitro até escama situada na base da nadadeira caudal. Tubo de linha lateral presente entre os lobos da nadadeira caudal. Escamas perfuradas da linha lateral 77-87 (tabela 1), com canal laterosensorial com apenas uma bifurcação, ramificação orientada postero-ventralmente; fileiras horizontais de escamas entre a origem da nadadeira dorsal e a linha lateral 14-19 (tabela 2); fileiras horizontais de escamas entre a linha lateral e a origem da nadadeira pélvica 11-16 (tabela 3); fileiras horizontais de escamas entre a linha lateral e origem da nadadeira anal 14-18 (tabela 4); fileiras horizontais de escamas ao redor do pedúnculo caudal 19-26 (tabela 10). 
Vértebras totais 39 (2), 40 (32), 41 (79) ou 42 (11), vértebras pré-caudais 16 (91) ou 17 (33), caudais 23 (3), 24 (62), 25 (50) ou 26 (9).

Pseudotímpano presente, limitado antero-ventralmente pelo músculo obliquus superioris, posteriormente pelo músculo obliquus superioris e pela costela associada à sexta vértebra, dorsalmente pelo músculo lateralis superficialis e pelo nervo da linha lateral. Costela associada à quinta vértebra visível anteriormente, não delimitando antreriormente o hiato muscular (figura 16).

Coloração em álcool: Corpo amarelado, região dorsal mais escura que região ventral devido à presença de cromatóforos no campo posterior das escamas. Faixa mediana dorsal escura conspícua do espinho do supraoccipital até base do primeiro raio da nadadeira dorsal, mancha escura na base do primeiro raio da nadadeira dorsal na maioria dos exemplares. Faixa mediana dorsal não distinguível posteriormente à nadadeira dorsal.

Crânio mais escuro na região dorsal até, aproximadamente, linha horizontal da margem dorsal da órbita, alguns indivíduos com cromatóforos esparsos na série infraorbital, principalmente infraorbitais 4, 5 e 6 . Margens dos lábios mais pigmentadas no pré-maxilar, maxilar e no dentário principalmente nas bases dos quatro dentes caninos da maxila inferior. Face lateral do maxilar com cromatóforos esparsos desde extremidade anterior até aproximadamente metade do seu comprimento.

Mancha na região umeral de aspecto oval, maior comprimento no sentido vertical. Alguns exemplares apresentam mancha com aspecto de "meia lua" com as pontas voltadas anteriormente (figuras 25 e 28 ).

Uma faixa longitudinal prateada no corpo dorsal à linha lateral, margem ventral da faixa alcançando linha lateral na maioria dos exemplares. Faixa longitudinal estende-se desde a margem posterior do supracleitro até a margem posterior da placa hipural, mais estreita em suas porções mais anterior e mais posterior, mais larga na região situada na vertical que passa pela base da nadadeira dorsal. Alguns indivíduos coma faixa longitudinal prateada gradualmente mais largado pedúnculo caudal até margem posterior da placa hipural, estes indivíduos com margem ventral da faixa longitudinal prateada ultrapassando, ventralmente, a linha lateral na região do pedúnculo caudal.

Uma faixa longitudinal escura dorsal à linha lateral, estendendo-se da margem posterior do supracleitro até aproximadamente metade do comprimento dos raios da nadadeira caudal, estreita na região anterior, gradualmente mais larga até região abaixo da base da nadadeira dorsal, gradualmente mais estreita posteriormente deste último ponto até o pedúnculo caudal. Faixa longitudinal alarga-se entre região do pedúnculo caudal e margem posterior da placa hipural, afunilando-se posteriormente, até ultrapassar a margem das escamas que cobrem a base dos raios da nadadeira caudal, 
formando mancha com formato de losango. Faixa escura não atinge mesma largura que faixa prateada exceto na região do pedúnculo caudal. Geralmente margens dorsais das faixas se sobrepõem. Faixa escura mais superficial em relação à faixa prateada.

Exemplares menores (até 103,7 mm CP) apresentam linhas de cromatóforos na região entre pterigióforos da nadadeira anal, dorsalmente estas linhas acompanham linhas de miosseptos da musculatura hipaxial, ventralmente acompanham os raios da nadadeira anal (figura 17).

Nadadeiras peitorais e pélvicas hialinas, alguns exemplares com raio não ramificado da peitoral pigmentado. Nadadeira dorsal com linhas de cromatóforos ao longo dos raios e cromatóforos esparsos na membrana inter-radial. Nadadeira adiposa pouco pigmentada.

Linha escura em forma de arco acompanhando base dos raios da nadadeira caudal, cromatóforos mais concentrados abaixo das escamas desta região, em alguns exemplares apenas extremidades dorsal e ventral da linha são evidentes (figura 26).

Dimorfismo sexual: Machos de Galeocharax gulo apresentam ganchos ósseos nas nadadeiras anal e pélvica. Ganchos da nadadeira anal dispostos nas superfícies laterais do ramo posterior dos raios ramificados, alguns exemplares com ganchos no raio não ramificado mais longo. Geralmente um ou dois, raramente três, ganchos por segmento do raio, orientados dorso posteriormente (figura 36). Ganchos presentes nos 8 até 28 raios anteriores (tabela 16). Ganchos da nadadeira pélvica situados apenas na face ventral da nadadeira, na superfície posterior do ramo posterior dos raios ramificados. Geralmente um ou dois, raramente três, ganchos por segmento, voltados para base do raio (figura 37). Distribuição dos ganchos bastante variável, geralmente do primeiro ao quinto raio ramificado mais laterais (tabela 17).

Algumas fêmeas grandes (MZUSP 10479, 179,0 mm CP) também apresentam ganchos ósseos na nadadeira anal, porém menos desenvolvidos, em menor número e distribuídos por um número menor de raios comparado aos machos (figura 20).

Não foram encontradas diferenças nas proporções corporais entre machos e fêmeas (tabela 18).

Variação geográfica: De modo geral, há grande sobreposição das amplitudes de variação de todos os caracteres merísticos e morfométricos ao longo da distribuição geográfica da espécie. Contudo, exemplares da bacia do alto rio Paraná e da bacia do Rio Tocantins são mais semelhantes entre si, o mesmo ocorrendo para os exemplares da bacia do rio Amazonas e bacia do rio Orinoco, no que se refere à amplitude de variação bem como distribuição de frequência do número de escamas acima da linha lateral (tabela 19), número de escamas entre a linha lateral e a origem da nadadeira pélvica (tabela 20), número de escamas abaixo da linha lateral na vertical da origem da 
nadadeira anal (tabela 21), e do número de dentes no maxilar (tabela 22). Apesar de haver sobreposição de valores, exemplares da bacia do Alto Paraná e da bacia do Rio Tocantins apresentam a distância interorbital semelhante e ligeiramente menor do que exemplares da bacia do rio Amazonas e bacia do rio Orinoco (figuras 38 e 39).

Exemplares da bacia do rio Tocantins apresentam valores maiores do diâmetro orbital quando comparados aos exemplares da bacia do rio Amazonas (figura 40), Os exemplares da bacia do alto rio Paraná e da bacia do rio Orinoco apresentam valores intermediários quando comparados aos exemplares das bacias do rio Amazonas e do rio Tocantins (figura 41).

Exemplares do Rio Tocantins apresentam amplitudes ligeiramente menores e distribuições de frequência distintas do número de raios ramificados na nadadeira anal (tabela 23) e número total de vértebras (tabela 24), do que os exemplares do restante da distribuição da espécie. Pouco mais de metade dos exemplares da bacia do alto rio Paraná possuem 17 vértebras pré-caudais $(n=33)$, enquanto que os demais exemplares de toda a área de distribuição da espécie apresentam 16 vértebras pré-caudais $(n=91)$ (tabela 25).

Não foram encontradas diferenças nas amplitudes de variação das proporções corporais (tabelas 26 e 27).

Distribuição: Galeocharax gulo ocorre nas bacias do rio Amazonas, exceto rio Negro, Xingu e Tapajós, bacia do rio Orinoco, dos rios Tocantins e Araguaia e do alto rio Paraná (figura 42).

Observações: Não foi possível examinar o exemplar tipo de G. gulo (figura 43) durante o presente estudo, porém foi realizada uma comparação com os dados sobre o exemplar tipo presentes na literatura.

Informações sobre o exemplar tipo: Cope (1870), na descrição original da espécie detatlhou as seguintes características: escamas acima da linha lateral 14; raios na nadadeira dorsal 12; raios na nadadeira anal 41; dentes na fileira externa do dentário 4; dentes caninos no pré-maxilar 2. Géry (1972) examinou o holótipo de G. gulo e descreveu as seguintes características raios na nadadeira anal iv,40; escamas na linha lateral 80-83; escamas acima da linha lateral 14; escamas abaixo da linha lateral 16; dentes na fileira externa do pré-maxilar 9-10, sendo dois deles caninos; dentes na fileira interna do pré-maxilar 3; dentes no maxilar 31-36, dentes na fileira externa do dentário 4 caninos; dentes na fileira interna do dentário 8; dentes na fileira posterior do dentário 22.

Dentre os dados sobre o exemplar tipo de G. gulo presentes na literatura apenas os seguintes não concordaram com as amplitudes de variação observadas durante o 
presente estudo: número de dentes na fileira interna do pré-maxilar (3 vs. 2) e o número de dentes no maxilar (31-36 vs. 35-55).

Informações dos sintipos de G. knerii (figura 44) presentes na literatura: Steindachner (1878), na descrição original detalha as seguintes características: dentes caninos no dentário 4; dentes caninos no pré-maxilar 2; raios nadadeira anal iv,40-45; escamas na linha lateral 79-90; escamas acima da linha lateral 14-18; escamas abaixo da linha lateral na vertical que passa pela origem da nadadeira pélvica 13-14. Todas as informações descritas na literatura apresentam sobreposição com as amplitudes de variação observadas para exemplares da bacia do rio Amazonas e do alto rio Paraná.

Exemplares da bacia do rio Tapajós foram tentativamente identificados como Galeocharax gulo. Foram examinados três lotes num total de 9 exemplares que apresentam as seguintes amplitudes de variação de caracteres merísticos: escamas na linha lateral 78 (1), 79 (3), 80 (1), 81 (1) e 82 (1); escamas acima da linha lateral 15 (4) e 16 (3); escamas abaixo da linha lateral na vertical que passa pela origem da nadadeira pélvica 10 (1), 11 (4) e 12 (2); escamas abaixo da linha lateral na vertical que passa pela origem da nadadeira anal 14 (4), 15 (2) e 16 (3); escamas ao redor do pedúnculo caudal 20 (1), 21 (2), 22 (1) e 24 (2); raios ramificados na nadadeira anal 34 (2), 35 (2), 36 (4), 37 (1); dentes no maxilar 47 (1), 48 (1), 52 (2), 53 (1), 54 (1), 56 (2) e 57 (1); dentes na fileira interna do dentário 7 (2), 8 (3) e 9 (1); dentes na fileira externa do pré-maxilar 10 (2), 11 (3) e 13 (4), vértebras pré-caudais 16 (7); vértebras caudais 24 (7) e vértebras totais 40 (7). O exame de mais material desta drenagem se faz necessário para avaliar melhor a variação dos dados merísticos e morfométricos.

Planquette e colaboradores (1996) registraram a ocorrência de Galeocharax no rio Oyapok, na Guiana Francesa, identificando os exemplares como Galeocharax aff. gulo uma amplitude de 76-84 é relatada para o número de escamas da linha lateral, que se aproxima mais à amplitude descrita neste trabalho para G. gulo (77-87), em contraste com as amplitudes descritas para G. humeralis (90-105) e G. goeldii (88-97). Durante a realização do presente estudo só foi possível obter acesso a fotografias de exemplares desta localidade depositados no Museu de História Natural de Paris. O exame das fotografias sugere que realmente se tratam de Galeocharax, porém, sem o exame detalhado de exemplares desta localidade não foi possível confirmar a identificação da espécie que ocorre naquela drenagem.

\section{Galeocharax goeldii (Fowler, 1913)}

Figuras 45-48 
Anacyrtus humeralis; Perugia, 1897: 26 [listado; Reyes, rio Beni, Bolívia; identificação equivocada]

Charax goeldii Fowler, 1913: 568 [descrição original; localidade tipo tributário do rio Madeira próximo a Porto Velho, Brasil]; Schultz, 1950: 62 [como sinônimo de Cyrtocharax amazonum (Günther)]; Menezes, 1976: 44 [como sinônimo de Galeocharax gulo (Cope)]; Lucena \& Menezes, 2003: 203 [como sinônimo de Galeocharax gulo (Cope)]

Cyrtocharax goeldii; Fowler, 1950: 311[listado]

Cynopotamus (Acestrocephalus) goeldii; Géry \& Vu-Tân-Tuê, 1963b: 240 [diagnose em chave de identificação]; Géry, 1972: 25 [descrição; diagnose em chave de identificação]; 1977: 306 [listado]

Galeocharax gulo; Barthen et al, 2003: 80 [listado, Madre de Dios]

Galeocharax kneri; Barthen et al, 2003: 80 [listado, Madre de Dios]; Goulding et al, 2003: 143 [listado, Madre de Dios]

Galeocharax goeldii; Menezes 2007: 21 [redescrição]; Rapp Py-Daniel, 2007: 111

[listado como Galeocharax sp.]; Lima et al 2013 : 253 [listado].

Diagnose: Galeocharax goeldii diferencia-se de G. humeralis pela ausência de pequenos dentes cônicos situados entre o terceiro e quarto dente da fileira externa do dentário (figura 11) (vs. 1 a 3 dentes entre o terceiro e o quarto dente da fileira externa do dentário em G. humeralis). Diferencia-se de G. gulo por possui mais escamas na linha lateral (88-97 vs. 77-87 em G. gulo, tabela 1) e pela frequência de distribuição das seguintes características: número de escamas acima da linha lateral (17-20 vs. 14-19 em G. gulo, tabela 2); número de escamas abaixo da linha lateral na vertical que passa pela origem da nadadeira pélvica (15-17 vs. 11-16 em G. gulo, tabela 3); e número de escamas abaixo da linha lateral na vertical que passa pela origem da nadadeira anal (1619 vs. $14-18$ em G. gulo, tabela 4).

Descrição. Dados morfométricos de Galeocharax goeldii apresentados na tabela 5. Maior exemplar examinado 213,3 mm CP. Corpo alongado, comprimido lateralmente e moderadamente alto. Maior altura do corpo na linha vertical que passa pela origem do primeiro raio da nadadeira dorsal. Perfil dorsal da cabeça levemente côncavo da ponta do focinho à extremidade posterior do espinho do supraoccipital. Perfil dorsal do corpo levemente convexo da extremidade posterior do espinho do supraoccipital até base do primeiro raio da nadadeira dorsal. Perfil ao longo da base da nadadeira dorsal levemente convexo. Perfil ao longo da base do último raio da nadadeira dorsal até linha vertical que passa pela menor altura do pedúnculo caudal reto. Perfil ventral da cabeça e corpo convexo da extremidade anterior do dentário até a base do primeiro raio da nadadeira 
anal. Perfil ao longo do primeiro raio da nadadeira anal até a linha vertical que passa pela menor altura do pedúnculo caudal reto. Perfil da margem posterior do opérculo geralmente apresentando leve concavidade ou reto, raramente convexo em toda a margem (figura 12).

Supraneurais 4 (1), orientados obliquamente, extremidade proximal orientada antero-ventralmente, mais anterior situado anteriormente ao espinho neural da $5^{\text {a }}$ vértebra, quarto situado entre os espinhos neurais da $7^{\mathrm{a}}$ e $8^{\mathrm{a}}$ vértebra. Base do primeiro raio da nadadeira dorsal situada anteriormente à metade do $\mathrm{CP}$, base do último raio posterior à origem da nadadeira anal. Radial proximal-medial do primeiro pterigióforo inserido posteriormente ao espinho neural da $9^{\text {a }}$ vértebra. Raios da nadadeira dorsal ii,9. Perfil da margem posterior da nadadeira dorsal geralmente reto. Base do primeiro raio da nadadeira anal situada aproximadamente na metade do $\mathrm{CP}$, radial proximal-medial do primeiro petrigióforo da nadadeira anal posterior ao espinho hemal da $17^{\mathrm{a}}$ vértebra. Raios da anal iv (1),40-44 (tabela 6). Lóbulo anterior da nadadeira anal pouco desenvolvido, perfil da margem distal da nadadeira anal côncavo nos dois terços anteriores, levemente convexo no terço posterior. Nadadeira peitoral i,13(1), 14(27), 15(31) ou 16(10), raio mais longo alcançando a origem da nadadeira pélvica quando nadadeira é deprimida. Perfil da margem posterior da nadadeira peitoral reto, quatro ou cinco últimos raios mais próximos ao corpo mais curtos que os demais, não alcançando a projeção do perfil reto criado pelos demais raios. Retenção da forma larval da nadadeira peitoral em exemplares de até $33,7 \mathrm{~mm}$ CP (figura 32). Nadadeira pélvica situada anteriormente à origem da nadadeira dorsal; raios i,7; raio mais longo alcançando a abertura urogenital, não alcançando origem da nadadeira anal. Perfil da margem posterior da nadadeira pélvica levemente convexo, nadadeira com aspecto de leque quando aberta. Nadadeira caudal furcada, raios do lobo superior i,9 (1), lobo inferior 8,i (1), raios prócorrentes dorsais 16 (1), raios procorrentes ventrais 13 (1); lobo inferior pouco mais longo e alto que superior. Nadadeira adiposa presente, situada anteriormente à vertical que passa pela base do último raio da nadadeira anal.

Escamas espinoides (figuras 49-51) distribuídas por todo o corpo com exceção das axilas das nadadeiras pares e região posterior às bases das nadadeiras dorsal e anal, que apresentam escamas cicloides. Escama axilar presente na nadadeira pélvica. Escamas cobrindo aproximadamente um quinto da extensão dos raios mais anteriores da nadadeira anal. Três fileiras horizontais de escamas na base dos raios anteriores, número de fileiras horizontais de escamas diminuindo gradualmente posteriormente até uma fileira de escamas nos raios mais posteriores. Base dos raios da nadadeira caudal coberta por escamas (figura 15). 
Boca terminal, obliquamente orientada em relação ao eixo longitudinal do corpo, maxila superior ligeiramente mais pronunciada anteriormente que inferior. Extremidade posterior do maxilar ultrapassando vertical que passa pela margem posterior da órbita. Infraorbitais 1 a 6 presentes, supraorbital ausente, infraorbital 3 não alcançando préopérculo. Dentes cônicos. Pré-maxilar com duas fileiras de dentes; fileira interna com dois dentes voltados para o interior da boca, fileira externa com 8-10 dentes (tabela 7), o mais medial e o mais lateral caninos. Maxilar com 38-48 dentes cônicos (tabela 8) distribuídos ao longo de toda a margem ventral do osso. Dentário com duas fileiras de dentes. Fileira interna com 7-13 dentes (tabela 9) voltados posteriormente. Fileira externa com grupo anterior formado por quatro dentes caninos espaçados entre si, terceiro mais desenvolvido, geralmente primeiro e quarto de tamanho similar, alguns exemplares com quarto dente de tamanho intermediário entre primeiro e terceiro, segundo sempre menor e mais externo. Terceiro e quarto dentes bem espaçados entre si. Grupo posterior de dentes da fileira externa do dentário formado por uma fileira adjacente ao quarto dente do grupo anterior com 23 (1) pequenos dentes cônicos.

Linha lateral completa, estendendo-se da escama imediatamente posterior ao supracleitro até a escama situada na base da nadadeira caudal. Tubo de linha lateral presente entre os lobos da nadadeira caudal. Escamas na linha lateral 88-97 (tabela 1) com apenas uma bifurcação, ramificação orientada postero-ventralmente; fileiras horizontais de escamas entre a origem da nadadeira dorsal e a linha lateral 17-20, (tabela 2); fileiras horizontais de escamas entre a linha lateral e a origem da nadadeira pélvica 15-17, (tabela 3); fileiras horizontais de escamas entre a linha lateral e a origem da nadadeira anal 16-19, (tabela 4); fileiras horizontais de escamas ao redor do pedúnculo caudal 23-28 (tabela 10).

Vértebras totais 41(11) ou 42(2), vértebras pré-caudais 16(12) ou 17(1), caudais 25(12) ou 26(1).

Pseudotímpano presente, limitado antero-ventralmente pelo músculo obliquus superioris, posteriormente pelo músculo obliquus superioris e pela costela associoada à sexta vértebra, postero-dorsalmente pelo músculo lateralis superficialis e pelo nervo da linha lateral. Costela associada à quinta vértebra visível anteriormente não delimitando anteriormente hiato muscular (figura 16).

Coloração em álcool. Corpo amarelado, região dorsal mais escura que a região ventral devido à presença de cromatóforos no campo posterior das escamas. Faixa mediana dorsal escura conspícua do espinho do supraoccipital até a base do primeiro raio da nadadeira dorsal, não distinguível na região posterior à nadadeira dorsal.

Crânio mais escuro na região dorsal até, aproximadamente, linha horizontal da margem dorsal da órbita. Alguns indivíduos com cromatóforos esparsos na série 
infraorbital, principalmente infraorbitais 4, 5 e 6 . Margens dos lábios mais pigmentadas no pré-maxilar, maxilar e no dentário principalmente nas bases dos quatro dentes caninos da maxila inferior. Face lateral do maxilar com cromatóforos esparsos desde extremidade anterior até aproximadamente metade de seu comprimento.

Mancha na região umeral de aspecto oval, maior comprimento no sentido vertical. Alguns exemplares apresentam esta mancha com o aspecto de "meia lua" com as pontas voltadas anteriormente (figura 48).

Uma faixa longitudinal prateada no corpo dorsal à linha lateral, margem ventral da faixa alcançando linha lateral na maioria dos exemplares. Faixa longitudinal estende-se desde margem posterior do supracleitro até margem posterior da placa hipural, mais estreita em suas porções mais anterior e mais posterior, mais larga na região situada na vertical que passa pela base da nadadeira dorsal. Alguns indivíduos com faixa longitudinal prateada gradualmente mais larga do pedúnculo caudal até margem posterior da placa hipural, estes indivíduos com margem ventral da faixa longitudinal prateada ultrapassando, ventralmente a linha lateral na região do pedúnculo caudal.

Faixa longitudinal escura dorsal à linha lateral, geralmente mais evidente a partir da região umeral, em alguns exemplares estende-se desde a margem posterior do supracleitro, até aproximadamente metade do comprimento dos raios da nadadeira caudal, estreita na região anterior, gradualmente mais larga posteriormente até região abaixo da base da nadadeira dorsal, gradualmente mais estreita posteriormente deste último ponto até o pedúnculo caudal. Faixa longitudinal escura alarga-se entre região do pedúnculo caudal e margem posterior da placa hipural, afunilando-se posteriormente até ultrapassar escamas que cobrem parte dos raios da nadadeira caudal, formando mancha com formato de losango. Faixa escura não atinge mesma largura que faixa prateada exceto na região do pedúnculo caudal. Geralmente margens dorsais das faixas se sobrepõem. A faixa escura é mais superficial em relação à faixa parateada.

Exemplares menores (até 48,0 $\mathrm{mm} \mathrm{CP}$ ) apresentam linhas de cromatóforos na região entre pterigióforos da nadadeira anal, dorsalmente estas linhas acompanham linha dos mioseptos da musculatura hipaxial, ventralmente acompanham os raios da nadadeira anal (figura 17).

Nadadeiras peitorais e pélvicas hialinas. Nadadeira dorsal com linhas de cromatóforos ao longo dos raios e cromatóforos esparsos na membrana interradial. Nadadeira adiposa geralmente com coloração pálida a não ser na margem anterodorsal que apresenta linha de cromatóforos.

Linha vertical escura em forma de arco acompanhando base dos raios da nadadeira caudal, cromatóforos mais concentrados abaixo das escamas desta região, em alguns exemplares apenas extremidades da linha são evidente (figura 48). 
Dimorfismo sexual: Machos de Galeocharax goeldii apresentam ganchos ósseos nas nadadeiras anal e pélvica. Ganchos da nadadeira anal dispostos nas superfícies laterais do ramo posterior dos raios ramificados, alguns exemplares com ganchos no raio não ramificado mais longo. Geralmente um ou dois, raramente três, ganchos por segmento do raio, orientados dorso posteriormente (figura 52). Ganchos presentes nos dez até 23 raios anteriores primeiros (tabela 28). Ganchos da nadadeira pélvica situados apenas na face ventral da nadadeira (um exemplar com ganchos apenas na face dorsal), na superfície posterior do ramo posterior dos raios ramificados. Geralmente um ou dois, raramente três, ganchos por segmento, voltados para base do raio (figura 52). Ganchos distribuídos pelos quatro ou cinco raios ramificados mais anteriores (tabela 29).

Não foram encontradas diferenças nas amplitudes de variação das proporções corporais (tabela 30).

Variação geográfica: não foram encontradas diferenças nos dados merísticos e morfométricos de exemplares oriundos da bacia do rio Madeira e da bacia do rio Madre de Dios. Há sobreposição total nas amplitudes de variação dos caracteres merísticos em quase sua totalidade. Também não foram encontradas diferenças nas amplitudes de variação das proporções corporais (tabela 31).

Distribuição: Galeocharax goeldii ocorre nas bacias dos rios Madre de Dios, Madeira, Beni, Guaporé e Mamoré (figura 53).

Observações Galeocharax goeldii foi originalmente descrito como Charax goeldii por Fowler (1913) com base em um exemplar de $56 \mathrm{~mm}$ de CP coletado em um tributário do rio Madeira próximo à cidade de Porto velho. Posteriormente, Schultz (1950) considerou Charax goeldii sinônimo de Cyrtocharax amazonum. Fowler (1950) considerou Cyrtocharax goeldii como espécie válida. Menezes (1976) demonstra que Cyrthocharax Fowler é sinônimo de Cynopotamus Valenciennes e propõe a realocação de Cynopotamus humeralis e Cynopotamus gulo em Galeocharax. No mesmo trabalho Menezes, baseando-se em dados de Géry (1972), inclui Charax goeldii na sinonímia de Galeocharax gulo.

Posteriormente Menezes (2007a) ao examinar o tipo de Charax goeldii, além de material adicional proveniente da bacia do rio Madeira reconhece a espécie como válida dentro de Galeocharax.

Como parte do presente trabalho foi examinado material proveniente das bacias do rio Madre de Dios, rio Beni, rio Mamoré e rio Guaporé. Todos os exemplares concordam com a delimitação da espécie feita por Menezes (2007a), não demonstrando variação geográfica dos caracteres meristicos e morfométricos. Galeocharax goeldii teve, portanto, sua distribuição geográfica ampliada, não sendo mais restrita à bacia do rio Madeira. 
Não foi possível examinar o exemplar tipo de G. goeldii (figura 54) durante o presente estudo, porém foi realizada uma comparação com os dados sobre o exemplar tipo presentes na literatura.

Dados sobre o exemplar tipo: Fowler (1913) na descrição original da espécie detalha as seguintes características: raios na nadadeira dorsal ii,9; raios na nadadeira anal iv,41,i; raios na nadadeira peitoral i,15; raios na nadadeira pélvica i,7; escamas na linha lateral 81 até a base da cauda e 6 na cauda; escamas acima da linha lateral "about" 18; escamas abaixo da linha lateral na vertical que passa pela origem da pélvica 18; escamas abaixo da linha lateral na vertical que passa pela origem da nadadeira anal 19; maxila superior com 2 pares de caninos; maxila inferior com 3 pares de caninos; escamas com espinhos. Géry (1972) examinou o exemplar tipo e descreveu as seguintes características: raios na nadadeira anal iv,40; escamas na linha lateral 86; escamas acima da linha lateral 17; escamas abaixo da linha lateral 16; dentes na fileira externa do pré-maxilar 11, sendo dois caninos; dentes na fileira interna do pré-maxilar 2; dentes no maxilar 36-39; dentes na fileira externa do dentário 5, sendo dois caninos; dentes na fileira posterior do dentário 10; dentes na fileira interna do dentário 8.

Dos dados sobre o exemplar tipo presentes na literatura, o número de escamas na linha lateral relatado por Fowler (1913) e Géry (1972), o número de dentes no maxilar, o número de escamas abaixo da linha lateral na vertical que passa pela origem da nadadeira pélvica e o número de dentes na fileira posterior do dentário relatado por Géry (1972) não concordaram com a amplitude de variação observada no presente estudo.

A amplitude de variação do número de escamas na linha lateral em G. goeldii observada no presente estudo é de 88-97 (tabela 1), o valor 87 relatado por Fowler (1913) na descrição original e o valor 86 relatado por Géry (1972) concordam com a amplitude de variação observada para G. gulo, porém os valores do número de escamas abaixo da linha lateral tanto na vertical que passa pela origem da nadadeira pélvica (18), quanto na vertical que passa pela nadadeira anal (19), relatadas por Fowler (1913) permitem diferenciar o exemplar tipo de G. goeldii de G. gulo com base nas amplitudes de variação observadas no presente estudo (tabelas 3 e 4).

\section{Discussão}

As únicas características que, segundo Menezes (1976), distinguem G. gulo de G. knerii são altura do corpo, G. gulo possui o corpo mais alto que G. knerii (Menezes, 1976: 82, figura 51), e número de dentes na fileira posterior do dentário, G. gulo possui menor número de dentes que G. knerii (Menezes, 1976: 84, figura 55). O presente 
estudo não encontrou diferenças na proporção entre altura do corpo e comprimento padrão nos exemplares da bacia do rio Amazonas e da bacia do alto rio Paraná, como pode ser observado no gráfico de dispersão de valores de altura do corpo pelo comprimento padrão (figura 55). Também foi observada grande sobreposição entre as amplitudes de variação do número de dentes na fileira posterior do dentário dos exemplares da bacia do rio Amazonas e do alto rio Paraná como pode ser observado na tabela 32. Menezes (1976) observou variação ontogenética no número de dentes na fileira externa do dentário, na qual exemplares maiores apresentam um maior número de dentes. Os exemplares examinados no presente estudo apresentaram uma leve tendência de aumento do número de dentes da fileira posterior do dentário com o aumento do comprimento padrão, porém não é possível distinguir formas com base na dispersão destes pontos em um gráfico (figura 56).

Menezes (1976) observou que as duas formas por ele reconhecidas apresentaram sobreposição das demais características, tanto merísticas quanto morfométricas. No presente estudo foi observado que as amplitudes de variação de quase todos os dados merísticos e morfométricos são maiores que as registradas por Menezes (1976), isso em parte se explica pelo maior número de exemplares examinados no presente estudo (tabelas 19 a 23). Foi também observada grande sobreposição das amplitudes de variação de exemplares da bacia do rio Amazonas e do alto rio Paraná (tabelas 21, 23, $24,32,33,34)$.

Mattox \& Toledo-Piza (2012), em sua análise filogenética de Characinae, relataram algumas diferenças osteológicas entre G. gulo e G. knerii.

I - G. gulo possui a margem anterior do palatino com duas regiões distintas de articulação, uma medial associada ao neurocrânio e uma lateral associada ao processo medial maxilar, estas regiões são separadas por uma abertura circular, pela qual passa a extremidade distal do maior dente canino do dentário (Mattox \& Toledo-Piza, 2012: 851). Segundo aqueles autores G. knerii possui a margem anterior do palatino arredondada com uma superfície de articulação única, uma condição mais generalizada entre os Characiformes. O exame de material utilizado pelos autores na realização do trabalho citado e de material diafanizado e corado adicional mostrou que as espécies de Galeocharax apresentam uma condição similar, possivelmente intermediária às condições descritas por Mattox \& Toledo-Piza (2012). Há duas regiões distintas de articulação na margem anterior do palatino, uma medial associada ao neurocrânio e uma lateral associada ao processo medial do maxilar (figura 57), diferente da superfície de articulação única observada na maioria dos Characiformes examinados pelos autores. Porém a separação entre as duas regiões de articulação é sutil, não há abertura como observado em Cynopotamus. 
II - G. knerii possui a margem lateral do ectopterigoide reta em toda sua extensão. Um ligamento conecta a superfície medial do maxilar à margem lateral do ectopterigoide (Mattox \& Toledo-Piza, 2012: 853) Alternativamente em G. gulo a margem lateral do ectopterigoide apresenta uma projeção óssea lateral achatada dorsoventralmente, onde o ligamento citado se liga (figura 57 (B)). O exame do material utilizado pelos autores confirmou a presença de tal projeção em G. gulo, porém um exemplar adicional diafanizado e corado de G. knerii, de tamanho similar ao exemplar de G. gulo examinado pelos autores, apresentou a projeção em questão (figura $57(\mathrm{~F})$ ). Isto pode indicar uma variação ontogenética desta característica na espécie, a gradual ossificação da base do ligamento em contato com a margem lateral do ectopterigóide.

III - Projeção antero-dorsal no metapterigóide. O metapterigóide em Characiformes geralmente possui uma projeção óssea antero-dorsal orientada medialmente associada ao endopterigóide. G. knerii possui uma projeção óssea antero-dorsal orientada medialmente associada ao endopterigóide Alternativamente G. gulo não apresenta tal projeção (Mattox \& Toledo-Piza, 2012: 854). Contudo, a condição observada no material utilizado por aqueles autores e de material adicional parece ser a mesma em todos os exemplares na qual a projeção antero-dorsal no metapterigóide é ausente. (figura 3).

Além das diferenças osteológicas entre G. gulo e G. knerii, Mattox \& Toledo-Piza (2012: 832) também reportaram uma diferença miológica entre as duas espécies, a posição relativa das margens posteriores dos músculos adductor operculi e levator operculi. Em G. knerii as margens posteriores destes músculos estão localizadas na mesma vertical, enquanto nas demais espécies do gênero a margem posterior do levator operculi está localizada posteriormente à margem posterior do adductor operculi. Não foi possível avaliar esta diferença durante o presente estudo.

A análise dos dados mostrou ainda que exemplares da bacia do rio Tocantins apresentam amplitudes de variação diferentes das apresentadas por exemplares da bacia do rio Amazonas e da bacia do alto rio Paraná para as características número de escamas na linha lateral (tabela 33), número de raios ramificados na nadadeira anal (tabela 23) e número total de vértebras (tabela 24). Os exemplares da bacia do rio Tocantins se mostraram similares aos exemplares da bacia do alto rio Paraná como pode ser observado nas características: número de escamas acima da linha lateral (tabela 19), número de escamas abaixo da linha lateral na vertical que passa pela origem da nadadeira pélvica (tabela 20) e número de escamas abaixo da linha lateral na vertical que passa pela origem da nadadeira anal (tabela 21). Sendo assim, foi considerada a alternativa de restringir o nome G. gulo para os exemplares da bacia do rio Amazonas e considerar que os exemplares da bacia do rio Tocantins e do alto rio Paraná fossem 
reconhecidos como G. knerii. Todavia a diferenciação entre as duas espécies reconhecidas desta maneira continuaria problemática, uma vez que até mesmo as características em que é observada maior semelhança entre os exemplares do rio Tocantins e os exemplares do alto rio Paraná citadas acima, apresentaram algum grau de sobreposição com as amplitudes de variação dos exemplares do rio Amazonas. As diferenças só ficam evidentes em relação às frequências de distribuição, como pode ser verificado nas tabelas 19 a 21 . O número de escamas abaixo da linha lateral na vertical que passa pela origem da nadadeira pélvica foi a característica que apresentou menor sobreposição, mesmo assim há sobreposição de $44 \%$ dos exemplares examinados quando exemplares da bacia do rio Amazonas são comparados com o agrupamento formado por exemplares do rio Tocantins e alto rio Paraná (tabela 20). Número de escamas acima da linha lateral e número de escamas abaixo da linha lateral na vertical que passa pela origem da nadadeira anal apresentaram sobreposição de $56 \%$ e $72 \%$, respectivamente, dos exemplares examinados (tabelas 19 e 21).

Menezes (1976) propôs uma conformação geográfica para as variações morfológicas de Galeocharax que consistia em um agrupamento para a bacia do rio Paraguai e baixo rio Paraná, um agrupamento para a bacia do alto rio Paraná e um agrupamento para as bacias dos rios Amazonas e Tocantins. Posteriormente Menezes (2007a) reconheceu um agrupamento para a bacia do rio Madeira. O presente estudo também reconheceu um agrupamento para as bacias dos rios Paraguai e baixo rio Paraná e um agrupamento para a bacia do rio Madeira, porém em contraste à proposta de Menezes (1976) não é reconhecido um agrupamento exclusivo das bacias dos rios Amazonas e Tocantins, uma vez que foi observado que os exemplares da bacia do rio Tocantins apresentam algumas características cujas amplitudes de variação que diferenciam-no das demais formas e que, notavelmente, estes exemplares se mostraram mais similares a exemplares da bacia do alto rio Paraná que a exemplares da bacia do rio Amazonas. Um agrupamento exclusivo para exemplares da bacia do rio Amazonas e exemplares da bacia do rio Tocantins mascararia grande parte deste padrão geográfico da variação morfológica.

Observa-se ainda que há uma descontinuidade da distribuição geográfica entre a região do alto rio Amazonas e rio Orinoco e a região do rio Tocantins e alto rio Paraná, uma vez que não há registro de Galeocharax para a bacia do rio Xingu e apenas três registros para a bacia do rio Tapajós. Neste estudo foram examinados três lotes (nove exemplares) provenientes da bacia do rio Tapajós (amplitudes de variação dos dados merísticos na seção observações de $G$. gulo), a amplitude de variação do número total de vértebras é a mesma daquela dos exemplares do rio Tocantins e as amplitudes de variação do número de raios ramificados na nadadeira anal, número de dentes no 
maxilar e número de escamas abaixo da linha lateral na vertical da origem da nadadeira pélvica para estes exemplares é a mesma daquelas observadas para os exemplares das bacias do rio Tocantins e do alto rio Paraná, não havendo sobreposição com a amplitude de variação dos exemplares da bacia do rio Amazonas.

O exame de mais material proveniente da bacia do rio Tapajós se faz necessário para verificar a qual agrupamento estes exemplares mais se assemelham. Faz-se também necessário um esforço de coleta voltado ao gênero na bacia do rio Xingu para verificar a sua ausência nessa localidade.

Considerando que as diferenças entre exemplares da bacia do rio Amazonas e da bacia do alto rio Paraná, em relação às características atualmente utilizadas para diferenciar G. gulo de G. knerii, não foram confirmadas pelo presente estudo, e que foi observada grande sobreposição das amplitudes de variação das características examinadas, conclui-se que, apesar da tendência de diferenciação, há grande sobreposição nos dados que seriam diagnósticos, optou-se, portanto, por considerar a espécie nomina Galeocharax knerii como sinônimo de Galeocharax gulo. Seguindo o Principio de Prioridade (ICZN: art. 23) o nome Galeocharax gulo tem precedência, Galeocharax knerii é considerado, portanto, sinônimo júnior de Galeocharax gulo, esta espécie passa a apresentar ampla distribuição geográfica pelas bacias do rio Amazonas, do rio Orinoco, dos rios Tocantins e Araguaia e do alto rio Paraná.

Taphorn (1992: 185) relatou a ocorrência do gênero Galeocharax no rio Apure, bacia do rio Orinoco, na Venezuela. O autor ressaltou que os exemplares examinados por ele não poderiam ser de G. humeralis pela diferença no número de escamas na linha lateral (98-101 em G. humeralis, como descrito por Menezes (1976) vs. 79-84 nos exemplares do rio Apure) e que a amplitude de variação desta característica concorda com as amplitudes de variação de G. gulo e G. knerii, observadas por Menezes (1976). $\mathrm{O}$ autor sugeriu que uma comparação cuidadosa deveria ser feita entre exemplares amazônicos de Galeocharax com os exemplares do rio Apure, que provavelmente representariam uma espécie ainda não descrita. No presente trabalho 42 exemplares provenientes da bacia do rio Orinoco tiveram seus dados merísticos e morfométricos tomados, a comparação deste material com exemplares do alto rio Amazonas não demonstrou diferenças nas amplitudes de variação em caracteres tanto merísticos, quanto morfométricos. Há sobreposição total em quase todas as características examinadas (tabelas 19 a 27, 33 e 34). Os exemplares de Galeocharax do rio Orinoco são considerados como G. gulo.

Dada a ampla distribuição da espécie G. gulo e as variações morfológicas já observadas a espécie se mostra como um potencial alvo de estudos baseados em dados 
moleculares como DNA Barcode para verificar qual é o grau de divergência genética entre exemplares das diferentes bacias de sua ampla distribuição geográfica.

Ganchos ósseos em Galeocharax: Os machos maduros das espécies de Galeocharax apresentam ganchos ósseos nas nadadeiras anal e pélvica (figuras 18, 19, 36, 37 e 52). Características sexualmente dimórficas são bastante comuns em representantes de Characiformes. A presença de pequenos ganchos ósseos nos raios das nadadeiras anal e pélvica de machos sexualmente maduros já foram registrados para de diversos gêneros de Characidae (Azpelicueta \& Garcia, 2000; Malabarba \& Weitzman, 2003; Camelier \& Zanata, 2014).

Como discutido por Camelier \& Zanata (2014), tais estruturas já foram consideradas como sazonais por diversos autores (Fink \& Weitzman, 1974; Collette, 1977; Garutti, 1990), baseando-se na alta frequência de ganchos nos raios dos machos durante o período reprodutivo sua ausência ou menor frequência nos períodos restantes (Gonçalves et al, 2005). Porém, outros autores (Andrade et al, 1984) afirmam que tais estruturas são permanentes uma vez formadas.

Os ganchos ósseos apresentam grande variedade de forma, número, distribuição e provavelmente função entre as espécies de Characidae, porém consistem sempre de projeções ósseas dos segmentos individuais das lepidotríquias. A presença de tais estruturas foi proposta por Malabarba \& Weitzman (2003) como sinapomorfia para um clado formado por Gasteropelecidae e grande parte dos Characidae.

Algumas fêmeas examinadas no presente trabalho também apresentaram ganchos ósseos na nadadeira anal (MZSUP2073, MZUSP10479, MZUSP10556, MZUSP20485, MZUSP35500, MZUSP 38869, MZUSP90473 e MCP28624 figura 20). A presença de ganchos ósseos em fêmeas de Characiformes é bastante incomum. Uma busca na literatura revelou apenas os seguintes relatos de presença de ganchos ósseos em fêmeas de: Cheirodon (Malabarba, 1998: 210, nos raios das nadadeiras pélvicas); Astyanax jordanensis (Alcaraz et al, 2009: 188, nos raios da nadadeira anal); Brycon n. sp. "Pardo" (Lima, 2001: 20, 82, nos raios da nadadeira anal) e Hyphessobrycon socolofi (Teixeira, 2010: 58, nos raios da nadadeira anal). Não foram encontrados registros de ganchos em fêmeas das espécies que compõe a subfamília Characinae, na qual Galeocharax está inserido.

Tais observações podem indicar que a ocorrência de ganchos ósseos em exemplares fêmeas é mais comum do que o registrado. É recomendável que a definição do sexo do exemplar não seja feita apenas com base na presença ou ausência dos ganchos ósseos nos raios das nadadeiras. 


\section{Conclusões}

- Foram reconhecidas como válidas as espécies: Galeocharax humeralis (Valenciennes, 1834); Galeocharax gulo (Cope, 1870) e Galeocharax goeldii (Fowler, 1913).

- Galeocharax knerii é considerado sinônimo júnior de Galeocharax gulo

- Galeocharax humeralis ocorre nas bacias dos rios Paraguai, baixo rio Paraná e rio Uruguai; Galeocharax gulo ocorre nas bacias do rio Amazonas, exceto rio Negro e rio Xingu, bacia do rio Orinoco, dos rios Tocantins e Araguaia e do alto rio Paraná e Galeocharax goeldii mostrou distribuição geográfica mais ampla que o registrado, pelas bacias dos rios Madeira, Madre de Dios, Beni, Guaporé e Mamoré.

- O padrão geográfico da variação morfológica observado neste trabalho difere em parte daquele proposto por Menezes (1976 e 2007a), que reconheceu uma forma para a bacia do alto rio Paraná e outra forma para as bacias do rio Amazonas e do rio Tocantins. O presente trabalho revelou que os exemplares da bacia do rio Tocantins são mais semelhantes aos exemplares da bacia do alto rio Paraná.

- Exemplares da bacia do rio Orinoco são mais semelhantes aos exemplares da bacia do rio Amazonas. 


\section{Referências bibliográficas}

Alcaraz, H. S., Pavanelli, C. S. \& Bertaco, V. A. 2009. Astyanax jordanensis (Ostariophysi: Characidae), a new species from the rio Iguaçu basin, Paraná, Brasil. Neotropicl Ichthyology. 7 (2): 185-190.

Andrade, D. R., Menin, E. \& Ribeiro, S. P. 1984. Periodicidade da característica sexual secundria em Astyanax bimaculatus (Linnaeus, 1758) Pisces, Characidae. Revista Seiva. 44: 9-12.

Apone, F., Oliveira, A. K. \& Garavello, J. C. 2008. Composição da ictiofauna do rio Quilombo, tributário do rio Mogi-Guaçu, bacia do alto rio Paraná, sudeste do Brasil. Biota Neotrop. 8 (1): 93-107.

Aramburu, A. S. A. 1953. Contribución a la sistematica de lós peces characidos llamados "dientudos". Not. Mus. Cienc. Nat. Eva Perón. 16 (145): 307-320.

Azpelicueta, M. M. \& Garcia, J. O. 2000. A new species of Astyanax (Characiformes: Characidae) from Uruguay river basin in Argentina, with remarks on hook presence in Characidae. Revue Suisse de Zoologie 107 (2): 245-257.

Barthem, R., Goulding, M., Forsberg, B., Cañas, C. \& Ortega, H. Aquatic ecology of the rio Madre de Dios. Scientific bases for Andes-Amazon headwaters conservation. Gráfica Bilbos. Lima. 117pp.

Bogotá-Gregory, J. D. \& Maldonado-Ocampo, J. A. 2006. Peces de la zona hidrogeográfica de la Amazonia, Colombia. Biota Colombiana. 7 (1): 55-94.

Boulenger, G. A. 1887. An account of the fishes collected by Mr. C. Buckley in eastern Ecuador. Proc. Zool. Soc. London. 8: 274-283.

Boulenger, G. A. 1898. On a collection of fishes from the Rio Juruá, Brazil. Trans. Zool. Soc. London. 14: 421-428.

Brandão, H.; Toledo, G. M.; Wunderlich, A. C.; Ramos, I. P.; Carvalho, E. D. \& Silva, R. J. 2013. Ocurrence of Braga cigarra (Cymothoidae) parasitizing Galeocharax knerii (Characidae) from affluents of Jurumirim reservoir, Brazil. Rev. Bras. Parasitol. Vet. 22 (2): 292-296.

Brandão, H., Vidotto-Magnoni, A. P., Ramos, I. P. \& Carvalho E. D. 2009. Assesment of the ichthyofauna in stretches under the influence of Salto Grande Reservoir (Middle Paranapanema River, SP/PR, Brazil). Acta Limnol. Bras. 21 (4): 452-463.

Britski, H.A., de Silimon, K. Z. S. \& Lopes, B.S. 1999. Peixes do Pantanal. Manual de identificação. Embrapa-SPI, Corumbá, 184 pp.

Buckup, P. A.; Menezes, N. A. \& Ghazzi M. S. 2007. Catálogo de Peixes de Água Doce do Brasil. Museu Nacional. Rio de Janeiro. 195pp.

Camelier, P. \& Zanata, A. M. 2014. A new species of Astyanax Baird \& Girard (Characiformes: Characidae) from rio Paraguaçu basin, Chapada Diamantina, Bahia, Brazil, with comments on bony hooks on all fins. Journal of Fish Biology. 84: 475-490.

Collette, B. B. 1977. Epidermal breeding tubercles and bony contact organs in fishes. IN Spearman, R. I. C. (Ed). Comparative Biology of the Skin. Symposia of the Zoological Society of London 39. p. 225-268.

Cope, E. D. 1870. Contribution to the ichthyology of the Marañon. Proc. Amer. Philos. Soc. Philadelphia. 11: 559-570. 
Copatti, C. E., Zanini, L. G. \& Valente, A. 2009. Ictiofauna da microbiologia do rio Jaguari, Jaguari/RS, Brasil. Biota Neotrop. 9 (2).

Eigenmann, C. H. 1903. New genera of South American fresh-water fishes, and new names for some old genera. Smithsonian Miscellaneous Collections 45: 144-148.

Eigenmann, C. H. 1907. Fowler's "Heterognathous Fishes" with a note on the Stethaprioninae. Amer. Nat. 41 (492): 767-772.

Eigenmann, C. H. 1910. Catalogue of the fresh-water fishes of tropical and south temperate America. IN Reports of the Princeton University expeditions to Patagonia 1896-1899. Zoology. 3 (4) 375-511.

Eigenmann, C. H. \& Allen, W. R. 1942. Fishes of Western South America. Univ. of Kentucky. Lexington. 494pp.

Egenmann, C. H. \& Eigenmann, R. S. 1891. A catalogue of the fresh-water fishes of South America. Proc. U. S. Natl. Mus. 14: 1-81.

Eigenmann, C. H., McAtee, W. L. \& Ward, D. P. 1907. On further collections of fishes from Parguay. Ann. Carnegie. Mus. 4 (7): 110-157.

Eigenmann, C. H. \& Norris, A. A. 1900. Sobre alguns peixes de S. Paulo, Brasil. Rev. Mus. Paulista. 4: 349-362.

Eigenmann, C. H. \& Ogle, F. 1907. An annotated listo f characin fishes in the United States National Museum and the Museum of Indiana University, with descriptions of new species. Proc. U. S. Natl. Mus. 33 (1556): 1-36.

Eschmeyer, W. N. \& Fong, J. D. Species by Family/Subfamily. (http://researcharchive.calacademy.org/research/ichthyology/catalog/SpeciesByFamily. asp). Electronic version.

Fink, W. L. \& Weitzman, S. H. 1974. The so-called cheirodontin fishes of Central America with description of two new species (Pisces, Characidae). Smithsonian Contributions to Zoology 172: 1-46.

Fowler, H. W. 1901. Note on the Odontostomidae. Proc. Acad. Nat. Sci. Philadelphia.53: 211-212.

Fowler, H. W. 1904. Note on the Characinidae. Proc. Acad. Nat. Sci. Philadelphia. 56: 119.

Fowler, H. W. 1907. Further knowledge of some heterognathous fishes. Part II. Proc. Acad. Nat. Sci. Philadelphia. 58: 431-483.

Fowler, H. W. 1910. The proper restrictionof Eucynopotamus. Science 31 (803): 790.

Fowler, H. W. 1913. Fishes of the Madeira River, Brasil. Proc. Acad. Nat. Sci. Philadelphia. 65 (3): 517-579.

Fowler, H. W. 1940. A collection of fishes obtained by Mr. William C. Morrow in the Ucayali River Basin, Peru. Proc. Acad. Nat. Sci. Philadelphia. v. 91 (for 1939): 219289.

Fowler, H. W. 1945. Los peces del Peru. Catalogo sistematico de los peces que habitan em aguas peruanas. Mus. Hist. Nat. Javier Prado. Univ. Mayor de San Marcos. Lima. 298pp. 
Fowler, H. W. 1950. Os peixes de água doce do Brasil. Arq. Zool. São Paulo. 6: 205404.

Freitas, I. S., Lucinda P. H. F., Soares, A. B., Pelicice, F. M. \& Akama, A. 2009. Variações espaciais na estrutura da ictiofauna entre os ambientes do reservatório de Peixe angical. IN Agostinho, C. S., Pelicica, F. M. \& Marques, E. E. (Orgs.) Reservatório de Peixe Angical. Bases ecológicas para o manejo da ictiofauna. Rima Editora. São Carlos. p 41-49.

Garutti, V. 1990. Caráter sexual secundário em Astyanax bimaculatus (Ostariophysi, Characidae), relacionado às nadadeiras anal e pélvicas. Naturalia. 15: 109-119.

Gandini, C. V., Boratto, I. A., Fagundes, D. C. \& Pompeu, P.S.; 2012; Estudo da alimentação dos peixes no rio Grande à jusante da usina hidrelétrica de Itutinga, Minas Gerais, Brasil. Iheringia, Sér. Zool. 102 (1): 56-61.

Galvis, G., Mojica, J. I., Duque, S. R., Castellanos, C., Sánchez-Duarte, P., Arce, M., Gutiérrez, A., Jiménez, L. F., Santos, M., Vejarano, S. Arbeláez, F., Prieto, E. \& Leiva, M. 2006. Peces del medio Amazonas: Region de Leticia. Conservación Internacional. Editorial Panamericana formas e Impresos. Bogotá. 548pp.

Garman, S. W. 1890. On the species of the genus Chalcinus in the Museum of Comparative Zoology at Cambridge, Mass. USA. On the species of Gasteropelecus. On the species of Cynopotamus. On the species of the genus Anostomus. Bull Essex Inst., Salem. 22 (1-3): 1-23.

Gealh, A. M. 2007. Ictiofauna dos rios Fortaleza, Iapó, alto e médio Tibagi. IN Patrimônio Natural dos Campos Gerais do Paraná. Melo, M. S., Moro, R. S. \& Guimarães (orgs.) Ponta Grossa. Editora UEPG, 230pp.

Géry, J. 1972. Corrected and suplemented descriptions of certain characoid fishes described by Henry W. Fowler, with revisions of several of their genera. Studies on the Neotropical Fauna. 7: 1-35.

Géry, J. 1977. Characoids of the world. T.F.H. Publications, Neptune City, 672 pp.

Géry, J. \& Vu-Tân-Tuê, 1963a. Définitions de Cynopotamus Val. et genres voisins (Pisces, Characoidei). Bull. Mus. Nat. Hist. Nat. Paris. (2) 35 (2): 143-150.

Géry, J. \& Vu-Tân-Tuê, 1963b. Définitions de Cynopotamus Val. et genres voisins (Pisces, Characoidei). Suite. Bull. Mus. Nat. Hist. Nat. Paris. (2) 35 (3): 238-246.

Godoy, M.P. 1975. Peixes do Brasil: subordem Characoidei. v. II, Franciscana,Piracicaba. 397 pp.

Goeldi, E. A. 1898. Primeira contribuição para o conhecimento dos peixes do vale do Amazonas e das Guyanas. Estudos ichthyologicos dos anos 1894-1898. Bol. Mus. Paraense. 2: 443-488.

Goulding, M., Cañas, C., Barthem, R., Forsberg, B. \& Ortega, H. 2003. Amazon Headwaters. Rivers, wildlife and conservation in Southeastern Peru. Gráfica Bilbos, Lima 198 pp.

Gomiero, L. M. \& Braga, F. M. S. 2006. Listo f species. Fish, Corumbataí and JacaréPepira river basins, São Paulo state, Brazil. Check List. 2 (1): 57-67.

Gonçalves, T. K., Azevedo, M. A., Malabarba, L. R. \& Fialho, C. B. 2005. Reproductive biology and development of sexually dimorphic structures in Aphyocharax anisitsi (Ostariophysi: Characidae). Neotropical Ichthyology 3: 433-438. 
Graça, W. J. \& Pavanelli, C. S. 2007. Peixes da planície de inundação do alto rio Paraná e áreas adjacentes. Maringá. EDUEM. 241 pp.

Günther, A. 1864. Catalogue of fishes in the British Museum. 5: XXII + 455pp.

Júlio Jr., H. F., Cunico, A. M., Gubiani, E. A., Fernandes, R., Dias, R. M., Graça, W. J. \& Gomes, L. C. 2003. Ictiofauna. 77-99. IN Agostinho, A. A., Thomaz, S. M., Rodrigues, L. \& Gomes, L. C. A Planície de Inundação do alto rio Paraná. Relatório 2003. Nupelia. UEM.

Kner, R. 1860. Zur Familie Characinen. II. Folge der ichthyologischen Beiträge. Denkschr. k. Akad. Wiss. Wien. 18: 9-62.

La Monte, F. 1935. Fishes from the Rio Juruá and Rio Purus, Brazilian Amazonas. Amer. Mus. Novit. 784: 1-8.

Langeani, F., Castro, R. M. C., Oyakawa, O. T., Shibatta, O. A., Pavanelli, C. S. \& Casatti, L. 2007. Diversidade da ictiofauna do Alto Rio Paraná: composição atual e perspectivas futuras. Biota Neotrop. 7 (3): 181-197.

Langeani, F. \& Rêgo, A. C. L. 2014. Guia ilustrado dos peixes dabacia do rio Araguari. Uberlândia. Grupo de Mídia Brasil Central. 195pp.

Lasso, C. A., Mojica, J. I., Usma, J. S., Maldonado-Ocampo, J. A., DoNascimiento, C.,Taphorn, D. C., Provenzano, F., Lasso-Alcalá, O. M., Galvis, G., Vásques, L., Lugo, M., Machado-Allison, A., Royero, R., Suárez, C. \& Ortega-Lara, A. 2004. Pesces de la cuenca del río Orinoco. Parte I: lista de espécies y distribución por subcuencas. Biota Colombiana. 5 (2): 95-158.

Le Bail, P. Y., Covain, R., Jégu, M., Fisch-Muller, S., Vigouroux, R. \& Keith, P. 2012. Updated checklist of the freshwater and estuarine fishes of French Guyana. Cybium. 36 (1): 239-319.

Lima, F.C.T. 2001. Revisão taxonômica do gênero Brycon Müller \& Troschel, 1844, dos rios da América do Sul cisandina (Pisces, Ostariophysi, Characiformes, Characidae). Dissertação de mestrado, não publicada. Instituto de Biociências, Universidade de São Paulo, São Paulo, 312 pp.

Lima, F. C. T., Pires, T. H. S.,Ohara, W. M., Jerep, F. C., Carvalho, F. R., Marinho, M. M. F. \& Zuanon, J. 2013 Characidae. IN Queiroz, L. J., Torrente-Vilara, G.,Ohara, W. M., Pires, T. H. S., Zuanon, J. \& Doria, C. R.C. Peixes do rio Madeira v I. Dialeto Latin American Documentary. São Paulo 399pp.

López, H. L., Menni R. C. \& Miquelarena, A. M. 1987. Lista de los peces de água Dulce de la Argentina. Biología Acuática n 12. Instituto de Limnología "Dr. Raúl A. Ringuelet". 36pp.

López, H. L., Miquelarena, A. M. \& Menni, R. C. 2003. Lista comentada de los peces continentales. ProBiota, Série Técnica y Didática. 5: 1-85.

Lowe-McConnell, R. H. 1991. Natural history of fishes in Araguaia and Zingu Amazonian tributaries, Serra do Roncador, Mato Grosso, Brazil. Ichthyol. Explor. Freshwaters. 2 (1): 67-82.

Lucena, C. A. S. 1998. Relações filogenéticas e definição do gênero Roeboides, Günther (Ostariophysi; Characiformes; Characidae). Comunicações do Museu de Ciências da PUCRS, Sér. Zoologia. 11: 19-59. 
Lucena, C. A. S. \& Menezes, N. A. 2003. Subfamily Characinae.IN: Reis, R. E.; Kullander, S. O. \& Ferraris Jr., C. J. (orgs). Check list of the freshwater fishes of South and Central America. Porto Alegre, Edipucrs. p.200-208.

Magalhães, A. L. B.; Bazzoli, N.; Santos, G. B.\& Rizzo, E. 2004. Reproduction of the South American dog fish characid, Galeocharax knerii, in two reservoirs from upper Paraná River basin, Brazil. Environmental Biology of Fishes 70: 415-425.

Malabarba, L. R. 1998. Monophyly of the Cheirodontinae, characters and major clades (Ostariophysi: Characidae). IN Malabarba, L. R., Reis, R. E., Vari, R. P., Lucena Z. M. S. \& Lucena C. A. S. (Eds). Phylogeny and Classification of Neotropical Fishes. Porto Alegre. EDIPUCRS. p. 193-233.

Malabarba, L. R. \& Weitzman, S. H. 2003. Description of a new genus with six new species from southern Brazil, Uruguay and Argentina, with a discussion of a putative characid clade (Teleostei: Characiformes: Characidae). Comunicações do Museu de Ciências e Tecnologia da PUCRS, Série Zoologia. 16: 67-151.

Maldonado-Ocampo, J. A., Vari, R. P. \& Usma, J. S. 2008. Checklist of the Freshwater Fishes of Colombia. Biota Colombiana. 9 (2): 143-237.

Mattox, G. M. T. \& Toledo-Piza, M. 2012. Phylogenetic study of the Characinae (Teleostei: Characiformes: Characidae). Zoological Journal of the Linnean Society. 165: 809-915.

Menezes, N. A. 1976. On the Cynopotaminae, a new subfamily of Characidae (Osteichthyes, Ostaiophysi, Characidae). Arquivos de Zoologia, São Paulo. 28 (2): 191.

Menezes, N.A. 1987. Three new species of the characid genus Cynopotamus Valenciennes, 1849, with remarks on the remaining species (pisces, Characiformes). Beaufortia, 37, 1-9.

Menezes, N. A. 2006. Description of Five new species of Acestrocephalus Eigenmann and redescription of $A$. sardina and A. boehlkei (Characiformes, Characidae). Neotropical Ichthyology, 4 (4): 385-300.

Menezes, N. A. 2007a. Charax goeldii Fowler, 1913 a valid species of Galeocharax Fowler (Characiformes: Characidae). Neotropical Ichthyology 5 (1): 21-24.

Menezes, N. A. 2007b. A new species of Cynopotamus Valenciennes, 1849 (Characiformes, Characidae) with a key to the species of the genus. Zootaxa. 1635: 5561.

Mérona, B., Juras, A. A., Santos, G. M. \& Cintra, I. H. A. 2010. Os peixes e a pesca no baixo rio Tocantins: vinte anos depois da UHE Tucuruí. Eletronorte. 208 pp.

Milko, P. Peixes do rio Paranapanema. Horizonte Geográfico, São Paulo. 112 pp.

Mirande, J. M. 2010. Phylogeny of the family Characidae (Teleostei: Characiformes): from characters to taxonomy. Neotropical Ichthyology. 8 (3): 385-568.

Mojica, J. I., Galvis, G., Arbeláez, F., Santos, M., Vejarano, S., Prieto-Piraquive, E., Arce, M., Sánchez-Duarte, P, Castellanos, C., Gutiérrez, A., Duque, S. R., LobónCerviá, J. \& Granado-Lorencio, C. 2005. Peces de la Cuenca Del Río Amazonas em Colombia: Región de Leticia. Biota Colombiana. 6 (2): 191-210.

Monteiro, A. S., Oliveira, A. H. M., Pelicice, F. M. \& Oliveira, R. J. 2009. Alterações na disponibilidade de recursos alimentares e na dieta das principais espécies de peixes. 
IN Agostinho, C. S., Pelicica, F. M. \& Marques, E. E. (Orgs.) Reservatório de Peixe Angical. Bases ecológicas para o manejo da ictiofauna. Rima Editora. São Carlos. p 7786.

Müller, J. \& Troschel, F. H. 1844. Synopsis generum et specierum familiae Characinorum. Arch. Naturgesch. 10 (1): 81-99.

Müller, J. \& Troschel, F. H. 1845. Horae Ichthyologicae. Beschreibung und Abbildung neuer Fische. Die Familie der Characinen, Erstes und Zweites Heft. Viet \& Comp. Berlin 40pp.

Neuberger, A. L., Marques, E. E., Agotinho, C. S. \& Pelicice, F. M. 2009. Variações espaciais na atividade reprodutiva de peixes na área de influência do reservatório de Peixe Angical. IN Agostinho, C. S., Pelicica, F. M. \& Marques, E. E. (Orgs.) Reservatório de Peixe Angical. Bases ecológicas para o manejo da ictiofauna. Rima Editora. São Carlos. p 59-68.

Oliveira, C.; Avelino, G. S.; Abe, K. T.; Mariguela, T. C.; Benine, R. C.; Ortí, G.; Vari, R. P. \& Castro, R. M. C. 2011. Phylogenetic relationships within the speciose family Characidae (Teleostei: Ostariophysi: Characiformes) based on multilocus analysis and extensive ingroup sampling. BMC Evolutionary Biology. 11: 275.

Ortega, H.; Hidalgo, M.; Trevejo, G.; Correa, E.; Cortijo, A. M.; Meza, V. \& Espino, J. 2012. Lista anotada de lós peces de águas continentales de Perú. Estado actual Del conocimiento, distribución y aspectos de conservación. Lima. Ministerio Del Ambiente. $56 \mathrm{pp}$.

Ortega, H., Mojica, J. I., Alonso, J. C. \& Hidalgo, M. 2006. Listado de los peces de la cuenca del río Putumayo em su sector colombo-peruano. Biota Colombiana. 7 (1): 95112.

Ortega, H \& Vari, R. P. 1986. Annotated Checklist of th Freshwater Fishes of Peru. Smithsonian Contribuitions to Zoology. 437. 25pp.

Pearson, N. E. 1937. The fishes of the Atlantic and Pacific slopes near Cajamarca, Peru. Proc. California Acad. Sci. (4) 23 (7): 87-98.

Pelicice, F. M., Akama, A., Oliveira, R. J. \& Silva, D. S. 2009 Padrões espaciais e temporais na distrubuição d ictiofauna, antes e após a formação do reseervatório de Peixe Angical. IN Agostinho, C. S., Pelicica, F. M. \& Marques, E. E. (Orgs.) Reservatório de Peixe Angical. Bases ecológicas para o manejo da ictiofauna. Rima Editora. São Carlos. p 29-39.

Pellegrin, J. 1899. Note sur les poissons recueillis oar M. F. Geay dans l'Apuré et ses affluentes. Bull. Mus. Hist. Nat. Paris. 5: 156-159.

Pellegrin, J. 1909. Characinidés américains nouveaux de la collection du Muséum d'Histoire Naturelle. Bull. Mus. Hist. Nat. Paris. 15 (1): 12-14.

Perugia, A. 1891. Appunti sopra alcuni sud-americani conservati nel Museo Civico di Storia Naturale di Genova. Ann. Mus. Civ. Storia Nat. Genova. serie 2. 10: 605-657.

Perugia, A. 1897. Di alcuni pesci raccolti in Bolivia dal Prof. Luigi Balzan. Ann. Mus. Civ. Storia Nat. Genova. 18: 16-27.

Petry, A. C., Agostinho, A. A. \& Gomes, L. C. 2003. Spatial variation of the fish assemblage structure from the upper rio Paraná floodplain, Brazil, in a dry year. Acta Limnol. Bras. 15 (1): 1-13. 
Planquette, P., P. Keith \& P.-Y. Le Bail. 1996. Atlas des poissons d'eau douce de Guyane. (tome 1). Collection du Patrimoine Naturel, vol. 22. IEGB - M.N.H.N., INRA, CSP, Min.Env., Paris, 429 pp.

Rapp Py-Daniel, L., Deus, C. P. Ribeiro, O. \& Sousa, L. M., Capítulo 8 Peixes. IN Rapp Py-Daniel, L., Deus, C. P., Henriques, A. L., Pimpão, D. M. \& Ribeiro O.M. (Orgs.). Biodiversidade do médio Madeira: bases científicas para propostas de conservação. INPA. Manaus. 89-125.

Ribeiro Neto, F. B.; Höfling, J. C.; Ferreira, L.I. \& Romano, C.E. A. 1998. Distribuição e alimentação de Galeocharax knerii no reeservatório de Salto Grande, macro-regiões de Campinas, SP. Bioikos. 12 (2): 19-25.

Schultz, L. P. 1944. The fishes of the family Characinidae from Venezuela, with descriptions of seventeen new forms. Proc. U. S. Natl. Mus. 95 (3181): 235-367

Schultz, L. P. 1950. Review of thirteen genera of South America fishes in the subfamilies Cynodontinae, Hepsetinae and Characinae, with description of a new Cyrthocharax. Stud. Honoring T. Kincaid, University of Washington, 43-73 pp.

Shibatta, O. A. \& Dias, J. H. P. 2006. 40 peixes do Brasil: CESP 40 anos. Doiis. Rio de Janeiro. 208 pp.

Steindachner, F. 1878. Zur Fisch-Fauna des Magdalenen Stromes. Denkschr. k. Akad. Wiss. Wien. 39: 19-78.

Sverlij, S. B., Schenke, R. L. D., López, H. L. \& Ros A. E. 1998. Peces del rio Uruguay. Guia ilustrada de las especies mas comúnes del río Uruguay inferior y El embalse de Salto Grande. Publicaciones de la Comission Administradora del río Uruguay. 89pp.

Taphorn, D. C. 1992. The characiform fishes of the Apure river drainage, Venezuela. Biollania, Edición Especial $n^{\circ}$ 4. Monografias Cientificas Del Museo de Ciencias Naturales. 537 pp.

Taylor, W. R. \& van Dyke, G. C. 1985. Revised procedures for staining and clearing small fishes and other vertebrates for bony and cartilage study. Cybium 9 (2): 107-119.

Teixeira, T. F. 2010. Revisão taxonômica das espécies de Hyphessobrycon Durbin do grupo rosáceo (Ostariophysi; Characiformes; Characidae): comentários sobre a biologia reprodutiva do grupo. Dissertação de mestrado, não publicada. Intituto Nacional de Pesquisas da Amazônia, Manaus, 144pp.

Santos, G. M., Mérona, B., Juras, A. A. \& Jégu, M. 2004. Peixes do baixo rio Tocantins: 20 anos depois da Usina Hidrelétrica de Tucuruí. Eletronorte. Brasília 216 pp.

Seindachner, F. 1878. Zur Fisch-Fauna des Magdalen Stromes. Denkschr.k. Akad.Wiss.Wien 39: 19-78.

Silvano, R. A. M., Oyakawa, O. T., Amaral, D. B. \& Begossi, A. 2001. Peixes do Alto rio Juruá. Editora da Universidade de São Paulo. São Paulo. 301 pp.

Valenciennes, A. 1834. IN D’Orbigny, Voyage dans l'Amérique Méridionale, Poissons, prancha 11, figura 2 .

Valenciennes, A. 1849. IN Cuvier \& Valenciennes, Histoire Naturelle des Poissons. 22: $\mathrm{XX}+92+322$ pp. 
Vaz, M. M., Torquato, V. C \& Barbosa, N. D. C. 2000. Guia ilustrado de peixes da bacia do rio Grande. CEMIG/CETEC. Belo Horizonte. 144 pp.

Zaniboni-Filho, E. Z., Meurer, S., Shibatta, O. A. \& Nuñer, A. P. O. 2004. Catálogo Ilustrado de peixes do alto rio Uruguai. Editora da Universidade federal de Santa Catarina. Florianópolis. 128 pp.

Zayas, M. A. \& Cordiviola, E. 2007. The conservation state of Characidae fish (Pisces: Characiformes) in área of the Plata basin, Argentina. Gayana. 71(2): 178-186.

Zeinad, A. K. \& Prado, R. A. 2012. Peixes fluviais do Brasil: espécies esportivas. Pescaventura. São Paulo 360 pp. 


\section{Apêndice 1: Figuras}
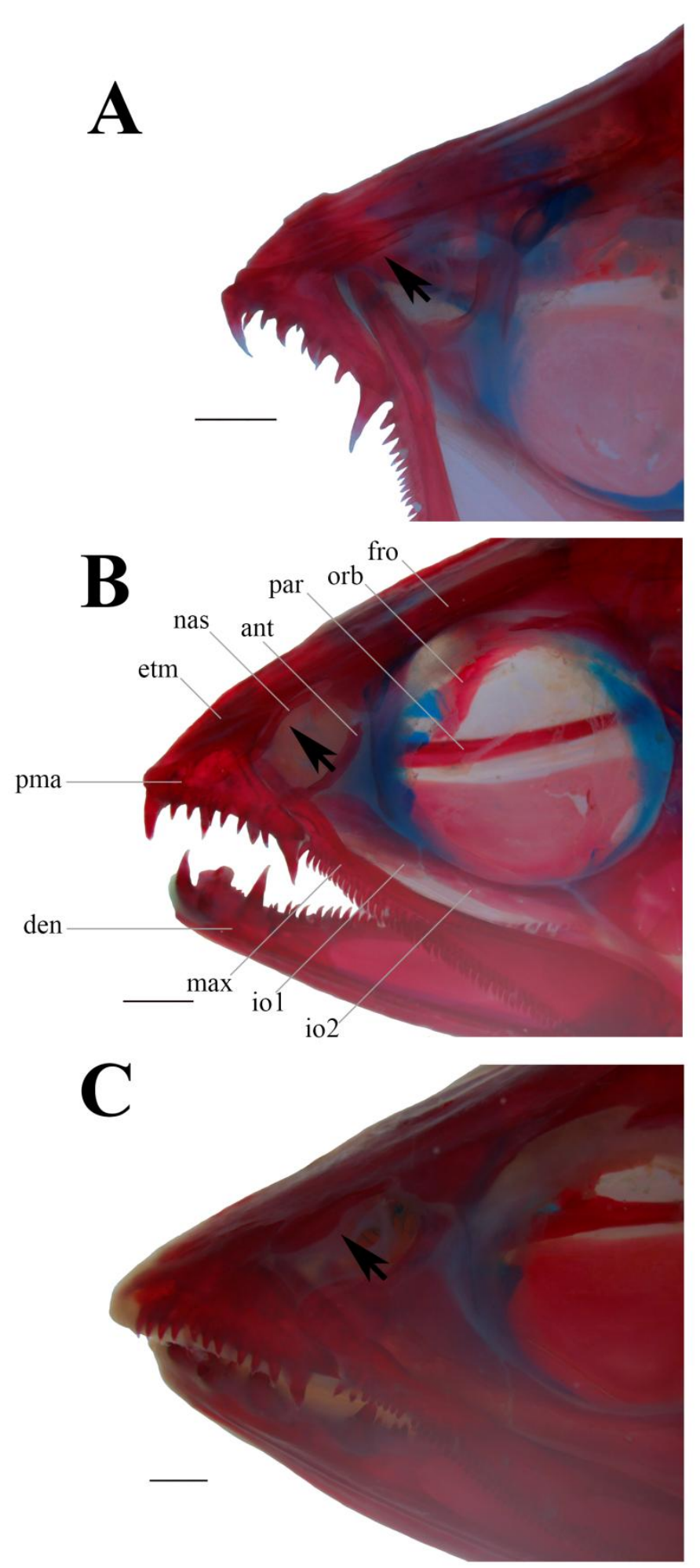

Figura 1 - Região anterior da cabeça de (A) Cynopotamus xinguano, MZUSP 94196, 97,9 mm CP; (B) Acentrocephalus stigmatus, MZUSP 94216, 85,0mm CP; (C) Galeocharax gulo MZUSP 62839 127,2 mm CP.. Setas indicam osso nasal. ant antorbital; den - dentário; etm - mesetmoide; fro - frontal; io1 - infraorbital 1; io2 infraorbital 2; max - maxilar; nas - nasal; orb - orbitoesfenoide; par - paraesfenóide; pma - pré-maxilar. Vista lateral, lado esquerdo. Barra de escala $2 \mathrm{~mm}$. 

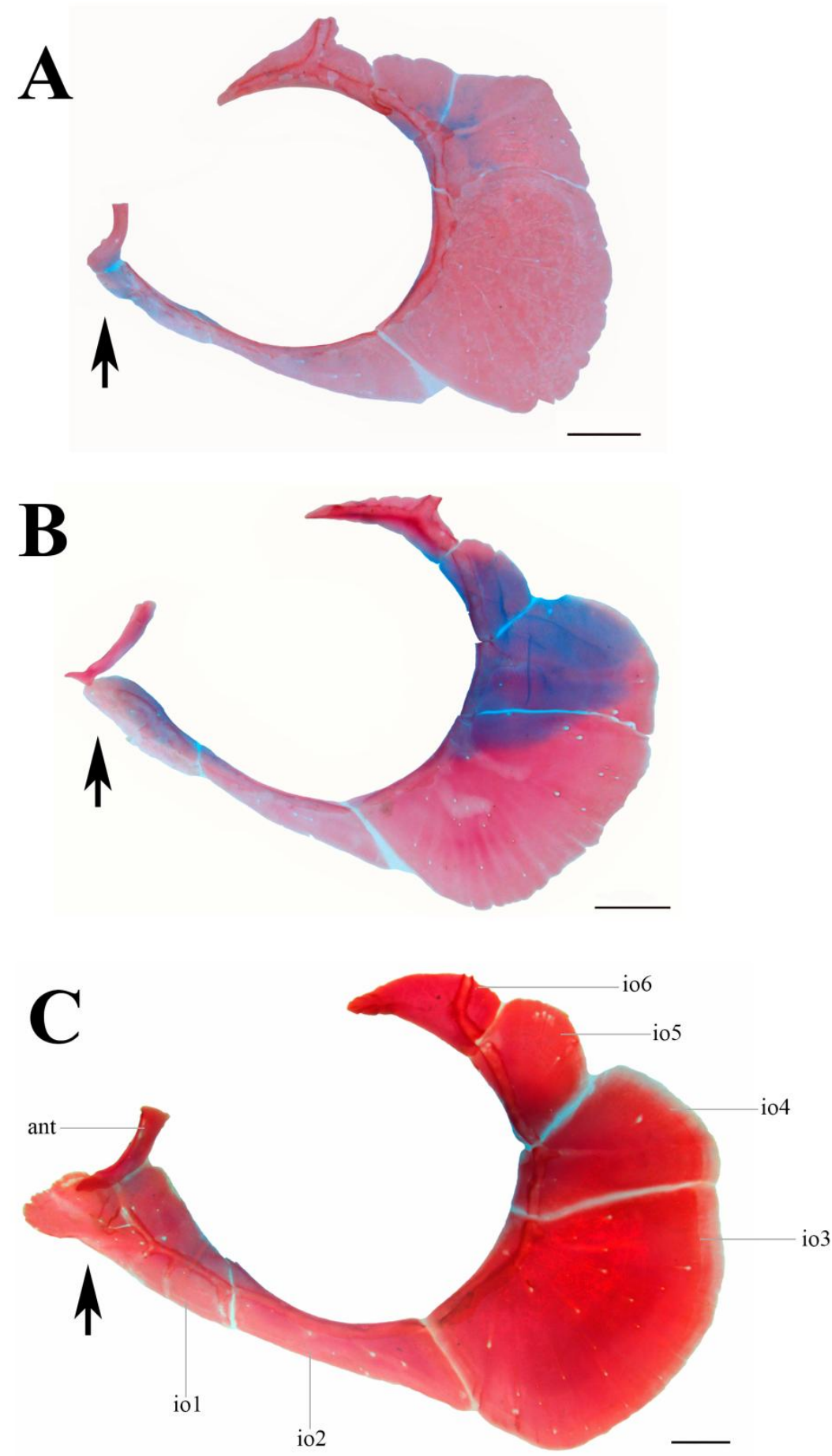

Figura 2 - Série infraorbital de (A) Cynopotamus xinguano, MZUSP 94196, 97,9 mm CP; (B) Acentrocephalus stigmatus, MZUSP 94216, 85,0mm CP; (C) Galeocharax gulo MZUSP 62839 127,2 mm CP. Setas indicam região anterior do infraorbital 1. ant antorbital; io1 - infraorbital 1; io2 - infraorbital 2; io3 - infraorbital 3; io4 - infraorbital 4; io5 - infraorbital 5; io6 - infraorbital 6. Vista lateral, lado esquerdo. Barra de escala 2 $\mathrm{mm}$. 

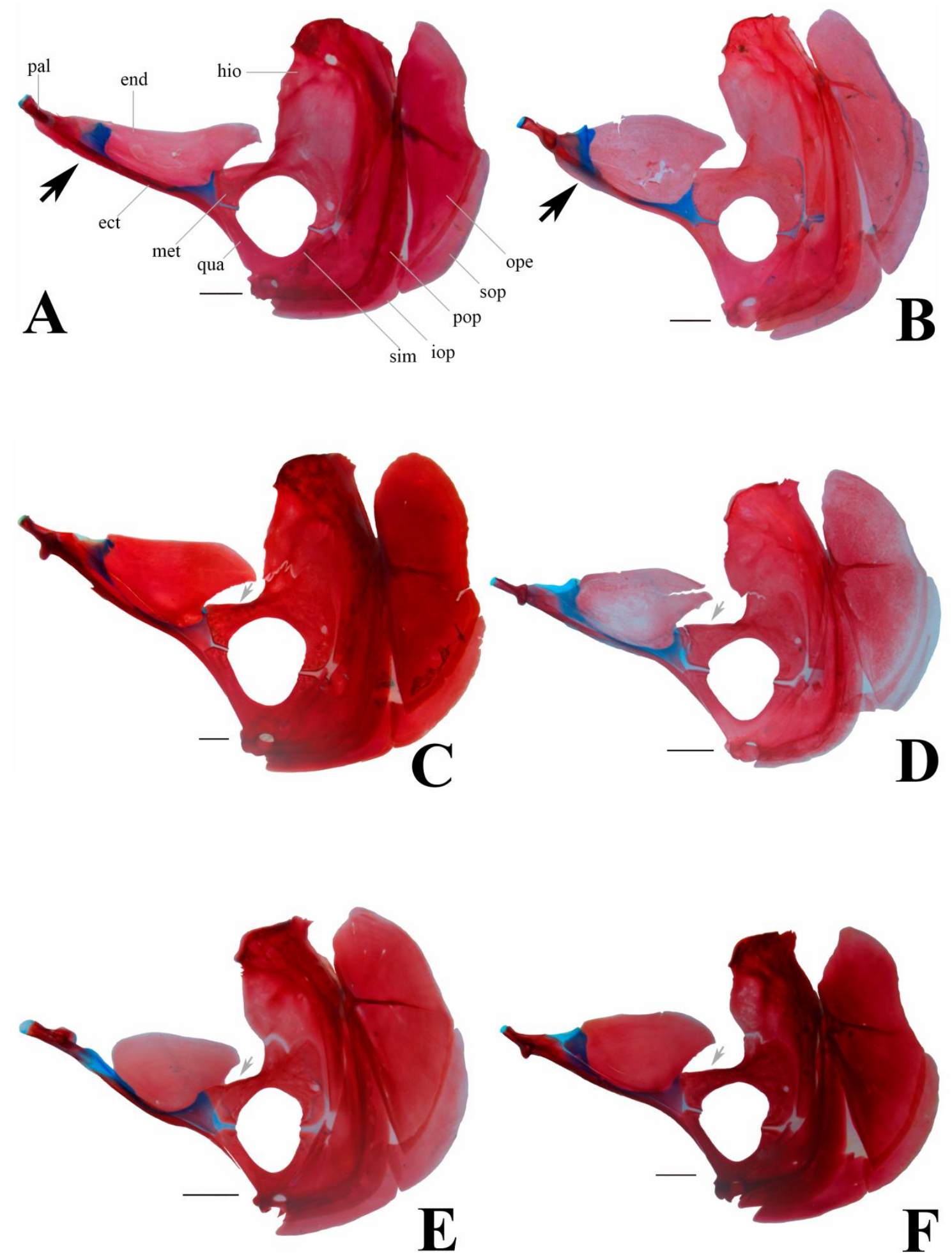

Figura 3 - Suspensório e serie opercular de (A) Acentrocephalus stigmatus, MZUSP 94216, 85,0 mm CP; (B) Cynopotamus xinguano, MZUSP 94196, 97,9 mm CP; (C) Galeocharax gulo, MZUSP 62839, 127,2 mm CP; (D) Galeocharax goeldii, UFRO-I 5468, 77,9 mm CP; (E) Galeocharax humeralis, MZUSP 19984, 66,0 mm CP; (F) Galeocharax gulo MZUSP 10480, 88,8 mm CP. Setas pretas indicam crista no ectopterigoide, setas cinzas indicam região anterior do metapterigoide. ect ectopterigoide; end - endopterigoide; hio - hiomandibular; iop - interopérculo; met metapterigoide; ope - opérculo; pal - palatino; pop - pré-opérculo; qua - quadrado; sim - simplético; sop - subopérculo. Vista lateral, lado esquerdo. Barra de escala $2 \mathrm{~mm}$. 

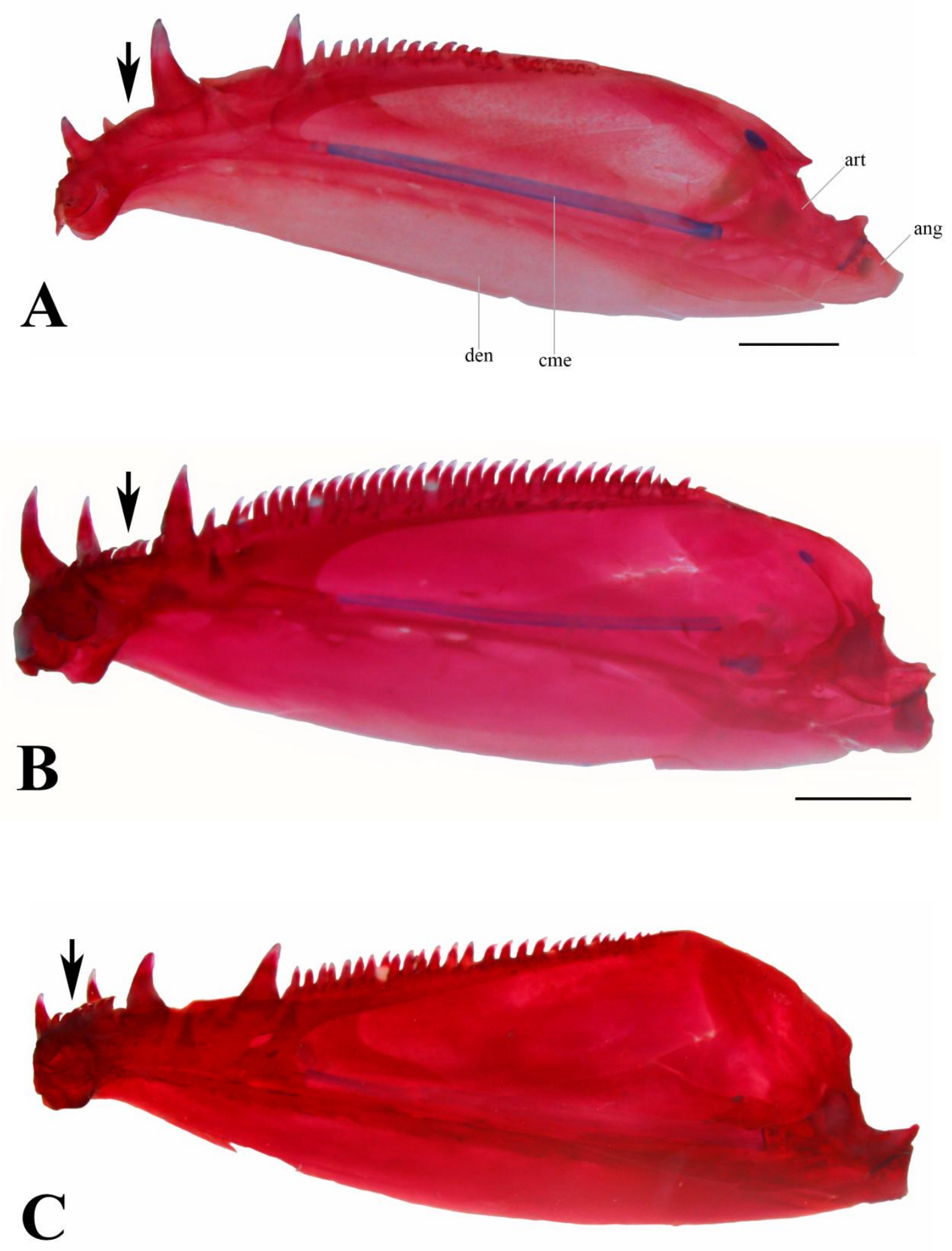

Figura 4 - Maxila inferior de (A) Cynopotamus xinguano, MZUSP 94196, 97,9 mm CP; (B) Acentrocephalus stigmatus, MZUSP 94216, 85,0mm CP; (C) Galeocharax gulo, MZUSP 62839 127,2 mm CP. Setas indicam presença ou ausência da fileira interna de dentes no dentário. ang - anguloarticular; art - retroarticular; cme - Cartilagem de Meckel; den - dentário. Vista medial, lado direito. Barra de escala 2 mm. 

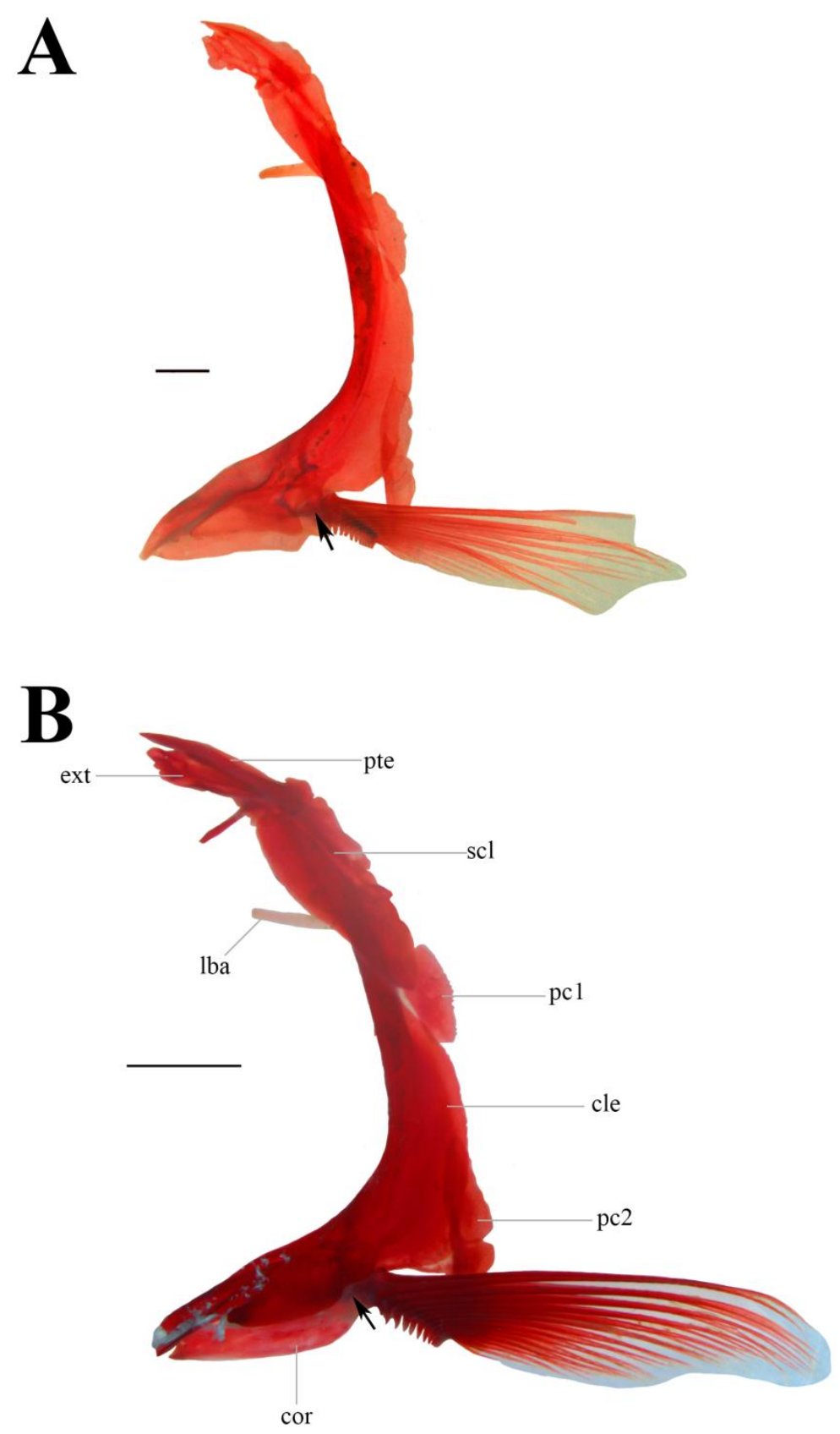

Figura 5 - Cintura peitoral de (A) Cynopotamus xinguano, MZUSP 94196, 97,9 mm CP, barra de escala 2 mm; (B) Galeocharax gulo, MZUSP 62839 127,2 mm CP, barra de escala $5 \mathrm{~mm}$. Setas indicam margem ventro-posterior do cleitro. cle - cleitro; cor coracoide; ext - extraescapular; lba - Ligamento de Baudelot ; pc1 - pós-cleitro 1; pc2 - pós-cleitro2; pte - pós-temporal; scl - supracleitro. Vista lateral, lado esquerdo. 


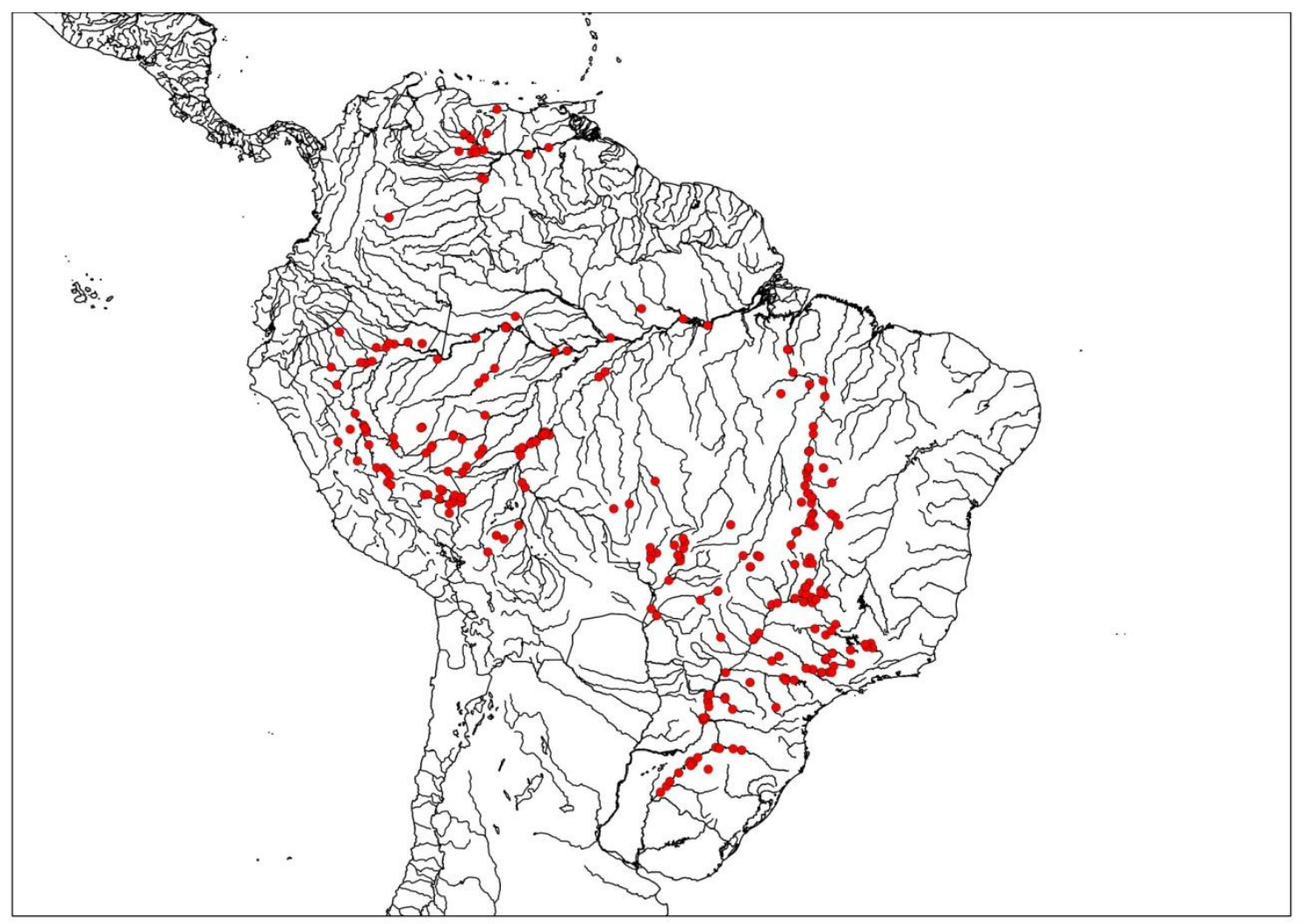

Figura 6 - Mapa da proção central e norte da América do Sul mostrando a distribuição geográfica do gênero Galeocharax.

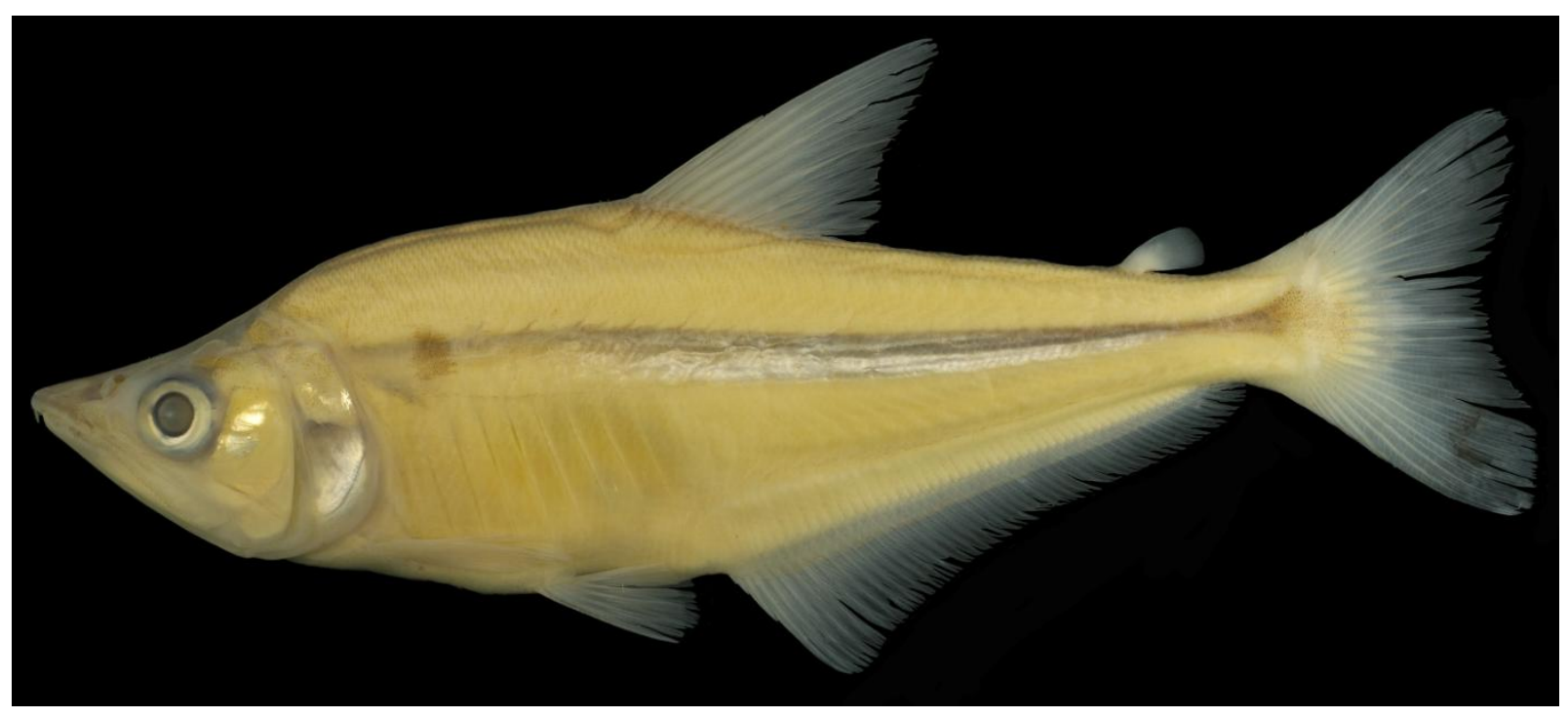

Figura 7 - Galeocharax humeralis, MZUSP 78865, 124,3 mm CP. Brasil, Mato Grosso, bacia do rio Paraguai, rio Cachoeirinha. 


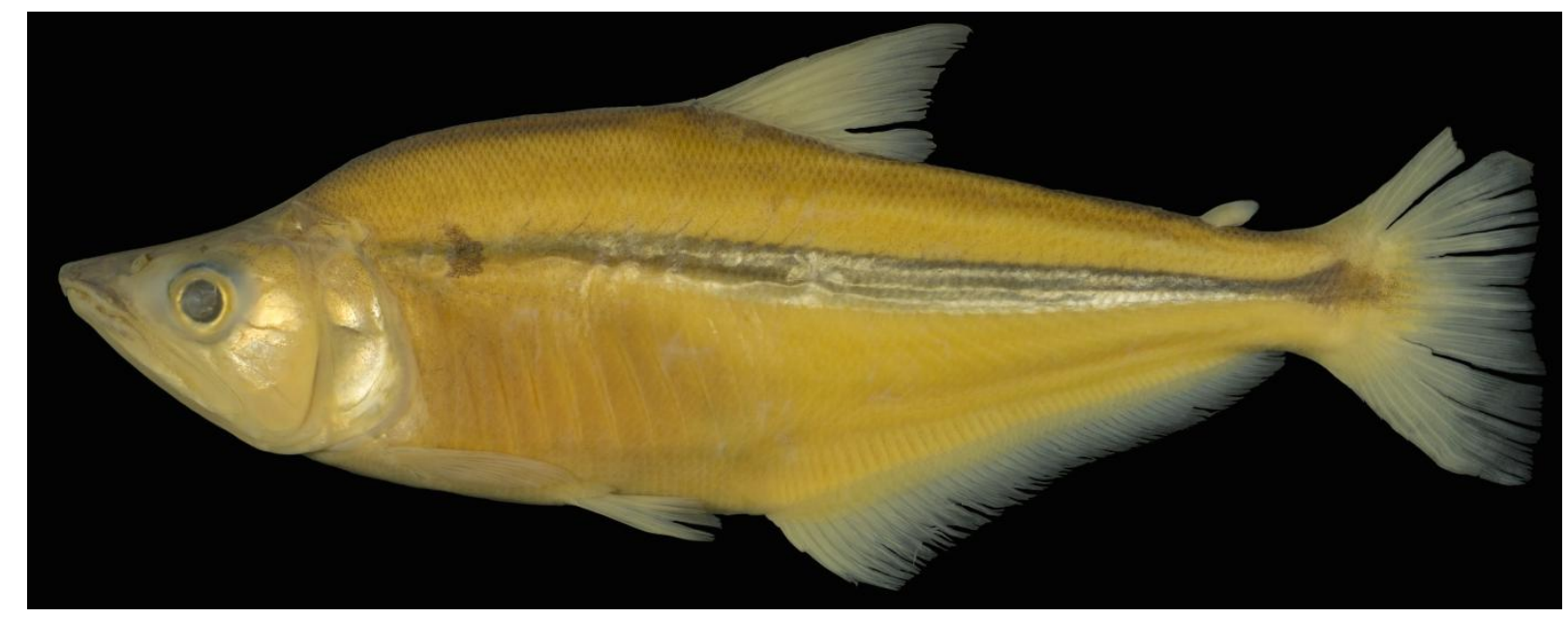

Figura 8 - Galeocharax humeralis, MZUSP 89961, 187,4 mm CP. Brasil, Mato Grosso, bacio do rio Paraguai, rio Sepotuba.

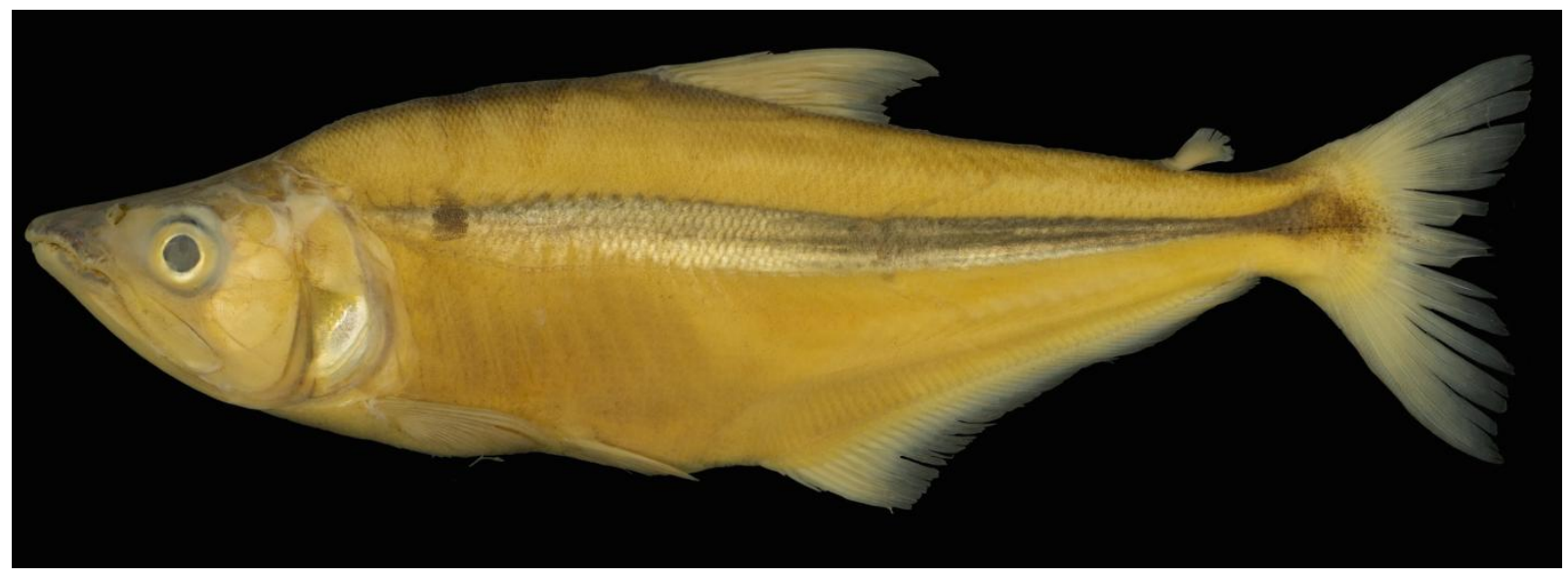

Figura 9 - Galeocharax humeralis, MCP 20401, 197,4 mm CP. Brasil, Santa Catarina, bacia do rio Uruguai, rio Uruguai.

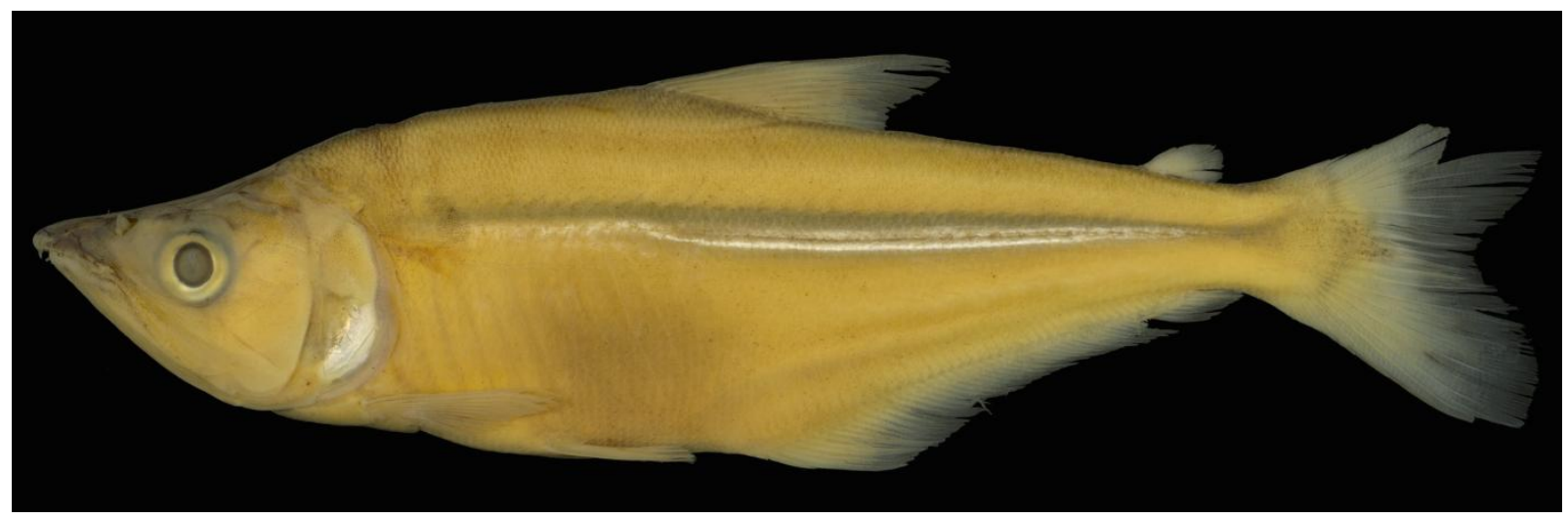

Figura 10 - Galeocharax humeralis, MCP 20401, 151,8 mm CP. Brasil, Santa Catarina, bacia do rio Uruguai, rio Uruguai. 

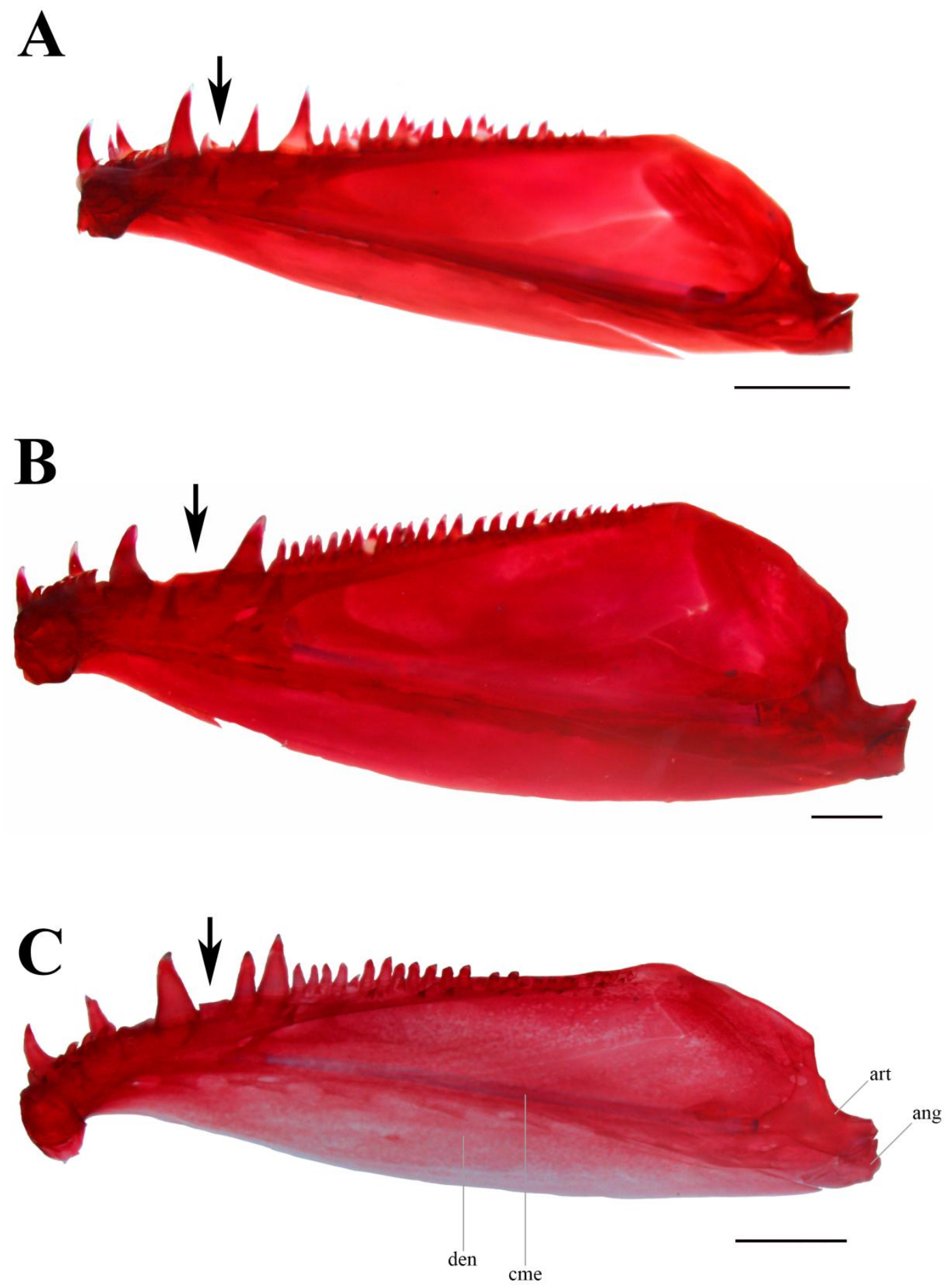

Figura 11 - Maxila inferior de (A) Galeocharax humeralis MZUSP 19984, 66,0 mm CP; (B) Galeocharax gulo MZUSP 62839 127,2 mm CP; (C) Galeocharax goeldii UFRO-I5468, 77,9 mm CP. Barra de escala $2 \mathrm{~mm}$. Vista medial. Setas indicam presença ou ausência de pequenos dentes entre o terceiro e quarto dentes caninos do dentário, ang - anguloarticular; art - retroarticular; cme - Cartilagem de Meckel; den dentário. 

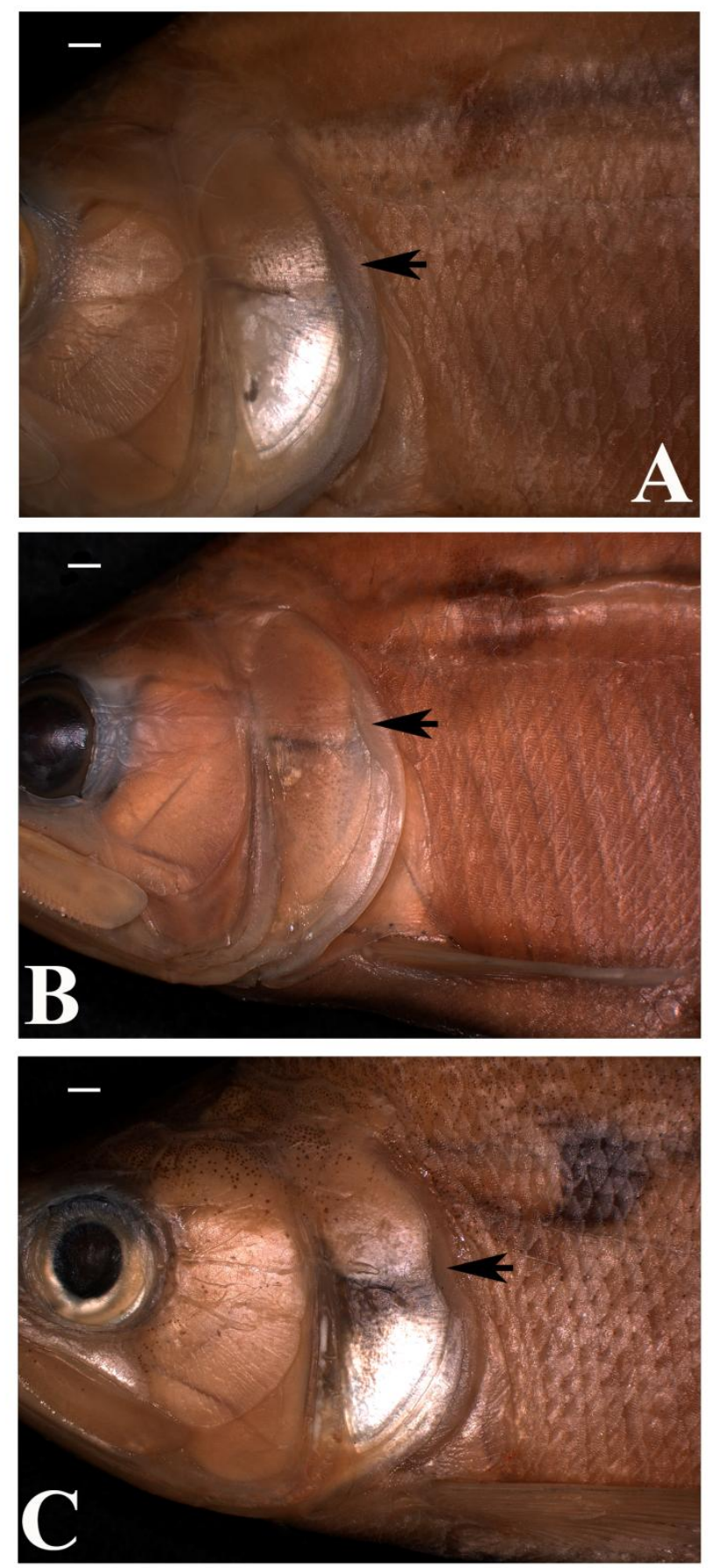

Figura 12 - Vista lateral da região anterior de (A) Galeocharax humeralis MZUSP 19907, 144,4 mm CP; (B) Galeocharax gulo MZUSP 10440, 115,3 mm CP; (C) Galeocharax goeldii USNM 305367 129,3 mm CP. Barra de escala 2 mm. Setas indicam margem posterior do opérculo. 

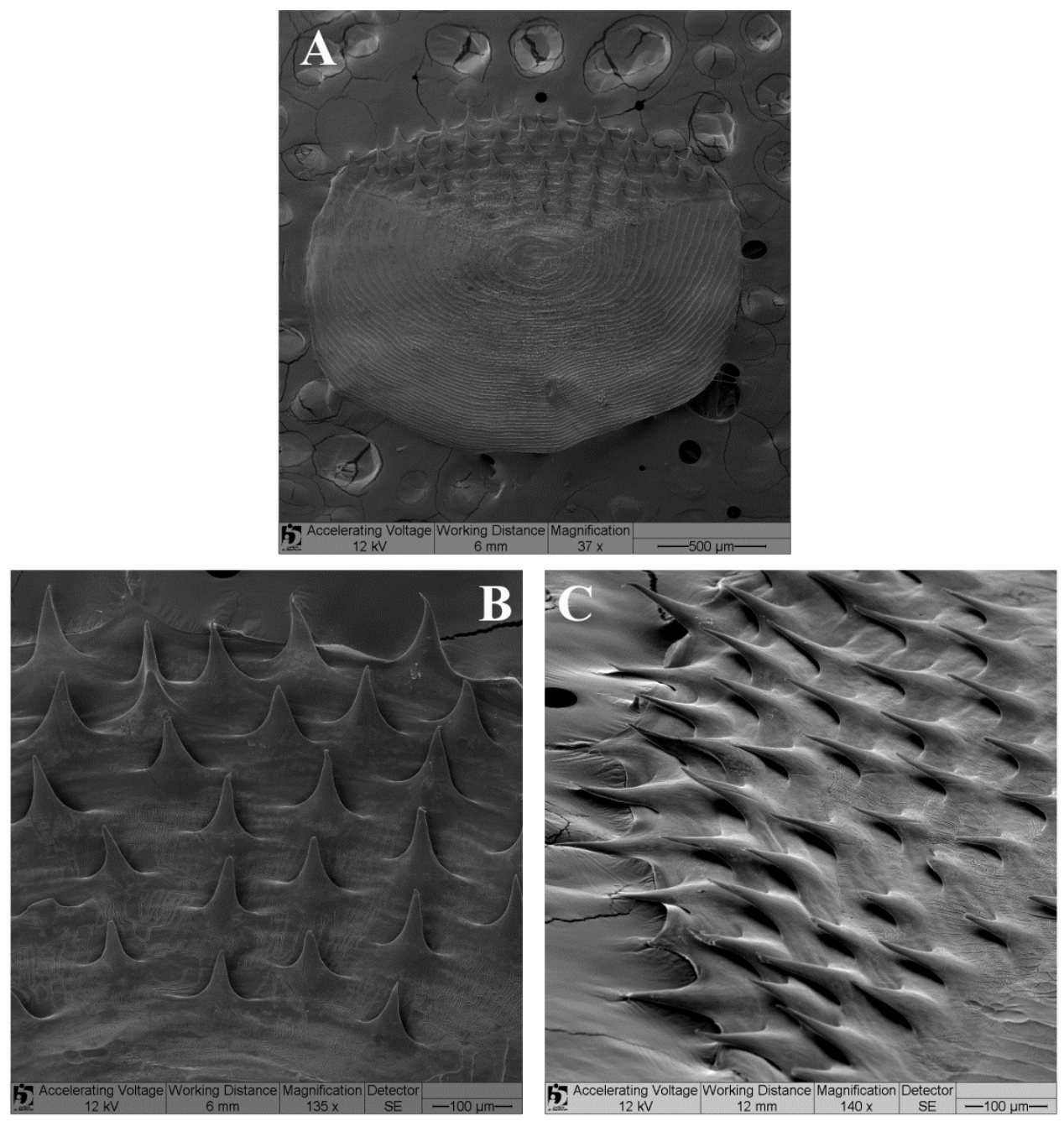

Figura 13 - Micrografias de varredura de escama de Galeocharax humeralis, MZUSP 78865, 124,3 mm CP. Brasil, Mato Grosso, bacia do rio Paraguai, rio Cachoeirinha. (A) vista geral, margem posterior da escama orientada para o topo da figura; (B) Detalhe do campo posterior da escama, margem posterior da escama orientada para o topo da figura; (C) Vista dorso-lateral do campo posterior, margem posterior da escama orientada para a esquerda da figura. 

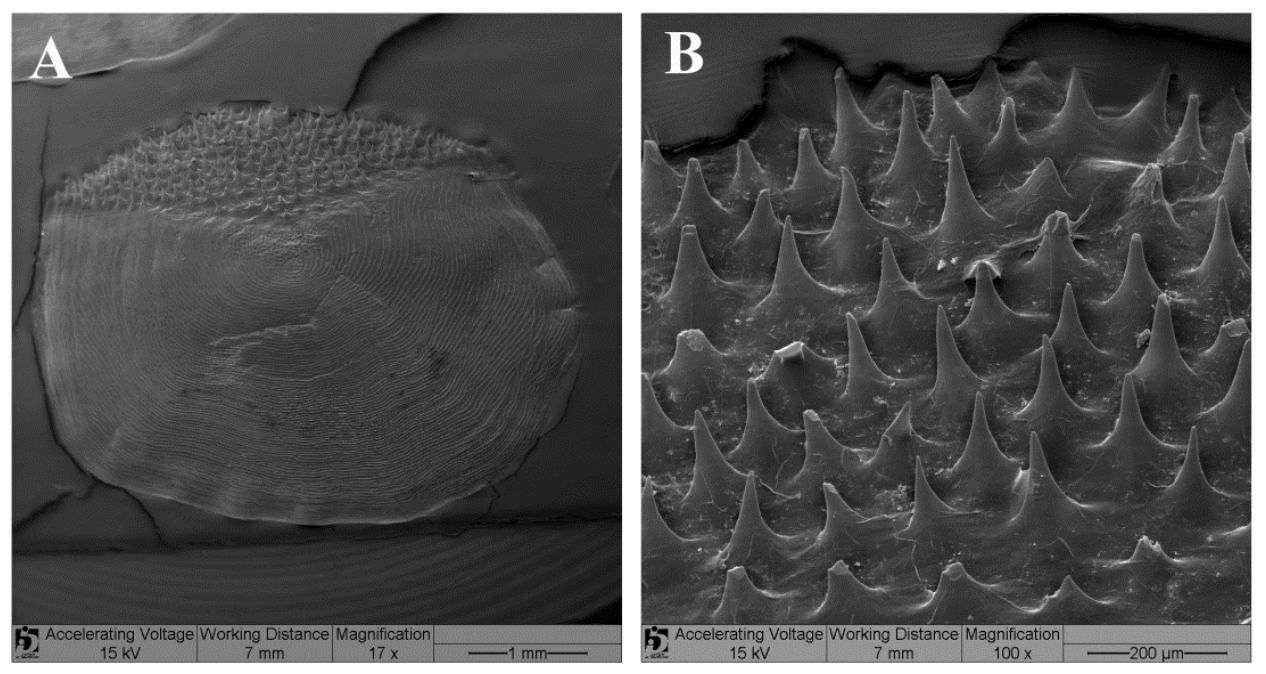

Figura 14 - Micrografias de varredura de escama de Galeocharax humeralis, MZUSP 90473, 210,5 mm CP. Brasil, Mato Grosso, bacia do rio Paraguai, rio Sepotuba. (A) vista geral, margem posterior da escama orientada para o topo da figura; (B) Detalhe do campo posterior da escama, margem posterior da escama orientada para o topo da figura. 

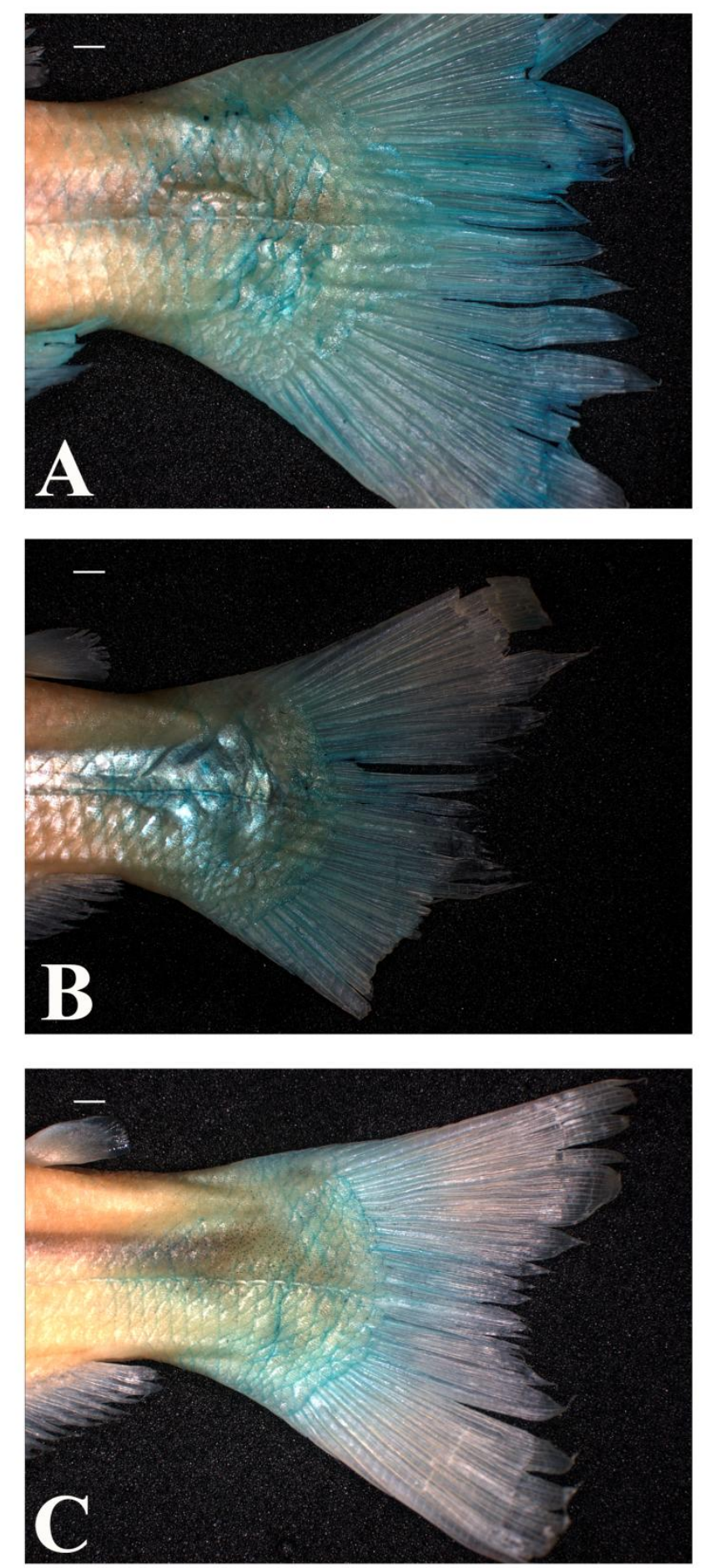

Figura 15 - Vista lateral do pedúnculo e nadadeira caudal de (A) Galeocharax humeralis MZUSP 27684, 140,4 mm CP; (B) Galeocharax gulo MZUSP 29882, 108,3 mm CP; (C) Galeocharax goeldii INPA 24598, 109,7 mm CP. Barra de escala 2 mm. 


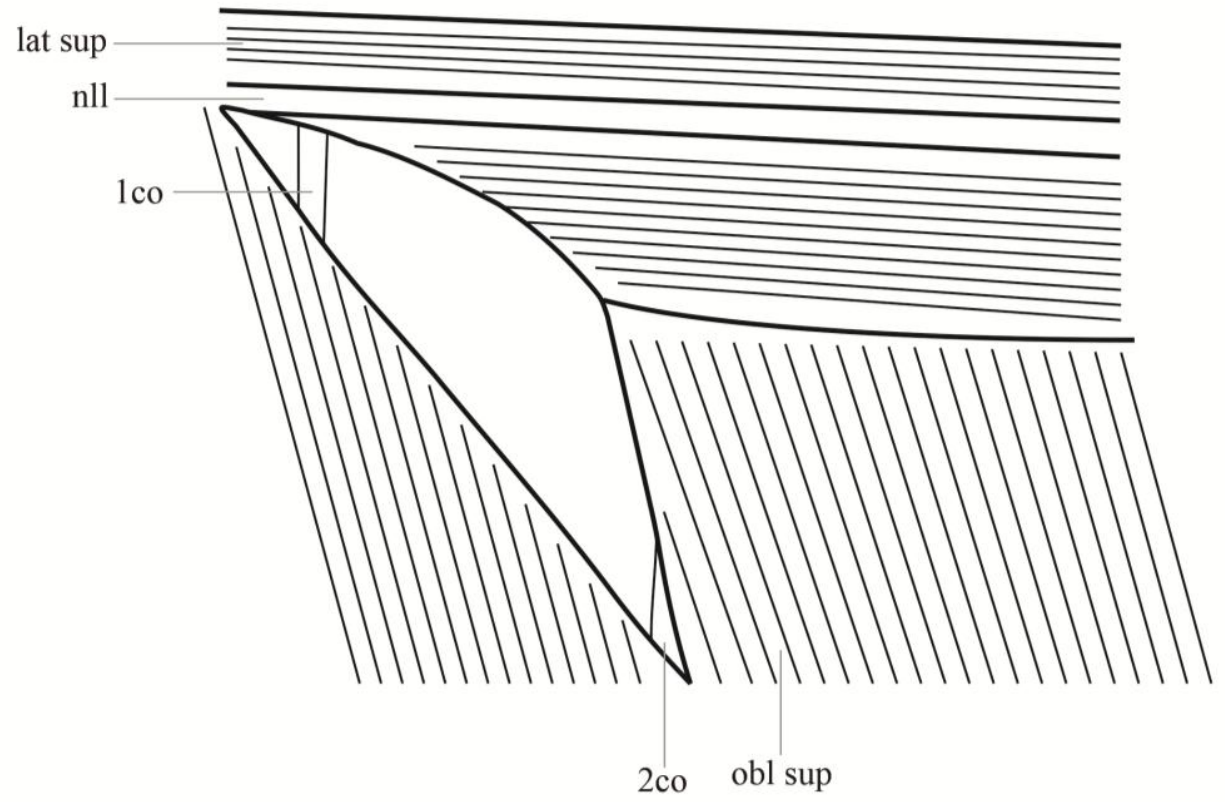

Figura 16 - Esquema da conformação dos músculos que formam o pseudotimpano de Galeocharax, 1co - primeira costela; 2co - segunda costela; lat sup - m. lateralis superficialis; nll - nervo da linha lateral; obl sup - m. obliquus superioris.

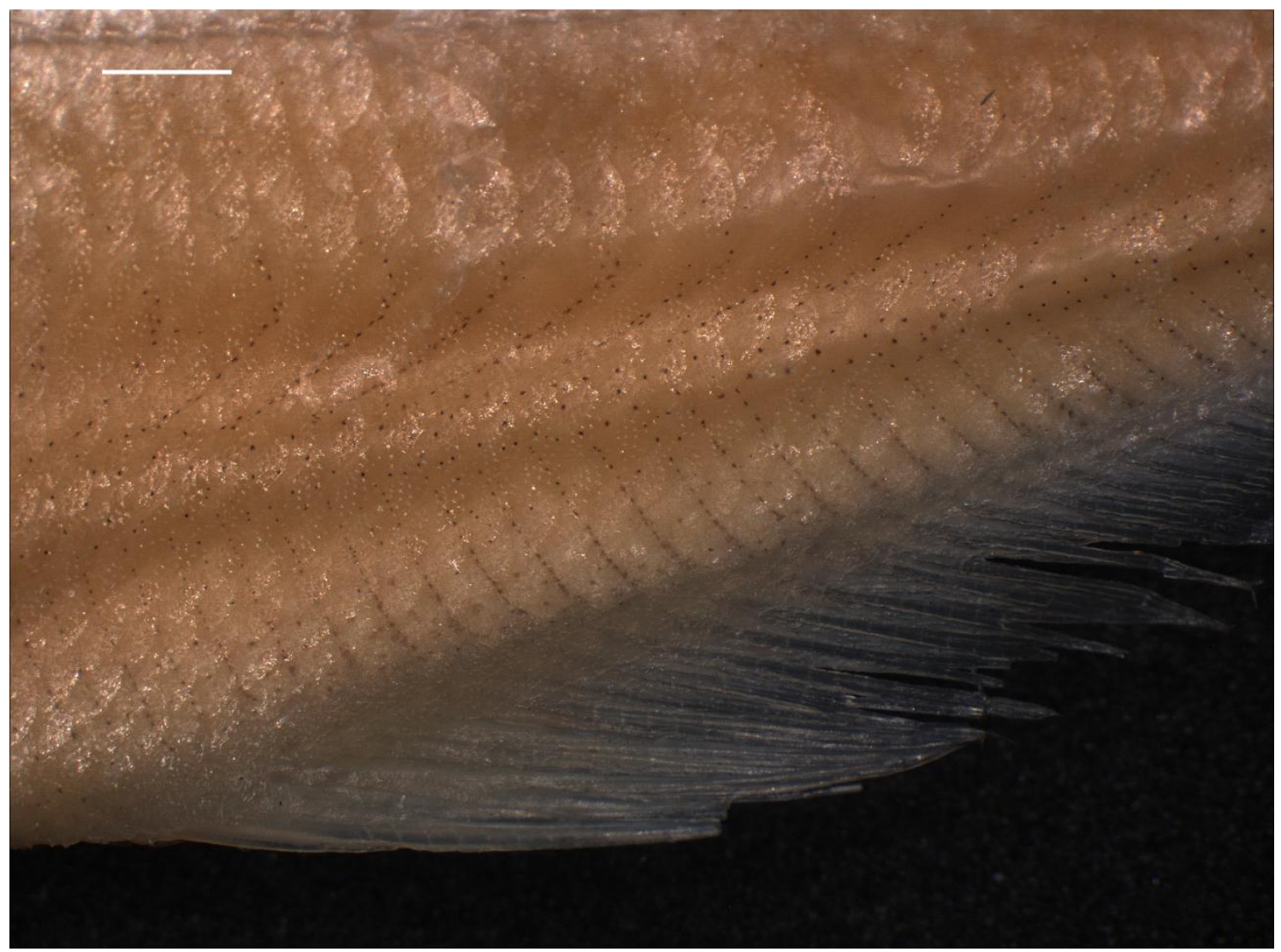

Figura 17 - Região anterior da nadadeira caudal de Galeocharax gulo MZUSP 53858, 111,8 mm CP. Vista lateral, lado esquerdo. Barra de escala $3 \mathrm{~mm}$. 

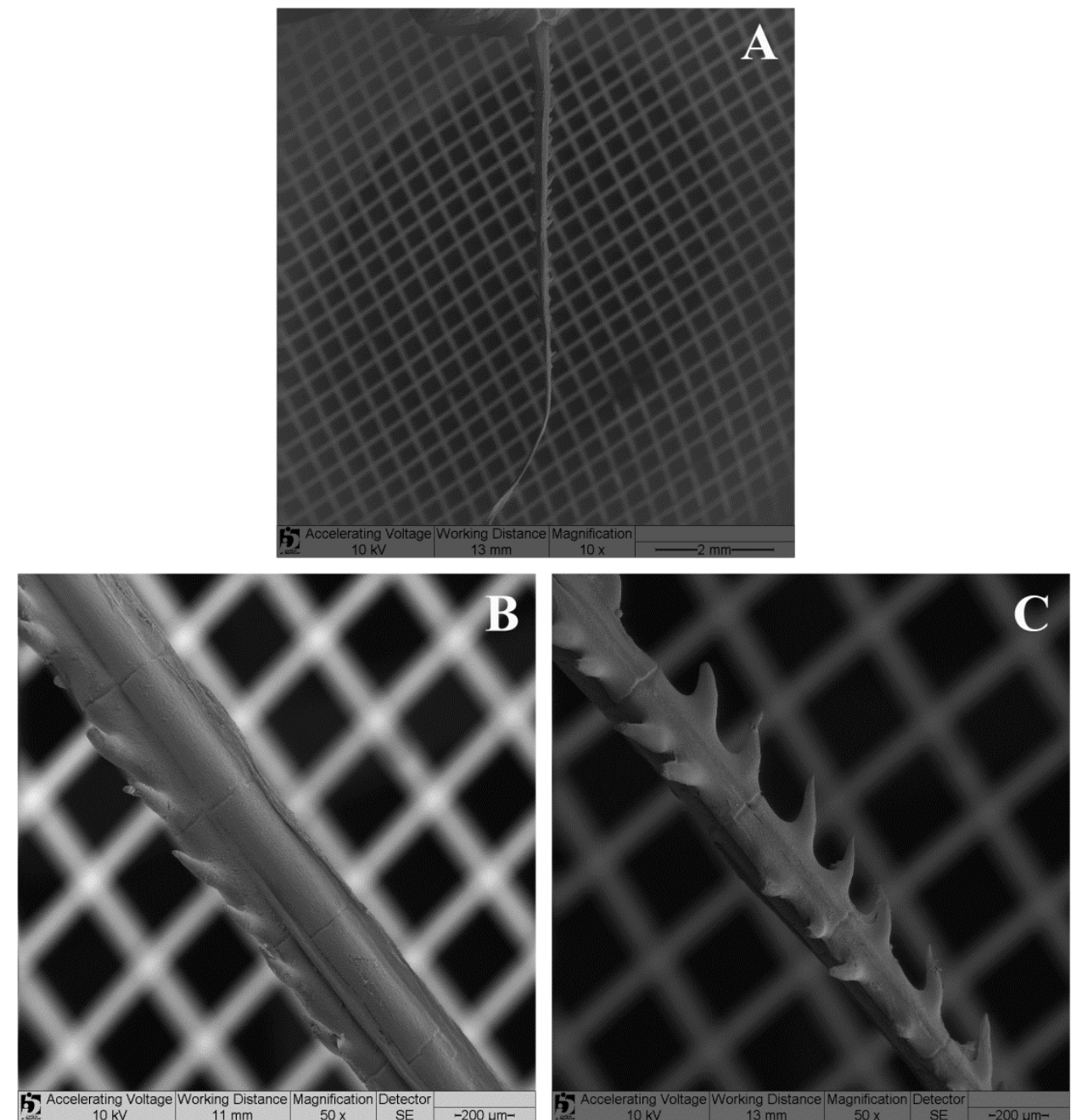

Figura 18 - Micrografias de varredura do segundo raio ramificado da nadadeira anal de um macho de Galeocharax humeralis MZUSP 19907, 111,5 mm CP, extremidade proximal do raio orientado para o topo da figura. (A) face anterior; (B) face lateral esquerda, detalhe dos ganchos ósseos; (C) face posterior, detalhe dos ganchos ósseos. 

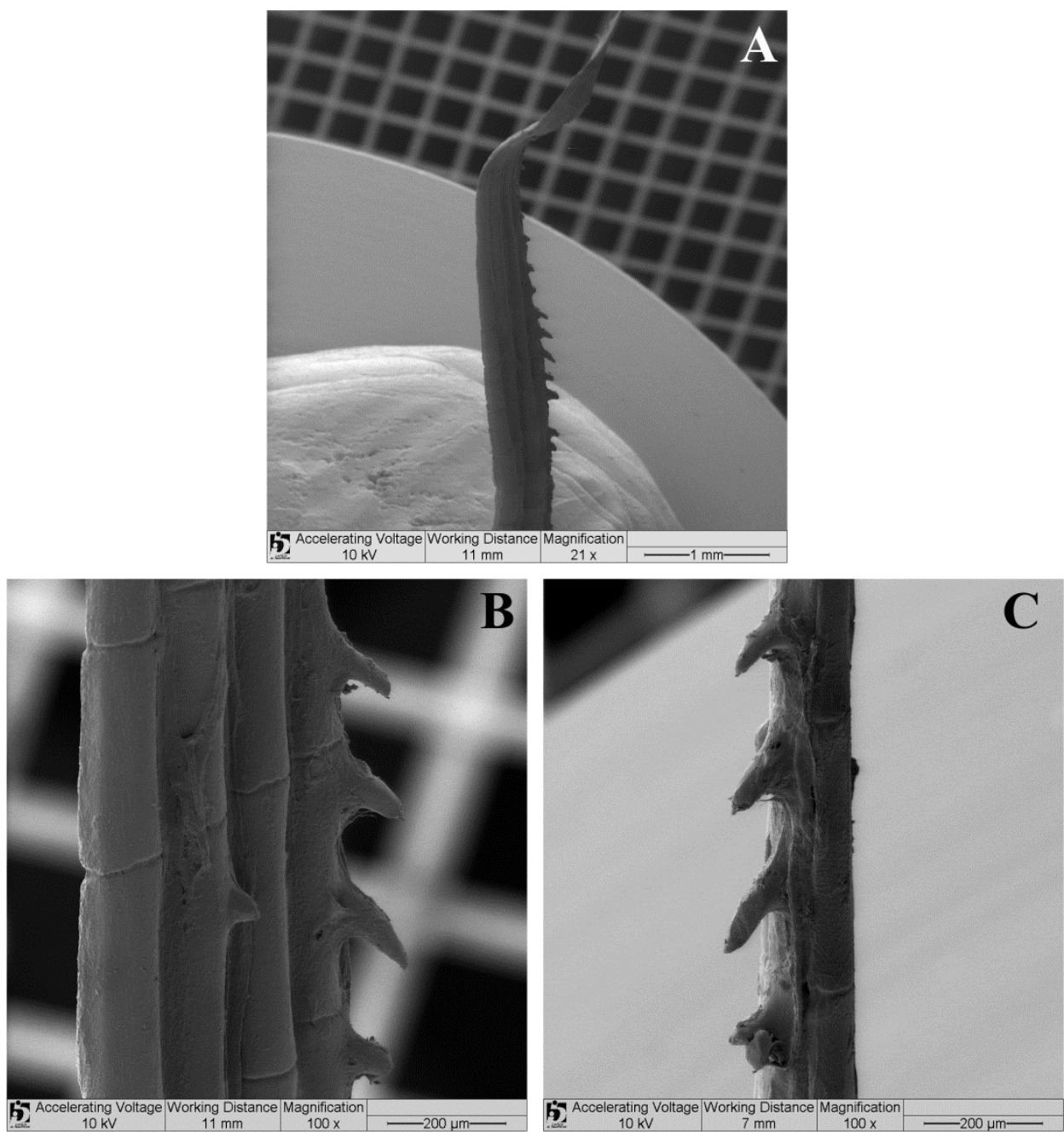

Figura 19 - Micrografias de varredura do primeiro raio ramificado da nadadeira pélvica de um macho de Galeocharax humeralis MZUSP 19907, 111,5 mm CP, extremidade distal do raio orientada para o topo da figura. (A) face ventral; (B) face ventral, detalhe dos ganchos; (C) face posterior. 

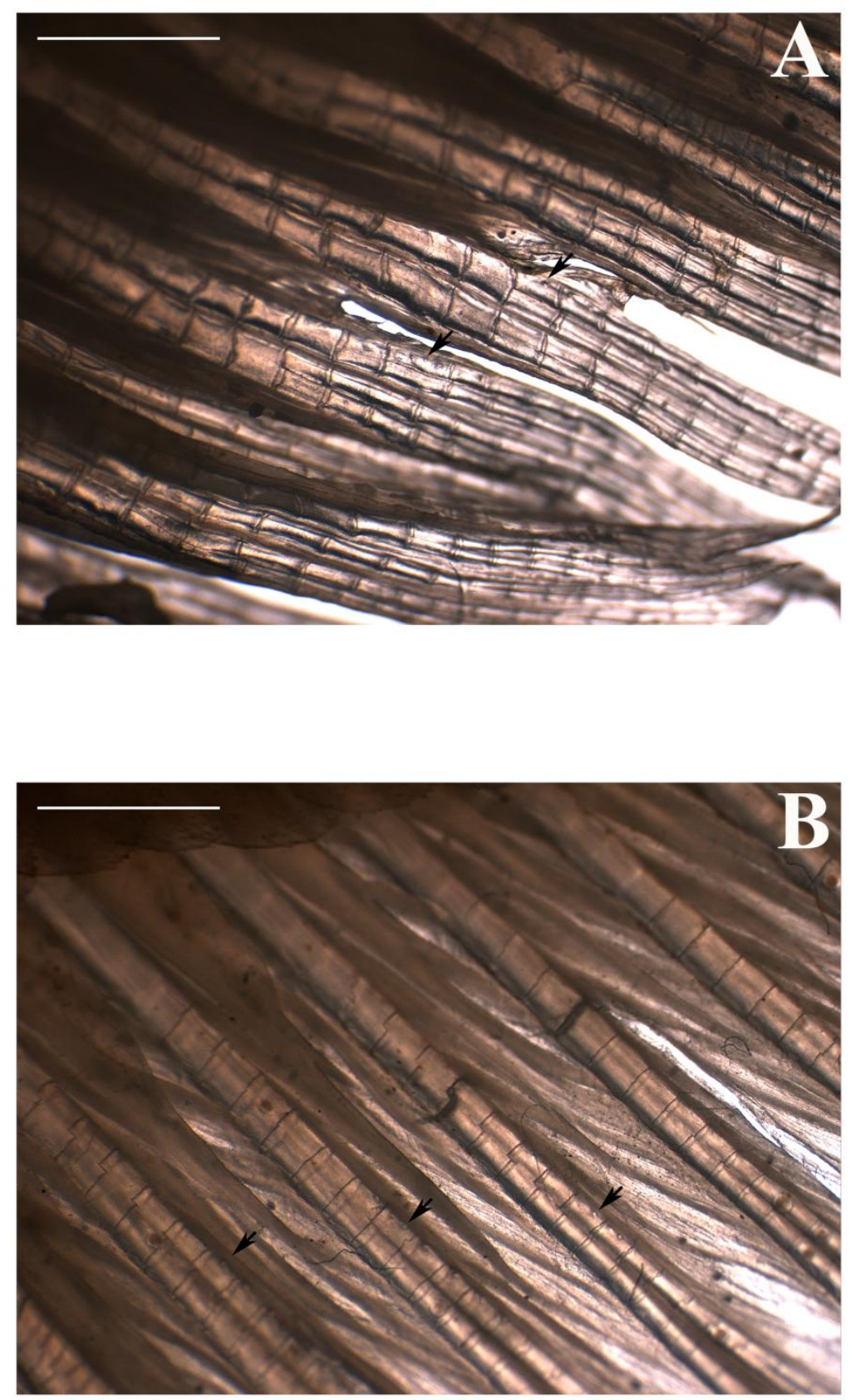

Figura 20 - Vista lateral dos raios anteriores da nadadeira anal de fêmeas de (A) Galeocharax humeralis MZUSP 90473, 210,5 mm CP; (B) Galeocharax gulo MZUSP 10479, 179,7 mm CP. Barra de escala 2 mm. Setas indicam ganchos ósseos. 


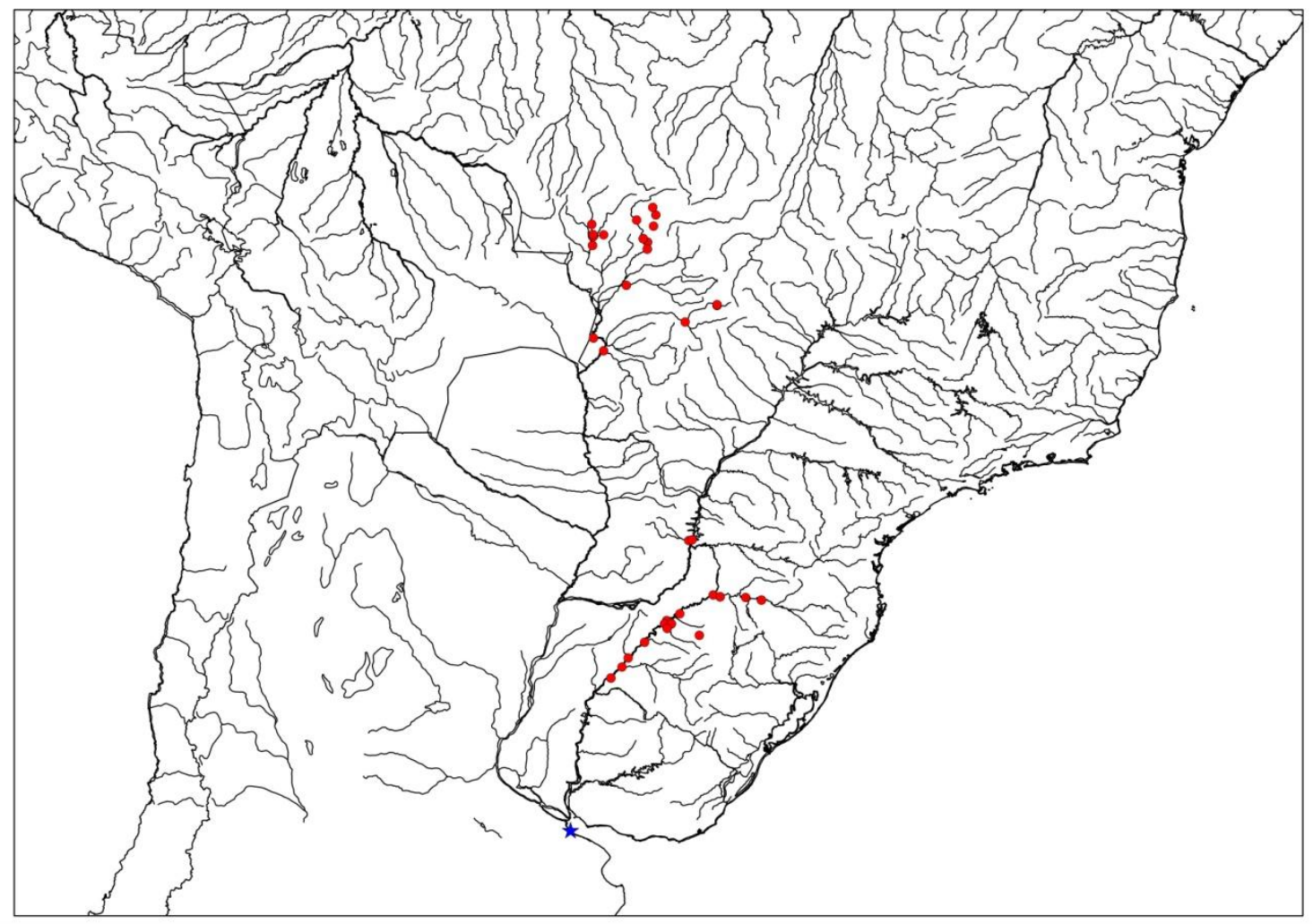

Figura 21 - Mapa da região central da América do Sul mostrando a distribuição geográfica de Galeocharax humeralis. Estrela indica localidade tipo.

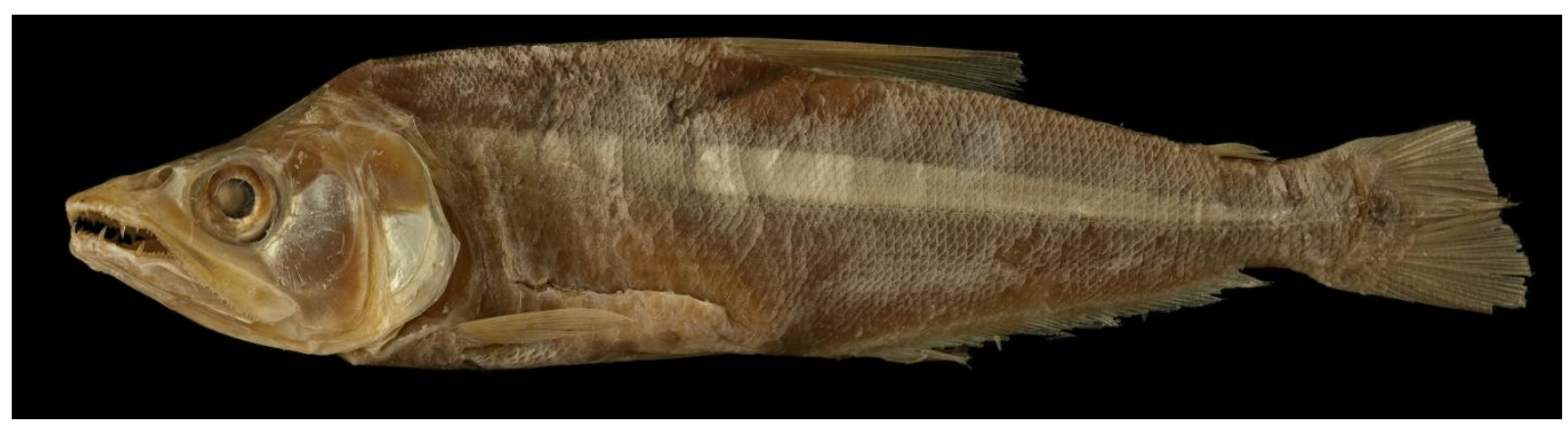

Figura 22 - Galeocharax humeralis, holótipo de Hydrocyon humeralis MNHN 9848 117,6 mm CP (Buenos Aires, Argentina).

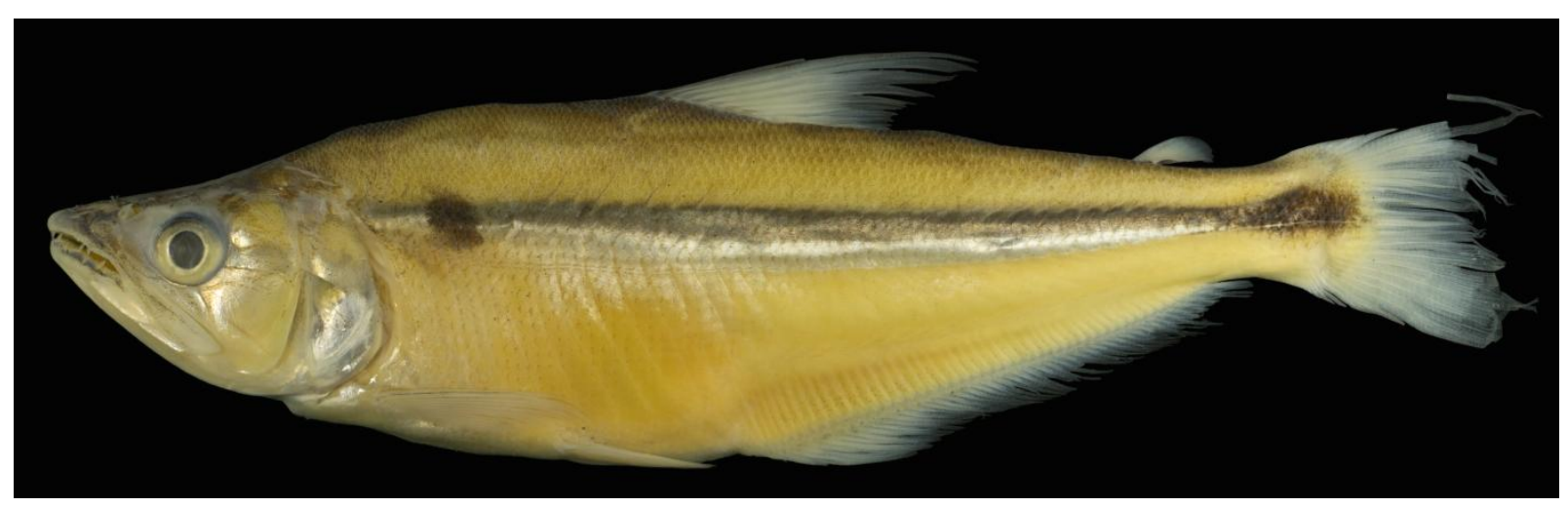

Figura 23 - Galeocharax gulo, MZUSP 110473, 148,2 mm CP. Peru, Huánuco, bacia do rio Ucayali, rio Huallaga. 


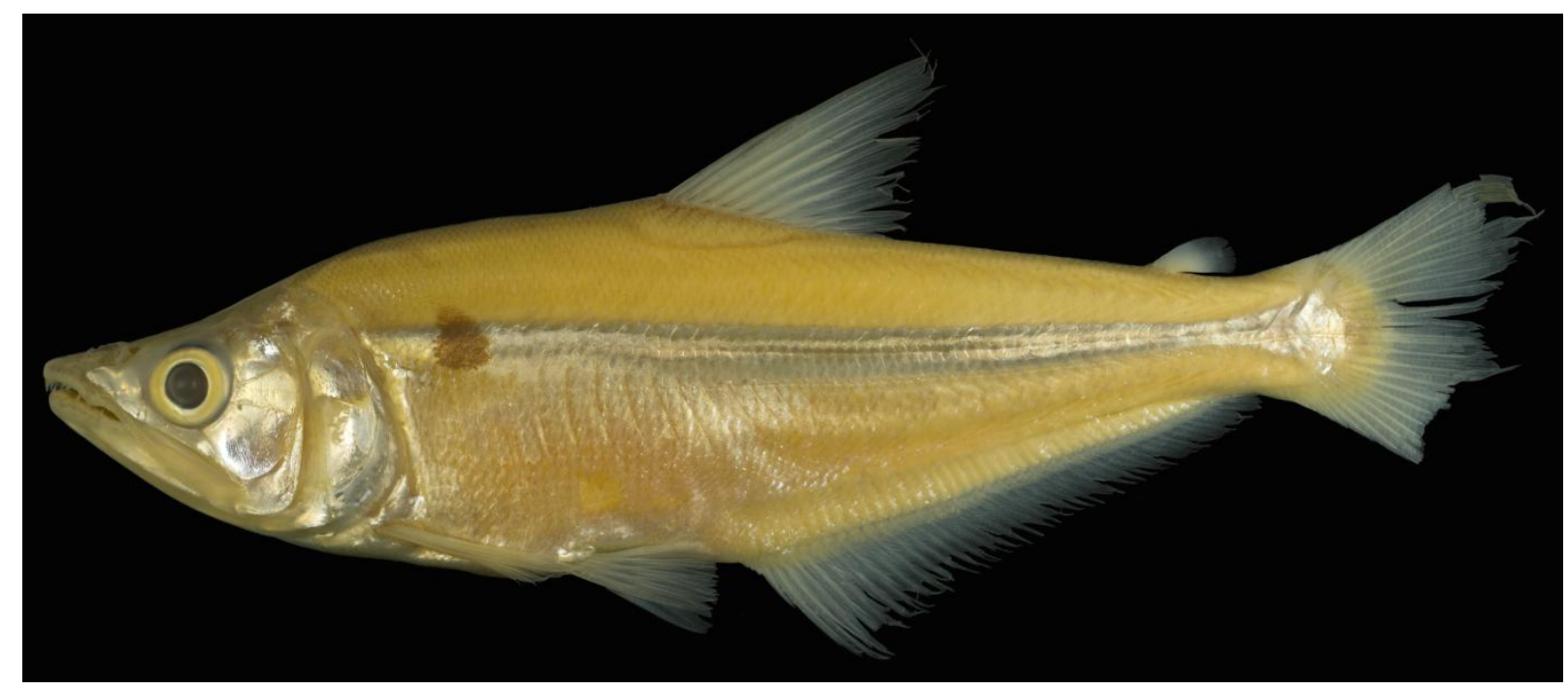

Figura 24 - Galeocharax gulo, MZUSP 29882, 108,3 mm CP. Brasil, Acre, bacia do rio Amazonas, rio Tarauacá.

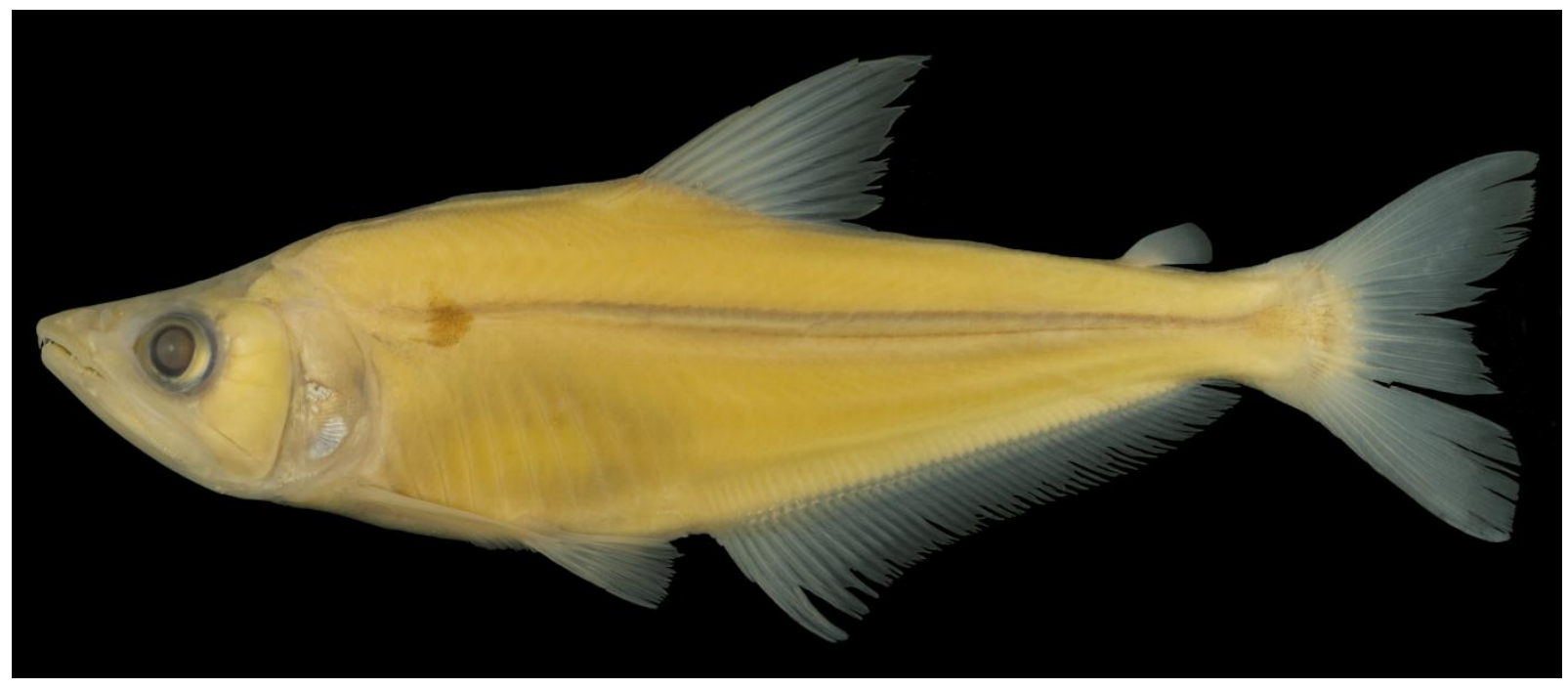

Figura 25 - Galeocharax gulo, MCNG 49082, 102,3 mm CP. Venezuela, Barinas, bacia do rio Orinoco, caño Bravo.

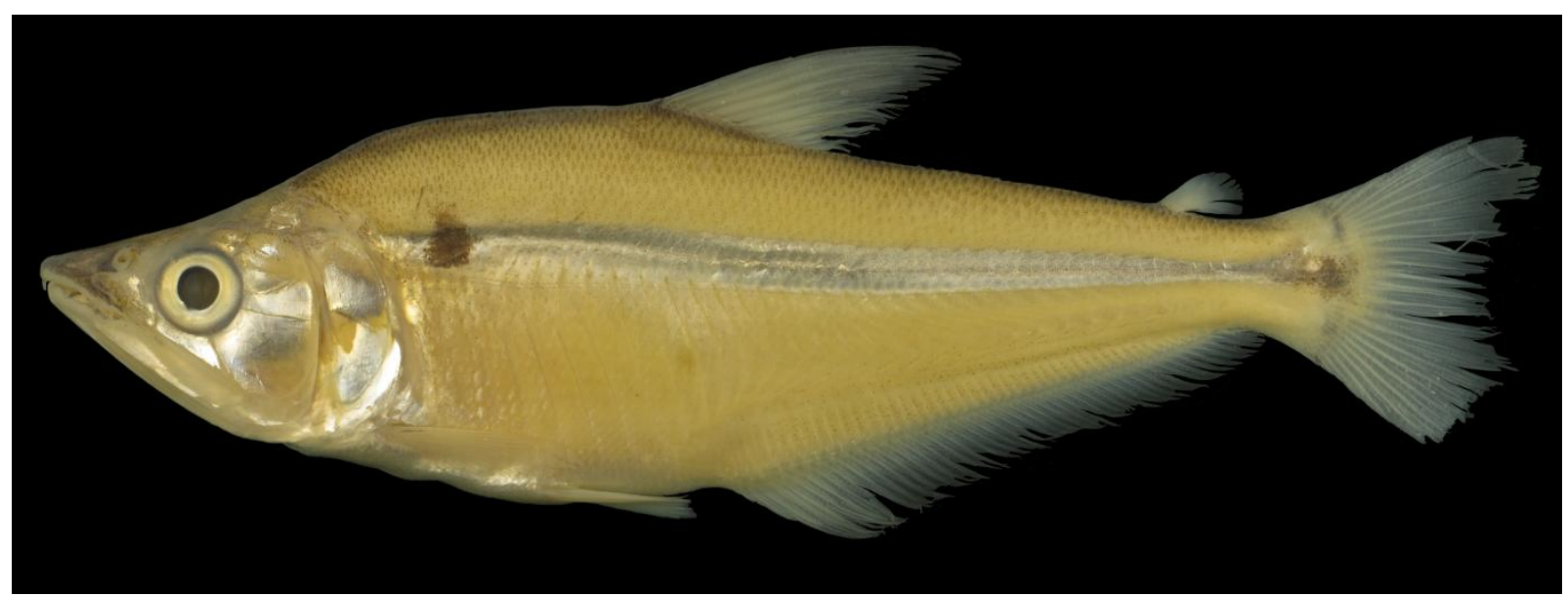

Figura 26 - Galeocharax gulo, USNM 258535, 113,6 mm CP. Venezuela, Guarico, bacia do rio Orinoco, rio Orituco. 


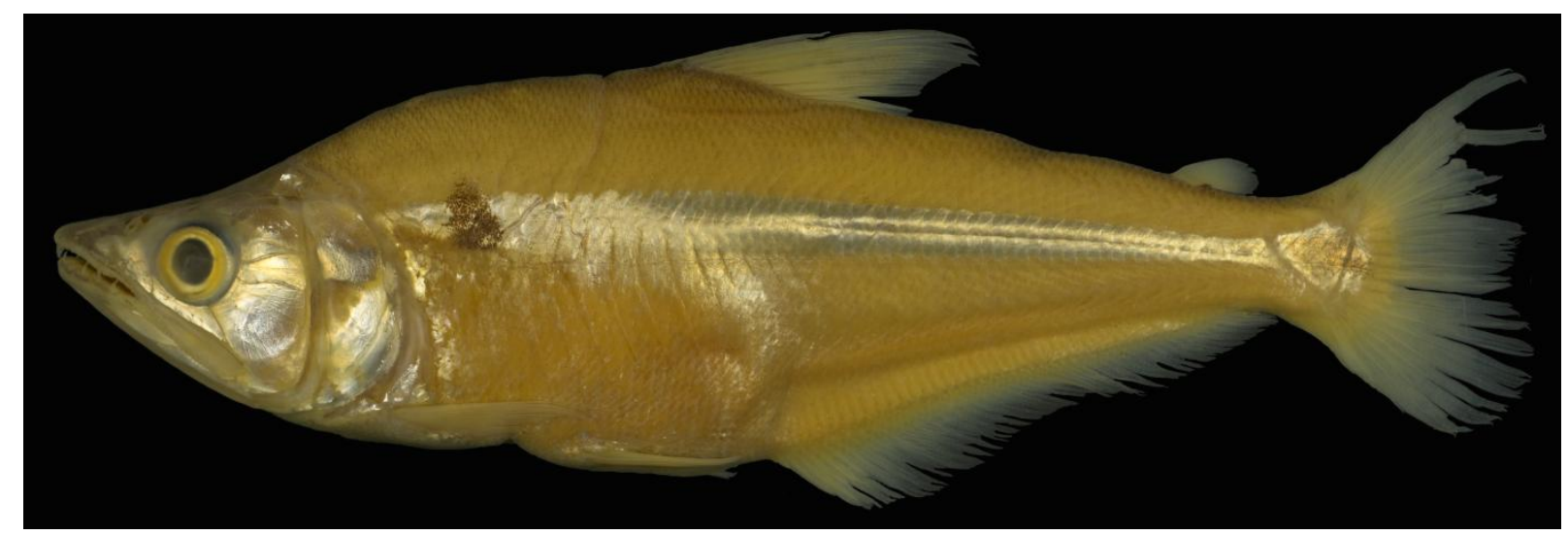

Figura 27 - Galeocharax gulo, MCP 36354, 128,6 mm CP. Brasil Pará, bacia do rio Amazonas, lago Grande.

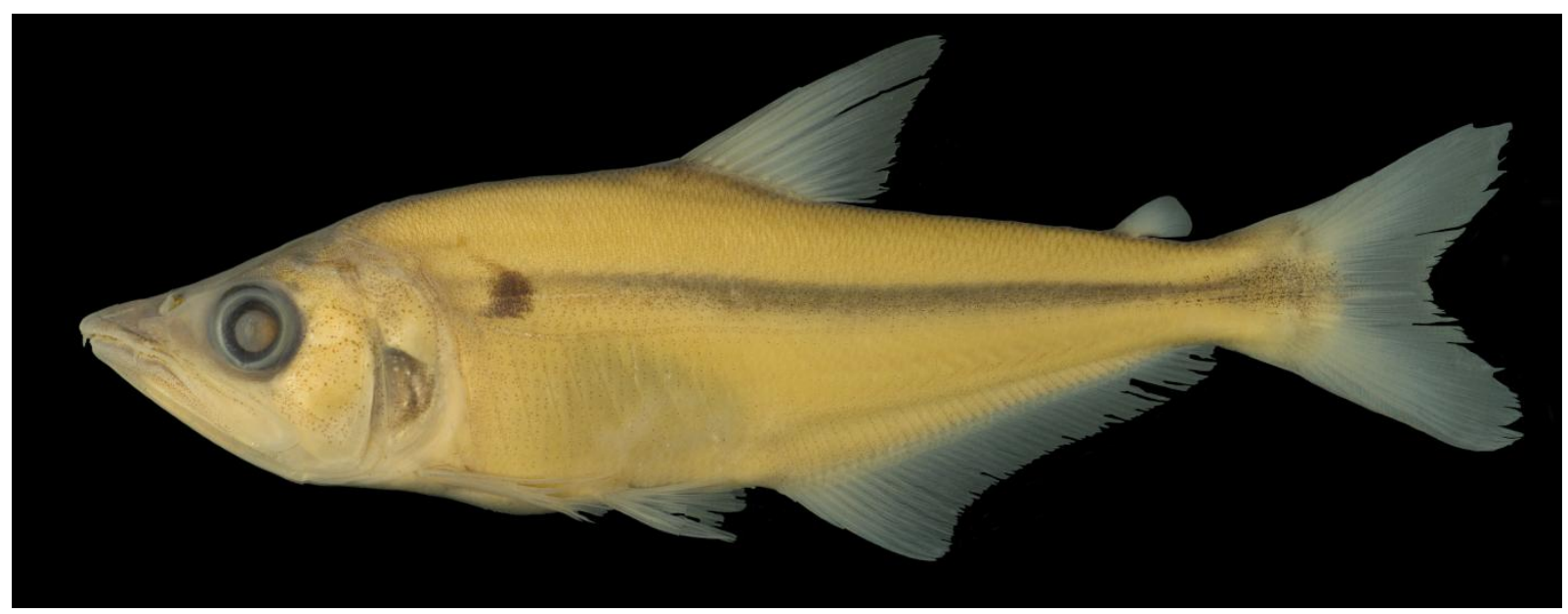

Figura 28 - Galeocharax gulo, UNT 2689, 88,3 mm CP. Brasil, Tocantins, bacia do rio Tocantins, rio Maranhão.

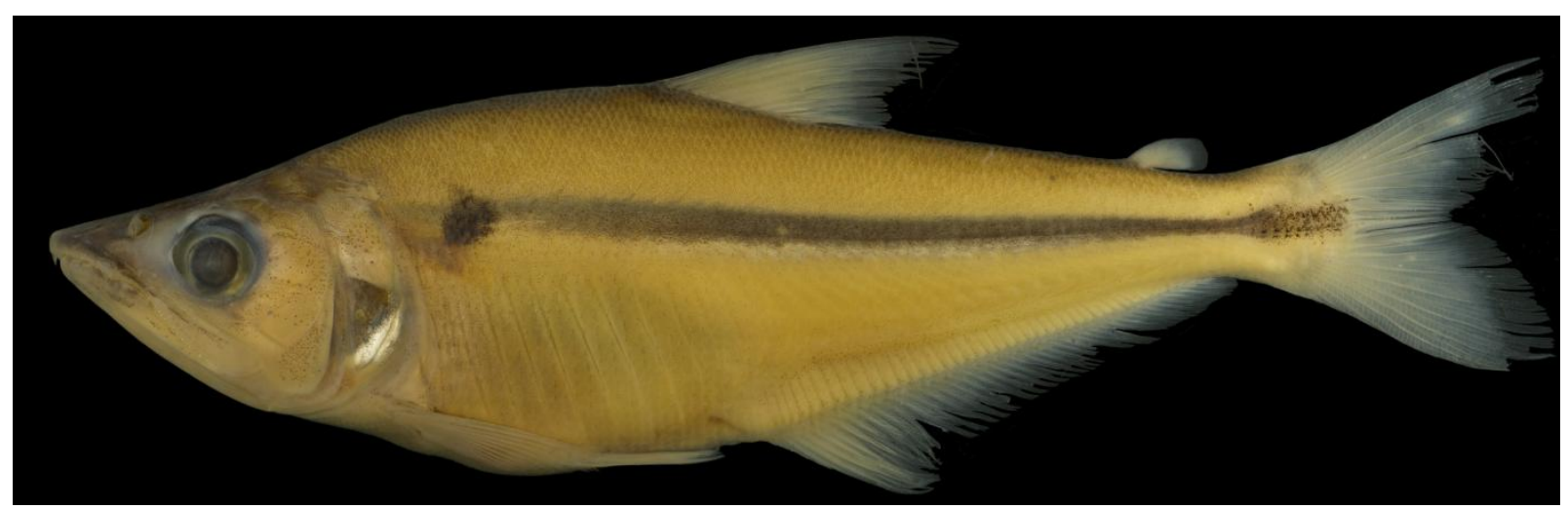

Figura 29 - Galeocharax gulo, MCN 19060, 132,8 mm CP. Brasil, Tocantins, bacia do rio Tocantins, igarapé Saranzal. 


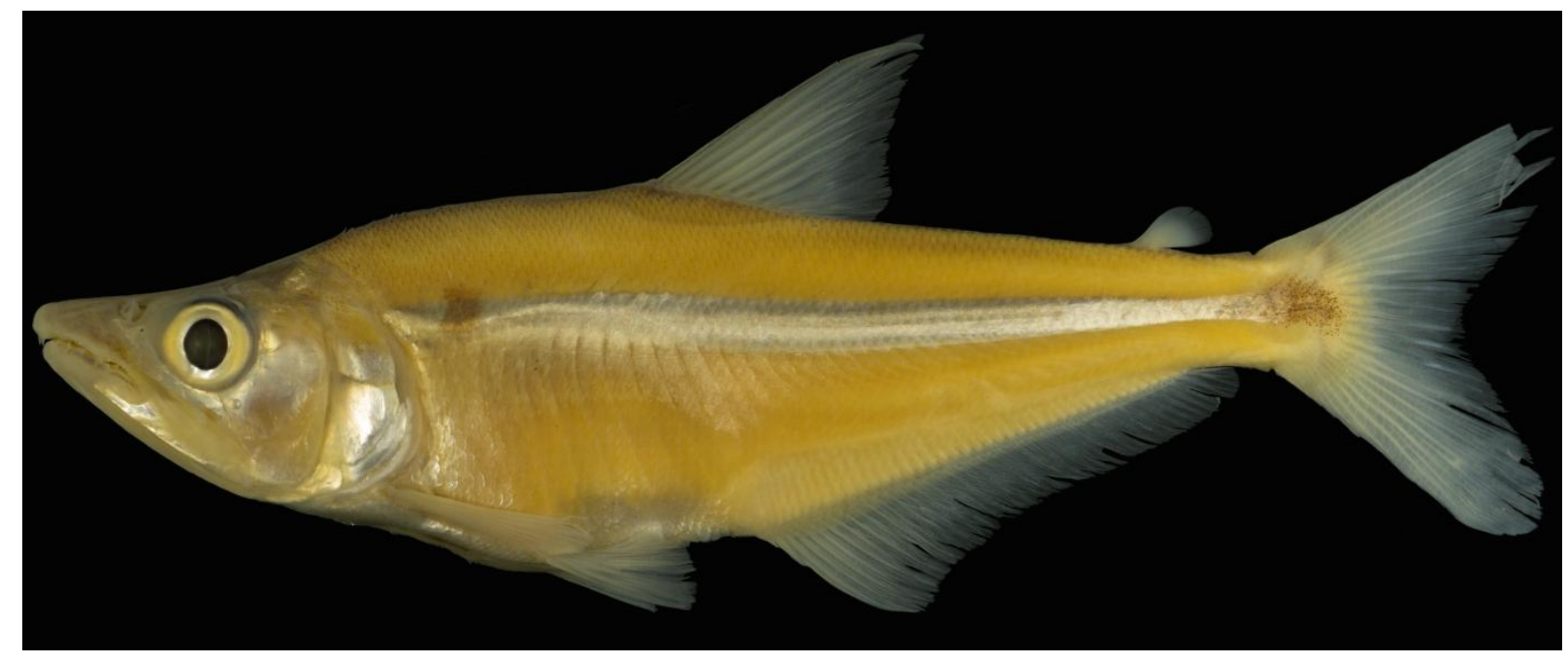

Figura 30 - Galeocharax gulo, MZUSP 10558-83, 119,1 mm CP. Brasil, São Paulo, bacia do alto rio Paraná, rio Pardo

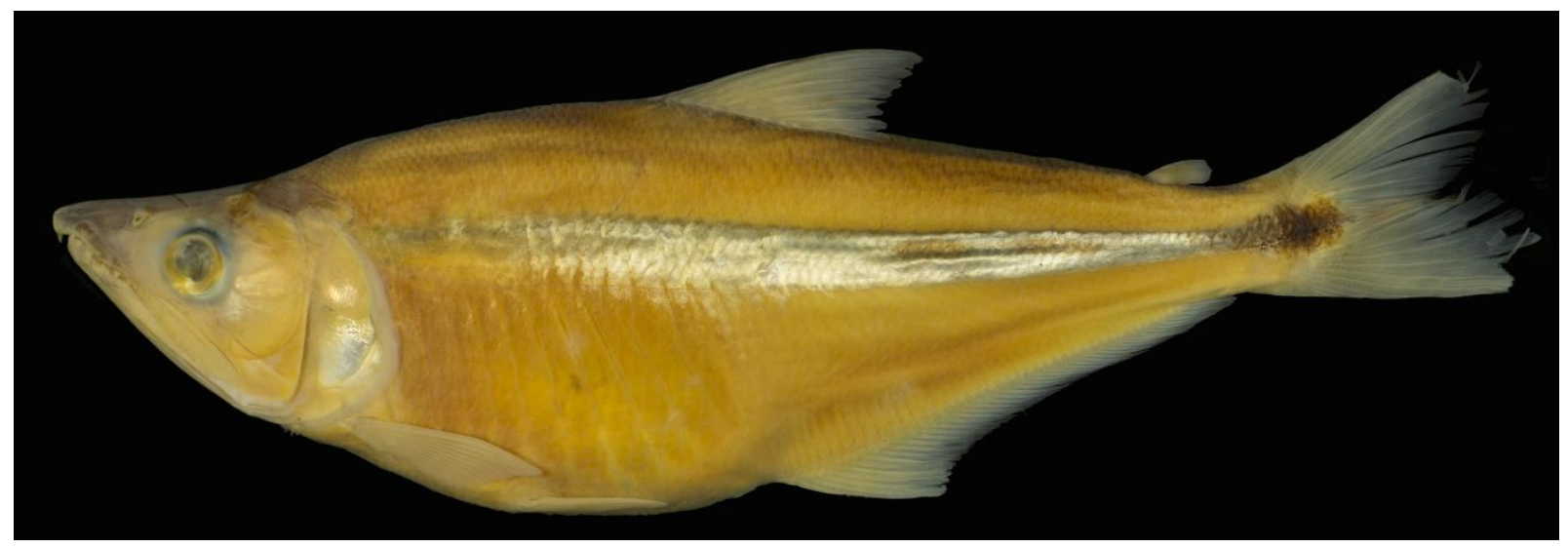

Figura 31 - Galeocharax gulo, MNRJ 19834, 224,9 mm CP. Brasil, Goiás, bacia do alto rio Paraná, rio São Marcos.

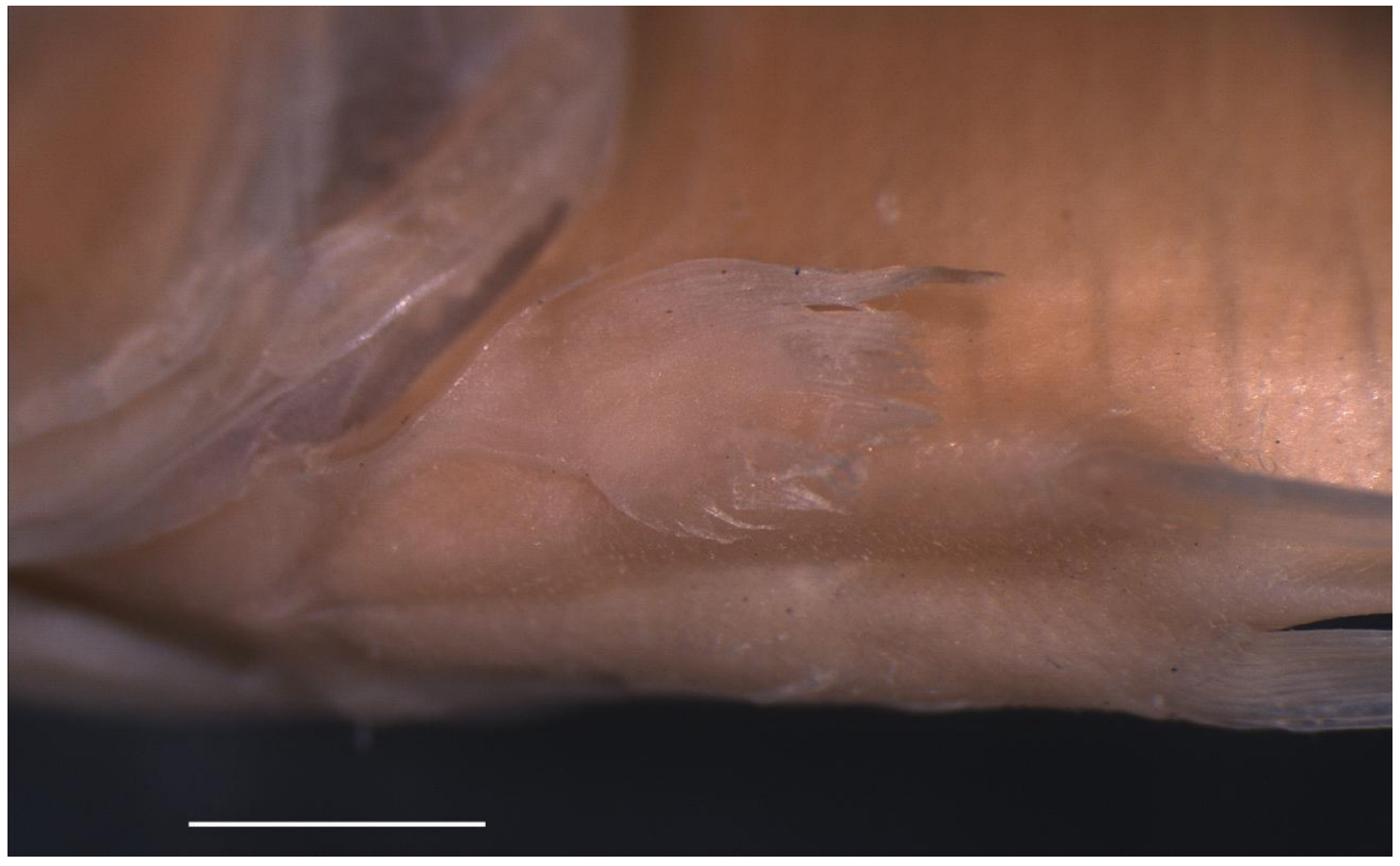

Figura 32- Vista ventro-lateral da nadadeira peitoral de Galeocharax gulo MCNG 54050, 34,0 mm CP. Barra de escala $2 \mathrm{~mm}$. 

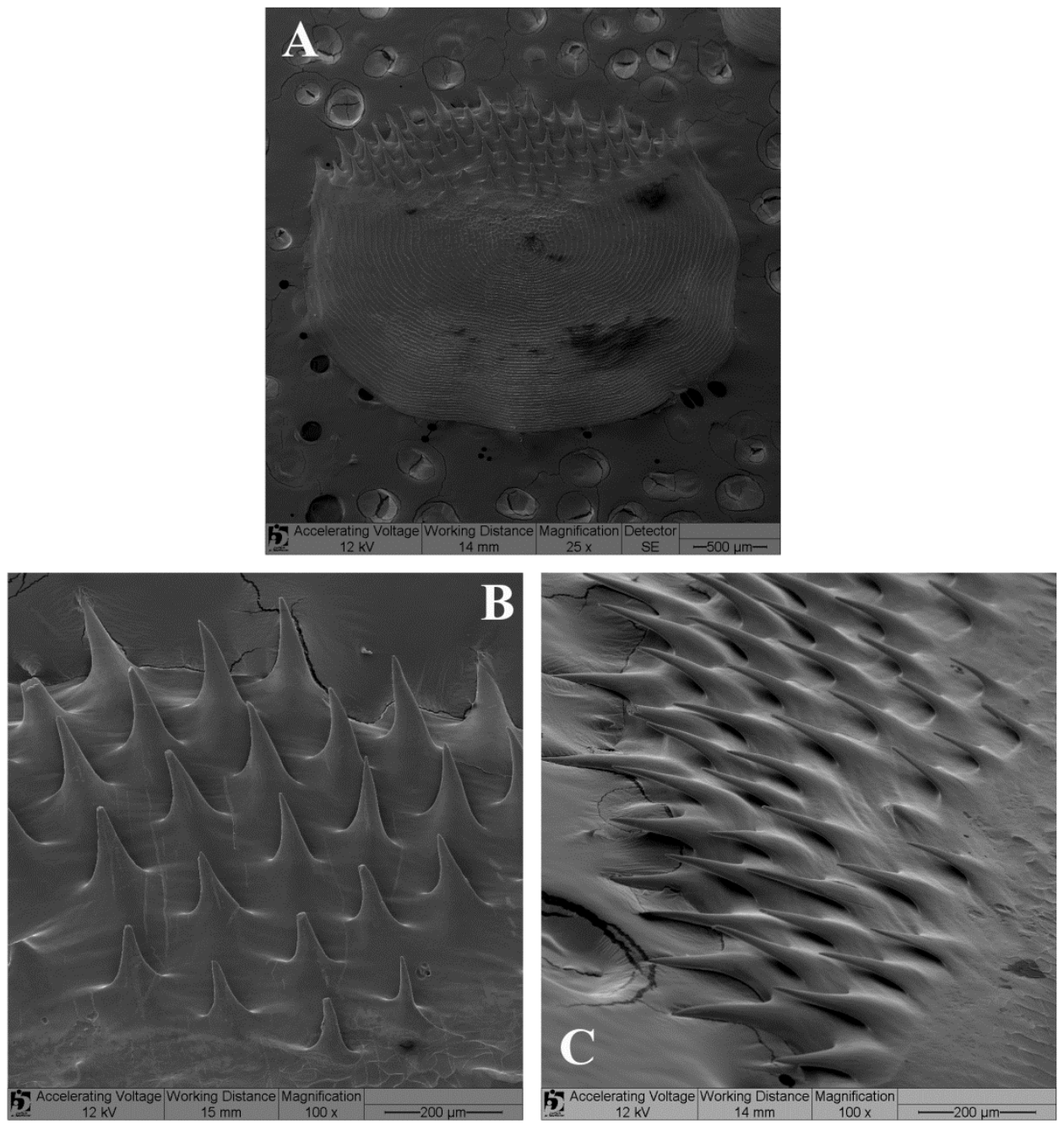

Figura 33 - Micrografias de varredura de escama de Galeocharax gulo, MUSM 22189, 134,1 mm CP. Peru, Madre de Dios, bacia do rio Amazonas, rio Purus. (A) vista geral, margem posterior da escama orientada para o topo da figura; (B) Detalhe do campo posterior da escama, margem posterior da escama orientada para o topo da figura; (C) Vista dorso-lateral do campo posterior, margem posterior da escama orientada para a esquerda da figura. 

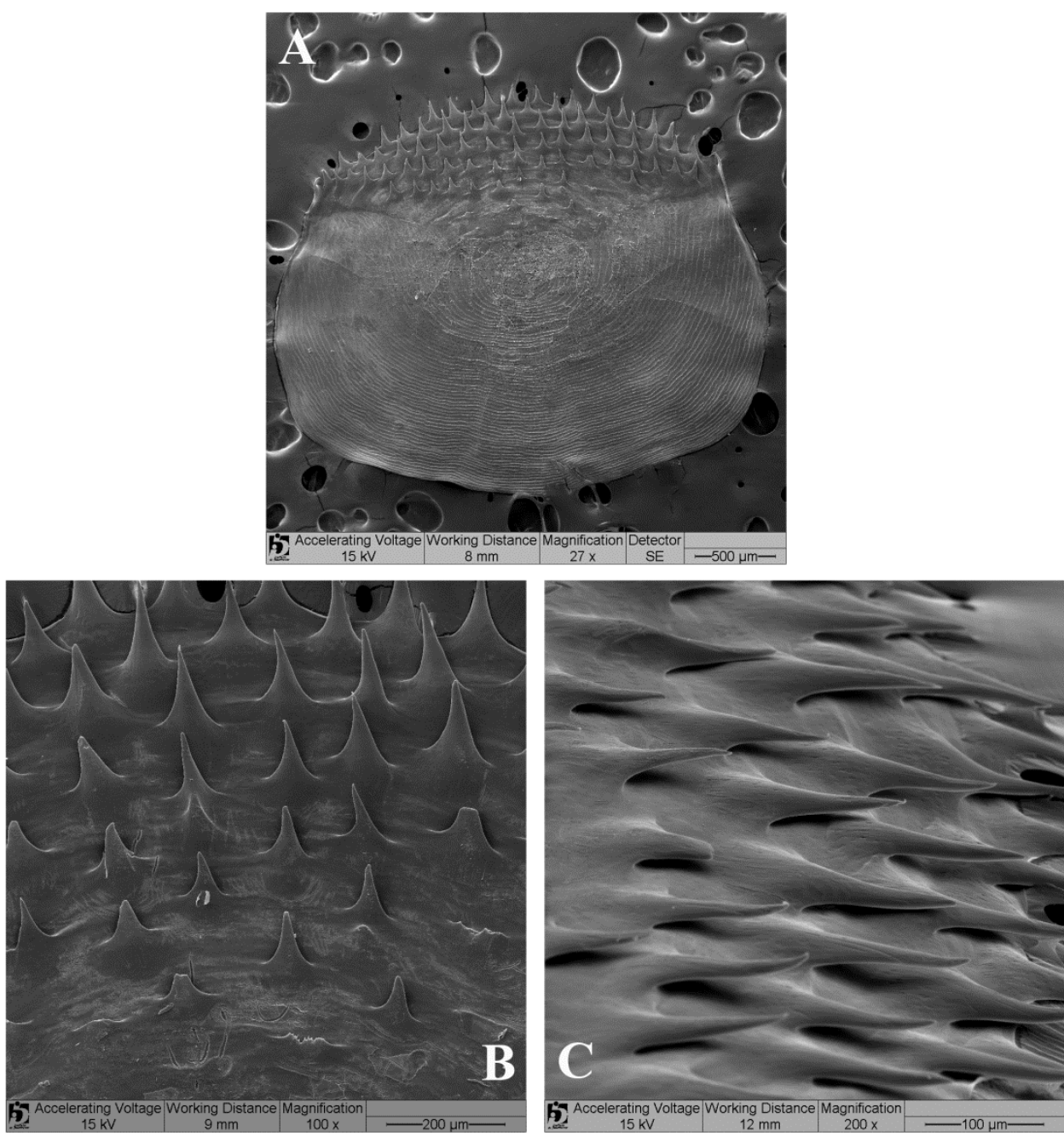

Figura 34 - Micrografias de varredura de escama de Galeocharax gulo, MCP 41380, 134,3 mm CP. Brasil, Goiás, bacia do rio Tocantins, rio Piranhas. (A) vista geral, margem posterior da escama orientada para o topo da figura; (B) Detalhe do campo posterior da escama, margem posterior da escama orientada para o topo da figura; (C) Vista dorso-ventral do campo posterior, margem posterior da escama orientada para a direita da figura. 

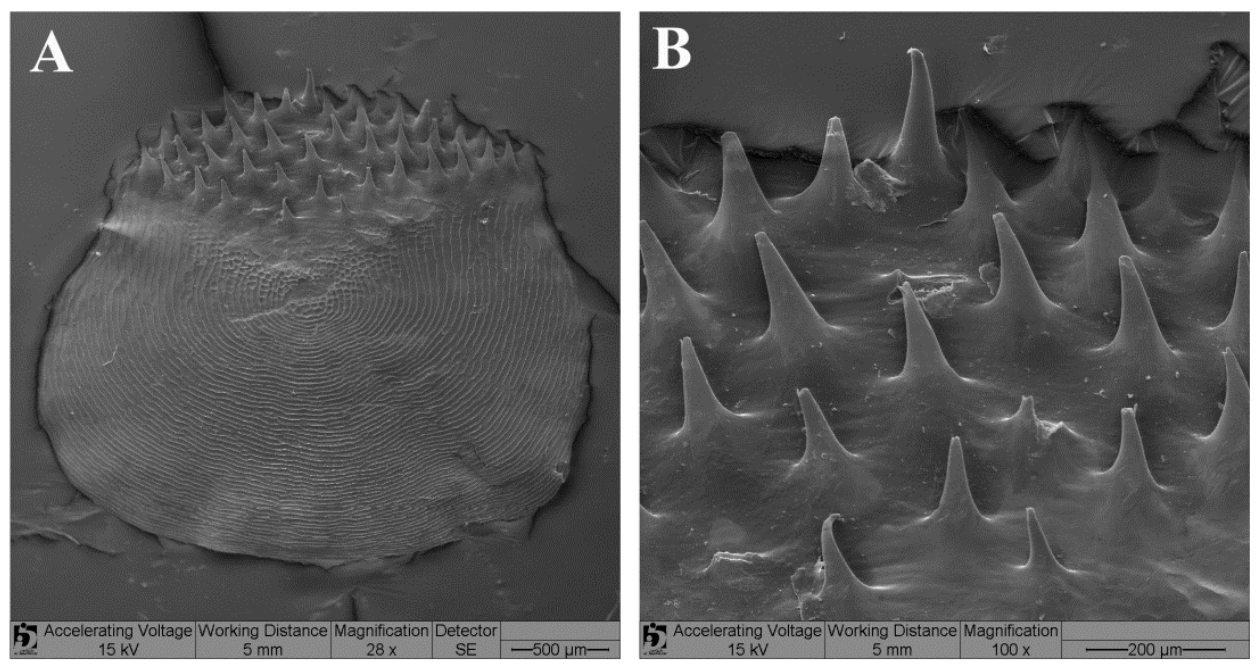

Figura 35 - Micrografias de varredura de escama de Galeocharax gulo, MZUSP 110473, 148,2 mm CP. Peru, Huánuco, bacia do rio Ucayali, rio Huallaga. Margem posterior da escama orientada para o topo da figura. (A) vista geral; (B) detalhe do campo posterior. 

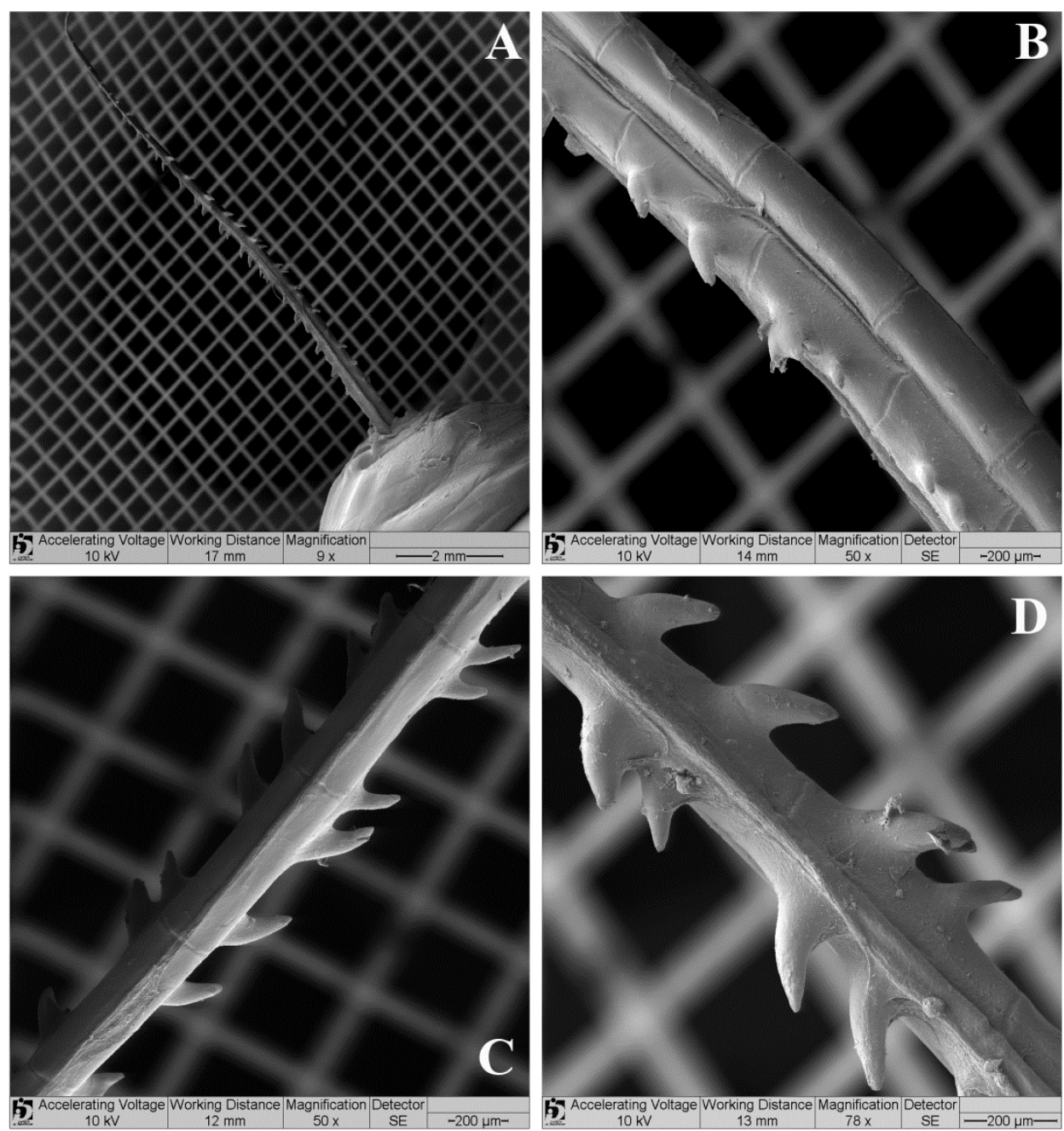

Figura 36 - Micrografias de varredura do segundo raio ramificado da nadadeira anal de um macho de Galeocharax gulo MZUSP 40901, 110,6mm CP. (A) face posterior, extremidade distal do raio orientada para o topo da figura; (B) face lateral esquerda, detalhe dos ganchos ósseos, extremidade distal do raio orientada para o topo da figura; (C) face anterior, detalhe dos ganchos ósseos, extremidade proximal do raio orientada para o topo da figura; (D) face posterior, detalhe dos ganchos, extremidade distal orientada para o topo da figura. 

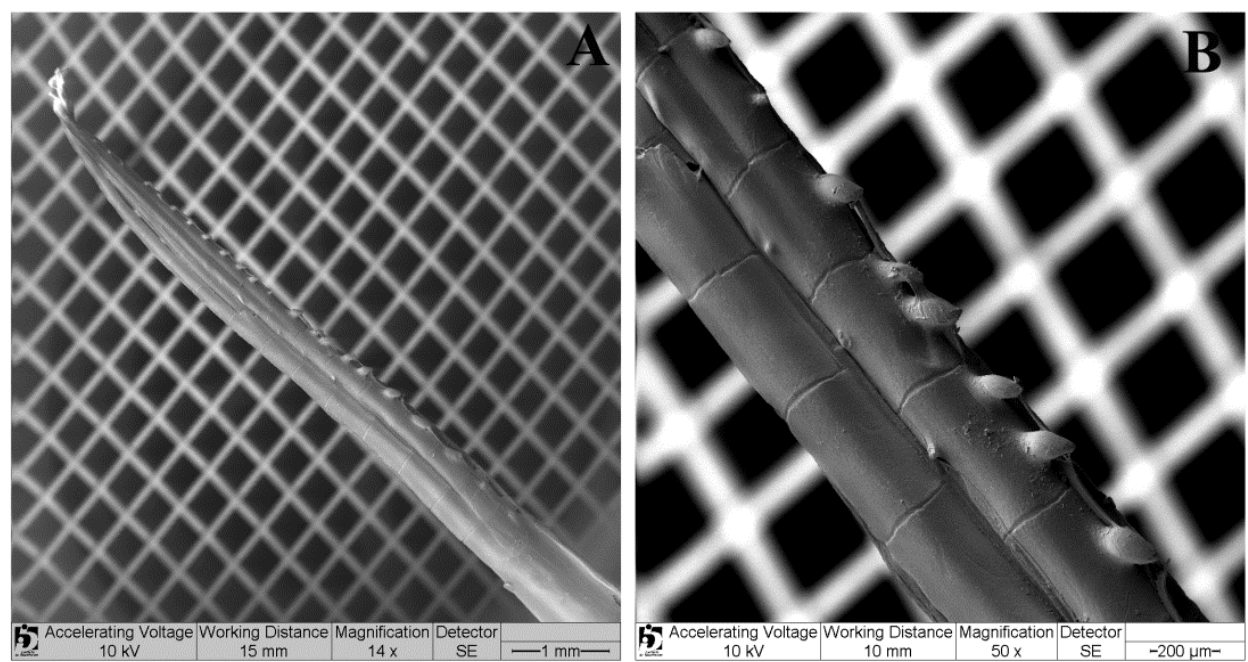

Figura 37- Micrografias de varredura do primeiro raio ramificado da nadadeira pélvica de um macho de Galeocharax gulo, MZUSP 40901, 110,6mm CP, Extremidade distal do raio orientada para o topo da figura. (A) face ventral; (B) face ventral, detalhe dos ganchos.

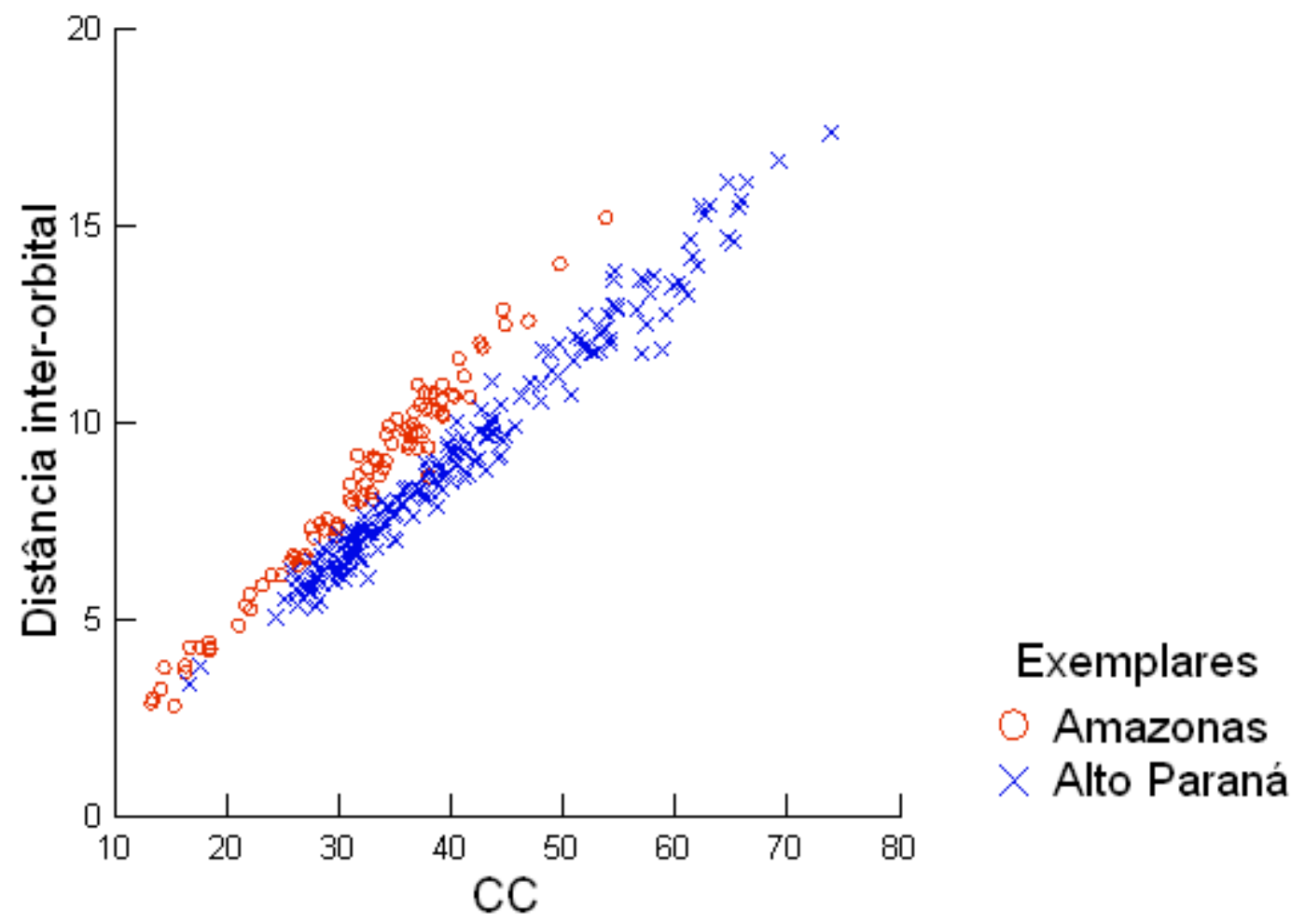

Figura 38 - Gráfico de dispersão dos valores de distância inter-orbital pelo comprimento da cabeça (CC) em exemplares de Galeocharax gulo da bacia dos rios Amazonas e alto rio Paraná. Medidas expressas em milímetros. 


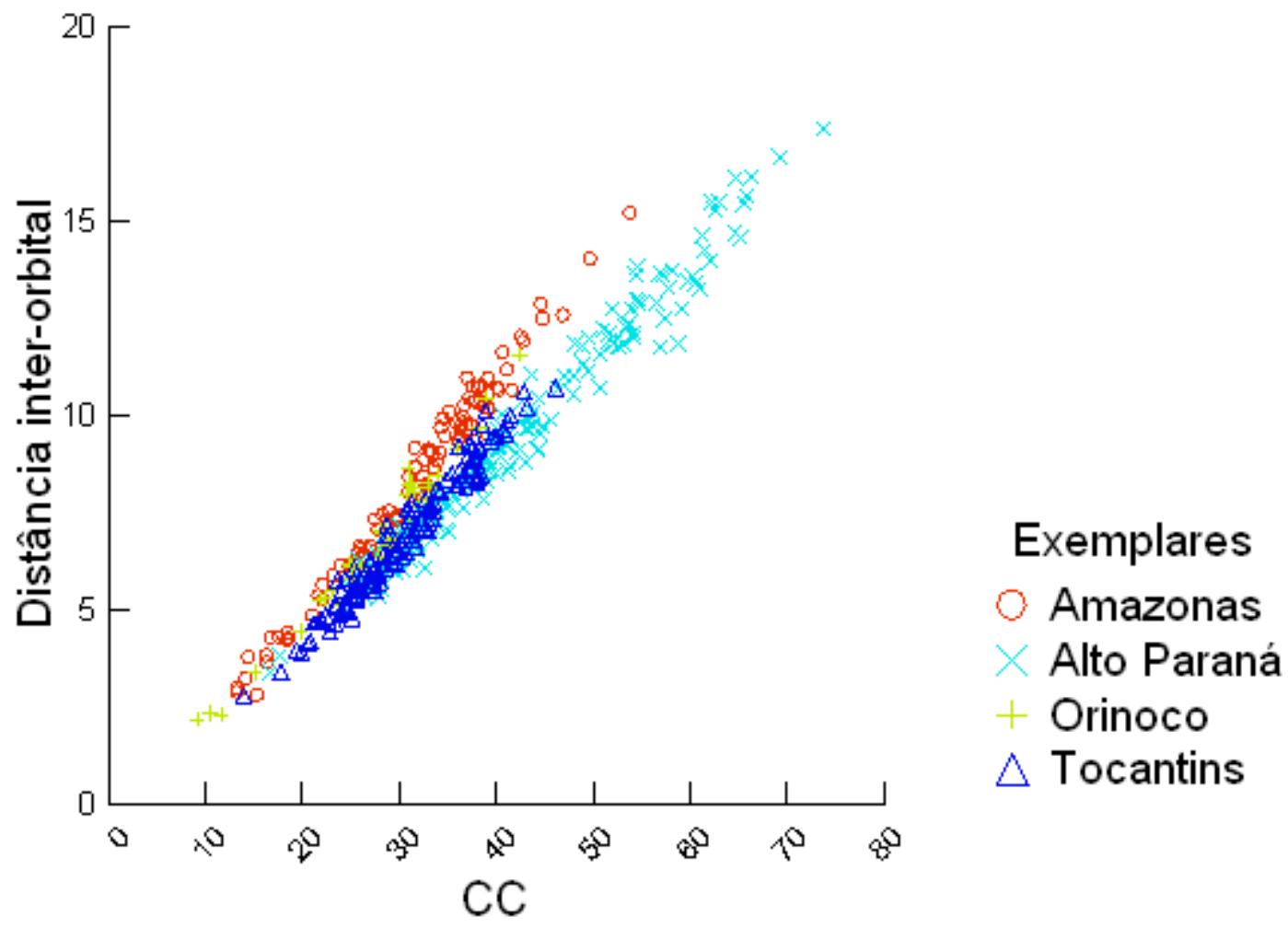

Figura 39 - Gráfico de dispersão dos valores de distância inter-orbital pelo comprimento da cabeça (CC) em exemplares de Galeocharax gulo da bacia dos rios Amazonas, Tocantins Orinoco e alto rio Paraná. Medidas expressas em milímetros.

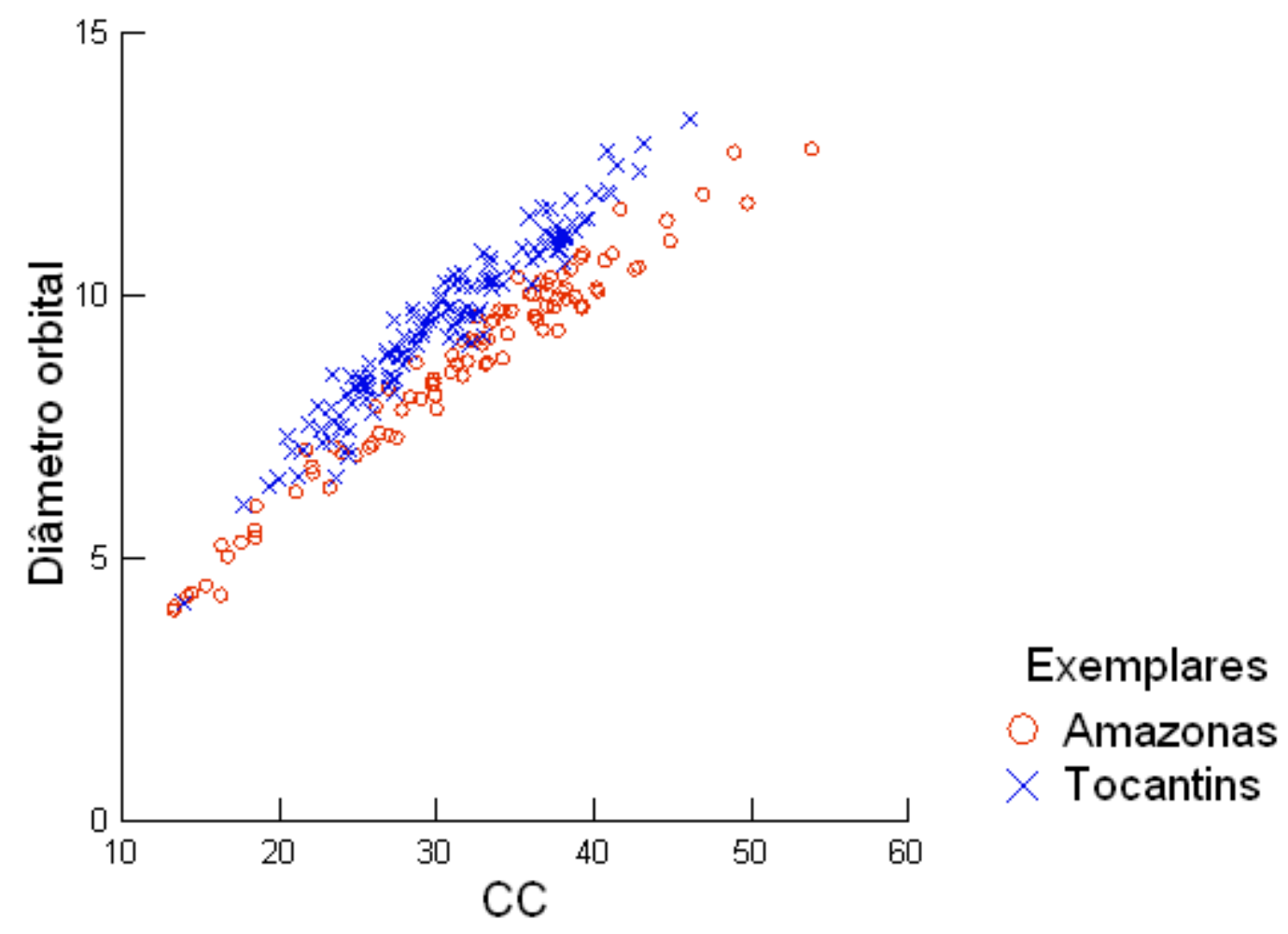

Figura 40 - Gráfico de dispersão dos valores de diâmetro orbital pelo comprimento da cabeça (CC) em exemplares de Galeocharax gulo da bacia do rio Amazonas e da bacia do rio Tocantins. Medidas expressas em milímetros. 


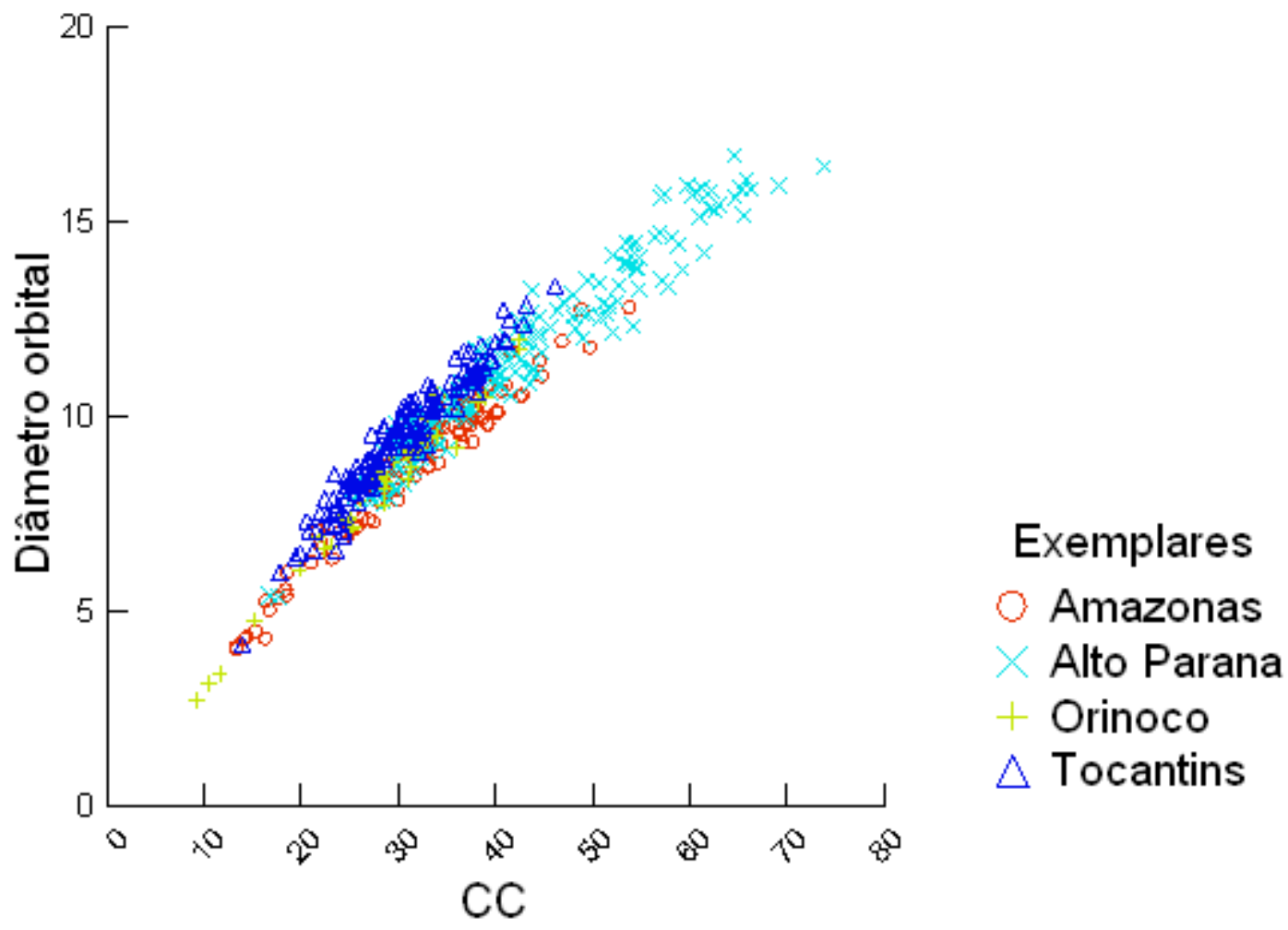

Figura 41 - Gráfico de dispersão dos valores de diâmetro orbital pelo comprimento da cabeça (CC) em exemplares de Galeocharax gulo da bacia dos rios Amazonas, Tocantins Orinoco e alto rio Paraná.

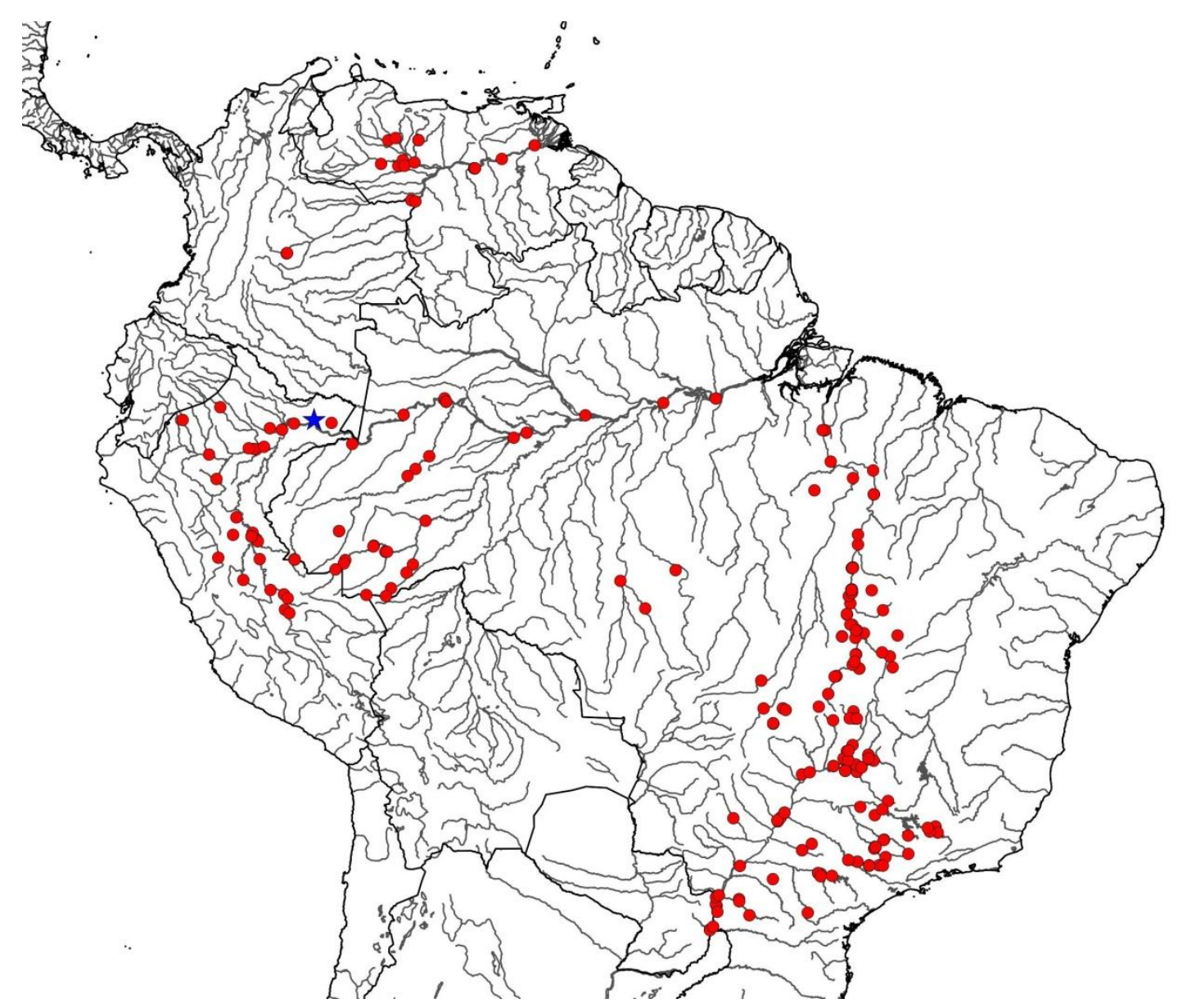

Figura 42 - Mapa da região central e norte da América do Sul mostrando a distribuição geográfica de Galeocharax gulo. Estrela indica localidade tipo. 


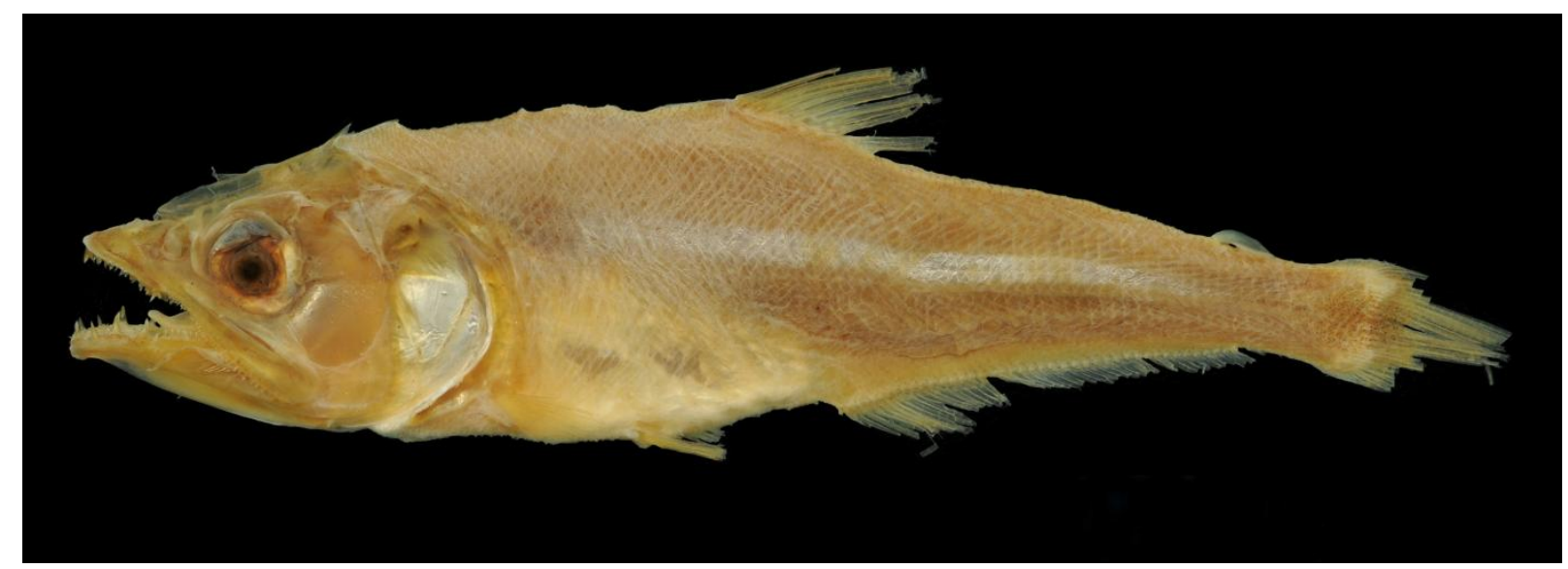

Figura 43 - Galeocharax gulo, holótipo de Cynopotamus gulo, ANSP 8053, 73,9 mm CP. (Pebas, Peru)
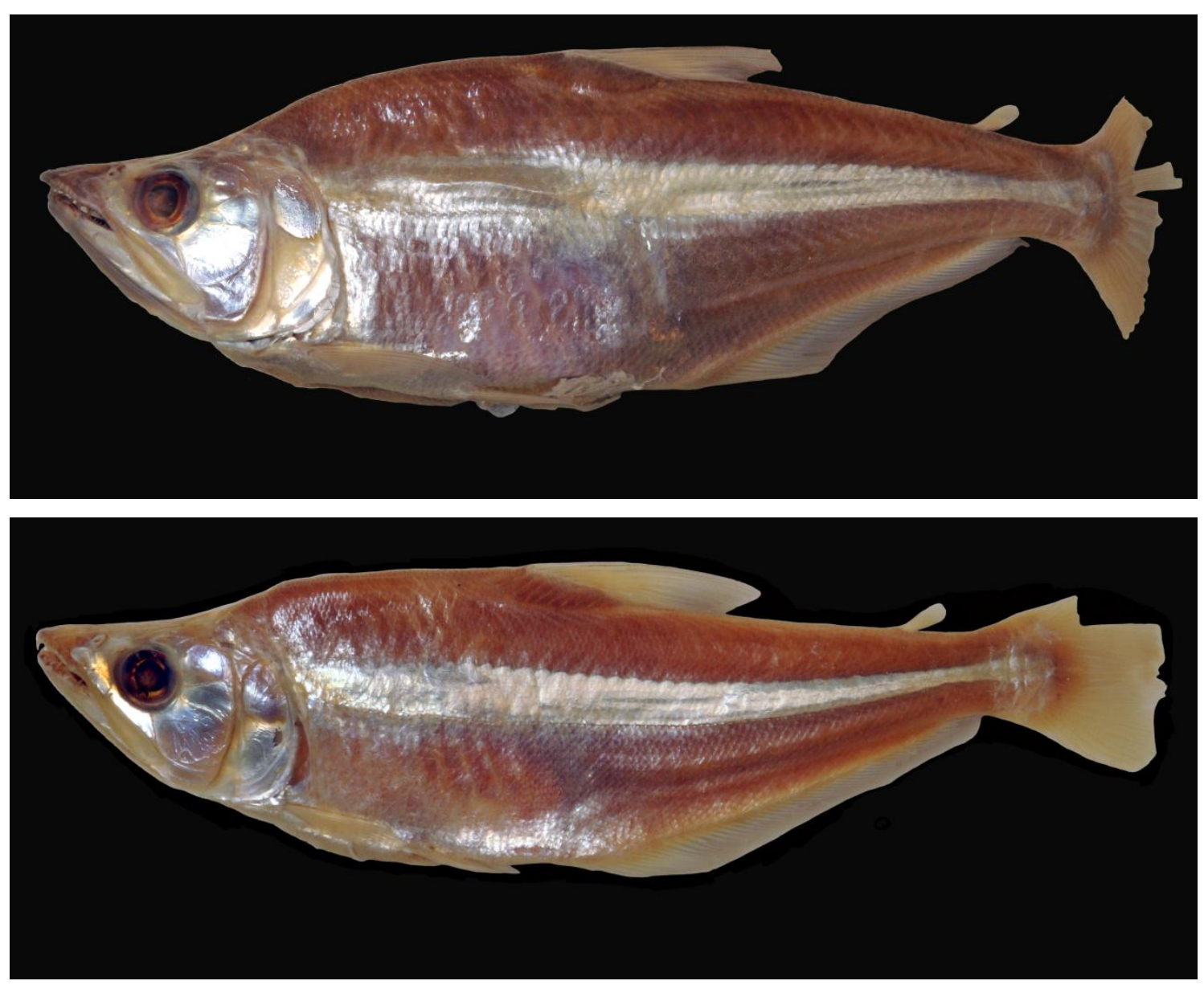

Figura 44 - Galeocharax gulo, síntipos de Anacyrtus (Cynopotamus) knerii, NMW 62660, 210,5 mm CP acima, 162,1 mm CP abaixo. (Oriçanga, São Paulo). 


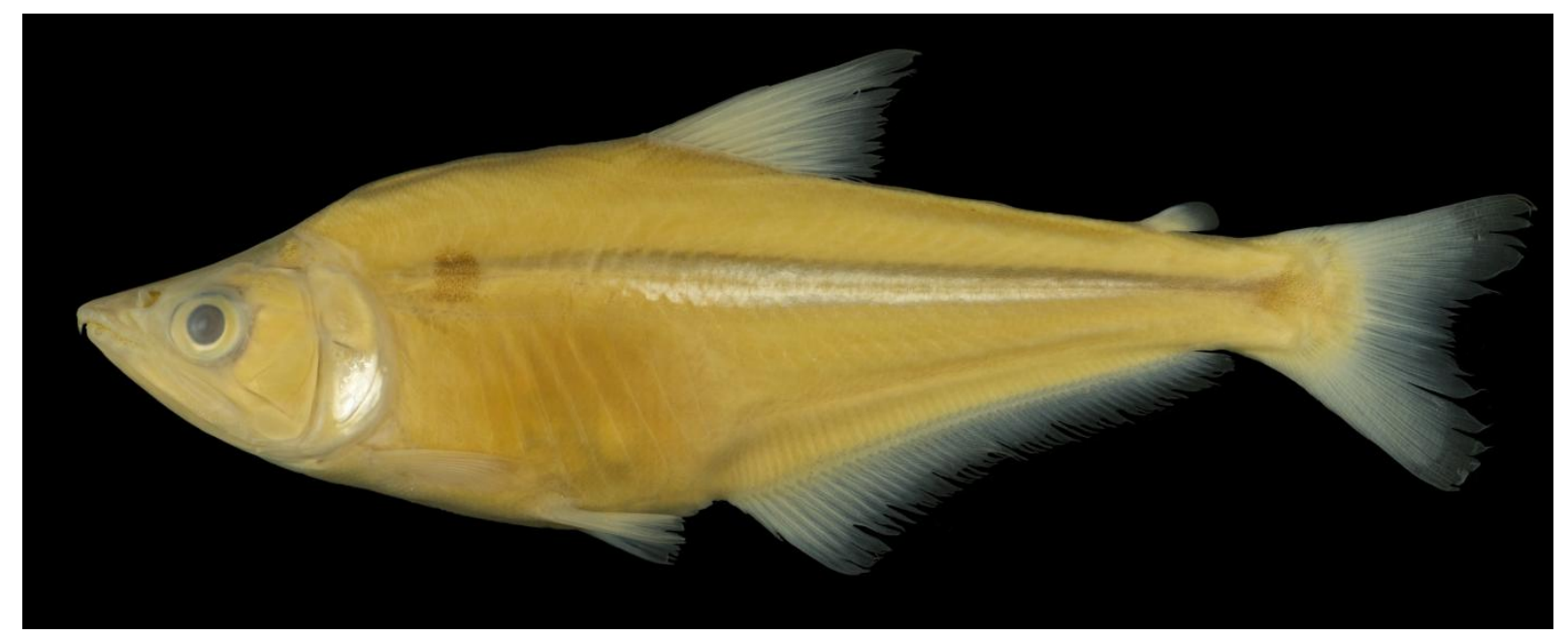

Figura 45 - Galeocharax goeldii, INPA 24598, 109,7 mm CP. Brasil, Amazonas, bacia do rio Madeira, Paraná do Uruá.

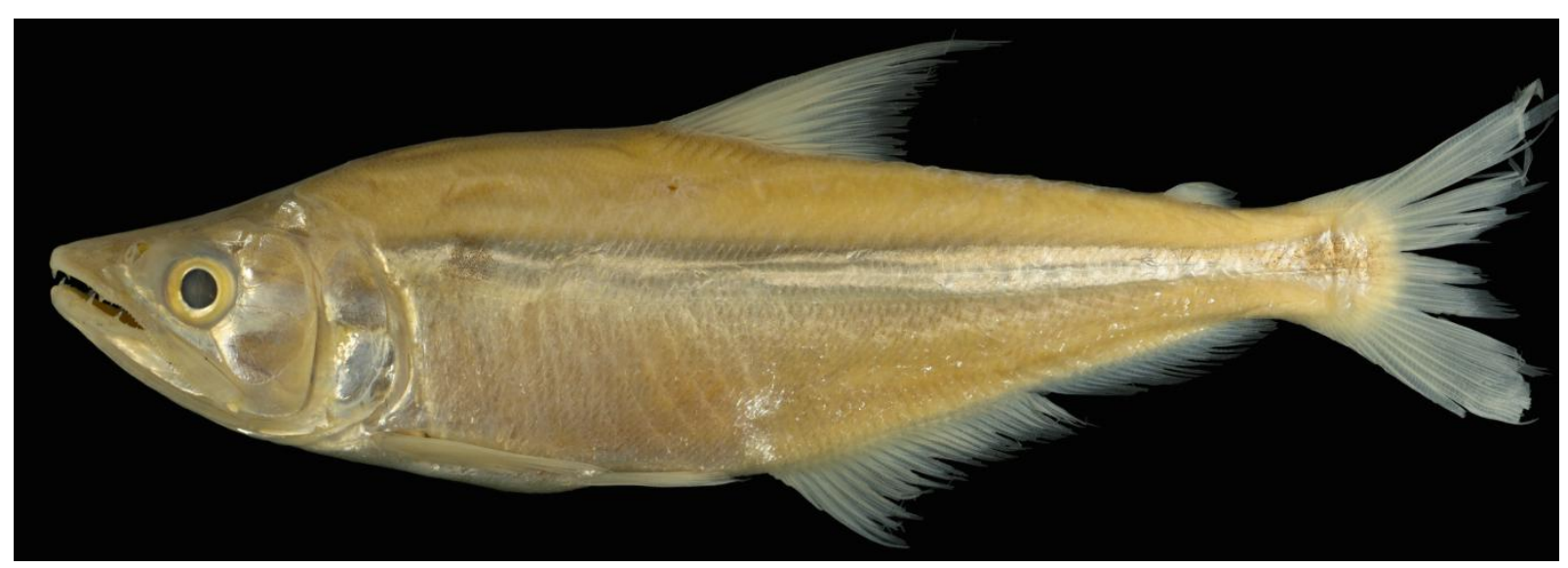

Figura 46 - Galeocharax goeldii, MUSM 8790, 143,4 mm CP. Peru, Madre de Dios, bacia do rio Madre de Dios, rio Tambopata.

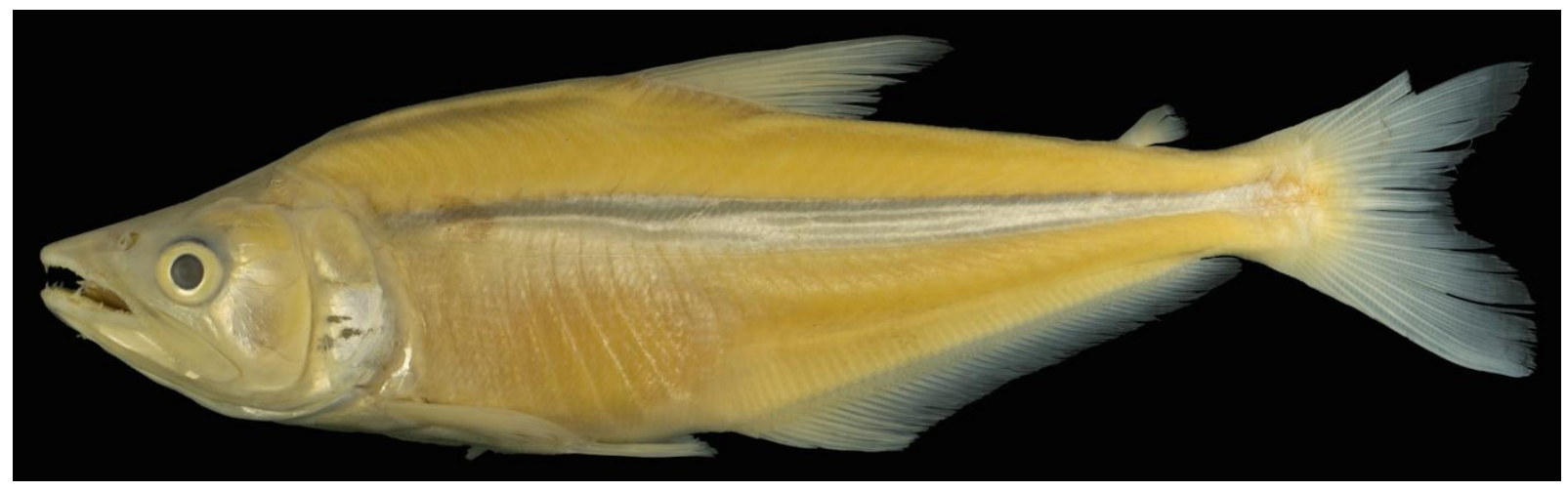

Figura 47 - Galeocharax goeldii, MZUSP 35951, 144,6 mm CP. Bolivia, La Paz, bacia do rio Beni, rio de La Paz. 


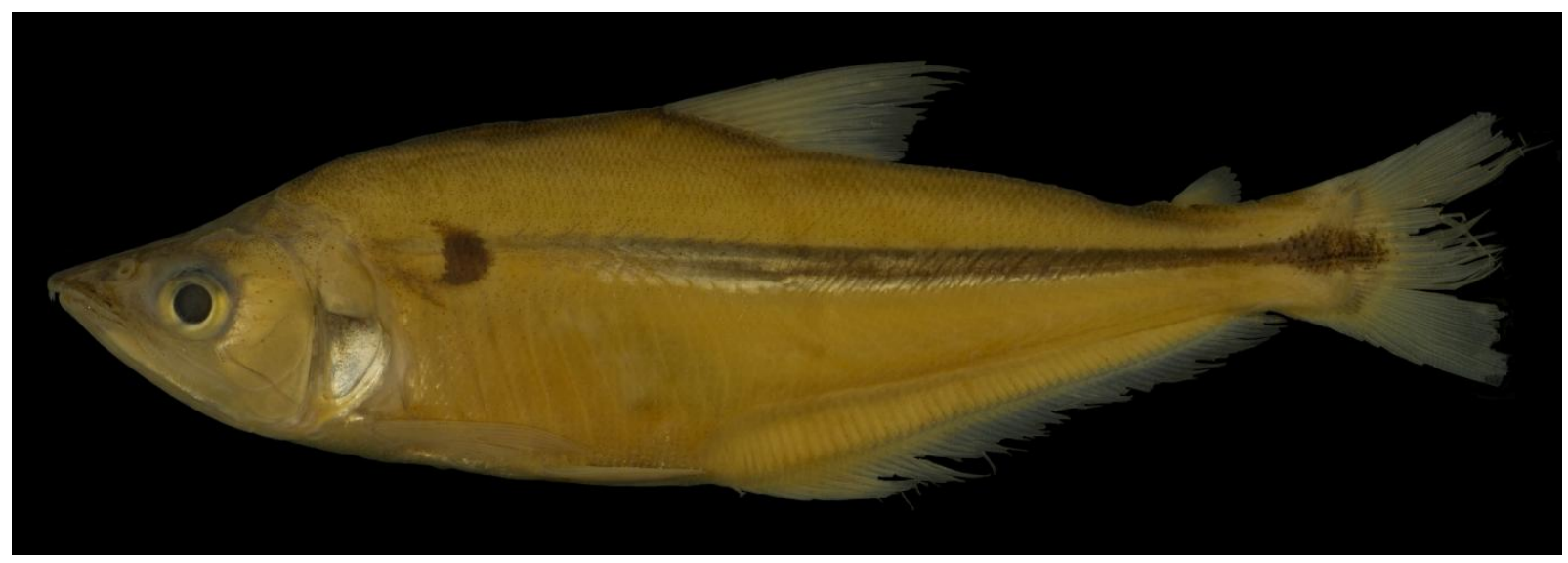

Figura 48 - Galeocharax goeldii, USNM 305367, 129,6mm CP. Bolivia, Beni, bacia do rio Beni, rio Curiraba.

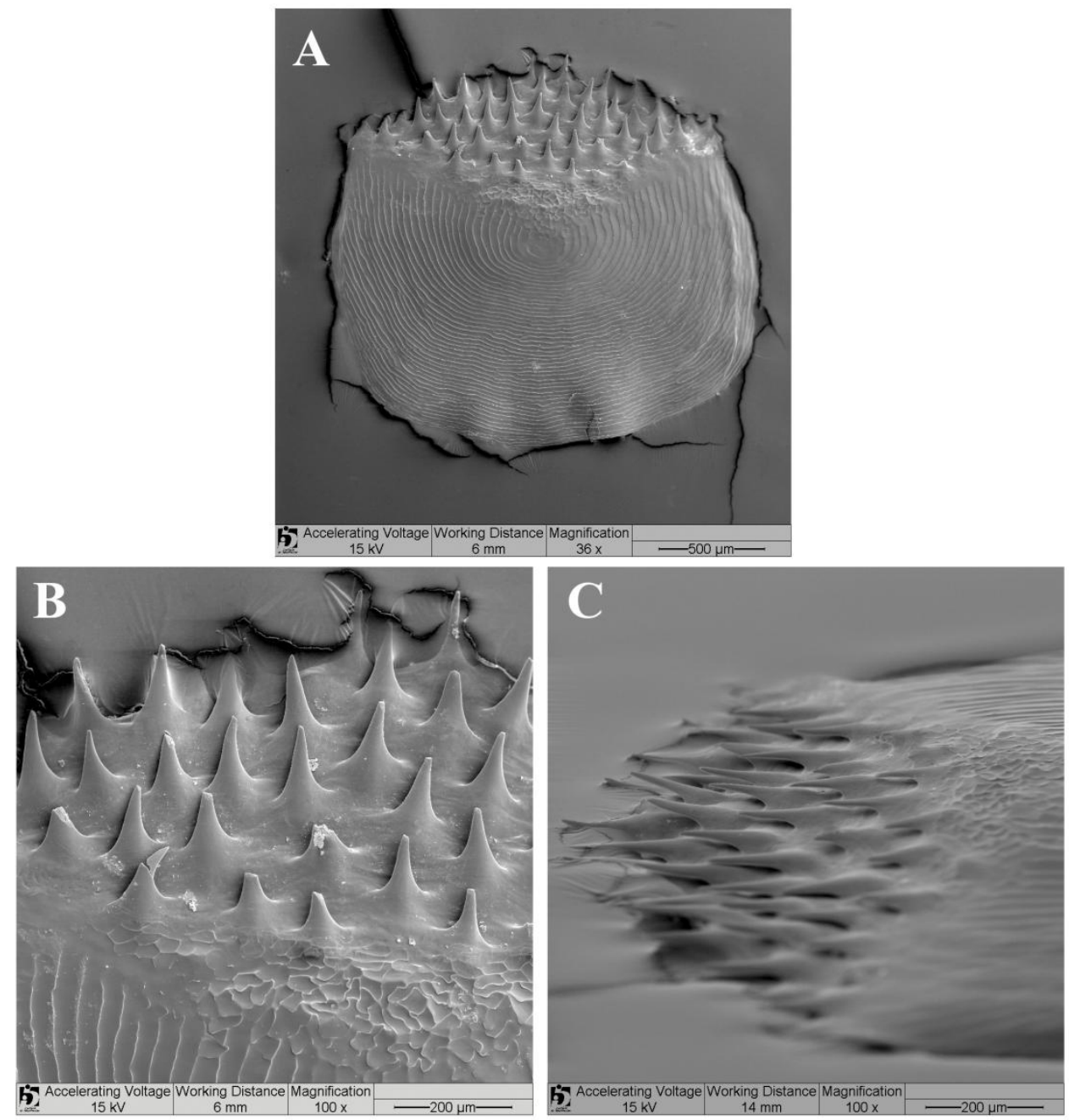

Figura 49 - Micrografias de varredura de escama de Galeocharax goeldii, MZUSP 92434, 108,0 mm CP. Brasil, Rondônia, bacia do rio Madeira, igarapé Jatuarana. (A) vista geral, margem posterior da escama orientada para o topo da figura; (B) detalhe do campo posterior, margem posterior da escama orientada para o topo da figura; (C) vista dorso-lateral, margem posterior da escama orientada para a esquerda da figura. 

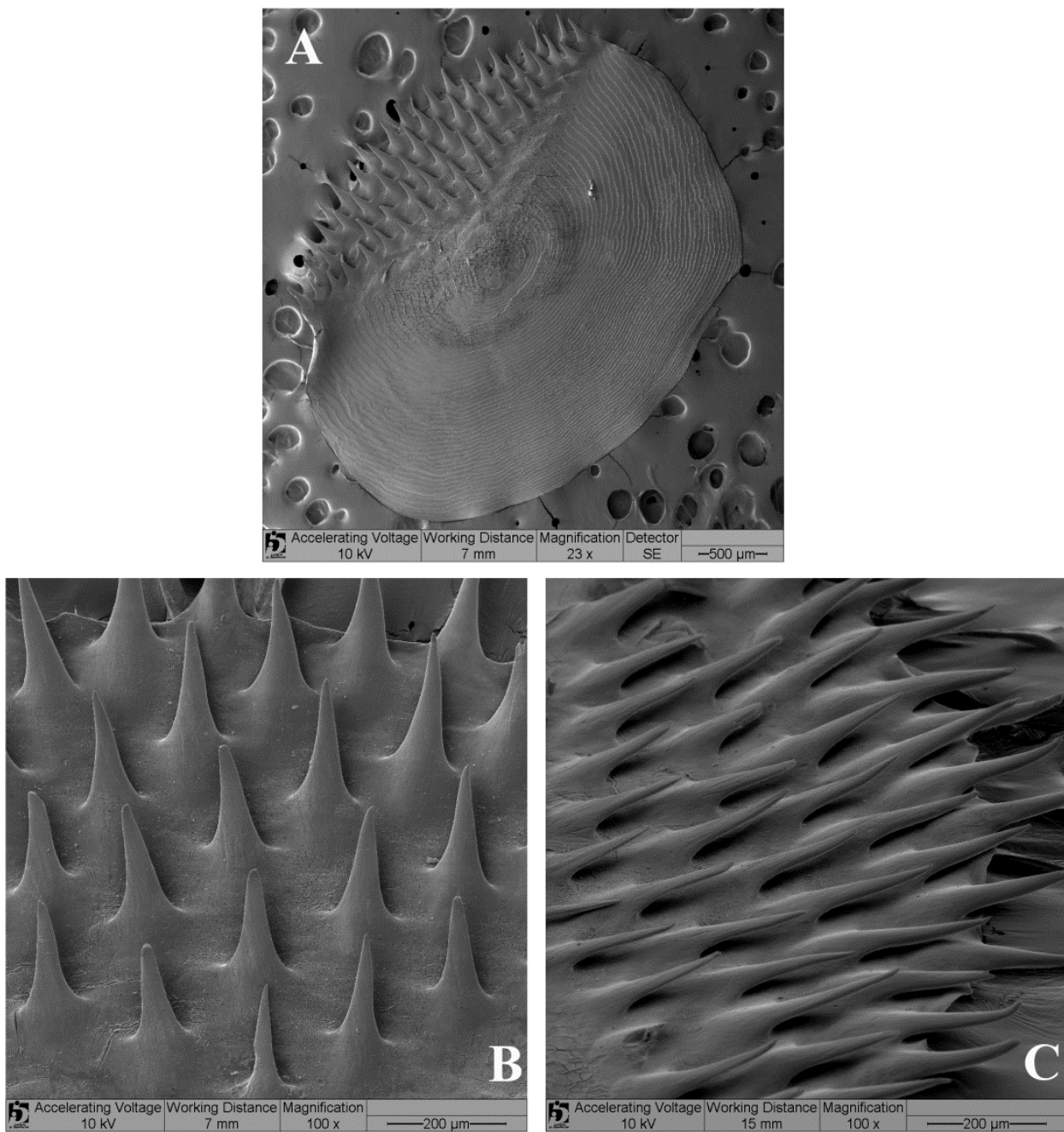

Figura 50 - Micrografias de varredura de escama de Galeocharax goeldii, UFRO-I 9668, 160,8 mm CP. Brasil, Rondônia, cachoeira de Jirau. (A) vista geral, margem posterior da escama orientada para o canto superior esquerdo da figura; (B) detalhe do campo posterior, margem posterior da escama orientada para o topo da figura; (C) vista dorso-lateral, margem posterior da escama orientada para a direita da figura. 

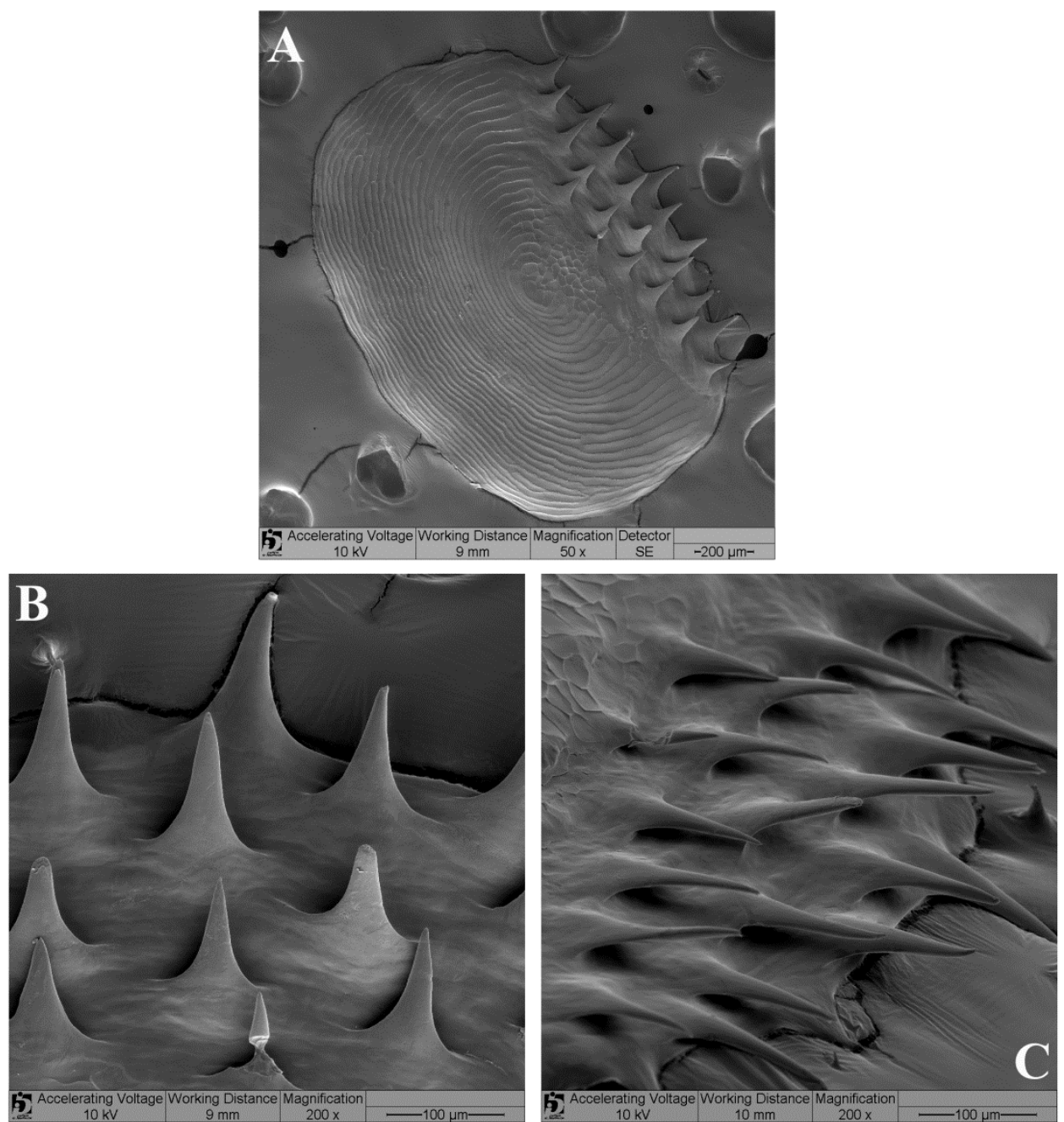

Figura 51 - Micrografias de varredura de escama de Galeocharax goeldii, UFRO-I 5468, 77,9 mm CP. Brasil, Rondônia, bacia do rio Madeira, rio Abunã. (A) vista geral, margem posterior da escama orientada para o topo da figura; (B) detalhe do campo posterior, margem posterior da escama orientada para o canto superior direito da figura; (C) vista dorso-lateral, margem posterior da escama orientada para a direita da figura. 

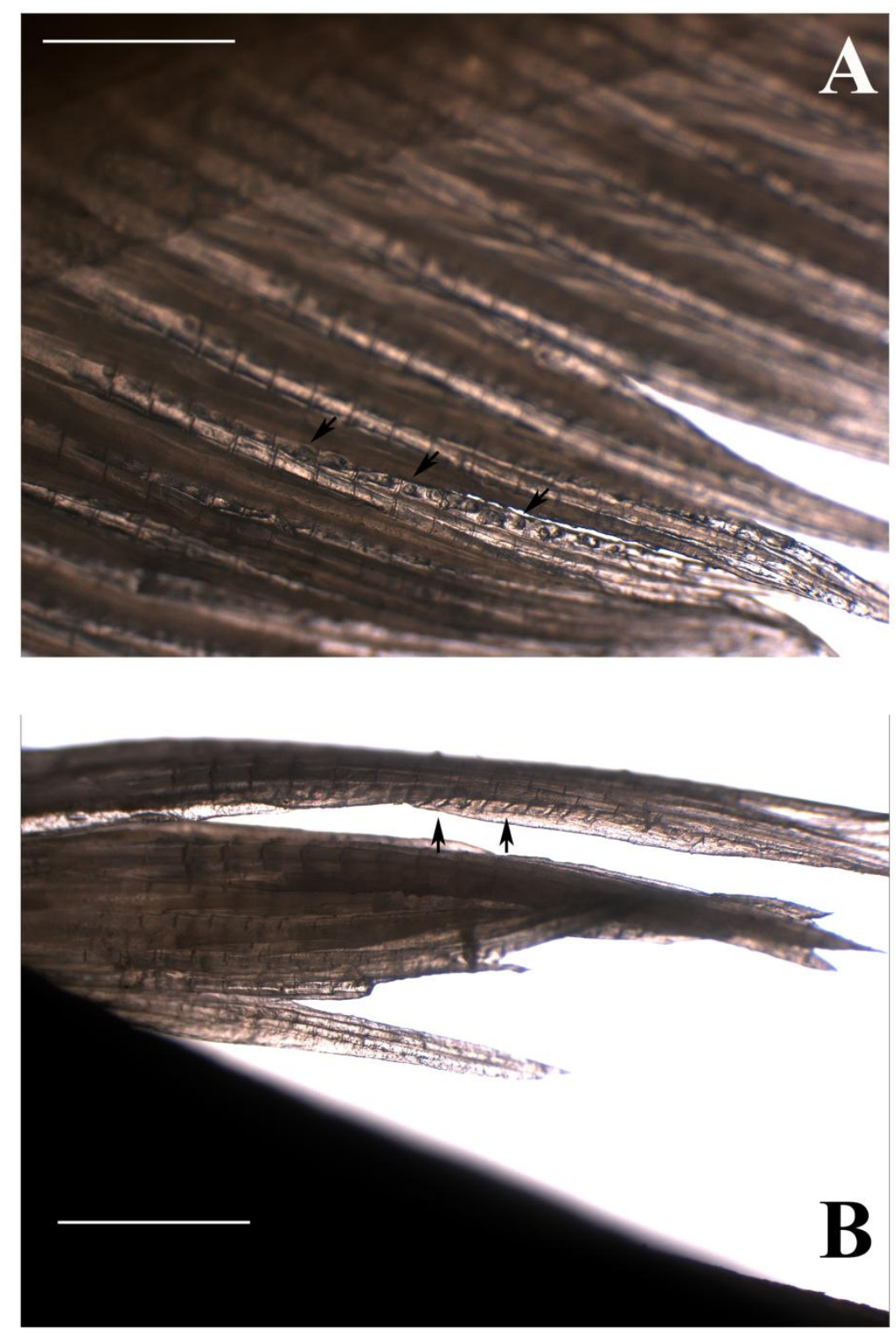

Figura 52 Vista lateral dos raios anteriores da nadadeira anal (A) e vista dorsal da nadadeira pélvica esquerda (B) em macho de Galeocharax goeldii MUSM 9564, 125,4 mm CP. Setas indicam ganchos ósseos. Barra de escala $2 \mathrm{~mm}$. 


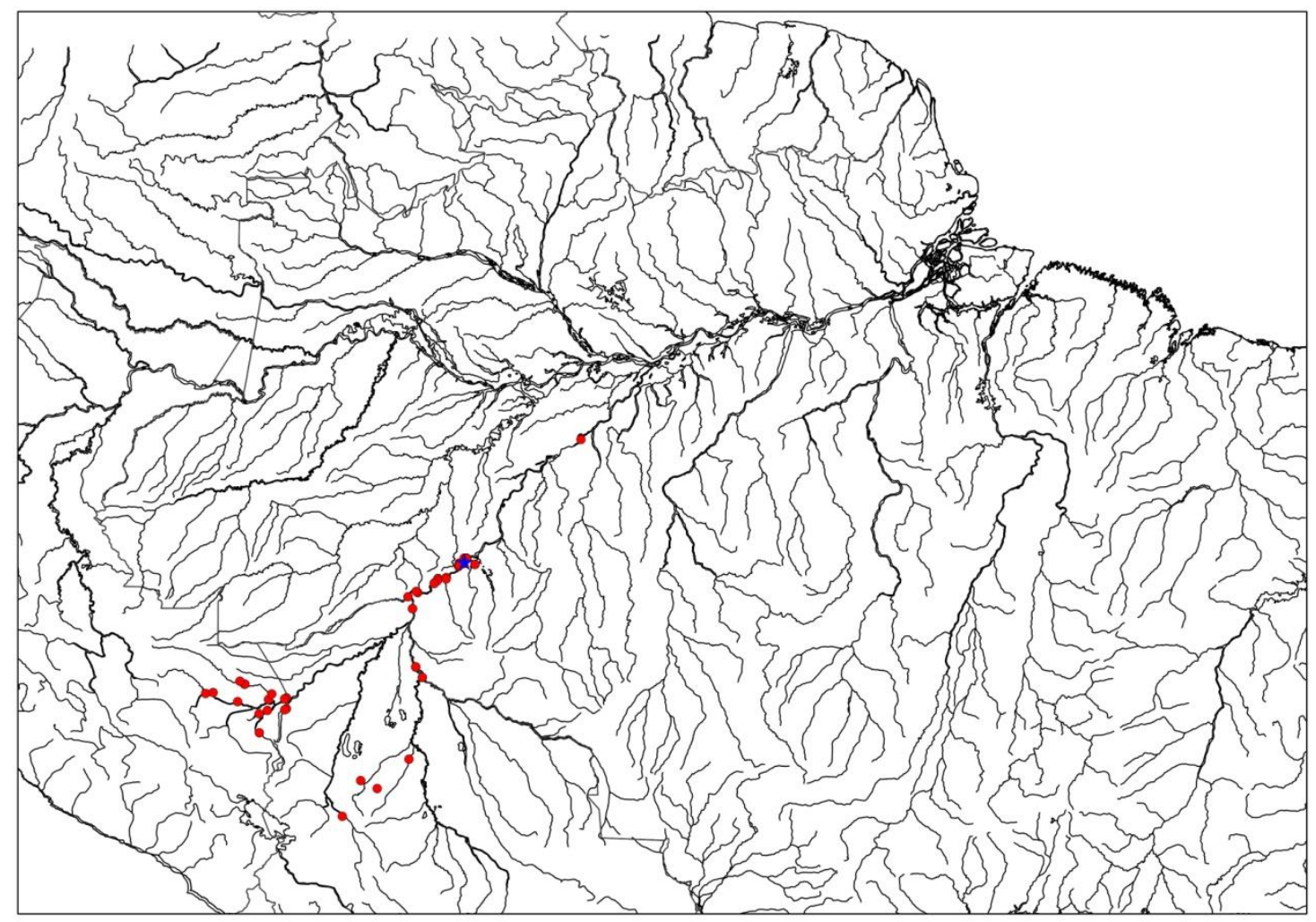

Figura 53 - Mapa da região norte da América do Sul mostrando a distribuição geográfica de Galeocharax goeldii. Estrela indica localidade tipo.

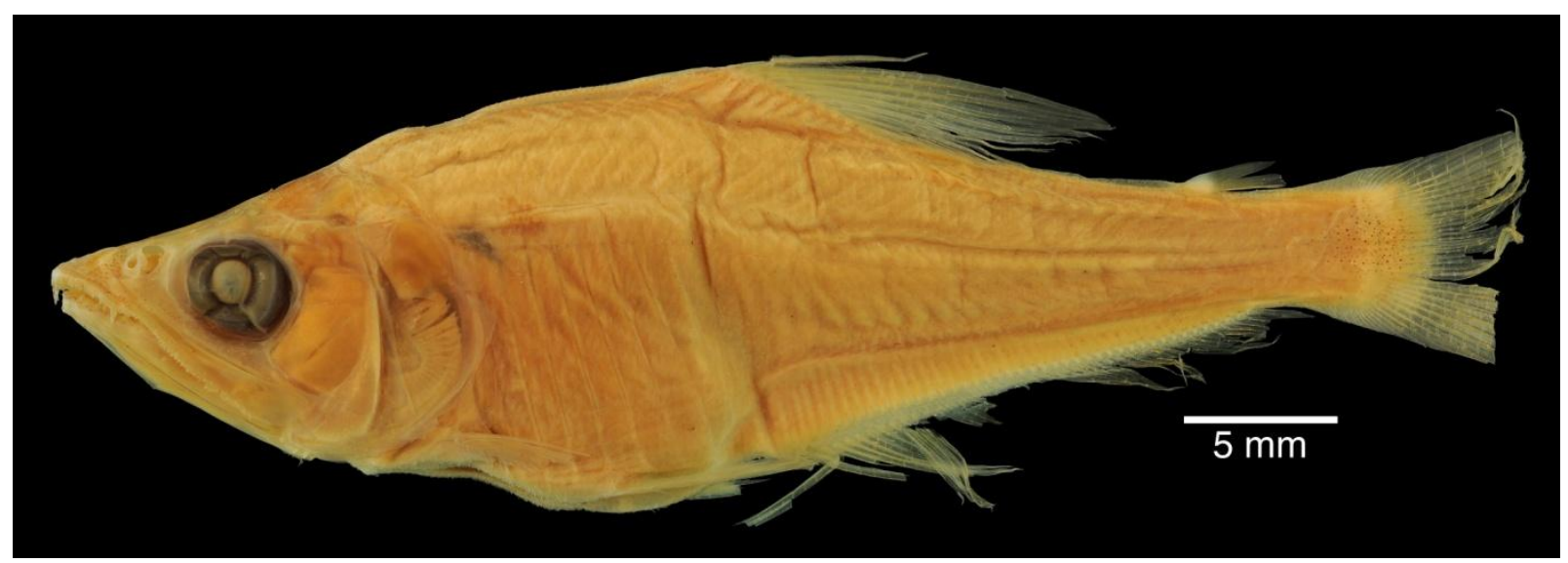

Figura 54 - Galeocharax goeldii, holótipo de Charax goeldii, ANSP 39308, 42,6 mm CP. (Rio Madeira). 


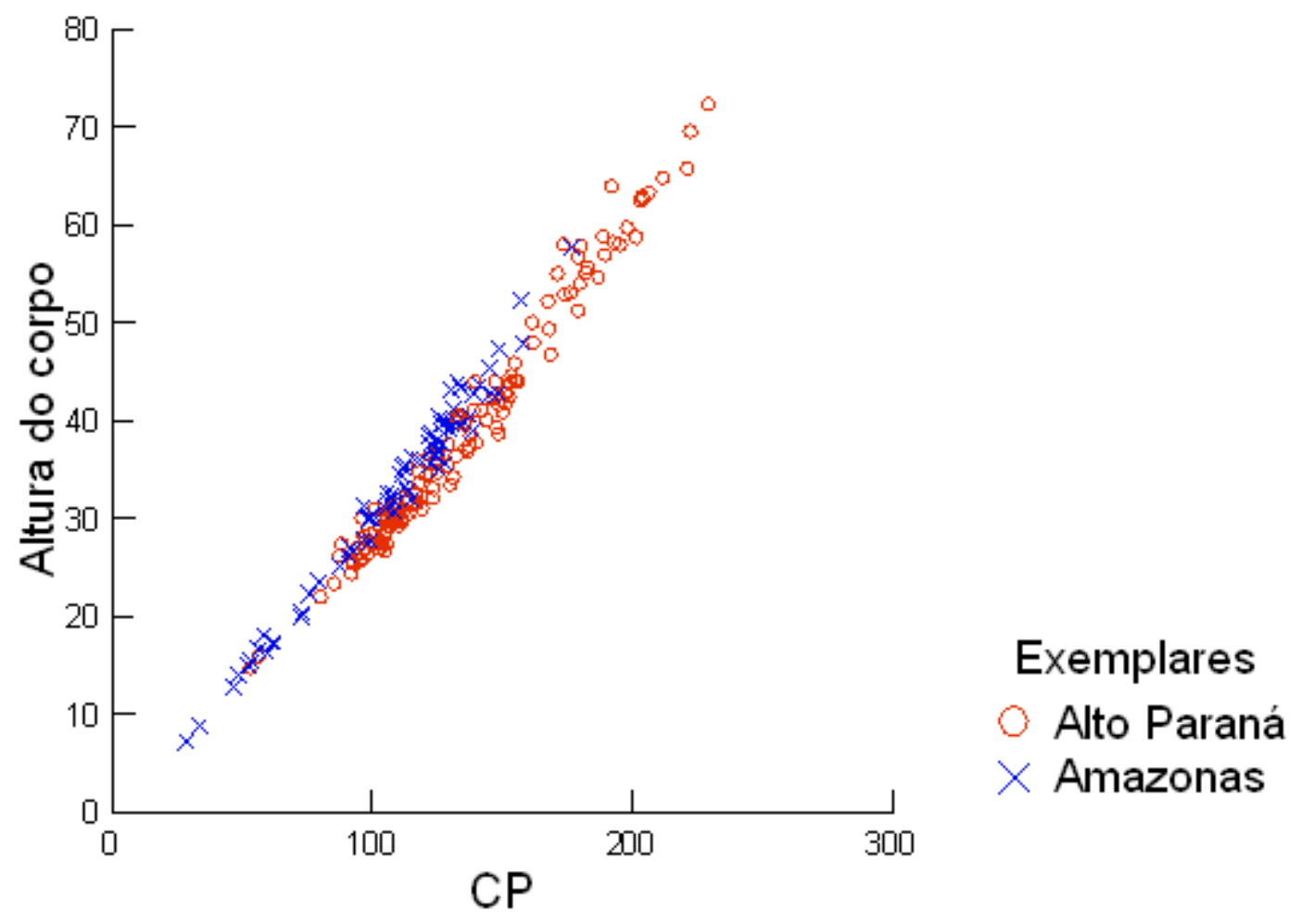

Figura 55 - Gráfico de dispersão dos valores de altura do corpo pelo comprimento padrão (CP) em exemplares de Galeocharax gulo das bacias do alto rio Paraná e Amazonas. Medidas expressas em milímetros.

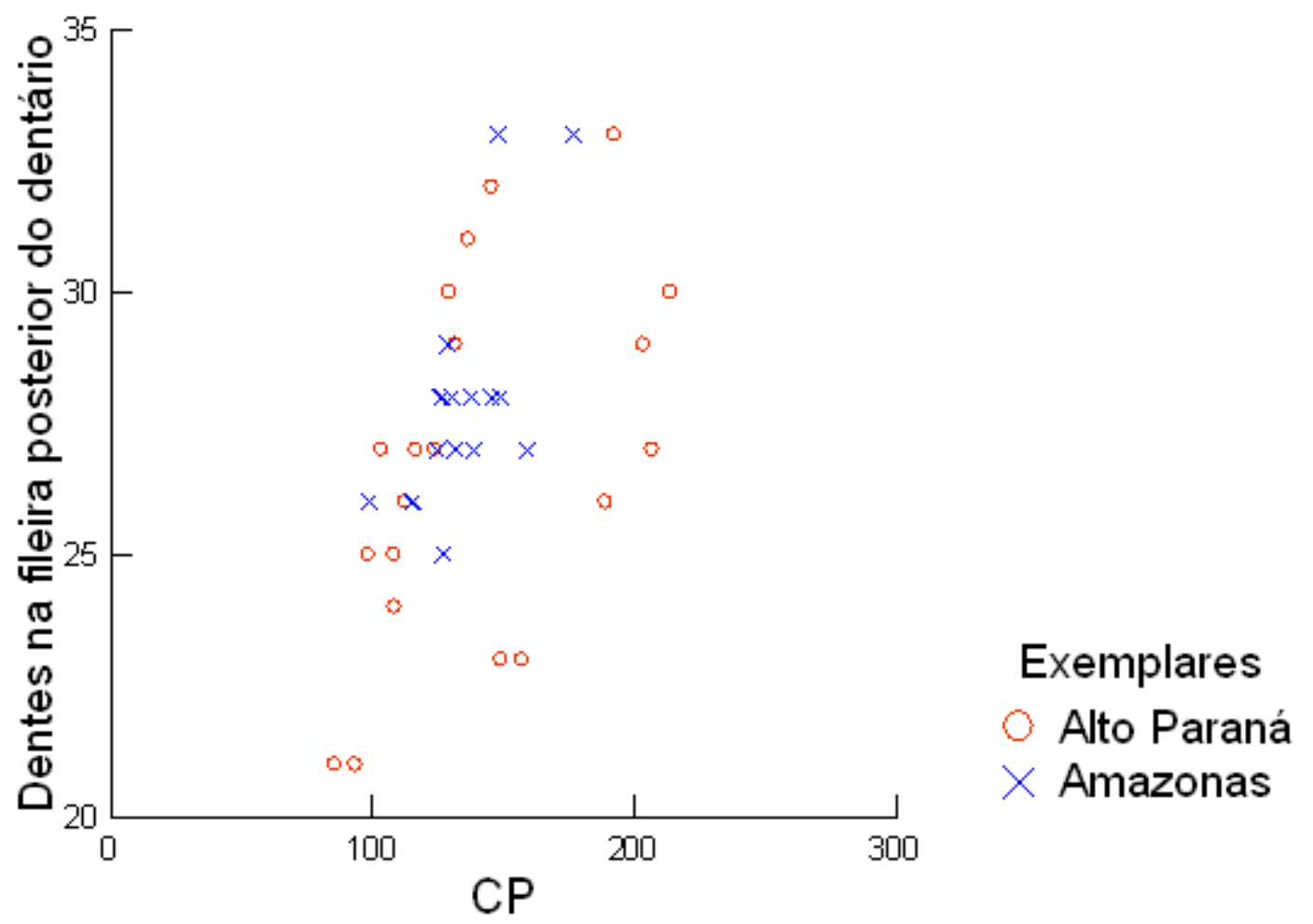

Figura 56 - Gráfico de dispersão dos valores de número de dentes na fileira posterior do detário pelo comprimento padrão $(\mathrm{CP})$ em exemplares de Galeocharax gulo das bacias do alto rio Paraná e Amazonas. Medidas expressas em milímetros. 

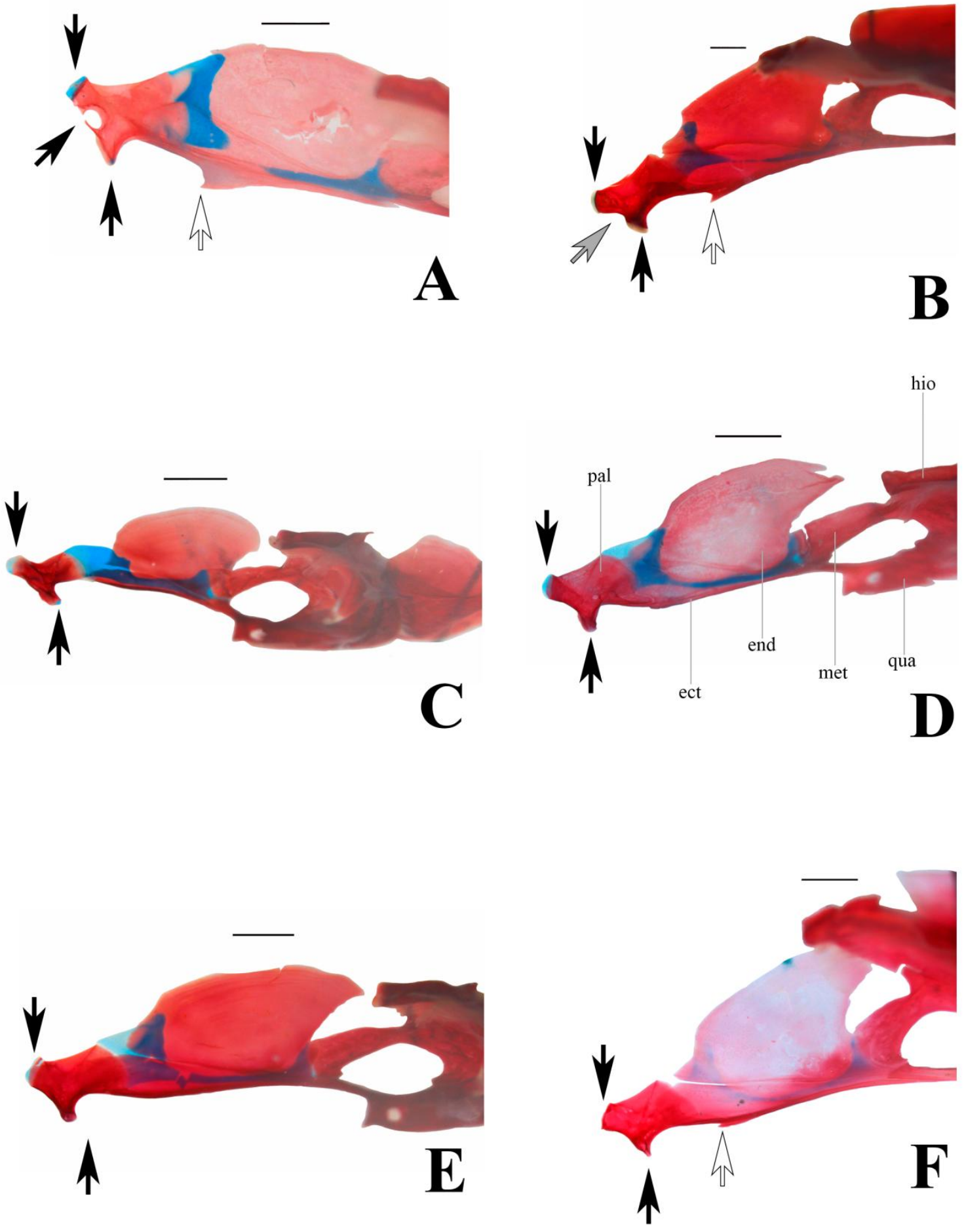

Figura 57 - Vista dorsal da região anterior do suspensório de (A) Cynopotamus xinguano, MZUSP 94196, 97,9 mm CP; (B) Galeocharax gulo, MZUSP 62839 127,2 mm CP; (C) Galeocharax humeralis, MZUSP 19984, 66,0 mm CP (D) Galeocharax goeldii, UFRO-I 5468, 77,9 mm CP; (E) Galeocharax gulo MZUSP 10480, 88,8 mm CP; (F) Galeocharax gulo NUP 3119, 94,4 mm CP. Barra de escala 2mm. Setas pretas indicam regiões de articulação do palatino, setas cinzas indicam porção entre regiões de articulação do palatino, setas brancas indicam projeção lateral do ectopterigoide, ect ectopterigoide; end - endopterigoide; hio - hiomandibular; met - metapterigoide; pal palatino; qua - quadrado. 


\section{Apêndice 2: Tabelas}

Tabela 1. Frequência de distribuição do número de escamas na linha lateral nas três espécies de Galeocharax reconhecidas no presente estudo.

\begin{tabular}{|c|c|c|c|c|c|c|c|c|c|c|c|c|c|c|c|c|c|c|c|c|c|c|c|c|c|c|c|c|c|c|}
\hline & 77 & 78 & 79 & 80 & 81 & 82 & 83 & 84 & 85 & 86 & 87 & 88 & 89 & 90 & 91 & 92 & 93 & 94 & 95 & 96 & 97 & 98 & 99 & 100 & 101 & 102 & 103 & 104 & 105 & Total \\
\hline G. humeralis & & & & & & & & & & & & & & 5 & 8 & 3 & 8 & 12 & 15 & 20 & 12 & 6 & 6 & 7 & 4 & 3 & 1 & 1 & 1 & 112 \\
\hline G. goeldii & & & & & & & & & & & & 3 & 8 & 14 & 5 & 7 & 11 & 7 & 3 & 4 & 5 & & & & & & & & & 67 \\
\hline G. gulo & 3 & 17 & 52 & 72 & 57 & 70 & 63 & 47 & 23 & 13 & 8 & & & & & & & & & & & & & & & & & & & 425 \\
\hline
\end{tabular}

Tabela 2. Frequência de distribuição do número de escamas acima da linha lateral nas três espécies de Galeocharax reconhecidas no presente estudo.

\begin{tabular}{lcccccccc}
\hline & $\mathbf{1 4}$ & $\mathbf{1 5}$ & $\mathbf{1 6}$ & $\mathbf{1 7}$ & $\mathbf{1 8}$ & $\mathbf{1 9}$ & $\mathbf{2 0}$ & Total \\
\hline G. humeralis & & & & 9 & 46 & 38 & 9 & 102 \\
G. goeldii & & & & 13 & 20 & 18 & 3 & 54 \\
G. gulo & 12 & 130 & 140 & 83 & 24 & 3 & & 392 \\
\hline
\end{tabular}

Tabela 3. Frequência de distribuição do número de escamas abaixo da linha lateral na vertical da origem da nadadeira pélvica nas três espécies de Galeocharax reconhecidas no presente estudo.

\begin{tabular}{lcccccccc}
\hline & $\mathbf{1 1}$ & $\mathbf{1 2}$ & $\mathbf{1 3}$ & $\mathbf{1 4}$ & $\mathbf{1 5}$ & $\mathbf{1 6}$ & $\mathbf{1 7}$ & Total \\
\hline G. humeralis & & & & 11 & 55 & 36 & & 102 \\
G. goeldii & & & & & 12 & 30 & 15 & 57 \\
G. gulo & 10 & 137 & 157 & 54 & 44 & 7 & & 409 \\
\hline
\end{tabular}

Tabela 4. Frequência de distribuição do número de escamas abaixo da linha lateral na vertical da origem da nadadeira anal nas três espécies de Galeocharax reconhecidas no presente estudo.

\begin{tabular}{lcccccccc}
\hline & $\mathbf{1 4}$ & $\mathbf{1 5}$ & $\mathbf{1 6}$ & $\mathbf{1 7}$ & $\mathbf{1 8}$ & $\mathbf{1 9}$ & $\mathbf{2 0}$ & Total \\
\hline G. humeralis & & & 7 & 15 & 33 & 29 & 14 & 98 \\
G. goeldii & & & 4 & 18 & 10 & 16 & & 48 \\
G. gulo & 105 & 155 & 97 & 29 & 11 & & & 397 \\
\hline
\end{tabular}


Tabela 5. Dados morfométricos das três espécies de Galeocharax reconhecidas no presente estudo. Comprimento padrão (CP) em milímetros. Medidas do corpo foram expressas em porcentagem do $\mathrm{CP}$ e medidas da cabeça em porcentagem do comprimento da cabeça (CC).

\begin{tabular}{|c|c|c|c|c|c|c|c|c|c|c|c|c|}
\hline & \multicolumn{4}{|c|}{ Galeocharax humeralis } & \multicolumn{4}{|c|}{ Galeocharax gulo } & \multicolumn{4}{|c|}{ Galeocharax goeldii } \\
\hline & $\mathrm{N}$ & Amplitude & Média & DP & $\mathrm{N}$ & Amplitude & Média & DP & $\mathrm{N}$ & Amplitude & Média & DP \\
\hline Comprimento padrão & 113 & $72,25-251,84$ & & & 472 & $28,3-245,2$ & & & 69 & $31,50-213,36$ & & \\
\hline \multicolumn{13}{|l|}{ Porcentagem do CP } \\
\hline Comprimento da cabeça & 28 & $24,5-29,7$ & 27,3 & 1,3 & 444 & $25,5-31,9$ & 28,3 & 1,0 & 57 & $25,2-34,5$ & 28,1 & 1,5 \\
\hline Comprimento da cabeça II & 109 & $25,4-31,3$ & 28,1 & 1,1 & 467 & $26,0-32,9$ & 29,4 & 1,0 & 66 & $25,9-36,8$ & 29,1 & 1,6 \\
\hline Altura do corpo & 75 & $25,2-33,3$ & 29,7 & 1,9 & 346 & $25,1-33,3$ & 28,8 & 1,6 & 57 & $25,1-32,0$ & 29,1 & 1,5 \\
\hline Comprimento da dorsal & 94 & $20,1-27,3$ & 24,0 & 1,4 & 338 & $20,2-29,4$ & 24,4 & 1,5 & 59 & $22,5-32,2$ & 26,0 & 1,8 \\
\hline Comprimento da base da dorsal & 112 & $11,0-13,3$ & 12,2 & 0,4 & 471 & $10,0-14,3$ & 12,0 & 0,6 & 69 & $10,0-13,0$ & 11,7 & 0,5 \\
\hline Comprimento da peitoral & 108 & $13,5-17,5$ & 15,6 & 0,7 & 443 & $13,2-19,1$ & 16,5 & 0,8 & 66 & $12,8-19,2$ & 16,4 & 1,1 \\
\hline Comprimento da pélvica & 108 & $10,4-13,3$ & 11,7 & 0,5 & 436 & $9,7-14,8$ & 12,2 & 0,6 & 64 & $11,0-15,3$ & 12,7 & 0,8 \\
\hline Comprimento da anal & 82 & $9,3-15,0$ & 12,2 & 1,0 & 336 & $9,8-19,5$ & 13,7 & 1,2 & 60 & $11,1-19,3$ & 13,9 & 2,0 \\
\hline Comprimento da base da anal & 107 & $33,2-41,6$ & 38,6 & 1,6 & 460 & $31,5-41,2$ & 36,2 & 1,6 & 67 & $32,3-41,3$ & 37,6 & 1,5 \\
\hline Distância pré-peitoral & 110 & $24,7-32,8$ & 29,3 & 1,3 & 465 & $26,9-36,1$ & 30,4 & 1,4 & 69 & $26,2-35,8$ & 30,1 & 1,9 \\
\hline Distância pré-pélvica & 81 & $39,8-47,0$ & 43,1 & 1,3 & 361 & $40,3-48,5$ & 43,9 & 1,3 & 62 & $39,5-50,6$ & 43,6 & 1,8 \\
\hline Distância pré-dorsal & 109 & $46,9-53,8$ & 49,6 & 1,1 & 466 & $47,5-54,2$ & 50,4 & 1,1 & 69 & $47,8-58,0$ & 50,4 & 1,4 \\
\hline Distância pré-anal & 106 & $52,8-62,5$ & 57,8 & 1,9 & 459 & $52,5-63,8$ & 58,6 & 1,7 & 68 & $53,2-64,6$ & 57,6 & 2,0 \\
\hline Altura do pedúnculo caudal & 111 & $7,3-9,0$ & 8,1 & 0,3 & 439 & $6,6-9,3$ & 8,0 & 0,4 & 69 & $7,2-9,1$ & 8,2 & 0,4 \\
\hline Comprimento do pedúnculo caudal & 105 & $8,0-10,7$ & 9,4 & 0,5 & 443 & $7,7-12,3$ & 9,9 & 0,7 & 67 & $8,1-11,3$ & 9,6 & 0,7 \\
\hline \multicolumn{13}{|l|}{ Porcentagem do CC } \\
\hline Comprimento do focinho & 112 & $30,9-38,1$ & 34,6 & 1,7 & 472 & $28,9-38,1$ & 32,6 & 1,4 & 66 & $27,7-35,7$ & 32,6 & 1,4 \\
\hline Diâmetro orbital & 112 & $22,5-31,2$ & 26,7 & 2,0 & 472 & $22,2-36,2$ & 28,8 & 2,5 & 66 & $22,3-33,5$ & 27,1 & 2,6 \\
\hline Distância interorbital & 112 & $21,2-29,4$ & 25,2 & 1,7 & 468 & $18,0-36,0$ & 23,2 & 2,1 & 65 & $17,3-30,7$ & 25,3 & 2,5 \\
\hline Comprimento da maxila superior & 112 & $63,0-71,0$ & 67,4 & 1,6 & 470 & $63,8-73,0$ & 68,0 & 1,5 & 66 & $65,1-71,6$ & 68,1 & 1,5 \\
\hline
\end{tabular}


Tabela 6. Frequência de distribuição do número de raios ramificados na nadadeira anal nas três espécies de Galeocharax reconhecidas no presente estudo.

\begin{tabular}{lccccccccccccccccc}
\hline & $\mathbf{3 3}$ & $\mathbf{3 4}$ & $\mathbf{3 5}$ & $\mathbf{3 6}$ & $\mathbf{3 7}$ & $\mathbf{3 8}$ & $\mathbf{3 9}$ & $\mathbf{4 0}$ & $\mathbf{4 1}$ & $\mathbf{4 2}$ & $\mathbf{4 3}$ & $\mathbf{4 4}$ & $\mathbf{4 5}$ & $\mathbf{4 6}$ & $\mathbf{4 7}$ & $\mathbf{4 8}$ & Total \\
\hline G. humeralis & & & & & & & & 2 & 4 & 8 & 26 & 24 & 19 & 11 & 2 & 4 & 100 \\
G. goeldii & & & & & & & & & 8 & 11 & 16 & 23 & 8 & & & & \\
G. gulo & 2 & 5 & 21 & 31 & 64 & 42 & 75 & 63 & 76 & 38 & 20 & 3 & 1 & 1 & & & 442 \\
\hline
\end{tabular}

Tabela 7. Frequência de distribuição do número de dentes na fileira externa do pré-maxilar nas três espécies de Galeocharax reconhecidas no presente estudo.

\begin{tabular}{lcccccccc}
\hline & $\mathbf{7}$ & $\mathbf{8}$ & $\mathbf{9}$ & $\mathbf{1 0}$ & $\mathbf{1 1}$ & $\mathbf{1 2}$ & $\mathbf{1 3}$ & Total \\
\hline G. humeralis & 1 & 6 & 23 & 47 & 20 & 11 & 3 & 111 \\
G. goeldii & & 4 & 28 & 38 & & & & 70 \\
G. gulo & 1 & 43 & 179 & 200 & 18 & & & 441 \\
\hline
\end{tabular}

Tabela 8. Frequência de distribuição do número de dentes no maxilar nas três espécies de Galeocharax reconhecidas no presente estudo.

\begin{tabular}{lcccccccccccccccccccccccc}
\hline & $\mathbf{3 5}$ & $\mathbf{3 6}$ & $\mathbf{3 7}$ & $\mathbf{3 8}$ & $\mathbf{3 9}$ & $\mathbf{4 0}$ & $\mathbf{4 1}$ & $\mathbf{4 2}$ & $\mathbf{4 3}$ & $\mathbf{4 4}$ & $\mathbf{4 5}$ & $\mathbf{4 6}$ & $\mathbf{4 7}$ & $\mathbf{4 8}$ & $\mathbf{4 9}$ & $\mathbf{5 0}$ & $\mathbf{5 1}$ & $\mathbf{5 2}$ & $\mathbf{5 3}$ & $\mathbf{5 4}$ & $\mathbf{5 5}$ & $\mathbf{5 6}$ & $\mathbf{5 7}$ & Total \\
\hline G. humeralis & & & & & 2 & 1 & 5 & 7 & 10 & 8 & 11 & 7 & 6 & 10 & 10 & 11 & 7 & 6 & 4 & 1 & 2 & 2 & 1 & 111 \\
G. goeldii & & & & 8 & 9 & 12 & 12 & 8 & 4 & 6 & 2 & 3 & 2 & 2 & & & & & & & & & 68 \\
G. gulo & 3 & 4 & 6 & 8 & 8 & 14 & 28 & 34 & 29 & 50 & 50 & 52 & 40 & 33 & 31 & 16 & 25 & 12 & 9 & 7 & 1 & & 460 \\
\hline
\end{tabular}

Tabela 9. Frequência de distribuição do número de dentes na fileira interna do dentário nas três espécies de Galeocharax reconhecidas no presente estudo.

\begin{tabular}{lccccccccc}
\hline & $\mathbf{6}$ & $\mathbf{7}$ & $\mathbf{8}$ & $\mathbf{9}$ & $\mathbf{1 0}$ & $\mathbf{1 1}$ & $\mathbf{1 2}$ & $\mathbf{1 3}$ & Total \\
\hline G. humeralis & & 3 & 28 & 35 & 19 & 4 & 2 & & 91 \\
G. goeldii & 14 & 28 & 16 & 2 & 1 & 2 & 2 & 65 \\
G. gulo & 2 & 110 & 219 & 57 & 9 & & & & 397 \\
\hline
\end{tabular}


Tabela 10. Frequência de distribuição do número de escamas ao redor do pedúnculo caudal nas três espécies de Galeocharax reconhecidas no presente estudo.

\begin{tabular}{lccccccccccc}
\hline & $\mathbf{1 9}$ & $\mathbf{2 0}$ & $\mathbf{2 1}$ & $\mathbf{2 2}$ & $\mathbf{2 3}$ & $\mathbf{2 4}$ & $\mathbf{2 5}$ & $\mathbf{2 6}$ & $\mathbf{2 7}$ & $\mathbf{2 8}$ & Total \\
\hline G. humeralis & & & & & 7 & 24 & 33 & 17 & 8 & & 89 \\
G. goeldii & & & & & 3 & 3 & 8 & 8 & 15 & 6 & 43 \\
G. gulo & 7 & 32 & 47 & 77 & 81 & 41 & 14 & 5 & & & 304 \\
\hline
\end{tabular}

Tabela 11. Distribuição de ganchos nos raios da nadadeira anal de exemplares de Galeocharax humeralis. As células marcadas em amarelo representam a presença de ganchos. Ult = raio não ramificado mais posterior, $\mathrm{CP}=$ Comprimento padrão.

\begin{tabular}{|c|c|c|c|c|c|c|c|c|c|c|c|c|c|c|c|c|c|c|c|c|c|c|c|c|c|c|c|c|c|}
\hline Exemplar & $\mathrm{CP}$ & Ult & 1 & 2 & 3 & 4 & 5 & 6 & 7 & 8 & 9 & 10 & 11 & 12 & 13 & 14 & 15 & 16 & 17 & 18 & 19 & 20 & 21 & 22 & 23 & 24 & 25 & 26 & 27 \\
\hline MZUSP19907a & 111,5 & $\bar{X}$ & $\mathrm{X}$ & $\mathrm{X}$ & $\mathrm{X}$ & $\mathrm{X}$ & $\mathrm{X}$ & $\mathrm{X}$ & $\mathrm{X}$ & $\mathrm{X}$ & $\mathrm{X}$ & $\mathrm{X}$ & $\bar{X}$ & $\mathrm{X}$ & $X$ & $\bar{X}$ & $X$ & $\mathrm{X}$ & $\mathrm{X}$ & $\mathrm{X}$ & $\mathrm{X}$ & & & & & & & & \\
\hline MZUSP90684c & 124,6 & $X$ & $\mathrm{X}$ & $X$ & $\mathrm{X}$ & $\mathrm{X}$ & $\mathrm{X}$ & $\mathrm{X}$ & $\mathrm{X}$ & $X$ & $\mathrm{X}$ & $\mathrm{X}$ & $X$ & $\mathrm{X}$ & $\mathrm{X}$ & $\mathrm{X}$ & $\mathrm{X}$ & $\mathrm{X}$ & $X$ & $\mathrm{X}$ & & & & & & & & & \\
\hline MCP20742d & 125,4 & $\mathrm{X}$ & $\mathrm{X}$ & $\mathrm{X}$ & $\mathrm{X}$ & $\mathrm{X}$ & $\mathrm{X}$ & $\mathrm{X}$ & $\mathrm{X}$ & $\mathrm{X}$ & $\mathrm{X}$ & $\mathrm{X}$ & $\mathrm{X}$ & $\mathrm{X}$ & $\mathrm{X}$ & $\mathrm{X}$ & $\mathrm{X}$ & $\mathrm{X}$ & $\mathrm{X}$ & $X$ & $\mathrm{X}$ & $\mathrm{X}$ & $\mathrm{X}$ & $\mathrm{X}$ & & & & & \\
\hline MCP20742b' & 130,4 & $X$ & $X$ & $X$ & $\mathrm{X}$ & $X$ & $\mathrm{X}$ & $\mathrm{X}$ & $X$ & $X$ & $X$ & $X$ & $X$ & $\mathrm{X}$ & $\mathrm{X}$ & $X$ & $X$ & $X$ & $X$ & $\mathrm{X}$ & $X$ & $X$ & & & & & & & \\
\hline MCP20742a' & 133,0 & $X$ & $X$ & $X$ & $\mathrm{X}$ & $\mathrm{X}$ & $\mathrm{X}$ & $\mathrm{X}$ & $X$ & $X$ & $X$ & $\mathrm{X}$ & $X$ & $\mathrm{X}$ & $X$ & $\mathrm{X}$ & $\mathrm{X}$ & $\mathrm{X}$ & $X$ & $\mathrm{X}$ & $X$ & $\mathrm{X}$ & $\mathrm{X}$ & $\mathrm{X}$ & $X$ & & & & \\
\hline NUP11343a & 139,3 & & & $\mathrm{X}$ & $\mathrm{X}$ & $\mathrm{X}$ & $\mathrm{X}$ & $\mathrm{X}$ & $\mathrm{X}$ & $\mathrm{X}$ & $\mathrm{X}$ & $\mathrm{X}$ & $\mathrm{X}$ & & & & & & & & & & & & & & & & \\
\hline MZUSP27684 & 140,4 & & $\mathrm{X}$ & $\mathrm{X}$ & $\mathrm{X}$ & $\mathrm{X}$ & $\mathrm{X}$ & $\mathrm{X}$ & $\mathrm{X}$ & $\mathrm{X}$ & & & & & & & & & & & & & & & & & & & \\
\hline MZUSP90684b & 141,2 & & $\mathrm{X}$ & $\mathrm{X}$ & $\mathrm{X}$ & $\mathrm{X}$ & $\mathrm{X}$ & $\mathrm{X}$ & $\mathrm{X}$ & $\mathrm{X}$ & $\mathrm{X}$ & $\mathrm{X}$ & $X$ & $\mathrm{X}$ & $\mathrm{X}$ & $X$ & & & & & & & & & & & & & \\
\hline MZUSP89961e & 142,2 & & $\mathrm{X}$ & $\mathrm{X}$ & $\mathrm{X}$ & $\mathrm{X}$ & $\mathrm{X}$ & $\mathrm{X}$ & $\mathrm{X}$ & $\mathrm{X}$ & $\mathrm{X}$ & $\mathrm{X}$ & $X$ & $\mathrm{X}$ & & & & & & & & & & & & & & & \\
\hline MCP20742b & 142,5 & $\mathrm{X}$ & $\mathrm{X}$ & $\mathrm{X}$ & $\mathrm{X}$ & $\mathrm{X}$ & $\mathrm{X}$ & $\mathrm{X}$ & $\mathrm{X}$ & $\mathrm{X}$ & $\mathrm{X}$ & $\mathrm{X}$ & $X$ & $\mathrm{X}$ & $\mathrm{X}$ & $X$ & $X$ & $\mathrm{X}$ & $\mathrm{X}$ & $\mathrm{X}$ & & & & & & & & & \\
\hline MZUSP19907b & 144,4 & $X$ & $X$ & $X$ & $\mathrm{X}$ & $X$ & $\mathrm{X}$ & $\mathrm{X}$ & $\mathrm{X}$ & $X$ & $\mathrm{X}$ & $\mathrm{X}$ & $X$ & $\mathrm{X}$ & $\mathrm{X}$ & $X$ & $X$ & $\mathrm{X}$ & $\mathrm{X}$ & $\mathrm{X}$ & $\mathrm{X}$ & $X$ & $X$ & $X$ & $X$ & $X$ & & & \\
\hline MCP20742c & 150,1 & $\mathrm{X}$ & $X$ & $\mathrm{X}$ & $\mathrm{X}$ & $X$ & $\mathrm{X}$ & $\mathrm{X}$ & $\mathrm{X}$ & $\mathrm{X}$ & $\mathrm{X}$ & $\mathrm{X}$ & $\mathrm{X}$ & $\mathrm{X}$ & $\mathrm{X}$ & $X$ & $\mathrm{X}$ & $X$ & $\mathrm{X}$ & $\mathrm{X}$ & $X$ & $\mathrm{X}$ & $X$ & $\mathrm{X}$ & & & & & \\
\hline MCP16803c & 151,6 & $\mathrm{X}$ & $X$ & $X$ & $\mathrm{X}$ & $\mathrm{X}$ & $\mathrm{X}$ & $X$ & $\mathrm{X}$ & $X$ & $X$ & $X$ & $X$ & $\mathrm{X}$ & $X$ & $X$ & $X$ & $\mathrm{X}$ & $\mathrm{X}$ & $X$ & $\mathrm{X}$ & $\mathrm{X}$ & $X$ & $\mathrm{X}$ & $\mathrm{X}$ & $X$ & & & \\
\hline MCP16803a' & 153,2 & $\mathrm{X}$ & $X$ & $\mathrm{X}$ & $\mathrm{X}$ & $\mathrm{X}$ & $\mathrm{X}$ & $\mathrm{X}$ & $\mathrm{X}$ & $\mathrm{X}$ & $\mathrm{X}$ & $X$ & $\mathrm{X}$ & $X$ & $\mathrm{X}$ & $X$ & $\mathrm{X}$ & $\mathrm{X}$ & $\mathrm{X}$ & $\mathrm{X}$ & $\mathrm{X}$ & $\mathrm{X}$ & $X$ & $X$ & $\mathrm{X}$ & $\mathrm{X}$ & $\mathrm{X}$ & & $\mathrm{X}$ \\
\hline MCP28624d & 157,4 & & & & & $X$ & $\mathrm{X}$ & & & & & & & & & & & & & & & & & & & & & & \\
\hline MCP11897a & 158,4 & & & $\mathrm{X}$ & $\mathrm{X}$ & $\mathrm{X}$ & $\mathrm{X}$ & $\mathrm{X}$ & $\mathrm{X}$ & $\mathrm{X}$ & $\mathrm{X}$ & $X$ & $X$ & $X$ & $\mathrm{X}$ & $X$ & $X$ & & & & & & & & & & & & \\
\hline NUP8499 & 162,4 & & $\mathrm{X}$ & $\mathrm{X}$ & $\mathrm{X}$ & $\mathrm{X}$ & $\mathrm{X}$ & $\mathrm{X}$ & $\mathrm{X}$ & $\mathrm{X}$ & $\mathrm{X}$ & $X$ & $\mathrm{X}$ & $X$ & $\mathrm{X}$ & & & & & & & & & & & & & & \\
\hline MCP11751d & 163,6 & $\mathrm{X}$ & $\mathrm{X}$ & $\mathrm{X}$ & $\mathrm{X}$ & $\mathrm{X}$ & $\mathrm{X}$ & $\mathrm{X}$ & $\mathrm{X}$ & $\mathrm{X}$ & $X$ & $X$ & $\mathrm{X}$ & $X$ & $\mathrm{X}$ & $X$ & $\mathrm{X}$ & $\mathrm{X}$ & $\mathrm{X}$ & $\mathrm{X}$ & $\mathrm{X}$ & $\mathrm{X}$ & $X$ & $\mathrm{X}$ & $X$ & $\mathrm{X}$ & & & \\
\hline
\end{tabular}




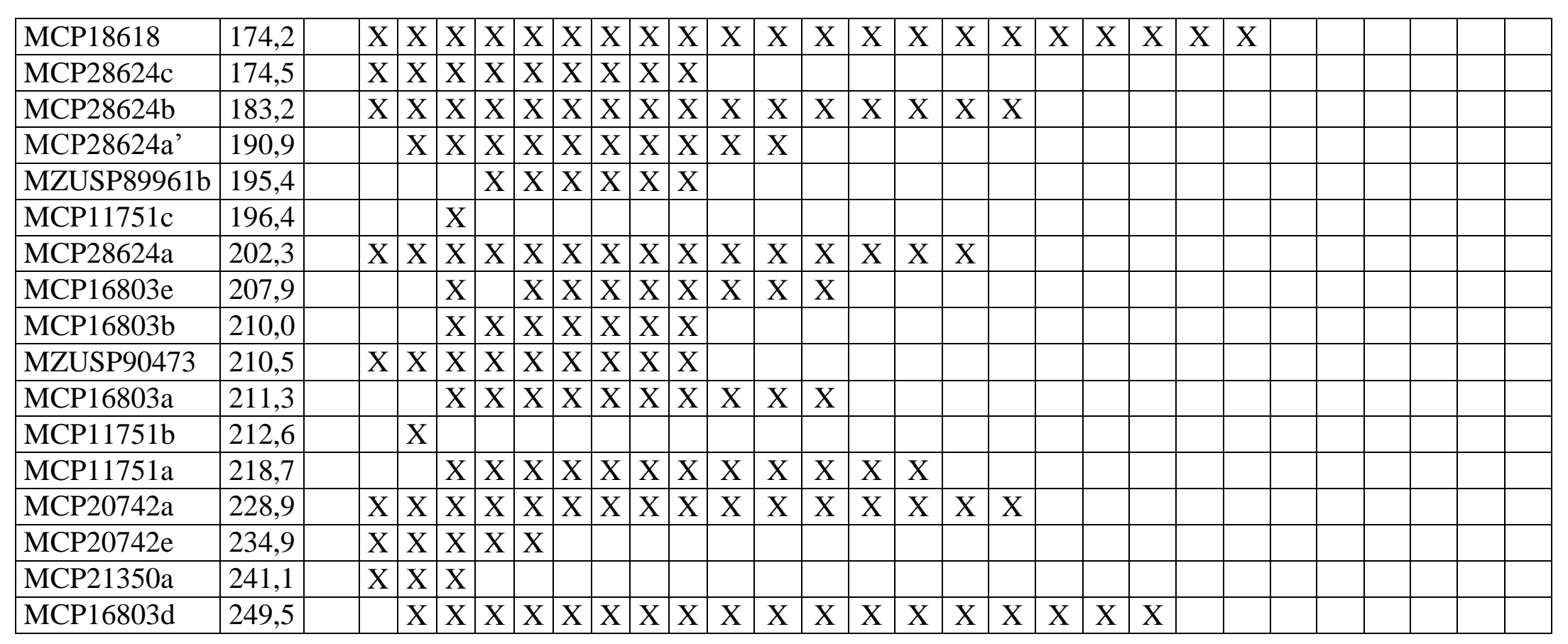


Tabela 12. Distribuição de ganchos nos raios da nadadeira pélvica de exemplares de Galeocharax humeralis. As células marcadas em amarelo representam a presença de ganchos. Ult = raio não ramificado mais posterior, $\mathrm{CP}=$ Comprimento padrão.

\begin{tabular}{|c|c|c|c|c|c|c|c|c|}
\hline Lote & $\mathrm{CP}$ & Ult & 1 & 2 & 3 & 4 & 5 & 6 \\
\hline MZUSP19907a & 111,5 & & $\mathrm{X}$ & $\mathrm{X}$ & $\mathrm{X}$ & $\mathrm{X}$ & $\mathrm{X}$ & \\
\hline MZUSP90684c & 124,6 & & $\mathrm{X}$ & $\mathrm{X}$ & $\mathrm{X}$ & $\mathrm{X}$ & $\mathrm{X}$ & \\
\hline MCP20742d & 125,4 & & $\mathrm{X}$ & $\mathrm{X}$ & $\mathrm{X}$ & $X$ & $X$ & \\
\hline MCP20742b' & 130,4 & & $\mathrm{X}$ & $\mathrm{X}$ & $X$ & $\mathrm{X}$ & $\mathrm{X}$ & $\mathrm{X}$ \\
\hline MCP20742a' & 133,0 & & $X$ & $\mathrm{X}$ & $\mathrm{X}$ & $\mathrm{X}$ & $X$ & \\
\hline MZUSP89961e & 142,2 & & $X$ & $\mathrm{X}$ & $X$ & & & \\
\hline MCP20742b & 142,5 & & $X$ & $X$ & $\mathrm{X}$ & $\mathrm{X}$ & $\mathrm{X}$ & \\
\hline MZUSP19907b & 144,4 & & $\mathrm{X}$ & $\mathrm{X}$ & $\mathrm{X}$ & $\mathrm{X}$ & $\mathrm{X}$ & $\mathrm{X}$ \\
\hline MCP20742c & 150,1 & & $X$ & $\mathrm{X}$ & $X$ & $\mathrm{X}$ & $\mathrm{X}$ & \\
\hline MCP16803c & 151,6 & & $X$ & $\mathrm{X}$ & $X$ & $\mathrm{X}$ & $X$ & \\
\hline MCP16803a' & 153,2 & & $\mathrm{X}$ & $\mathrm{X}$ & $X$ & $\mathrm{X}$ & $\mathrm{X}$ & \\
\hline MCP11897 & 158,4 & & $\mathrm{X}$ & $\mathrm{X}$ & $X$ & $\mathrm{X}$ & & \\
\hline NUP8499 & 162,4 & & $\mathrm{X}$ & $\mathrm{X}$ & $X$ & $\mathrm{X}$ & & \\
\hline MCP11751d & 163,6 & & $\mathrm{X}$ & $\mathrm{X}$ & $X$ & $\mathrm{X}$ & $X$ & \\
\hline MCP18618 & 174,2 & & $X$ & $\mathrm{X}$ & $X$ & $X$ & $\mathrm{X}$ & \\
\hline MCP28624b & 183,2 & & $X$ & $\mathrm{X}$ & $X$ & $\mathrm{X}$ & & \\
\hline MCP28624a & 202,3 & & $X$ & $\mathrm{X}$ & & & & \\
\hline MCP11751b & 212,6 & & $\mathrm{X}$ & $\mathrm{X}$ & & & & \\
\hline MCP20742a & 228,9 & & $\mathrm{X}$ & $\mathrm{X}$ & $X$ & $X$ & & \\
\hline
\end{tabular}


Tabela 13. Dados morfométricos dos exemplares machos maduros e fêmeas e machos imaturos de Galeocharax humeralis. Comprimento padrão (CP) em milímetros. Medidas do corpo foram expressas em porcentagem do CP e medidas da cabeça em porcentagem do comprimento da cabeça (CC)

\section{Galeocharax humeralis}

\begin{tabular}{|c|c|c|c|c|c|c|c|c|}
\hline & \multicolumn{4}{|c|}{ Machos maduros } & \multicolumn{4}{|c|}{ Fêmeas e machos imaturos } \\
\hline & $\mathrm{N}$ & Amplitude & Média & DP & $\mathrm{N}$ & Amplitude & Média & DP \\
\hline Comprimento padrão & 19 & $111,5-228,9$ & & & 74 & $112,3-227,5$ & & \\
\hline \multicolumn{9}{|l|}{ Porcentagem do CP } \\
\hline Comprimento da cabeça & 5 & $24,5-27,6$ & 25,9 & 1,2 & 13 & $26,2-28,8$ & 27,2 & 0,7 \\
\hline Comprimento da cabeça II & 18 & $25,4-28,3$ & 26,9 & 0,8 & 72 & $26,0-30,0$ & 28,3 & 0,9 \\
\hline Altura do corpo & 15 & $25,9-33,3$ & 28,9 & 1,8 & 44 & $26,7-33,2$ & 30,1 & 1,8 \\
\hline Comprimento da dorsal & 17 & $20,1-26,1$ & 23,9 & 1,3 & 60 & $20,9-26,3$ & 24,0 & 1,2 \\
\hline Comprimento da base da dorsal & 19 & $11,5-13,3$ & 12,2 & 0,4 & 73 & $11,0-13,3$ & 12,2 & 0,4 \\
\hline Comprimento da peitoral & 18 & $15,1-17,5$ & 16,1 & 0,6 & 70 & $13,5-17,4$ & 15,5 & 0,7 \\
\hline Comprimento da pélvica & 19 & $10,5-12,5$ & 11,7 & 0,4 & 69 & $10,4-13,0$ & 11,7 & 0,5 \\
\hline Comprimento da anal & 16 & $10,5-13,5$ & 12,0 & 0,8 & 54 & $9,3-15,0$ & 12,2 & 1,1 \\
\hline Comprimento da base da anal & 18 & $37,3-41,3$ & 39,7 & 1,1 & 69 & $34,2-41,6$ & 38,4 & 1,6 \\
\hline Distância pré-peitoral & 18 & $27,0-29,4$ & 28,0 & 0,7 & 73 & $24,7-32,3$ & 29,5 & 1,2 \\
\hline Distância pré-pélvica & 15 & $39,8-44,5$ & 41,5 & 1,1 & 50 & $40,6-47,0$ & 43,6 & 1,1 \\
\hline Distância pré-dorsal & 18 & $46,9-52,2$ & 48,9 & 1,3 & 73 & $47,4-53,8$ & 49,8 & 1,1 \\
\hline Distância pré-anal & 16 & $52,8-61,7$ & 56,4 & 2,3 & 72 & $53,6-62,1$ & 58,1 & 1,7 \\
\hline Altura do pedúnculo caudal & 18 & $7,3-8,7$ & 8,1 & 0,3 & 73 & $7,4-9,0$ & 8,1 & 0,3 \\
\hline Comprimento do pedúnculo caudal & 17 & $8,0-10,6$ & 9,5 & 0,7 & 69 & $8,3-10,7$ & 9,4 & 0,5 \\
\hline \multicolumn{9}{|l|}{ Porcentagem do CC } \\
\hline Comprimento do focinho & 18 & $30,9-37,0$ & 33,6 & 1,9 & 72 & $31,3-38,1$ & 34,9 & 1,6 \\
\hline Diâmetro orbital & 18 & $23,5-30,5$ & 27,8 & 2,1 & 72 & $22,5-29,8$ & 26,3 & 1,7 \\
\hline Distância interorbital & 18 & $22,9-28,1$ & 24,8 & 1,5 & 72 & $22,3-29,2$ & 25,4 & 1,5 \\
\hline Comprimento da maxila superior & 18 & $63,0-68,6$ & 65,9 & 1,6 & 72 & $63,6-70,8$ & 67,5 & 1,5 \\
\hline
\end{tabular}


Tabela 14. Dados morfométricos dos exemplares de Galeocharax humeralis das bacias do rio Paraguai e do rio Uruguai. Comprimento padrão (CP) em milímetros. Medidas do corpo foram expressas em porcentagem do CP e medidas da cabeça em porcentagem do comprimento da cabeça (CC)

Galeocharax humeralis

\begin{tabular}{|c|c|c|c|c|c|c|c|c|}
\hline & \multicolumn{4}{|c|}{ Paraguai } & \multicolumn{4}{|c|}{ Uruguai } \\
\hline & $\mathrm{N}$ & Amplitude & Média & DP & $\mathrm{N}$ & Amplitude & Média & DP \\
\hline Comprimento padrão & 51 & $72,2-251,8$ & & & 57 & $108,1-249,4$ & & \\
\hline \multicolumn{9}{|l|}{ Porcentagem do CP } \\
\hline Comprimento da cabeça & 8 & $28,0-29,7$ & 28,7 & 0,5 & 20 & $24,5-28,2$ & 26,7 & 1,0 \\
\hline Comprimento da cabeça II & 50 & $26,0-31,3$ & 28,7 & 1,0 & 54 & $25,4-29,6$ & 27,6 & 0,9 \\
\hline Altura do corpo & 34 & $25,2-33,2$ & 29,9 & 1,8 & 39 & $25,9-33,3$ & 29,3 & 1,8 \\
\hline Comprimento da dorsal & 44 & $21,4-27,3$ & 24,3 & 1,4 & 49 & $20,1-26,1$ & 23,7 & 1,3 \\
\hline Comprimento da base da dorsal & 51 & $11,0-13,1$ & 12,2 & 0,5 & 56 & $11,4-13,3$ & 12,3 & 0,4 \\
\hline Comprimento da peitoral & 47 & $13,6-16,9$ & 15,7 & 0,7 & 56 & $13,5-17,5$ & 15,6 & 0,7 \\
\hline Comprimento da pélvica & 48 & $10,5-13,3$ & 11,8 & 0,6 & 56 & $10,4-12,7$ & 11,7 & 0,5 \\
\hline Comprimento da anal & 32 & $9,3-14,5$ & 12,1 & 1,2 & 48 & $10,3-15,0$ & 12,2 & 0,9 \\
\hline Comprimento da base da anal & 49 & $33,2-41,6$ & 38,3 & 1,8 & 53 & $34,5-41,6$ & 38,8 & 1,4 \\
\hline Distância pré-peitoral & 49 & $26,6-32,8$ & 29,8 & 1,2 & 56 & $24,7-31,1$ & 28,8 & 1,3 \\
\hline Distância pré-pélvica & 36 & $39,8-47,0$ & 43,3 & 1,3 & 41 & $40,3-45,3$ & 42,9 & 1,4 \\
\hline Distância pré-dorsal & 50 & $47,2-53,8$ & 50,0 & 1,1 & 54 & $46,9-52,2$ & 49,4 & 1,1 \\
\hline Distância pré-anal & 50 & $52,8-62,1$ & 57,5 & 1,7 & 51 & $53,5-62,5$ & 57,8 & 2,1 \\
\hline Altura do pedúnculo caudal & 51 & $7,3-8,9$ & 8,1 & 0,3 & 56 & $7,3-9,0$ & 8,0 & 0,3 \\
\hline Comprimento do pedúnculo caudal & 46 & $8,0-10,5$ & 9,3 & 0,5 & 54 & $8,3-10,7$ & 9,4 & 0,5 \\
\hline \multicolumn{9}{|l|}{ Porcentagem do CC } \\
\hline Comprimento do focinho & 53 & $31,3-37,4$ & 34,1 & 1,6 & 54 & $30,9-38,1$ & 35,1 & 1,8 \\
\hline Diâmetro orbital & 53 & $23,5-31,2$ & 27,3 & 1,8 & 54 & $22,5-30,5$ & 26,4 & 2,1 \\
\hline Distância interorbital & 53 & $21,2-28,6$ & 24,6 & 1,5 & 54 & $22,3-29,4$ & 25,6 & 1,6 \\
\hline Comprimento da maxila superior & 53 & $64,4-71,0$ & 67,7 & 1,4 & 54 & $63,0-71,0$ & 67,1 & 1,8 \\
\hline
\end{tabular}


Tabela 15. Frequência de distribuição do número de dentes na fileira posterior do dentário em Galeocharax gulo, como definido do presente estudo. \begin{tabular}{lllllllllllllll}
21 & 22 & 23 & 24 & 25 & 26 & 27 & 28 & 29 & 30 & 31 & 32 & 33 & 34 & Total \\
\hline
\end{tabular}

\begin{tabular}{lllllllllllllll}
\hline G. gulo & 2 & 2 & 1 & 3 & 7 & 11 & 10 & 5 & 7 & 4 & 2 & 5 & 1 & 60 \\
\hline
\end{tabular}

Tabela 16. Distribuição de ganchos nos raios da nadadeira anal de exemplares de Galeocharax gulo. As células marcadas em amarelo representam a presença de ganchos. Ult = raio não ramificado mais posterior, $\mathrm{CP}=$ Comprimento padrão.

\begin{tabular}{|c|c|c|c|c|c|c|c|c|c|c|c|c|c|c|c|c|c|c|c|c|c|c|c|c|c|c|c|c|c|c|}
\hline Lote & $\mathrm{CP}$ & Ult & 1 & 2 & 3 & \begin{tabular}{|l|l}
4 &
\end{tabular} & 5 & $\begin{array}{ll}6 & \end{array}$ & 7 & \begin{tabular}{l|l}
8 \\
3
\end{tabular} & 9 & 10 & 11 & 12 & 13 & 14 & 15 & 16 & 17 & 18 & 19 & 20 & 21 & 22 & 23 & 24 & 25 & 26 & 27 & 28 \\
\hline UNT2588 & 86,5 & & & $\mathrm{X}$ & $\mathrm{X}$ & \begin{tabular}{|l|l|l}
$X$ & $Y$
\end{tabular} & $\mathrm{X}$ & $\mathrm{X}$ & & & & & & & & & & & & & & & & & & & & & & \\
\hline MZUSP 10487b' & 97,6 & & & & $X$ & & $\mathrm{X}$ & & & & & & & & & & & & & & & & & & & & & & & \\
\hline USNM258535b' & 98,6 & & & & $\mathrm{X}$ & \begin{tabular}{|l|l}
$\mathrm{X}$ & $\mathrm{X}$ \\
\end{tabular} & $\mathrm{X}$ & & & & & & & & & & & & & & & & & & & & & & & \\
\hline MZUSP 10487e & 98,7 & & & $\mathrm{X}$ & $\mathrm{X}$ & \begin{tabular}{|l|l|}
$\mathrm{X}$ & $\mathrm{Z}$ \\
\end{tabular} & $\mathrm{X}$ & $\mathrm{X}$ & & & & & & & & & & & & & & & & & & & & & & \\
\hline MNRJ39674a' & 98,8 & & & & $\mathrm{X}$ & \begin{tabular}{|l|l|}
$X$ & $Y$ \\
\end{tabular} & $\mathrm{X}$ & \begin{tabular}{l|l}
$X$ \\
$X$
\end{tabular} & $\mathrm{X}$ & $\mathrm{X}$ & & & & & & & & & & & & & & & & & & & & \\
\hline INPA2482 & 98,9 & & & $\bar{X}$ & $\mathrm{X}$ & \begin{tabular}{|l|l|l}
$X$ & $Y$
\end{tabular} & $\mathrm{X}$ & & & & & & & & & & & & & & & & & & & & & & & \\
\hline INPA12320a & 99,1 & & & $\mathrm{X}$ & $\mathrm{X}$ & \begin{tabular}{|l|l|}
$\mathrm{X}$ & $\mathrm{Z}$ \\
\end{tabular} & $\mathrm{X}$ & $\mathrm{X}$ & & & & & & & & & & & & & & & & & & & & & & \\
\hline MCN19060d' & 99,8 & $\mathrm{X}$ & $\mathrm{X}$ & $\mathrm{X}$ & $\mathrm{X}$ & \begin{tabular}{|l|l}
$\mathrm{X}$ & $\mathrm{X}$ \\
\end{tabular} & $\mathrm{X}$ & \begin{tabular}{l|l}
$X$ & $Y$ \\
$X$
\end{tabular} & $\mathrm{X}$ & $\bar{X} 2$ & $\mathrm{X}$ & $\mathrm{X}$ & $\mathrm{X}$ & $X$ & $X$ & $X$ & $X$ & $\bar{X}$ & & & & & & & & & & & & \\
\hline MZUSP10437 & 99,8 & & $\mathrm{X}$ & $\mathrm{X}$ & $\mathrm{X}$ & \begin{tabular}{|l|l|}
$X$ & $Y$ \\
\end{tabular} & $\mathrm{X}$ & $\bar{X} \bar{X}$ & $\mathrm{X}$ & $\bar{X} 2$ & $\mathrm{X}$ & $\mathrm{X}$ & $\mathrm{X}$ & & & & & & & & & & & & & & & & & \\
\hline MNRJ39674d & 100,4 & & $\mathrm{X}$ & $\mathrm{X}$ & $\mathrm{X}$ & \begin{tabular}{|l|l|}
$\mathrm{X}$ & $\mathrm{Z}$ \\
\end{tabular} & $\mathrm{X}$ & $X Y$ & $\mathrm{X}$ & $\mathrm{X} 2 \mathrm{2}$ & $\mathrm{X}$ & $X$ & $X$ & & & & & & & & & & & & & & & & & \\
\hline ANSP128277a & 100,8 & $X$ & $X$ & $\mathrm{X}$ & $\mathrm{X}$ & \begin{tabular}{|l|l}
$\mathrm{X}$ & $\mathrm{X}$ \\
\end{tabular} & $\mathrm{X}$ & \begin{tabular}{l|l}
$X$ & $Y$ \\
\end{tabular} & $X$ & $\mathrm{X} Y$ & $X$ & $X$ & $X$ & $\mathrm{X}$ & $X$ & & & & & & & & & & & & & & & \\
\hline MZUSP 27982d & 101,5 & & & $\mathrm{X}$ & $\mathrm{X}$ & \begin{tabular}{|l|l|}
$\mathrm{X}$ & $\mathrm{Z}$ \\
\end{tabular} & $\mathrm{X}$ & $\mathrm{X} 2 \mathrm{Z}$ & $\mathrm{X}$ & $\mathrm{X} 2 \mathrm{2}$ & $\mathrm{X}$ & $\mathrm{X}$ & & & & & & & & & & & & & & & & & & \\
\hline ANSP128277b & 102,2 & $X$ & $\mathrm{X}$ & $\mathrm{X}$ & $\mathrm{X}$ & \begin{tabular}{|l|l}
$\mathrm{X}$ & $\mathrm{Z}$ \\
\end{tabular} & $\mathrm{X}$ & $\begin{array}{ll}X & 2 \\
\end{array}$ & $\mathrm{X}$ & \begin{tabular}{l|l}
$x$ \\
\end{tabular} & $\mathrm{X}$ & $\mathrm{X}$ & $\mathrm{X}$ & $\mathrm{X}$ & $X$ & & & & & & & & & & & & & & & \\
\hline MCNG49082 & 102,4 & & & $\mathrm{X}$ & $X$ & \begin{tabular}{|l|l|}
$\mathrm{X}$ & $\mathrm{Z}$ \\
\end{tabular} & $\mathrm{X}$ & $\begin{array}{ll}X \\
X\end{array}$ & $\mathrm{X}$ & $\begin{array}{ll}X \\
2\end{array}$ & $\mathrm{X}$ & $\mathrm{X}$ & & & & & & & & & & & & & & & & & & \\
\hline NUP1199e' & 102,8 & & $\mathrm{X}$ & $\mathrm{X}$ & $\mathrm{X}$ & \begin{tabular}{|l|l|l}
$\mathrm{X}$ & $\mathrm{X}$ \\
\end{tabular} & $\mathrm{X}$ & & & & & & & & & & & & & & & & & & & & & & & \\
\hline MCN19060c' & 103,4 & & $\mathrm{X}$ & $X$ & $\mathrm{X}$ & \begin{tabular}{|l|l|l}
$X$ & $Y$ \\
\end{tabular} & $\mathrm{X}$ & $\begin{array}{ll}X & 2 \\
\end{array}$ & $\mathrm{X}$ & $\mathrm{X} 2 \mathrm{z}$ & $\mathrm{X}$ & $\mathrm{X}$ & $\mathrm{X}$ & $\mathrm{X}$ & $\mathrm{X}$ & $X$ & $\mathrm{X}$ & $\mathrm{X}$ & & & & & & & & & & & & \\
\hline MNRJ19834a' & 103,4 & & & $\mathrm{X}$ & $\mathrm{X}$ & \begin{tabular}{|l|l|l}
$\mathrm{X}$ & $\mathrm{Z}$ \\
\end{tabular} & $\mathrm{X}$ & $\mathrm{X} 2$ & $\mathrm{X}$ & & & & & & & & & & & & & & & & & & & & & \\
\hline MZUSP 10558a', & 103,9 & & & & & \begin{tabular}{|l|l|l}
$\mathrm{X}$ & $Y$ \\
\end{tabular} & $\mathrm{X}$ & $\mathrm{X}$ & $\mathrm{X}$ & & & & & & & & & & & & & & & & & & & & & \\
\hline USNM258535c' & 104,0 & & & $\mathrm{X}$ & $X$ & \begin{tabular}{|l|l|l}
$\mathrm{X}$ & $\mathrm{X}$ \\
\end{tabular} & $\mathrm{X}$ & $\mathrm{X} 2$ & $\mathrm{X}$ & $\mathrm{X}$ & & & & & & & & & & & & & & & & & & & & \\
\hline MZUSP 10558c' & 104,3 & & & & $\mathrm{X}$ & \begin{tabular}{|l|l|l}
$\mathrm{X}$ & $\mathrm{Z}$ \\
\end{tabular} & $\mathrm{X}$ & $X$ & $\mathrm{X}$ & & & & & & & & & & & & & & & & & & & & & \\
\hline UNT9060e & 105,1 & & $\mathrm{X}$ & $\mathrm{X}$ & $\mathrm{X}$ & \begin{tabular}{|l|l|}
$\mathrm{X}$ & $\mathrm{Z}$ \\
\end{tabular} & $\mathrm{X}$ & $\mathrm{X}$ & $X$ & $\mathrm{X}$ & $\mathrm{X}$ & $\mathrm{X}$ & $X$ & $\mathrm{X}$ & $\mathrm{X}$ & $X$ & $\mathrm{X}$ & $X$ & & & & & & & & & & & & \\
\hline MCN19060b' & 105,3 & & $\mathrm{X}$ & $\mathrm{X}$ & $\mathrm{X}$ & \begin{tabular}{|l|l|}
$\mathrm{X}$ & $\mathrm{Z}$ \\
\end{tabular} & $\mathrm{X}$ & $\mathrm{X} 2$ & $\mathrm{X}$ & $\mathrm{X}$ & $\mathrm{X}$ & $\mathrm{X}$ & $X$ & $\mathrm{X}$ & & & & & & & & & & & & & & & & \\
\hline
\end{tabular}




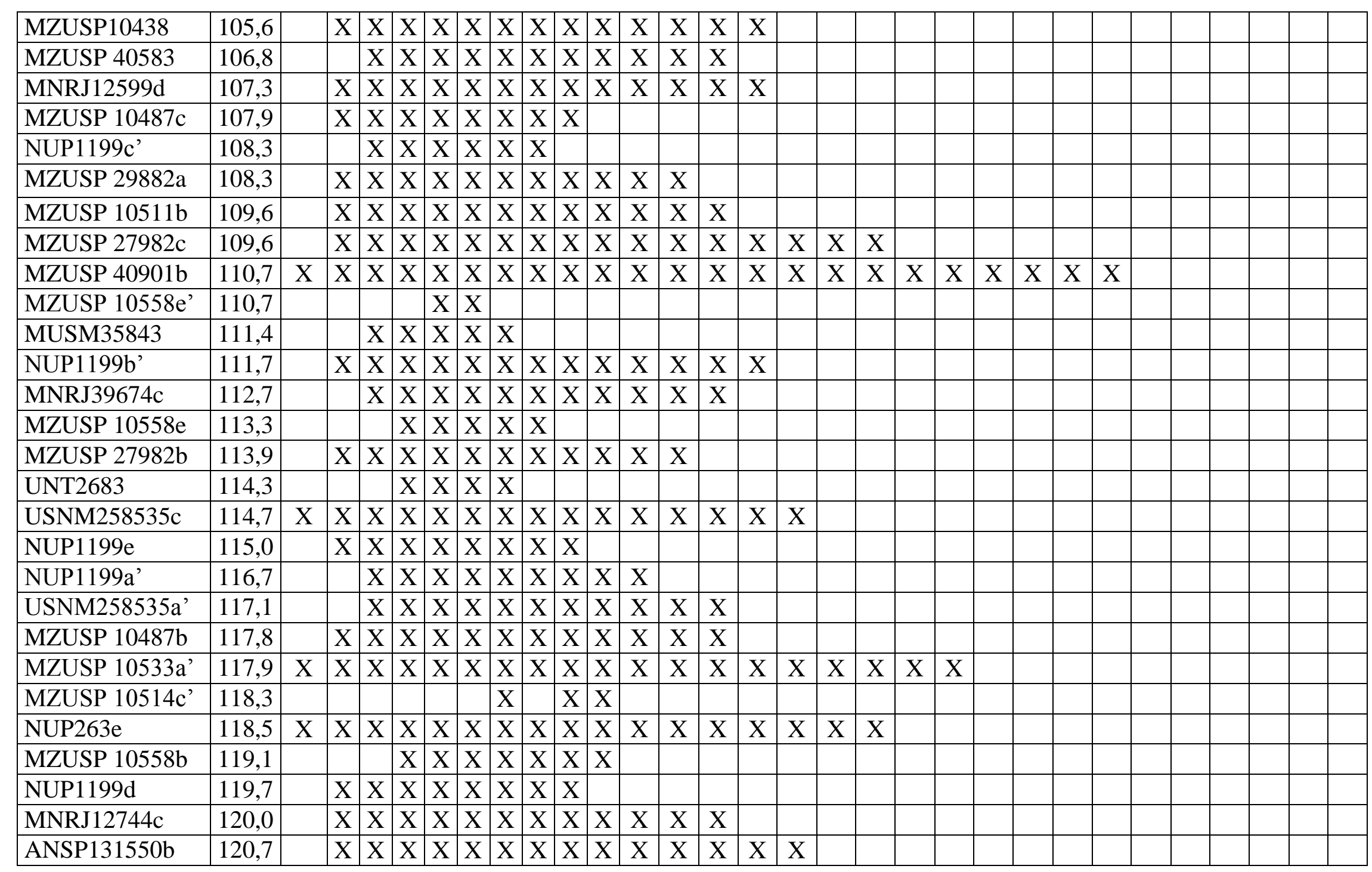




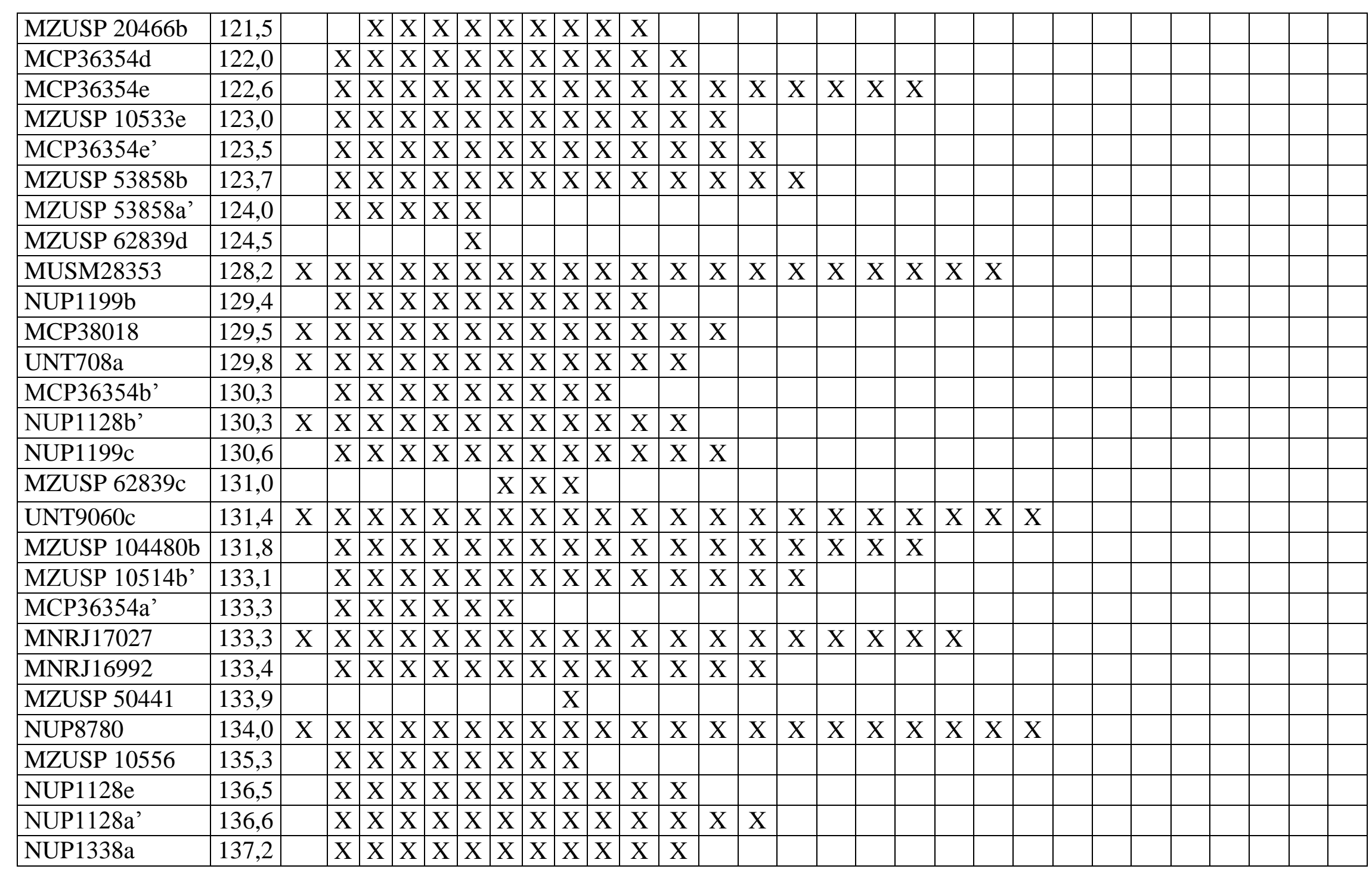




\begin{tabular}{|c|c|c|c|c|c|c|c|c|c|c|c|c|c|c|c|c|c|c|c|c|c|c|c|c|c|c|c|c|c|c|c|c|}
\hline MZUSP 20515 & 137,7 & $\mathrm{X}$ & $\mathrm{X}$ & $\mathrm{X}$ & $\mathrm{X}$ & $\mathrm{X}$ & $\mathrm{X}$ & $\mathrm{X}$ & $\mathrm{X}$ & $\mathrm{X}$ & $\mathrm{X}$ & $\mathrm{X}$ & $\mathrm{X}$ & $X$ & $X$ & $\mathrm{X}$ & $\mathrm{X}$ & & & & & & & & & & & & & & & \\
\hline MZUSP 62839b & 138,3 & & & & $X$ & $X$ & $\mathrm{X}$ & $X$ & $\mathrm{X}$ & $\mathrm{X}$ & $\mathrm{X}$ & & & & & & & & & & & & & & & & & & & & & \\
\hline MNRJ19834d & 138,4 & $X$ & $X$ & $\mathrm{X}$ & $\mathrm{X}$ & $\mathrm{X}$ & $\mathrm{X}$ & $\mathrm{X}$ & $X$ & $\mathrm{X}$ & $\mathrm{X}$ & $X$ & $X$ & $X$ & X & $X$ & $X$ & $X$ & $X$ & $X$ & $X$ & $X$ & $X$ & X & & & & & & & & \\
\hline NUP1128c & 138,7 & & $\mathrm{X}$ & $\mathrm{X}$ & $\mathrm{X}$ & $\mathrm{X}$ & $\mathrm{X}$ & $X$ & $\mathrm{X}$ & $\mathrm{X}$ & $X$ & $\mathrm{X}$ & $\mathrm{X}$ & $X$ & $X$ & $\mathrm{X}$ & & & & & & & & & & & & & & & & \\
\hline MUSM25807 & 138,9 & X & $X$ & $\mathrm{X}$ & $\mathrm{X}$ & $\mathrm{X}$ & $\mathrm{X}$ & $X$ & $\mathrm{X}$ & $\mathrm{X}$ & $X$ & $X$ & $\mathrm{X}$ & $X$ & $\mathrm{X}$ & $\mathrm{X}$ & X & $X$ & $X$ & $X$ & & $X$ & & & & & & & & & & \\
\hline MZUSP10439 & 138,9 & & $X$ & $\mathrm{X}$ & $\mathrm{X}$ & $\mathrm{X}$ & $\mathrm{X}$ & $X$ & $X$ & $\mathrm{X}$ & $X$ & & & & & & & & & & & & & & & & & & & & & \\
\hline MZUSP $10533 d$ & 138,9 & $\mathrm{X}$ & $\mathrm{X}$ & $\mathrm{X}$ & $\mathrm{X}$ & $\mathrm{X}$ & $\mathrm{X}$ & $\mathrm{X}$ & $\mathrm{X}$ & $\mathrm{X}$ & $\mathrm{X}$ & $\mathrm{X}$ & $X$ & $\mathrm{X}$ & $\mathrm{X}$ & $\mathrm{X}$ & $X$ & & & & & & & & & & & & & & & \\
\hline MZUSP 10443c & 139,1 & & $X$ & $\mathrm{X}$ & $\mathrm{X}$ & $\mathrm{X}$ & $\mathrm{X}$ & $\mathrm{X}$ & $\mathrm{X}$ & $\mathrm{X}$ & $\mathrm{X}$ & $X$ & $X$ & $\mathrm{X}$ & $X$ & $\mathrm{X}$ & $\mathrm{X}$ & & & & & & & & & & & & & & & \\
\hline MZUSP $10502^{\mathrm{a}}$ & 139,5 & & $\mathrm{X}$ & $\mathrm{X}$ & $\mathrm{X}$ & $\mathrm{X}$ & $\mathrm{X}$ & $\mathrm{X}$ & $X$ & $\mathrm{X}$ & $X$ & $\mathrm{X}$ & $X$ & $\mathrm{X}$ & & & & & & & & & & & & & & & & & & \\
\hline NUP2487c & 139,6 & & $\mathrm{X}$ & $\mathrm{X}$ & $\mathrm{X}$ & $\mathrm{X}$ & $\mathrm{X}$ & $\mathrm{X}$ & $\mathrm{X}$ & $\mathrm{X}$ & $\mathrm{X}$ & $\mathrm{X}$ & $\mathrm{X}$ & $\mathrm{X}$ & $\mathrm{X}$ & & & & & & & & & & & & & & & & & \\
\hline MZUSP 10533c & 140,2 & $X$ & $\mathrm{X}$ & $\mathrm{X}$ & $\mathrm{X}$ & $\mathrm{X}$ & $\mathrm{X}$ & $X$ & $\mathrm{X}$ & $\mathrm{X}$ & $\mathrm{X}$ & $\mathrm{X}$ & $\mathrm{X}$ & $\mathrm{X}$ & $\mathrm{X}$ & $X$ & $X$ & $X$ & $X$ & $\mathrm{X}$ & $\mathrm{X}$ & & & & & & & & & & & \\
\hline NUP1128d & 140,3 & & $\mathrm{X}$ & $\mathrm{X}$ & $\mathrm{X}$ & $\mathrm{X}$ & $\mathrm{X}$ & $\mathrm{X}$ & $\mathrm{X}$ & $\mathrm{X}$ & $\mathrm{X}$ & $X$ & $\mathrm{X}$ & $\mathrm{X}$ & $\mathrm{X}$ & $\mathrm{X}$ & $X$ & & & & & & & & & & & & & & & \\
\hline NUP263d & 140,4 & $\mathrm{X}$ & $\mathrm{X}$ & $\mathrm{X}$ & $\mathrm{X}$ & $\mathrm{X}$ & $\mathrm{X}$ & $\mathrm{X}$ & $\mathrm{X}$ & $\mathrm{X}$ & $\mathrm{X}$ & $\mathrm{X}$ & $X$ & $\mathrm{X}$ & $\mathrm{X}$ & $\mathrm{X}$ & $\mathrm{X}$ & & & & & & & & & & & & & & & \\
\hline MZUSP 10514a' & 142,7 & & $\mathrm{X}$ & $\mathrm{X}$ & $\mathrm{X}$ & $\mathrm{X}$ & $\mathrm{X}$ & $\mathrm{X}$ & $\mathrm{X}$ & $\mathrm{X}$ & $\mathrm{X}$ & $\mathrm{X}$ & $X$ & $\mathrm{X}$ & $\mathrm{X}$ & $\mathrm{X}$ & $X$ & & & & & & & & & & & & & & & \\
\hline MZUSP 10533a & 143,5 & & $X$ & $X$ & $X$ & $\mathrm{X}$ & $\mathrm{X}$ & $X$ & $\mathrm{X}$ & $\mathrm{X}$ & $X$ & $X$ & $X$ & $\mathrm{X}$ & & & & & & & & & & & & & & & & & & \\
\hline MZUSP 25689d & 143,8 & $\mathrm{X}$ & $X$ & $\mathrm{X}$ & $\mathrm{X}$ & $\mathrm{X}$ & $\mathrm{X}$ & $X$ & $\mathrm{X}$ & $\mathrm{X}$ & $X$ & $X$ & $X$ & $X$ & $X$ & $\mathrm{X}$ & $\mathrm{X}$ & $X$ & $X$ & & & & & & & & & & & & & \\
\hline MZUSP 2039c & 144,5 & & $\mathrm{X}$ & $\mathrm{X}$ & $\mathrm{X}$ & $\mathrm{X}$ & $\mathrm{X}$ & $\mathrm{X}$ & $\mathrm{X}$ & $\mathrm{X}$ & $\mathrm{X}$ & $X$ & $\mathrm{X}$ & $X$ & $\mathrm{X}$ & $\mathrm{X}$ & & & & & & & & & & & & & & & & \\
\hline MZUSP 10533b & 144,5 & $X$ & $\mathrm{X}$ & $\mathrm{X}$ & $\mathrm{X}$ & $\mathrm{X}$ & $\mathrm{X}$ & $\mathrm{X}$ & $\mathrm{X}$ & $\mathrm{X}$ & $\mathrm{X}$ & $X$ & $\mathrm{X}$ & $\mathrm{X}$ & $\mathrm{X}$ & $\mathrm{X}$ & $\mathrm{X}$ & & & & & & & & & & & & & & & \\
\hline MZUSP 25689c & 144,7 & $\mathrm{X}$ & $\mathrm{X}$ & $\mathrm{X}$ & $\mathrm{X}$ & $\mathrm{X}$ & $\mathrm{X}$ & $\mathrm{X}$ & $X$ & $\mathrm{X}$ & $\mathrm{X}$ & $\mathrm{X}$ & $\mathrm{X}$ & $X$ & $\mathrm{X}$ & $\mathrm{X}$ & $\mathrm{X}$ & $\bar{X}$ & $\bar{X}$ & & & & & & & & & & & & & \\
\hline MZUSP 38869b' & 145,2 & $\mathrm{X}$ & $\mathrm{X}$ & $\mathrm{X}$ & $\mathrm{X}$ & $\mathrm{X}$ & $\mathrm{X}$ & $\mathrm{X}$ & $\mathrm{X}$ & $\mathrm{X}$ & $\mathrm{X}$ & $X$ & $\mathrm{X}$ & $\mathrm{X}$ & $X$ & $\mathrm{X}$ & $\mathrm{X}$ & $X$ & $\mathrm{X}$ & $\mathrm{X}$ & $\mathrm{X}$ & & & & & & & & & & & \\
\hline MUSM32516 & 145,6 & & $X$ & $\mathrm{X}$ & $\mathrm{X}$ & $\mathrm{X}$ & $\mathrm{X}$ & $X$ & $\mathrm{X}$ & $X$ & $X$ & $X$ & $X$ & $\mathrm{X}$ & $X$ & $X$ & $X$ & $X$ & $X$ & & & & & & & & & & & & & \\
\hline MZUSP 38869a' & 145,6 & $\mathrm{X}$ & $\mathrm{X}$ & $\mathrm{X}$ & $\mathrm{X}$ & $\mathrm{X}$ & $\mathrm{X}$ & $\mathrm{X}$ & $\mathrm{X}$ & $\mathrm{X}$ & $\mathrm{X}$ & $\mathrm{X}$ & $\mathrm{X}$ & $X$ & $\mathrm{X}$ & $\mathrm{X}$ & $X$ & $X$ & $X$ & & & & & & & & & & & & & \\
\hline NUP9275 & 146,5 & $X$ & $X$ & $\mathrm{X}$ & $\mathrm{X}$ & $\mathrm{X}$ & $\mathrm{X}$ & $X$ & $\mathrm{X}$ & $\mathrm{X}$ & $X$ & $X$ & $\mathrm{X}$ & $X$ & $\mathrm{X}$ & $X$ & $X$ & $X$ & $X$ & $\mathrm{X}$ & $X$ & $X$ & $X$ & $\mathrm{X}$ & $X$ & & $\mathrm{X}$ & $\mathrm{X}$ & $\mathrm{X}$ & $\mathrm{X}$ & $X$ & $X$ \\
\hline MZUSP 110473a & 148,3 & $\mathrm{X}$ & $\mathrm{X}$ & $\mathrm{X}$ & $\mathrm{X}$ & $\mathrm{X}$ & $\mathrm{X}$ & $\mathrm{X}$ & $\mathrm{X}$ & $\mathrm{X}$ & $X$ & $\mathrm{X}$ & $\mathrm{X}$ & $\mathrm{X}$ & $\mathrm{X}$ & $\mathrm{X}$ & $\mathrm{X}$ & & & & & & & & & & & & & & & \\
\hline MZUSP $10514 \mathrm{e}$ & 148,3 & & & & & & & $\mathrm{X}$ & $\mathrm{X}$ & $\mathrm{X}$ & $\mathrm{X}$ & $\mathrm{X}$ & $\mathrm{X}$ & $\mathrm{X}$ & & & & & & & & & & & & & & & & & & \\
\hline MZUSP 20485b & 148,3 & $\mathrm{X}$ & $\mathrm{X}$ & $\mathrm{X}$ & $\mathrm{X}$ & $\mathrm{X}$ & $\mathrm{X}$ & $\mathrm{X}$ & $\mathrm{X}$ & $\mathrm{X}$ & $\mathrm{X}$ & $X$ & $\mathrm{X}$ & $\mathrm{X}$ & $\mathrm{X}$ & $\mathrm{X}$ & $X$ & $X$ & $\mathrm{X}$ & & & & & & & & & & & & & \\
\hline MZUSP 10528b & 148,5 & & & $\mathrm{X}$ & $\mathrm{X}$ & $\mathrm{X}$ & $\mathrm{X}$ & $\mathrm{X}$ & $\mathrm{X}$ & $\mathrm{X}$ & $\mathrm{X}$ & $\mathrm{X}$ & $\mathrm{X}$ & $\mathrm{X}$ & $\mathrm{X}$ & $\mathrm{X}$ & & & & & & & & & & & & & & & & \\
\hline MZUSP 62841c & 149,0 & & $\mathrm{X}$ & $\mathrm{X}$ & $\mathrm{X}$ & $\mathrm{X}$ & $\mathrm{X}$ & $\mathrm{X}$ & $\mathrm{X}$ & $\mathrm{X}$ & $\mathrm{X}$ & $X$ & $\mathrm{X}$ & $X$ & & & & & & & & & & & & & & & & & & \\
\hline
\end{tabular}




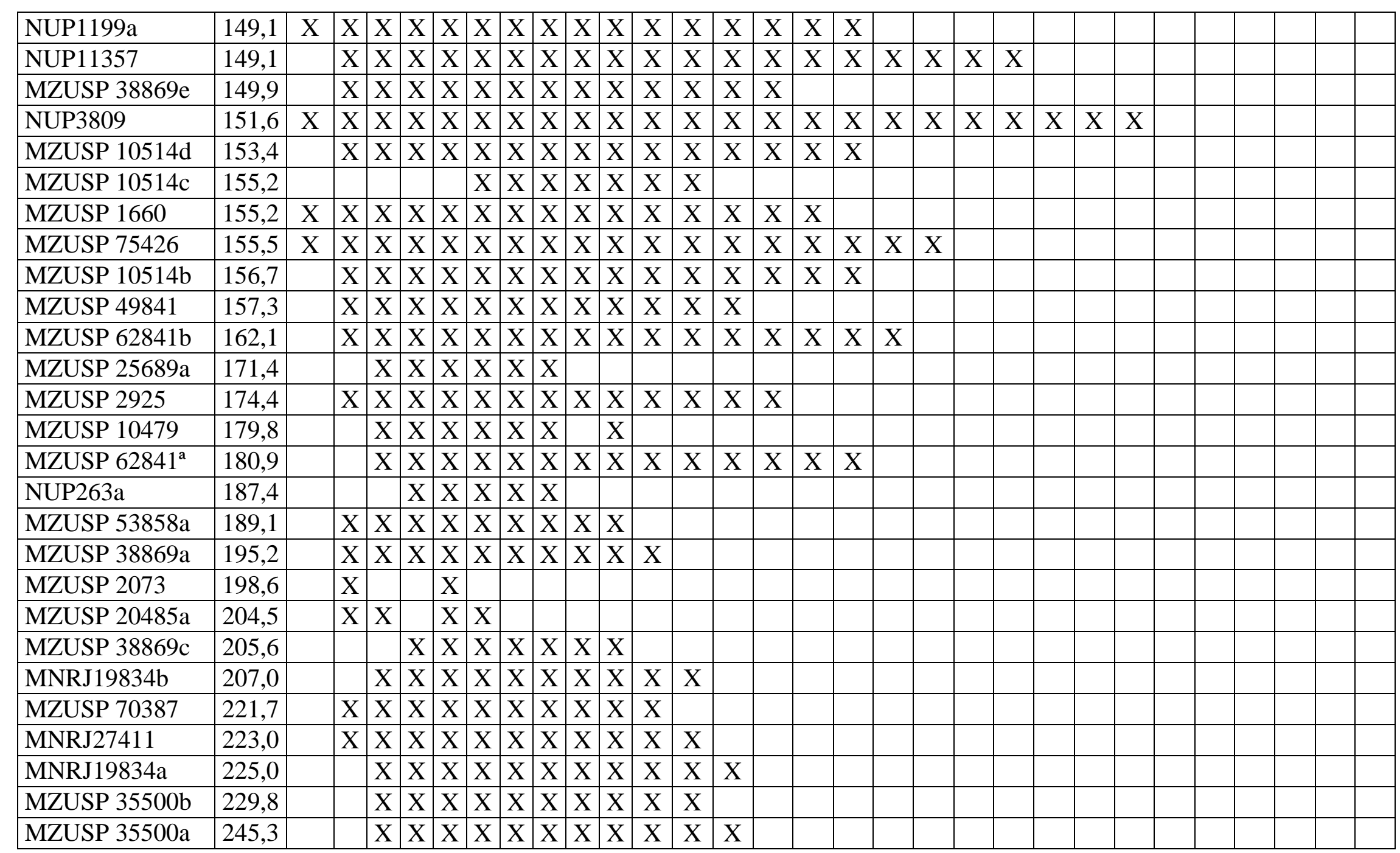


Tabela17. Distribuição de ganchos nos raios da nadadeira pélvica de exemplares de Galeocharax gulo. As células marcadas em amarelo representam a presença de ganchos. Ult = raio não ramificado mais posterior, $\mathrm{CP}=$ Comprimento padrão.

\begin{tabular}{|l|r|r|r|l|l|l|l|l|}
\hline Lote & CP & Ult & 1 & 2 & 3 & 4 & 5 & 6 \\
\hline MNRJ39674a' & 98,8 & & & X & X & & & \\
\hline MZUSP 10437 & 99,8 & & X & X & X & & & \\
\hline MNRJ39674d & 100,4 & & X & X & X & X & X & \\
\hline ANSP128277a & 100,8 & & X & X & X & X & X & \\
\hline MZUSP 27982d & 101,4 & & & X & & & & \\
\hline ANSP128277b & 102,2 & & X & X & X & X & X & \\
\hline MCNG49082 & 102,3 & & & & X & & & \\
\hline MCN19060c' & 103,3 & & $\mathrm{X}$ & $\mathrm{X}$ & $\mathrm{X}$ & $\mathrm{X}$ & $\mathrm{X}$ & $\mathrm{X}$ \\
\hline UNT9060e & 105,1 & & $\mathrm{X}$ & $\mathrm{X}$ & $\mathrm{X}$ & $\mathrm{X}$ & $\mathrm{X}$ & \\
\hline MCN19060b' & 105,2 & & $\mathrm{X}$ & $\mathrm{X}$ & $\mathrm{X}$ & $\mathrm{X}$ & $\mathrm{X}$ & $\mathrm{X}$ \\
\hline MZUSP 10438 & 105,5 & & & $\mathrm{X}$ & $\mathrm{X}$ & $\mathrm{X}$ & & \\
\hline MZUSP 40583 & 106,7 & & & $\mathrm{X}$ & $\mathrm{X}$ & $\mathrm{X}$ & $\mathrm{X}$ & \\
\hline MNRJ12599d & 107,3 & & $\mathrm{X}$ & $\mathrm{X}$ & $\mathrm{X}$ & $\mathrm{X}$ & $\mathrm{X}$ & $\mathrm{X}$ \\
\hline MZUSP 10487c & 107,8 & & $\mathrm{X}$ & $\mathrm{X}$ & & & & \\
\hline MZUSP 10511b & 109,5 & & $\mathrm{X}$ & $\mathrm{X}$ & $\mathrm{X}$ & $\mathrm{X}$ & $\mathrm{X}$ & \\
\hline MZUSP 40901b & 110,6 & & $\mathrm{X}$ & $\mathrm{X}$ & $\mathrm{X}$ & $\mathrm{X}$ & $\mathrm{X}$ & \\
\hline MUSM35843 & 111,3 & & & $\mathrm{X}$ & $\mathrm{X}$ & & & \\
\hline MNRJ39674c & 112,6 & & $\mathrm{X}$ & $\mathrm{X}$ & $\mathrm{X}$ & $\mathrm{X}$ & $\mathrm{X}$ & $\mathrm{X}$ \\
\hline USNM258535c & 114,6 & & $\mathrm{X}$ & $\mathrm{X}$ & $\mathrm{X}$ & $\mathrm{X}$ & $\mathrm{X}$ & \\
\hline NUP1199e & 114,9 & & & $\mathrm{X}$ & $\mathrm{X}$ & & & \\
\hline NUP1199a' & 116,6 & & & $\mathrm{X}$ & $\mathrm{X}$ & & & \\
\hline USNM258535a' & 117,1 & & & & $\mathrm{X}$ & $\mathrm{X}$ & & \\
\hline MZUSP 10487b & 117,8 & & $\mathrm{X}$ & $\mathrm{X}$ & $\mathrm{X}$ & $\mathrm{X}$ & & \\
\hline MZUSP 10533a' & 117,9 & & $\mathrm{X}$ & $\mathrm{X}$ & $\mathrm{X}$ & $\mathrm{X}$ & $\mathrm{X}$ & \\
\hline NUP263e & 118,4 & & $\mathrm{X}$ & $\mathrm{X}$ & $\mathrm{X}$ & $\mathrm{X}$ & $\mathrm{X}$ & $\mathrm{X}$ \\
\hline
\end{tabular}




\begin{tabular}{|l|l|l|l|l|l|l|l|l|}
\hline MZUSP 10558b & 119,1 & & & $\mathrm{X}$ & & & & \\
\hline MNRJ12744c & 119,9 & & $\mathrm{X}$ & $\mathrm{X}$ & $\mathrm{X}$ & $\mathrm{X}$ & $\mathrm{X}$ & \\
\hline ANSP131550b & 120,7 & & $\mathrm{X}$ & $\mathrm{X}$ & $\mathrm{X}$ & $\mathrm{X}$ & $\mathrm{X}$ & \\
\hline MZUSP 20466b & 121,5 & & & $\mathrm{X}$ & $\mathrm{X}$ & & & \\
\hline MCP36354d & 121,9 & & & $\mathrm{X}$ & & & & \\
\hline MCP36354e & 122,6 & & $\mathrm{X}$ & $\mathrm{X}$ & $\mathrm{X}$ & $\mathrm{X}$ & & \\
\hline MZUSP 10533e & 122,9 & & $\mathrm{X}$ & $\mathrm{X}$ & $\mathrm{X}$ & $\mathrm{X}$ & $\mathrm{X}$ & \\
\hline MCP36354e' & 123,4 & & & $\mathrm{X}$ & $\mathrm{X}$ & & & \\
\hline MZUSP 53858b & 123,6 & & $\mathrm{X}$ & $\mathrm{X}$ & $\mathrm{X}$ & $\mathrm{X}$ & $\mathrm{X}$ & $\mathrm{X}$ \\
\hline MUSM28353 & 128,2 & & $\mathrm{X}$ & $\mathrm{X}$ & $\mathrm{X}$ & $\mathrm{X}$ & $\mathrm{X}$ & \\
\hline NUP1199b & 129,3 & & $\mathrm{X}$ & $\mathrm{X}$ & $\mathrm{X}$ & $\mathrm{X}$ & $\mathrm{X}$ & \\
\hline MCP38018 & 129,4 & & $\mathrm{X}$ & $\mathrm{X}$ & $\mathrm{X}$ & $\mathrm{X}$ & $\mathrm{X}$ & \\
\hline UNT708a & 129,8 & $\mathrm{X}$ & $\mathrm{X}$ & $\mathrm{X}$ & $\mathrm{X}$ & $\mathrm{X}$ & $\mathrm{X}$ & $\mathrm{X}$ \\
\hline MCP36354b & 130,2 & & $\mathrm{X}$ & $\mathrm{X}$ & $\mathrm{X}$ & & & \\
\hline NUP1128b' & 130,3 & & $\mathrm{X}$ & $\mathrm{X}$ & $\mathrm{X}$ & $\mathrm{X}$ & $\mathrm{X}$ & \\
\hline NUP1199c & 130,6 & & $\mathrm{X}$ & $\mathrm{X}$ & $\mathrm{X}$ & $\mathrm{X}$ & & \\
\hline UNT9060c & 131,4 & & $\mathrm{X}$ & $\mathrm{X}$ & $\mathrm{X}$ & $\mathrm{X}$ & & \\
\hline MZUSP 104480b & 131,8 & & $\mathrm{X}$ & $\mathrm{X}$ & $\mathrm{X}$ & $\mathrm{X}$ & & \\
\hline MZUSP 10514b' & 133,1 & & $\mathrm{X}$ & $\mathrm{X}$ & $\mathrm{X}$ & & & \\
\hline MCP36354a' & 133,3 & & $\mathrm{X}$ & $\mathrm{X}$ & $\mathrm{X}$ & $\mathrm{X}$ & & \\
\hline MNRJ17027 & 133,3 & & $\mathrm{X}$ & $\mathrm{X}$ & $\mathrm{X}$ & $\mathrm{X}$ & $\mathrm{X}$ & $\mathrm{X}$ \\
\hline MNRJ16992 & 133,4 & & $\mathrm{X}$ & $\mathrm{X}$ & $\mathrm{X}$ & & & \\
\hline NUP8780 & 134,0 & & $\mathrm{X}$ & $\mathrm{X}$ & $\mathrm{X}$ & $\mathrm{X}$ & $\mathrm{X}$ & $\mathrm{X}$ \\
\hline NUP1128e & 136,5 & & $\mathrm{X}$ & $\mathrm{X}$ & $\mathrm{X}$ & $\mathrm{X}$ & $\mathrm{X}$ & \\
\hline NUP1128a' & 136,5 & & $\mathrm{X}$ & $\mathrm{X}$ & $\mathrm{X}$ & $\mathrm{X}$ & $\mathrm{X}$ & \\
\hline NUP1338a & 137,1 & & $\mathrm{X}$ & $\mathrm{X}$ & $\mathrm{X}$ & $\mathrm{X}$ & $\mathrm{X}$ & \\
\hline MZUSP 20515 & 137,7 & & $\mathrm{X}$ & $\mathrm{X}$ & $\mathrm{X}$ & $\mathrm{X}$ & $\mathrm{X}$ & \\
\hline MNRJ19834d & 138,3 & & $\mathrm{X}$ & $\mathrm{X}$ & $\mathrm{X}$ & $\mathrm{X}$ & $\mathrm{X}$ & \\
\hline
\end{tabular}




\begin{tabular}{|l|l|l|l|l|l|l|l|l|}
\hline NUP1128c & 138,7 & & $\mathrm{X}$ & $\mathrm{X}$ & $\mathrm{X}$ & $\mathrm{X}$ & & \\
\hline MUSM25807 & 138,8 & & $\mathrm{X}$ & $\mathrm{X}$ & $\mathrm{X}$ & $\mathrm{X}$ & $\mathrm{X}$ & \\
\hline MZUSP 10439 & 138,8 & & $\mathrm{X}$ & $\mathrm{X}$ & $\mathrm{X}$ & $\mathrm{X}$ & $\mathrm{X}$ & \\
\hline MZUSP 10533d & 138,9 & & $\mathrm{X}$ & $\mathrm{X}$ & $\mathrm{X}$ & $\mathrm{X}$ & $\mathrm{X}$ & \\
\hline MZUSP 10443c & 139,1 & & $\mathrm{X}$ & $\mathrm{X}$ & $\mathrm{X}$ & $\mathrm{X}$ & $\mathrm{X}$ & \\
\hline MZUSP 10533c & 140,1 & & $\mathrm{X}$ & $\mathrm{X}$ & $\mathrm{X}$ & $\mathrm{X}$ & $\mathrm{X}$ & \\
\hline NUP1128d & 140,3 & & $\mathrm{X}$ & $\mathrm{X}$ & $\mathrm{X}$ & $\mathrm{X}$ & & \\
\hline NUP263d & 140,4 & & $\mathrm{X}$ & $\mathrm{X}$ & $\mathrm{X}$ & $\mathrm{X}$ & $\mathrm{X}$ & $\mathrm{X}$ \\
\hline MZUSP 10514a & 142,6 & & & $\mathrm{X}$ & $\mathrm{X}$ & $\mathrm{X}$ & $\mathrm{X}$ & \\
\hline MZUSP 25689d & 143,7 & & $\mathrm{X}$ & $\mathrm{X}$ & $\mathrm{X}$ & $\mathrm{X}$ & $\mathrm{X}$ & $\mathrm{X}$ \\
\hline MZUSP 2039c & 144,5 & & $\mathrm{X}$ & $\mathrm{X}$ & $\mathrm{X}$ & $\mathrm{X}$ & $\mathrm{X}$ & \\
\hline MZUSP 10533b & 144,5 & & $\mathrm{X}$ & $\mathrm{X}$ & $\mathrm{X}$ & $\mathrm{X}$ & $\mathrm{X}$ & \\
\hline MZUSP 25689c & 144,7 & & $\mathrm{X}$ & $\mathrm{X}$ & $\mathrm{X}$ & $\mathrm{X}$ & $\mathrm{X}$ & \\
\hline MZUSP 38869b & 145,2 & & $\mathrm{X}$ & $\mathrm{X}$ & $\mathrm{X}$ & $\mathrm{X}$ & & \\
\hline MUSM32516 & 145,5 & & $\mathrm{X}$ & $\mathrm{X}$ & $\mathrm{X}$ & $\mathrm{X}$ & & \\
\hline MZUSP 38869a & 145,6 & & $\mathrm{X}$ & $\mathrm{X}$ & $\mathrm{X}$ & $\mathrm{X}$ & $\mathrm{X}$ & \\
\hline NUP9275 & 146,4 & & $\mathrm{X}$ & $\mathrm{X}$ & $\mathrm{X}$ & $\mathrm{X}$ & $\mathrm{X}$ & \\
\hline MZUSP 110473 & 148,2 & & $\mathrm{X}$ & $\mathrm{X}$ & $\mathrm{X}$ & $\mathrm{X}$ & $\mathrm{X}$ & $\mathrm{X}$ \\
\hline MZUSP 10514e & 148,3 & & & & $\mathrm{X}$ & $\mathrm{X}$ & & \\
\hline MZUSP 20485b & 148,3 & & $\mathrm{X}$ & $\mathrm{X}$ & $\mathrm{X}$ & $\mathrm{X}$ & $\mathrm{X}$ & \\
\hline MZUSP 10528b & 148,5 & & $\mathrm{X}$ & $\mathrm{X}$ & $\mathrm{X}$ & & & \\
\hline MZUSP 62841c & 148,9 & & & & & $\mathrm{X}$ & & \\
\hline NUP1199a & 149,0 & & $\mathrm{X}$ & $\mathrm{X}$ & $\mathrm{X}$ & $\mathrm{X}$ & $\mathrm{X}$ & $\mathrm{X}$ \\
\hline NUP11357 & 149,1 & & $\mathrm{X}$ & $\mathrm{X}$ & $\mathrm{X}$ & $\mathrm{X}$ & $\mathrm{X}$ & \\
\hline NUP3809 & 151,5 & & $\mathrm{X}$ & $\mathrm{X}$ & $\mathrm{X}$ & $\mathrm{X}$ & $\mathrm{X}$ & \\
\hline MZUSP 10514d & 153,4 & & & & & $\mathrm{X}$ & & \\
\hline MZUSP 10514c & 155,2 & & & & & $\mathrm{X}$ & & \\
\hline MZUSP 1660 & 155,2 & & $\mathrm{X}$ & $\mathrm{X}$ & $\mathrm{X}$ & $\mathrm{X}$ & $\mathrm{X}$ & \\
\hline
\end{tabular}




\begin{tabular}{|l|l|l|l|l|l|l|l|l|}
\hline MZUSP 75426 & 155,4 & & $\mathrm{X}$ & $\mathrm{X}$ & $\mathrm{X}$ & $\mathrm{X}$ & $\mathrm{X}$ & \\
\hline MZUSP 10514b & 156,6 & & & $\mathrm{X}$ & $\mathrm{X}$ & $\mathrm{X}$ & & \\
\hline MZUSP 49841 & 157,3 & & $\mathrm{X}$ & $\mathrm{X}$ & $\mathrm{X}$ & $\mathrm{X}$ & & \\
\hline MZUSP 62841 $^{\mathrm{a}}$ & 180,8 & & & & & $\mathrm{X}$ & & \\
\hline
\end{tabular}


Tabela 18. Dados morfométricos dos exemplares machos maduros e fêmeas e machos imaturos de Galeocharax gulo. Comprimento padrão (CP) em milímetros. Medidas do corpo foram expressas em porcentagem do CP e medidas da cabeça em porcentagem do comprimento da cabeça (CC).

Galeocharax gulo

\begin{tabular}{|c|c|c|c|c|c|c|c|c|}
\hline & \multicolumn{4}{|c|}{ Machos maduros } & \multicolumn{4}{|c|}{ Fêmeas e machos imaturos } \\
\hline & $\mathrm{N}$ & Amplitude & Média & DP & $\mathrm{N}$ & Amplitude & Média & DP \\
\hline Comprimento padrão & 80 & $98,8-157,3$ & & & 192 & $98,9-157,1$ & & \\
\hline \multicolumn{9}{|l|}{ Porcentagem do CP } \\
\hline Comprimento da cabeça & 71 & $25,5-30,8$ & 27,5 & 0,9 & 184 & $26,2-30,3$ & 28,2 & 0,8 \\
\hline Comprimento da cabeça II & 78 & $26,0-31,5$ & 28,5 & 0,9 & 192 & $27,0-31,7$ & 29,3 & 0,8 \\
\hline Altura do corpo & 58 & $25,5-33,3$ & 28,7 & 1,7 & 155 & $25,2-32,0$ & 28,9 & 1,5 \\
\hline Comprimento da dorsal & 59 & $20,4-26,6$ & 23,7 & 1,3 & 137 & $20,6-27,2$ & 24,3 & 1,2 \\
\hline Comprimento da base da dorsal & 79 & $10,5-13,2$ & 11,8 & 0,5 & 192 & $10,5-13,4$ & 12,1 & 0,6 \\
\hline Comprimento da peitoral & 76 & $14,6-19,1$ & 16,8 & 0,8 & 180 & $14,2-18,8$ & 16,5 & 0,7 \\
\hline Comprimento da pélvica & 72 & $10,7-13,3$ & 12,1 & 0,5 & 177 & $9,7-13,8$ & 12,2 & 0,6 \\
\hline Comprimento da anal & 56 & $11,2-15,2$ & 13,1 & 0,8 & 137 & $11,2-15,5$ & 13,5 & 0,9 \\
\hline Comprimento da base da anal & 78 & $32,9-41,0$ & 36,5 & 1,4 & 191 & $32,1-41,2$ & 36,3 & 1,6 \\
\hline Distância pré-peitoral & 79 & $27,6-32,9$ & 29,6 & 1,0 & 191 & $27,2-36,1$ & 30,3 & 1,2 \\
\hline Distância pré-pélvica & 62 & $40,5-45,9$ & 43,0 & 1,2 & 161 & $40,3-48,5$ & 43,8 & 1,2 \\
\hline Distância pré-dorsal & 80 & $47,5-51,7$ & 49,8 & 0,9 & 191 & $48,0-53,9$ & 50,4 & 1,0 \\
\hline Distância pré-anal & 79 & $54,7-62,5$ & 58,1 & 1,4 & 187 & $54,7-63,0$ & 58,4 & 1,5 \\
\hline Altura do pedúnculo caudal & 75 & $7,1-9,0$ & 8,1 & 0,4 & 181 & $7,1-9,0$ & 8,1 & 0,3 \\
\hline Comprimento do pedúnculo caudal & 75 & $8,4-11,6$ & 10,1 & 0,6 & 185 & $7,7-12,3$ & 9,8 & 0,7 \\
\hline \multicolumn{9}{|l|}{ Porcentagem do CC } \\
\hline Comprimento do focinho & 79 & $30,3-35,2$ & 32,3 & 0,9 & 192 & $30,1-36,1$ & 32,7 & 1,2 \\
\hline Diâmetro orbital & 79 & $24,5-32,8$ & 28,5 & 1,9 & 192 & $24,5-33,5$ & 28,8 & 1,8 \\
\hline Distância interorbital & 79 & $20,1-29,4$ & 23,3 & 2,1 & 188 & $18,5-28,7$ & 23,6 & 2,1 \\
\hline Comprimento da maxila superior & 78 & $64,1-71,4$ & 67,1 & 1,4 & 192 & $64,5-71,8$ & 68,1 & 1,4 \\
\hline
\end{tabular}


Tabela 19. Frequência de distribuição do número de escamas acima da linha lateral em exemplares de Galeocharax gulo, como definido no presente estudo. Grupamentos formados baseando-se na localidade de ocorrência.

\begin{tabular}{lccccccc}
\hline & $\mathbf{1 4}$ & $\mathbf{1 5}$ & $\mathbf{1 6}$ & $\mathbf{1 7}$ & $\mathbf{1 8}$ & $\mathbf{1 9}$ & Total \\
\hline Alto Paraná & 10 & 94 & 55 & 3 & & & 162 \\
Amazonas & & & 17 & 43 & 18 & 2 & 80 \\
Orinoco & & & 2 & 24 & 6 & 1 & 33 \\
Tocantins & 2 & 36 & 66 & 13 & & & 117 \\
\hline
\end{tabular}

Tabela 20. Frequência de distribuição do número de escamas abaixo da linha lateral na vertical da origem da nadadeira pélvica em exemplares de Galeocharax gulo, como definido no presente estudo. Grupamentos formados baseando-se na localidade de ocorrência.

\begin{tabular}{lccccccc}
\hline & $\mathbf{1 1}$ & $\mathbf{1 2}$ & $\mathbf{1 3}$ & $\mathbf{1 4}$ & $\mathbf{1 5}$ & $\mathbf{1 6}$ & Total \\
\hline Alto Paraná & 5 & 79 & 73 & 8 & & & 165 \\
Amazonas & & & 7 & 34 & 37 & 7 & 85 \\
Orinoco & & & 18 & 12 & 7 & & 37 \\
Tocantins & 5 & 58 & 59 & & & & 122 \\
\hline
\end{tabular}

Tabela 21. Frequência de distribuição do número de escamas abaixo da linha lateral na vertical da origem da nadadeira anal em exemplares de Galeocharax gulo, como definido no presente estudo. Grupamentos formados baseando-se na localidade de ocorrência.

\begin{tabular}{lcccccc}
\hline & $\mathbf{1 4}$ & $\mathbf{1 5}$ & $\mathbf{1 6}$ & $\mathbf{1 7}$ & $\mathbf{1 8}$ & Total \\
\hline Alto Paraná & 50 & 83 & 27 & 2 & & 162 \\
Amazonas & & 14 & 30 & 18 & 11 & 73 \\
Orinoco & & 4 & 20 & 9 & & 33 \\
Tocantins & 55 & 54 & 20 & & & 129 \\
\hline
\end{tabular}


Tabela 22. Frequência de distribuição do número de dentes no maxilar em exemplares de Galeocharax gulo, como definido no presente estudo. Grupamentos formados baseando-se na localidade de ocorrência.

\begin{tabular}{lcccccccccccccccccccccc}
\hline & $\mathbf{3 5}$ & $\mathbf{3 6}$ & $\mathbf{3 7}$ & $\mathbf{3 8}$ & $\mathbf{3 9}$ & $\mathbf{4 0}$ & $\mathbf{4 1}$ & $\mathbf{4 2}$ & $\mathbf{4 3}$ & $\mathbf{4 4}$ & $\mathbf{4 5}$ & $\mathbf{4 6}$ & $\mathbf{4 7}$ & $\mathbf{4 8}$ & $\mathbf{4 9}$ & $\mathbf{5 0}$ & $\mathbf{5 1}$ & $\mathbf{5 2}$ & $\mathbf{5 3}$ & $\mathbf{5 4}$ & $\mathbf{5 5}$ & Total \\
\hline Alto Paraná & & & & & & 5 & 7 & 12 & 15 & 22 & 21 & 27 & 23 & 17 & 12 & 10 & 16 & 5 & 1 & 2 & & 195 \\
Amazonas & 3 & 3 & 5 & 8 & 8 & 7 & 19 & 13 & 9 & 10 & 4 & 5 & & & & & & & & & & 94 \\
Orinoco & & 1 & 1 & & & 2 & 2 & 5 & 2 & 9 & 9 & 4 & 3 & & & & & & & & & 38 \\
Tocantins & & & & & & & & 4 & 3 & 9 & 16 & 16 & 14 & 16 & 19 & 6 & 9 & 7 & 8 & 5 & 1 & 133 \\
\hline
\end{tabular}

Tabela 23. Frequência de distribuição do número de raios ramificados na nadadeira anal em exemplares de Galeocharax gulo, como definido no presente estudo. Grupamentos formados baseando-se na localidade de ocorrência.

\begin{tabular}{lccccccccccccccc}
\hline & $\mathbf{3 3}$ & $\mathbf{3 4}$ & $\mathbf{3 5}$ & $\mathbf{3 6}$ & $\mathbf{3 7}$ & $\mathbf{3 8}$ & $\mathbf{3 9}$ & $\mathbf{4 0}$ & $\mathbf{4 1}$ & $\mathbf{4 2}$ & $\mathbf{4 3}$ & $\mathbf{4 4}$ & $\mathbf{4 5}$ & $\mathbf{4 6}$ & Total \\
\hline Alto Paraná & & & 2 & 3 & 12 & 24 & 54 & 47 & 34 & 11 & 5 & & & & 192 \\
Amazonas & & & & & 2 & 2 & 10 & 14 & 29 & 19 & 6 & 2 & & 1 & 85 \\
Orinoco & & & & & & & 2 & 2 & 13 & 8 & 9 & 1 & 1 & & 36 \\
Tocantins & 2 & 5 & 19 & 28 & 50 & 16 & 9 & & & & & & & 129 \\
\hline
\end{tabular}

Tabela 24. Frequência de distribuição do número total de vértebras em exemplares de Galeocharax gulo, como definido no presente estudo. Grupamentos formados baseando-se na localidade de ocorrência.

\begin{tabular}{lccccc}
\hline & 39 & $\mathbf{4 0}$ & $\mathbf{4 1}$ & $\mathbf{4 2}$ & Total \\
\hline Alto Paraná & & 1 & 48 & 4 & 53 \\
Amazonas & & & 18 & 6 & 24 \\
Orinoco & & 2 & 9 & 1 & 12 \\
Tocantins & 2 & 29 & 4 & & 35 \\
\hline
\end{tabular}


Tabela 25. Frequência de distribuição do número de vértebras pré-caudais em exemplares de Galeocharax gulo, como definido no presente estudo. Grupamentos formados baseando-se na localidade de ocorrência.

\begin{tabular}{lccc}
\hline & $\mathbf{1 6}$ & $\mathbf{1 7}$ & Total \\
\hline Alto Paraná & 20 & 33 & 53 \\
Amazonas & 24 & & 24 \\
Orinoco & 12 & & 12 \\
Tocantins & 35 & & 35 \\
\hline
\end{tabular}


Tabela 26. Dados morfométricos dos exemplares de Galeocharax gulo das bacias do rio Orinoco e do rio Tocantins. Comprimento padrão (CP) em milímetros. Medidas do corpo foram expressas em porcentagem do CP e medidas da cabeça em porcentagem do comprimento da cabeça (CC)

Galeocharax gulo

\begin{tabular}{|c|c|c|c|c|c|c|c|c|}
\hline & \multicolumn{4}{|c|}{ Orinoco } & \multicolumn{4}{|c|}{ Tocantins } \\
\hline & $\mathrm{N}$ & Amplitude & Média & DP & $\mathrm{N}$ & Amplitude & Média & DP \\
\hline Comprimento padrão & 41 & $29,7-151,3$ & & & 135 & $44,1-152,2$ & & \\
\hline \multicolumn{9}{|l|}{ Porcentagem do CP } \\
\hline Comprimento da cabeça & 40 & $25,8-29,4$ & 27,7 & 0,9 & 131 & $27,2-31,3$ & 29,1 & 0,7 \\
\hline Comprimento da cabeça II & 41 & $27,0-31,1$ & 28,8 & 1,1 & 134 & $27,8-32,5$ & 30,2 & 0,8 \\
\hline Altura do corpo & 32 & $26,6-31,1$ & 29,5 & 1,1 & 104 & $25,1-31,6$ & 28,4 & 1,3 \\
\hline Comprimento da dorsal & 29 & $22,4-29,4$ & 25,7 & 1,5 & 110 & $20,6-27,3$ & 24,2 & 1,2 \\
\hline Comprimento da base da dorsal & 41 & $11,0-13,3$ & 12,1 & 0,5 & 135 & $10,8-14,3$ & 12,2 & 0,5 \\
\hline Comprimento da peitoral & 38 & $14,5-18,5$ & 16,8 & 0,8 & 126 & $14,7-19,1$ & 16,7 & 0,8 \\
\hline Comprimento da pélvica & 37 & $10,8-14,4$ & 12,5 & 0,7 & 118 & $9,8-13,9$ & 12,1 & 0,6 \\
\hline Comprimento da anal & 27 & $11,5-19,5$ & 13,8 & 1,8 & 98 & $11,6-17,4$ & 14,1 & 1,1 \\
\hline Comprimento da base da anal & 41 & $36,7-41,2$ & 38,9 & 1,0 & 132 & $32,1-38,0$ & 35,4 & 1,0 \\
\hline Distância pré-peitoral & 40 & $27,3-35,0$ & 29,5 & 1,5 & 133 & $28,4-35,9$ & 31,2 & 1,3 \\
\hline Distância pré-pélvica & 34 & $40,3-45,9$ & 42,6 & 1,1 & 110 & $41,5-48,5$ & 44,8 & 1,3 \\
\hline Distância pré-dorsal & 41 & $48,2-52,2$ & 50,1 & 0,8 & 135 & $48,1-53,5$ & 50,6 & 0,9 \\
\hline Distância pré-anal & 40 & $54,7-59,4$ & 56,9 & 1,2 & 135 & $55,9-63,0$ & 59,2 & 1,4 \\
\hline Altura do pedúnculo caudal & 41 & $6,9-8,4$ & 7,7 & 0,3 & 132 & $6,9-9,0$ & 7,8 & 0,3 \\
\hline Comprimento do pedúnculo caudal & 38 & $8,0-10,9$ & 9,2 & 0,6 & 130 & $8,5-11,3$ & 10,1 & 0,5 \\
\hline \multicolumn{9}{|l|}{ Porcentagem do CC } \\
\hline Comprimento do focinho & 42 & $30,2-34,9$ & 31,9 & 1,1 & 135 & $28,9-36,1$ & 32,4 & 1,3 \\
\hline Diâmetro orbital & 42 & $25,4-32,4$ & 29,1 & 1,4 & 135 & $27,7-36,2$ & 31,2 & 1,7 \\
\hline Distância interorbital & 41 & $19,7-27,7$ & 24,1 & 1,6 & 135 & $19,0-26,0$ & 22,3 & 1,4 \\
\hline Comprimento da maxila superior & 42 & $63,8-70,1$ & 67,3 & 1,3 & 135 & $64,5-71,8$ & 68,3 & 1,4 \\
\hline
\end{tabular}


Tabela 27. Dados morfométricos dos exemplares de Galeocharax gulo das bacias do rio Amazonas e do alto rio Paraná. Comprimento padrão (CP) em milímetros. Medidas do corpo foram expressas em porcentagem do CP e medidas da cabeça em porcentagem do comprimento da cabeça (CC)

Galeocharax gulo

\begin{tabular}{|c|c|c|c|c|c|c|c|c|}
\hline & & \multicolumn{4}{|c|}{ Alto Paraná } \\
\hline & $\mathrm{N}$ & Amplitude & Média & DP & $\mathrm{N}$ & Amplitude & Média & DP \\
\hline Comprimento padrão & 97 & $28,3-176,92$ & & & 198 & $53,8-245,2$ & & \\
\hline \multicolumn{9}{|l|}{ Porcentagem do CP } \\
\hline Comprimento da cabeça & 85 & $25,5-31,9$ & 28,4 & 1,0 & 187 & $26,0-30,0$ & 27,8 & 0,7 \\
\hline Comprimento da cabeça II & 95 & $26,7-32,9$ & 29,3 & 1,1 & 196 & $26,0-31,2$ & 29,1 & 0,8 \\
\hline Altura do corpo & 73 & $25,5-33,3$ & 29,8 & 1,6 & 136 & $25,2-33,2$ & 28,4 & 1,7 \\
\hline Comprimento da dorsal & 70 & $22,7-28,6$ & 25,6 & 1,1 & 128 & $20,2-27,2$ & 23,6 & 1,3 \\
\hline Comprimento da base da dorsal & 97 & $10,5-13,4$ & 12,0 & 0,5 & 197 & $10,0-13,8$ & 11,8 & 0,6 \\
\hline Comprimento da peitoral & 93 & $13,2-18,8$ & 16,7 & 0,8 & 185 & $14,2-18,0$ & 16,1 & 0,5 \\
\hline Comprimento da pélvica & 94 & $11,3-14,8$ & 12,6 & 0,6 & 186 & $9,7-13,2$ & 12,0 & 0,5 \\
\hline Comprimento da anal & 60 & $11,2-16,1$ & 13,4 & 1,2 & 149 & $11,1-15,9$ & 13,4 & 0,9 \\
\hline Comprimento da base da anal & 92 & $33,5-40,4$ & 37,5 & 1,1 & 194 & $31,5-39,0$ & 35,6 & 1,2 \\
\hline Distância pré-peitoral & 97 & $27,7-34,8$ & 30,4 & 1,3 & 194 & $26,9-36,1$ & 30,1 & 1,1 \\
\hline Distância pré-pélvica & 74 & $41,7-47,0$ & 44,0 & 1,1 & 142 & $40,5-47,5$ & 43,5 & 1,2 \\
\hline Distância pré-dorsal & 96 & $47,8-54,2$ & 50,6 & 1,0 & 193 & $47,5-53,9$ & 50,1 & 1,2 \\
\hline Distância pré-anal & 96 & $52,5-61,8$ & 57,7 & 1,4 & 187 & $54,7-63,8$ & 58,9 & 1,7 \\
\hline Altura do pedúnculo caudal & 86 & $6,6-9,3$ & 8,3 & 0,4 & 179 & $6,9-9,3$ & 8,0 & 0,4 \\
\hline Comprimento do pedúnculo caudal & 84 & $7,7-10,8$ & 9,5 & 0,6 & 190 & $7,7-12,3$ & 10,1 & 0,6 \\
\hline \multicolumn{9}{|l|}{ Porcentagem do CC } \\
\hline Comprimento do focinho & 96 & $29,9-35,9$ & 32,7 & 1,2 & 198 & $30,0-38,1$ & 32,9 & 1,6 \\
\hline Diâmetro orbital & 96 & $23,5-32,3$ & 27,4 & 1,8 & 198 & $22,2-33,1$ & 27,8 & 2,3 \\
\hline Distância interorbital & 94 & $18,0-29,4$ & 25,7 & 1,9 & 196 & $18,5-25,3$ & 22,3 & 1,2 \\
\hline Comprimento da maxila superior & 96 & $64,1-71,4$ & 68,3 & 1,2 & 196 & $64,2-73,0$ & 67,8 & 1,7 \\
\hline
\end{tabular}


Tabela 28. Distribuição de ganchos nos raios da nadadeira anal de exemplares de Galeocharax goeldii. As células marcadas em amarelo representam a presença de ganchos. Ult = raio não ramificado mais posterior, $\mathrm{CP}=$ Comprimento padrão.

\begin{tabular}{|c|c|c|c|c|c|c|c|c|c|c|c|c|c|c|c|c|c|c|c|c|c|c|c|c|c|}
\hline Lote & $\mathrm{CP}$ & Ult & 1 & 2 & 3 & 4 & 5 & 6 & 7 & 8 & \begin{tabular}{|l|}
9 \\
\end{tabular} & 10 & 11 & 12 & 13 & 14 & 15 & 16 & 17 & 18 & 19 & 20 & 21 & 22 & 23 \\
\hline UFRO-I13077b & 96,9 & $\mathrm{X}$ & $\mathrm{X}$ & $\bar{X}$ & $\mathrm{X}$ & $\mathrm{X}$ & $\mathrm{X}$ & $\mathrm{X}$ & $\mathrm{X}$ & $\mathrm{X}$ & $\mathrm{X}$ & $\mathrm{X}$ & $\bar{X}$ & $\bar{X}$ & $\mathrm{X}$ & $\mathrm{X}$ & $\bar{X}$ & $\mathrm{X}$ & & & & & & & \\
\hline UFRO-I13090b & 101,6 & & $\mathrm{X}$ & $\mathrm{X}$ & $\mathrm{X}$ & $\mathrm{X}$ & $\mathrm{X}$ & $\mathrm{X}$ & $\mathrm{X}$ & $X$ & $\mathrm{X}$ & $X$ & $\mathrm{X}$ & $X$ & $\mathrm{X}$ & $\mathrm{X}$ & $\mathrm{X}$ & & & & & & & & \\
\hline UFRO-I13090a & 105,7 & & $\mathrm{X}$ & $\mathrm{X}$ & $\mathrm{X}$ & $\mathrm{X}$ & $\mathrm{X}$ & $\mathrm{X}$ & $X$ & $X$ & $\mathrm{X}$ & $X$ & $X$ & $X$ & & & & & & & & & & & \\
\hline MUSM131 & 106,9 & $X$ & $\mathrm{X}$ & $\mathrm{X}$ & $\mathrm{X}$ & $\mathrm{X}$ & $X$ & $\mathrm{X}$ & $X$ & $\mathrm{X}$ & $\mathrm{X}$ & $\mathrm{X}$ & $\mathrm{X}$ & $\mathrm{X}$ & $X$ & $X$ & $X$ & & & $X$ & & & & & \\
\hline MZSUSP92434 & 108,0 & & $\mathrm{X}$ & $\mathrm{X}$ & $\mathrm{X}$ & $\mathrm{X}$ & $\mathrm{X}$ & $\mathrm{X}$ & $\mathrm{X}$ & $\mathrm{X}$ & $\mathrm{X}$ & $\mathrm{X}$ & $\mathrm{X}$ & $X$ & $X$ & $X$ & $X$ & $X$ & $X$ & $\mathrm{X}$ & $\mathrm{X}$ & $X$ & & & \\
\hline INPA24598 & 109,7 & $X$ & $\mathrm{X}$ & $\mathrm{X}$ & $\mathrm{X}$ & $\mathrm{X}$ & $\mathrm{X}$ & $\mathrm{X}$ & $\mathrm{X}$ & $\mathrm{X}$ & $\mathrm{X}$ & $\mathrm{X}$ & $\mathrm{X}$ & $X$ & $\mathrm{X}$ & $\mathrm{X}$ & $\mathrm{X}$ & $X$ & & & & & & & \\
\hline UFRO-I19051 & 120,1 & & $\mathrm{X}$ & $\mathrm{X}$ & $\mathrm{X}$ & $\mathrm{X}$ & $\mathrm{X}$ & $\mathrm{X}$ & $\mathrm{X}$ & $X$ & $\mathrm{X}$ & $\mathrm{X}$ & $X$ & & & & & & & & & & & & \\
\hline UFRO-I9705 & 120,8 & $X$ & $\mathrm{X}$ & $\mathrm{X}$ & $\mathrm{X}$ & $\mathrm{X}$ & $\mathrm{X}$ & $\mathrm{X}$ & $\mathrm{X}$ & $X$ & $\mathrm{X}$ & $\mathrm{X}$ & $X$ & $X$ & $\mathrm{X}$ & $X$ & & & & & & & & & \\
\hline UFRO-I6846 & 123,2 & & $\mathrm{X}$ & $\mathrm{X}$ & $\mathrm{X}$ & $\mathrm{X}$ & $\mathrm{X}$ & $\mathrm{X}$ & $\mathrm{X}$ & $X$ & $\mathrm{X}$ & $\mathrm{X}$ & $X$ & $X$ & $\mathrm{X}$ & & & & & & & & & & \\
\hline MUSM9564 & 125,4 & $X$ & $\mathrm{X}$ & $\mathrm{X}$ & $\mathrm{X}$ & $\mathrm{X}$ & $\mathrm{X}$ & $\mathrm{X}$ & $\mathrm{X}$ & $\mathrm{X}$ & $\mathrm{X}$ & $\mathrm{X}$ & $X$ & $X$ & $X$ & $\mathrm{X}$ & $X$ & $X$ & X & $X$ & $X$ & & & & \\
\hline USMN305367b' & 126,1 & & $\mathrm{X}$ & $\mathrm{X}$ & $\mathrm{X}$ & $\mathrm{X}$ & $\mathrm{X}$ & $\mathrm{X}$ & $\mathrm{X}$ & $\mathrm{X}$ & $\mathrm{X}$ & $\mathrm{X}$ & $X$ & $X$ & $X$ & $\mathrm{X}$ & $\mathrm{X}$ & $\mathrm{X}$ & & & & & & & \\
\hline USMN305367a' & 129,6 & $\mathrm{X}$ & $\mathrm{X}$ & $\mathrm{X}$ & $\mathrm{X}$ & $\mathrm{X}$ & $\mathrm{X}$ & $\mathrm{X}$ & $\mathrm{X}$ & $\mathrm{X}$ & $\mathrm{X}$ & $\mathrm{X}$ & $\mathrm{X}$ & $X$ & $\mathrm{X}$ & $X$ & $X$ & & & & & & & & \\
\hline USMN305367e & 141,0 & $\mathrm{X}$ & $\mathrm{X}$ & $\mathrm{X}$ & $\mathrm{X}$ & $\mathrm{X}$ & $\mathrm{X}$ & $\mathrm{X}$ & $\mathrm{X}$ & $X$ & $\mathrm{X}$ & $\mathrm{X}$ & $X$ & $X$ & $\mathrm{X}$ & $X$ & $\mathrm{X}$ & $X$ & & & & & & & \\
\hline USMN305367d' & 141,1 & & $\mathrm{X}$ & $\mathrm{X}$ & $\mathrm{X}$ & $\mathrm{X}$ & $\mathrm{X}$ & $\mathrm{X}$ & $\mathrm{X}$ & $\mathrm{X}$ & $\mathrm{X}$ & $\mathrm{X}$ & $X$ & $X$ & $X$ & $\mathrm{X}$ & $X$ & $\mathrm{X}$ & $X$ & $\mathrm{X}$ & $\mathrm{X}$ & $\mathrm{X}$ & $X$ & & \\
\hline MUSM8790 & 143,4 & $X$ & $\mathrm{X}$ & $\mathrm{X}$ & $\mathrm{X}$ & $\mathrm{X}$ & $\mathrm{X}$ & $\mathrm{X}$ & $\mathrm{X}$ & $\mathrm{X}$ & $\mathrm{X}$ & $\mathrm{X}$ & $\mathrm{X}$ & $X$ & $\mathrm{X}$ & $\mathrm{X}$ & $X$ & $\mathrm{X}$ & $\mathrm{X}$ & $\mathrm{X}$ & $\mathrm{X}$ & $\mathrm{X}$ & $X$ & & \\
\hline USMN305367d & 163,8 & $X$ & $\mathrm{X}$ & $\mathrm{X}$ & $\mathrm{X}$ & $\mathrm{X}$ & $\mathrm{X}$ & $\mathrm{X}$ & $\mathrm{X}$ & $X$ & $\mathrm{X}$ & $\mathrm{X}$ & $\mathrm{X}$ & $\mathrm{X}$ & $\mathrm{X}$ & $X$ & $\mathrm{X}$ & $X$ & $X$ & $\mathrm{X}$ & $\mathrm{X}$ & $\mathrm{X}$ & $\mathrm{X}$ & $X$ & $X$ \\
\hline USMN305367c' & 165,7 & & $\mathrm{X}$ & $\mathrm{X}$ & $\mathrm{X}$ & $\mathrm{X}$ & $\mathrm{X}$ & $\mathrm{X}$ & $\mathrm{X}$ & $\mathrm{X}$ & $\mathrm{X}$ & $\mathrm{X}$ & $\mathrm{X}$ & $\mathrm{X}$ & $\mathrm{X}$ & $\mathrm{X}$ & \begin{tabular}{|l|l}
$X$ & \\
\end{tabular} & $\mathrm{X}$ & $X$ & & & & & & \\
\hline
\end{tabular}


Tabela 29. Distribuição de ganchos nos raios da nadadeira pélvica de exemplares de Galeocharax goeldii. As células marcadas em amarelo representam a presença de ganchos. Ult = raio não ramificado mais posterior, $\mathrm{CP}=$ Comprimento padrão.

\begin{tabular}{|l|r|r|c|c|c|c|c|}
\hline Lote & \multicolumn{1}{l|}{ CP } & Ult & 1 & 2 & 3 & 4 & 5 \\
\hline UFRO-I13077b & 96,9 & & $\mathrm{X}$ & $\mathrm{X}$ & $\mathrm{X}$ & $\mathrm{X}$ & $\mathrm{X}$ \\
\hline UFRO-I13090b & 101,6 & & $\mathrm{X}$ & $\mathrm{X}$ & $\mathrm{X}$ & $\mathrm{X}$ & \\
\hline UFRO-I13090a & 105,7 & & $\mathrm{X}$ & $\mathrm{X}$ & $\mathrm{X}$ & $\mathrm{X}$ & $\mathrm{X}$ \\
\hline MUSM131 & 106,9 & & $\mathrm{X}$ & $\mathrm{X}$ & $\mathrm{X}$ & $\mathrm{X}$ & \\
\hline MZUSP92434 & 108,0 & & $\mathrm{X}$ & $\mathrm{X}$ & $\mathrm{X}$ & $\mathrm{X}$ & $\mathrm{X}$ \\
\hline INPA24598 & 109,7 & & $\mathrm{X}$ & $\mathrm{X}$ & $\mathrm{X}$ & $\mathrm{X}$ & $\mathrm{X}$ \\
\hline UFRO-I19051 & 120,1 & & $\mathrm{X}$ & $\mathrm{X}$ & $\mathrm{X}$ & $\mathrm{X}$ & \\
\hline UFRO-I9705 & 120,8 & & $\mathrm{X}$ & $\mathrm{X}$ & $\mathrm{X}$ & $\mathrm{X}$ & $\mathrm{X}$ \\
\hline UFRO-I6846 & 123,2 & & $\mathrm{X}$ & $\mathrm{X}$ & $\mathrm{X}$ & $\mathrm{X}$ & \\
\hline MUSM9564 & 125,4 & & $\mathrm{X}$ & $\mathrm{X}$ & $\mathrm{X}$ & $\mathrm{X}$ & $\mathrm{X}$ \\
\hline USMN305367b' & 126,1 & & $\mathrm{X}$ & $\mathrm{X}$ & $\mathrm{X}$ & $\mathrm{X}$ & $\mathrm{X}$ \\
\hline USMN305367a' & 129,6 & & $\mathrm{X}$ & $\mathrm{X}$ & $\mathrm{X}$ & $\mathrm{X}$ & $\mathrm{X}$ \\
\hline USMN305367e & 141,0 & & $\mathrm{X}$ & $\mathrm{X}$ & $\mathrm{X}$ & $\mathrm{X}$ & $\mathrm{X}$ \\
\hline USMN305367d' & 141,1 & & $\mathrm{X}$ & $\mathrm{X}$ & $\mathrm{X}$ & $\mathrm{X}$ & $\mathrm{X}$ \\
\hline MUSM8790 & 143,4 & & $\mathrm{X}$ & $\mathrm{X}$ & $\mathrm{X}$ & $\mathrm{X}$ & $\mathrm{X}$ \\
\hline USMN305367d & 163,8 & & $\mathrm{X}$ & $\mathrm{X}$ & $\mathrm{X}$ & $\mathrm{X}$ & \\
\hline
\end{tabular}


Tabela 30. Dados morfométricos dos exemplares machos maduros e fêmeas e machos imaturos de Galeocharax goeldii. Comprimento padrão (CP) em milímetros. Medidas do corpo foram expressas em porcentagem do CP e medidas da cabeça em porcentagem do comprimento da cabeça (CC).

\section{Galeocharax goeldii}

\begin{tabular}{|c|c|c|c|c|c|c|c|c|}
\hline & \multicolumn{4}{|c|}{ Machos maduros } & \multicolumn{4}{|c|}{ Fêmeas e machos imaturos } \\
\hline & $\mathrm{N}$ & Amplitude & Média & DP & $\mathrm{N}$ & Amplitude & Média & DP \\
\hline Comprimento padrão & 16 & $96,9-163,8$ & & & 26 & $97,1-162,9$ & & \\
\hline \multicolumn{9}{|l|}{ Porcentagem do CP } \\
\hline Comprimento da cabeça & 11 & $25,2-27,3$ & 26,8 & 0,6 & 22 & $26,2-29,2$ & 27,6 & 0,6 \\
\hline Comprimento da cabeça II & 14 & $25,9-28,4$ & 27,5 & 0,7 & 26 & $27,2-29,9$ & 28,6 & 0,6 \\
\hline Altura do corpo & 15 & $26,1-30,8$ & 28,9 & 1,2 & 21 & $27,8-32,0$ & 29,9 & 1,1 \\
\hline Comprimento da dorsal & 14 & $23,5-28,2$ & 25,3 & 1,3 & 23 & $22,5-26,7$ & 25,0 & 1,0 \\
\hline Comprimento da base da dorsal & 16 & $11,0-12,4$ & 11,8 & 0,4 & 26 & $10,5-12,8$ & 11,8 & 0,4 \\
\hline Comprimento da peitoral & 16 & $15,7-19,2$ & 17,2 & 0,8 & 26 & $15,3-17,8$ & 16,5 & 0,6 \\
\hline Comprimento da pélvica & 16 & $11,3-12,9$ & 12,3 & 0,4 & 26 & $9,5-14,0$ & 12,4 & 0,8 \\
\hline Comprimento da anal & 12 & $12,1-13,4$ & 12,7 & 0,4 & 22 & $11,2-14,2$ & 12,7 & 0,8 \\
\hline Comprimento da base da anal & 16 & $36,2-41,1$ & 38,0 & 1,4 & 26 & $32,3-39,3$ & 37,4 & 1,5 \\
\hline Distância pré-peitoral & 16 & $26,2-29,6$ & 28,3 & 0,8 & 26 & $27,1-31,9$ & 29,6 & 1,1 \\
\hline Distância pré-pélvica & 16 & $39,5-44,8$ & 42,1 & 1,3 & 23 & $41,1-45,8$ & 43,4 & 1,0 \\
\hline Distância pré-dorsal & 16 & $47,8-50,9$ & 49,6 & 0,9 & 26 & $48,4-51,8$ & 49,9 & 0,8 \\
\hline Distância pré-anal & 16 & $53,5-61,3$ & 57,3 & 2,1 & 25 & $54,5-61,7$ & 57,8 & 1,7 \\
\hline Altura do pedúnculo caudal & 16 & $7,7-8,8$ & 8,3 & 0,3 & 26 & $7,3-8,9$ & 8,2 & 0,4 \\
\hline Comprimento do pedúnculo caudal & 16 & $8,4-10,8$ & 9,6 & 0,7 & 26 & $8,5-11,3$ & 9,8 & 0,7 \\
\hline \multicolumn{9}{|l|}{ Porcentagem do CC } \\
\hline Comprimento do focinho & 14 & $30,8-34,4$ & 32,4 & 1,0 & 26 & $30,6-35,7$ & 33,1 & 1,0 \\
\hline Diâmetro orbital & 14 & $23,3-28,9$ & 26,2 & 1,6 & 26 & $23,5-29,3$ & 25,9 & 1,6 \\
\hline Distância interorbital & 14 & $25,8-27,8$ & 26,5 & 0,7 & 25 & $23,4-29,6$ & 26,3 & 1,5 \\
\hline Comprimento da maxila superior & 14 & $65,1-68,3$ & 66,6 & 0,8 & 26 & $67,0-71,6$ & 69,0 & 1,2 \\
\hline
\end{tabular}


Tabela 31. Dados morfométricos dos exemplares de Galeocharax goeldii das bacias do rio Madeira e do rio Madre de Dios. Comprimento padrão (CP) em milímetros. Medidas do corpo foram expressas em porcentagem do CP e medidas da cabeça em porcentagem do comprimento da cabeça (CC).

\section{Galeocharax goeldii}

\begin{tabular}{|c|c|c|c|c|c|c|c|c|}
\hline & & \multicolumn{4}{|c|}{ Madre de Dios } \\
\hline & $\mathrm{N}$ & Amplitude & Média & DP & $\mathrm{N}$ & Amplitude & Média & DP \\
\hline Comprimento padrão & 54 & $31,5-213,3$ & & & 17 & $98,3-143,4$ & & \\
\hline \multicolumn{9}{|l|}{ Porcentagem do CP } \\
\hline Comprimento da cabeça & 44 & $25,8-34,5$ & 28,3 & 1,6 & 15 & $25,2-28,4$ & 27,5 & 0,7 \\
\hline Comprimento da cabeça II & 51 & $26,3-36,8$ & 29,3 & 1,8 & 17 & $25,9-29,3$ & 28,3 & 0,8 \\
\hline Altura do corpo & 43 & $25,1-32,0$ & 29,0 & 1,6 & 15 & $26,1-31,5$ & 29,2 & 1,5 \\
\hline Comprimento da dorsal & 46 & $22,5-32,2$ & 26,2 & 1,9 & 15 & $23,5-28,2$ & 25,1 & 1,2 \\
\hline Comprimento da base da dorsal & 54 & $10,0-13,0$ & 11,6 & 0,6 & 17 & $11,2-12,8$ & 12,0 & 0,3 \\
\hline Comprimento da peitoral & 51 & $12,8-17,9$ & 16,3 & 1,1 & 17 & $15,3-19,2$ & 16,7 & 0,9 \\
\hline Comprimento da pélvica & 49 & $11,0-15,3$ & 12,9 & 0,8 & 17 & $9,5-13,5$ & 12,2 & 0,8 \\
\hline Comprimento da anal & 46 & $11,1-19,3$ & 14,3 & 2,1 & 15 & $11,9-13,8$ & 12,7 & 0,6 \\
\hline Comprimento da base da anal & 52 & $32,3-41,3$ & 37,5 & 1,6 & 17 & $36,9-39,5$ & 38,1 & 0,7 \\
\hline Distância pré-peitoral & 54 & $26,2-35,8$ & 30,2 & 2,1 & 17 & $27,3-31,9$ & 29,7 & 1,0 \\
\hline Distânci & 48 & $40,7-50,6$ & 43,7 & 2,0 & 15 & $39,5-44,8$ & 43,4 & 1,2 \\
\hline Distância pré-dorsal & 54 & $48,3-58,0$ & 50,6 & 1,4 & 17 & $47,8-51,1$ & 49,5 & 0,8 \\
\hline Distância pré-anal & 53 & $53,2-64,6$ & 57,8 & 2,2 & 17 & $53,5-59,2$ & 56,9 & 1,5 \\
\hline Altura do pedúnculo caudal & 54 & $7,2-9,1$ & 8,3 & 0,4 & 17 & $7,3-8,8$ & 8,1 & 0,4 \\
\hline Comprimento do pedúnculo caudal & 52 & $8,1-11,3$ & 9,7 & 0,7 & 17 & $8,4-11,1$ & 9,5 & 0,6 \\
\hline \multicolumn{9}{|l|}{ Porcentagem do CC } \\
\hline Comprimento do focinho & 51 & $27,7-35,7$ & 32,5 & 1,5 & 17 & $31,3-33,9$ & 32,7 & 0,7 \\
\hline Diâmetro orbital & 51 & $22,3-33,5$ & 27,2 & 2,9 & 17 & $24,6-28,9$ & 26,8 & 1,2 \\
\hline Distância interorbital & 50 & $17,3-30,7$ & 25,1 & 2,8 & 17 & $23,4-28,2$ & 25,8 & 1,1 \\
\hline Comprimento da maxila superior & 51 & $65,1-71,0$ & 67,9 & 1,4 & 17 & $66,4-71,6$ & 68,8 & 1,3 \\
\hline
\end{tabular}


Tabela 32. Frequência de distribuição do número de dentes na fileira posterior do dentário em exemplares de Galeocharax gulo, como definido no presente estudo. Grupamentos formados baseando-se na localidade de ocorrência.

\begin{tabular}{lccccccccccccccc}
\hline & $\mathbf{2 1}$ & $\mathbf{2 2}$ & $\mathbf{2 3}$ & $\mathbf{2 4}$ & $\mathbf{2 5}$ & $\mathbf{2 6}$ & $\mathbf{2 7}$ & $\mathbf{2 8}$ & $\mathbf{2 9}$ & $\mathbf{3 0}$ & $\mathbf{3 1}$ & $\mathbf{3 2}$ & $\mathbf{3 3}$ & $\mathbf{3 4}$ & Total \\
\hline Alto Paraná & 2 & & 2 & 1 & 2 & 2 & 4 & & 2 & 2 & 1 & 1 & 1 & & 20 \\
Amazonas & & & & & 1 & 3 & 4 & 6 & 1 & & & & 2 & & 17 \\
Tocantins & & & & & & 1 & 3 & 3 & 1 & 5 & 3 & 1 & 2 & 1 & 20 \\
\hline
\end{tabular}

Tabela 33. Frequência de distribuição do número de escamas na linha lateral em exemplares de Galeocharax gulo, como definido no presente estudo. Grupamentos formados baseando-se na localidade de ocorrência.

\begin{tabular}{lcccccccccccc}
\hline & $\mathbf{7 7}$ & $\mathbf{7 8}$ & $\mathbf{7 9}$ & $\mathbf{8 0}$ & $\mathbf{8 1}$ & $\mathbf{8 2}$ & $\mathbf{8 3}$ & $\mathbf{8 4}$ & $\mathbf{8 5}$ & $\mathbf{8 6}$ & $\mathbf{8 7}$ & Total \\
\hline Alto Paraná & & & 6 & 18 & 24 & 41 & 37 & 19 & 14 & 10 & 6 & 175 \\
Amazonas & & & & 11 & 11 & 11 & 20 & 18 & 9 & 3 & 2 & 85 \\
Orinoco & & & & 6 & 12 & 7 & 4 & 7 & & & & 36 \\
Tocantins & 3 & 17 & 46 & 37 & 10 & 11 & 2 & 3 & & & & 129 \\
\hline
\end{tabular}

Tabela 34. Frequência de distribuição do número de escamas ao redor do pedúnculo caudal em exemplares de Galeocharax gulo, como definido no presente estudo. Grupamentos formados baseando-se na localidade de ocorrência.

\begin{tabular}{lccccccccc}
\hline & $\mathbf{1 9}$ & $\mathbf{2 0}$ & $\mathbf{2 1}$ & $\mathbf{2 2}$ & $\mathbf{2 3}$ & $\mathbf{2 4}$ & $\mathbf{2 5}$ & $\mathbf{2 6}$ & Total \\
\hline Alto Paraná & 6 & 26 & 22 & 32 & 21 & 4 & & & 111 \\
Amazonas & & 3 & 8 & 16 & 14 & 15 & 10 & 5 & 71 \\
Orinoco & 1 & 3 & 2 & 4 & 8 & 3 & 4 & & 25 \\
Tocantins & & & 15 & 25 & 38 & 19 & & & 97 \\
\hline
\end{tabular}




\section{Apêndice 3: Material examinado}

Lista de material examinado, separado por países. Os estados ou departamentos estão sublinhados. Segue o código da instituição e número do lote, número de indivíduos examinados do lote, amplitude de variação do comprimento padrão em milímetros, localidade de coleta, nome dos coletores e data de coleta. Os lotes que não contavam com as coordenadas geográficas da localidade de coleta tiveram essa informação estimada com base na informação disponível. As siglas das instituições significam: AMNH - American Museum of Natural History, Nova Iorque; ANSP Academy of Natural Sciences of Drexel University, Filadélfia; INPA - Instituto Nacional de Pesquisas Amazônicas, Manaus; MCN - Museu de Ciências Naturais, Fundação Zoobotânica do Rio Grande do Sul, Porto Alegre; MCNG - Museo de Ciencias Naturales de Guanare, Guanare; MCP - Museu de Ciências e Tecnologia, Pontifícia Universidade Católica do Rio Grande do Sul, Porto Alegre; MNRJ - Museu Nacional, Rio de Janeiro; MUSM - Museo de Historia Natural, Universidad Nacional Mayor de San Marcos, Lima; MZUSP - Museu de Zoologia, Universidade de São Paulo; NUP - Núcleo de Pesquisas em Limnologia, Ictiologia e Aquicultura, Universidade Estadual de Maringá, Maringá; UFRO-I - Universidade Federal de Rondônia, Porto Velho; UNT - Universidade Federal do Tocantins, Porto Nacional; USNM - National Museum of Natural History, Smithsonian Institution, Washington D. C.

\section{Galeocharax humeralis}

Brasil:

Mato Grosso:

MZUSP $4413(1,136,5)$ rio Cuiabá, Santo Antonio do Leverger, 1551'48'’S, 5604'36'’W Olson, G, 1965; MZUSP 19887 (3, 132,2 - 152,8), Região do Pantanal, CEPIPAM, 1977; MZUSP 19907 (3, 111,5 - 144,4) Cachoeira das palmeiras, rio Taquari, Coxim, 18³0’00’'S, 5444'60'’W, CEPIPAM, 8/12/1977; MZUSP 19982 (4, 89,5 - 204,8) rio Cuiabá, Volta Grande, Santo Antonio do Leverger, 1551'51'’S, 5604'39'’W Machado, F.A. \& J.B. Silva, 31/03 - 01/04/1980; MZUSP 19984 (5, 1 Di\&Co, 72,2 - 79,5) alagados marginais do rio Cuiabá, Santo Antonio do Leverger, 15'51'54'’S, 5604'37'’W, Machado, F.A., 04/03/1980; MZUSP 27684 (1, 140,4) Volta Grande, rio Cuiabá, 15¹6’24'’S, 56²17'22'’W, Machado, F., 06/07/1979; MZUSP $42755(1,91,6)$ rio Cuiabá, Barão do Melgaço, $16^{\circ} 11^{\prime} 35^{\prime}$ 'S, 55 56 $56^{\prime} 56^{\prime \prime} \mathrm{W}, 4$ 10/05/1977; MZUSP 56752 (1, ) rio Cuiabá, Santo Antonio do Leverger, 1551'51'’S, 5604'36'’W, Silimon, K. \& A.C. de Oliveira, 8-9/03/1999; MZUSP 56758 (1, ) rio 


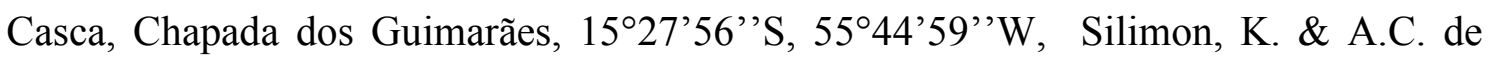
Oliveira, 13/05/1999; MZUSP $78865(1,124,3)$ rio Cachoeirinha, estrada Cáceres/Porto Estrela, Cáceres, $15^{\circ} 48^{\prime} 58^{\prime}$ 'S, 57 $7^{\circ} 9^{\prime} 53^{\prime}$ 'W, Britski, H. A., O. Froehlich \& F. A. Machado, 27/02/2002; MZUSP 89961 (5, 142,2 - 195,4) rio Sepotuba, Cáceres,

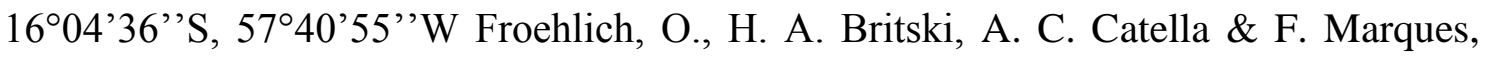
03/2005; MZUSP 90224 (6, 135,7 - 229,9) rio Sepotuba, Cáceres, 1547’33’'S, 57'39'20',W, Britski, H. A., O. Froehlich, A. Catella \& F. Marques, 02/03/2002; MZUSP 90473 (2, 174,4 - 210,5) rio Sepotuba, Cáceres, 1543'53''S, 57³9'53'’W, Britski, H. A., O. Froehlich, A. Catella \& F. Marques, 03-04/03/2002; MZUSP 90680 (4, 137,9 - 170,1) rio Sepotuba, Cáceres, 1604’36’'S, 5740'56’'W Britski, H. A., O. Froehlich, A. Catella \& F. Marques, 03-04/03/2002; MZUSP 90684 (3, 124,6 - 171,5) rio Sepotuba, Cáceres, $15^{\circ} 24^{\prime} 37^{\prime}$ 'S, 5742’20' W, Britski, H. A., O. Froehlich, A. Catella \& F. Marques, 04/03/2002; MNRJ 21678 (1, 90,5) rio Cuiabá, Barão de Melgaço, 16 ${ }^{\circ} 11^{\prime} 36^{\prime \prime}$ S, 5556'54'’W Caramaschi, E.P., 16/01/1978; INPA 2029 (2, 90,5 - 87,7) lago Croara, Barão de Melgaço, 16¹1'38'’S, 5556'54'’W, Eq. Ictiológica INPA, 28/04/1979; NUP 912 (11, 91,8 - 251,8) reservatório Manso, afluente do rio

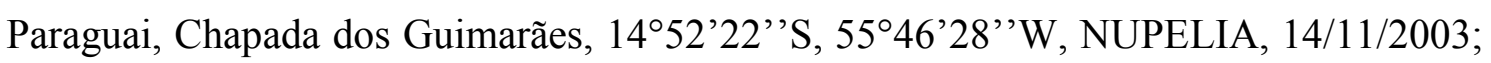
NUP 3464 (10, 87,8 - 224,6) rio Cuiabá (Cb3), afluente do rio Paraguai, Santo Antonio do Leverger, 15 58'26' 'S, 5556'26' 'W, NUPELIA, 25/05/2003; NUP 3541(4, 142,8 169,1) rio Cuiabá (Cb3) afluente do rio Paraguai, Santo Antonio do Leverger, 1558'26'’S, 55 56'26'’W, NUPELIA, 11/12/2001; NUP 4283 (6, 123,9 - 203,6) rio Cuiabá (Cb3), afluente do rio Paraguai, Santo Antonio do Leverger, 1558'26'’S, 5556'26' 'W, NUPELIA, 04/2004; NUP 7927 (1, 248,0) rio Ariranha, afluente do rio Taquari, bacia do rio Paraguai, $17^{\circ} 56^{\prime} 55^{\prime}$ 'S, 5344'19' 'W, NUPELIA, 05/05/2009; NUP $8499(1,162,4)$ rio Ariranha, afluente do rio Taquari, bacia do rio Paraguai, Alto Araguaia, $17^{\circ} 58^{\prime} 42^{\prime}$ 'S, 5344'18' 'W, NUPELIA 05/05/2009; NUP 11343 (2, 139,3 145,8) rio Quilombo (Qu1) afluente do rio Cuiabá, bacia do rio Paraguai, Chapada dos Guimarães, $15^{\circ} 06^{\prime} 05^{\prime}$ 'S, 5540’38' 'W, NUPELIA, 14/01/2004.

Mato Grosso do Sul:

MZUSP $19901(1,204,7)$ rio Paraguai, porto da cidade de Corumbá, 1900'26' 'S, 57³9'05'’W CEPIPAM, 12/10/1977; NUP 1927 (1, 214,8) baia da Medalha, afluente do rio Miranda, bacia do rio Paraguai, Corumbá, 19²4'46' S, 57¹9'55' 'W, Agostinho, A. A., 16-18/09/1993.

Paraná:

MZUSP 19851 (8, 210,4 - 235,1) rio Paraná, Porto Mendes, 25²3’38’'S, 54³1'45' 'W, CETESB, 07-08/1977; NUP 255 (3, 163,7 - 222,3) reservatório de Itaipu, 
bacia do alto rio Paraná, Foz do Iguaçu, 29²5'S, 54³8'W, NUPELIA, 07/198604/1989.

\section{Rio Grande do Sul:}

MZUSP $40967(1,176,6)$ rio Ibicuí, próximo à foz, afluentedo rio Uruguai, Itaqui, 2907'54'’S, 56 33'06' 'W, Reis, R. E., L. A. Bergmann \& P. V. Azevedo, 2021/07/1986; MCP 6949 (1, 127,4) rio Uruguai, entre os rios Salso e Itapitocai, fundos da fazenda da família Trojan, Uruguaiana, 2946'00'’S, 5706'00' 'W, Pena, L. R., 08/1985; MCP $10950(1,159,8)$ rio Ibicuí, próximo à sua foz, drenagem do rio Uruguai, Itaqui, 29²5'00''S, 5645'00' W, Reis, R. E., L. A. Bergmann \& P. V. Azevedo, 21/08/1985; MCP 11751 (6, 218,7 - 163,6) rio Uruguai, Rancho da Amizade, São Borja, 28³8'00''S, 5602'00'’W, Bertoletti, J., C. Lucena, E. Lerner \& P. Azevedo 10/11/1987; MCP 11897 (2, 146.1 - 158,4) rio Uruguai, Uruguaiana, 2946’00’’S, 5706'00'’W, Lucena, C. A., C. Mardini \& Ricardo, 12-16/12/1987; MCP 12392 (1, 198,9) rio Piratini, próximo à balsa de São Nicolau, São Nicolau, 28¹2'00' 'S, 55¹9'00'’W, Lerner, E., P. Azevedo, L. Bergmann \& E. Pereira, 10/04/1988; MCP

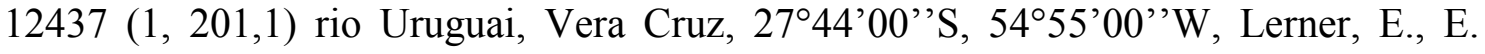
Pereira, A. Bergmann, P. Azevedo \& R. Rossi, 09/04/1988; MCP13191 (1, 126,8) foz do rio Ijuí-Mirim, afluente do rio Ihuí, drenagem do rio Uruguai, Pirapó, 2803'00'`S, 5511'00'’W, Lucena, C. A., P. V. Azevedo, J. F. Pezzi \& W. Koch, 13-14/03/1989; MCP13217 (1, 130,1) rio Uruguai no porto de Santo Izidro, São Nicolau, 2803'00'’S, 55²4'00'’W, Lucena, C. A., P. V. Azevedo, J. F. Pezzi \& W. Koch, 11-12/03/1989; MCP13283 (2, 126,5 - 138,7) barra do rio Ijuí, Roque Gonzales 2757’00’’S, 55²0’00'’W, Pereira, E., P. Azevedo, M. Vargas \& J. Pezzi, 24/05/1989; MCP 13298 (4, 127,9 - 204,3) foz do rio Ijuí-Mirim, afluente do rio Ijuí, drenagem do rio Uruguai,

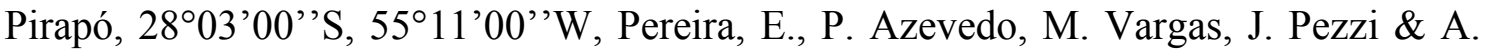
Ramirez, 22-23/05/1989; MCP $13522(1,196,7)$ foz do rio Ijuí-Mirim, afluente do rio

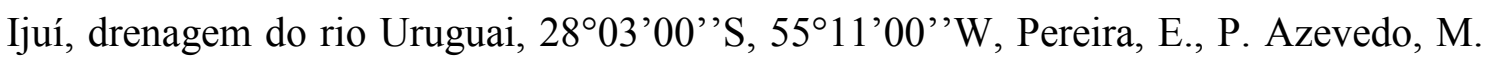
Vargas \& J. Pezzi, 31/07-01/08/1989; MCP 13523 (3, 112,3 - 180,3) rio Uruguai, no

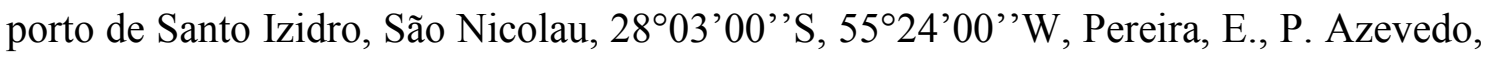
M. Vargas \& J. Pezzi, 30/07/1989; MCP13531 (1, 126,3) barra do rio Ijuí, afluente do

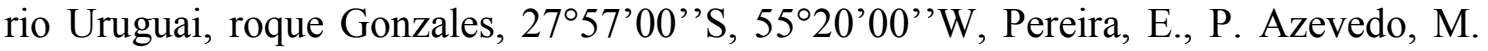
Vargas \& J. Pezzi, 01-02/08/1989; MCP 16803 (6, 151,6 - 249,4) rio Ijuízinho na fazenda do senhor Alfredo Grenwald, local da barragem de Cremissões, Entre-Ijuís, 28²5'00'’S, 54¹8'00'’W, Reis, R. E., J. F. P. da Silva \& M. P. Barros, 12/12/1993; MCP 19019 (3, 144,1 - 164,5) rio Uruguai, entre a foz dos rios Passo Fundo e Chapecó,

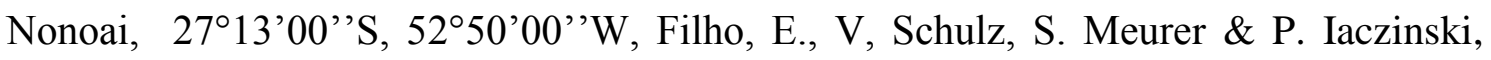


19/04/1996; MCP 28624 (7, 150,8 - 202,3) rio Uruguai, ilhotes, cerca de 3500m do início do salto do Yucumã, Parque Estadual do Turvo, Derrubadas, 2708'13'’S 5351'35'’W, Câmara, L. F., L, Hahn, T. R. Melo \& E. Silva, 29/06/2001.

\section{Santa Catarina:}

MCP $18618(1,174,2)$ rio Uruguai, Itá, 2718’00'’S, 52²0’00’'W, Filho, E., V, Schulz, S. Meurer \& P. Iaczinski, 18/09/1995; MCP 19020 (4, 157,1 - 207,9) rio

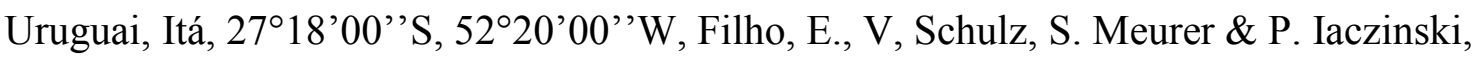
16/04/1996; MCP 20401 (7, 108,1 - 197,4) rio Uruguai, próximo à pedra da Fortaleza, Itapiranga, 27¹1'42'’S, 5338'34'’W, Câmara, E.F. \& E. Silva, 31/05/1997; MCP $20742(10,125,4$ - 234,9) rio Uruguai, próximo à pedra da Fortaleza, Itapiranga, 27¹1'42'’S, 5338'34'’W, Câmara, E.F. \& E. Silva, 14/01/1998; MCP 21350 (2, 240,6 -241,1) ) rio Uruguai, próximo à pedra da Fortaleza, Itapiranga, $27^{\circ} 11^{\prime} 42$ '’S, 5338'34'’W, Câmara, L.F., L. Hahn \& E. Silva, 02/09/1998.

Galeocharax gulo

Brasil:

Acre:

MZUSP 20512 (1, xx) Seringal União, baixo rio Acre, 09²5'36'’S, 70²9'34' 'W, Vanzolini, 03-04/12/1974; MZUSP 29882 (4, 23,6 - 108,3) rio Tarauacá, Tarauacá, 0809'58''S, 7045'54' 'W, Goulding, M., 01/08/1984; MZUSP 31754 (1, 99,1) rio Tarauacá, Tarauacá, 0809'48' 'S, 7045'54'’W, Goulding, M., 08/1984; MZUSP 35791 $(1,59,3)$ igarapé da Maternidade, Rio Branco, 0958'33'’S, 6749'30'’W, Manoel P. Filho, 13/04/1981; MZUSP $49649(1,53,4)$ rio Acre, seringal do Acre, 1059'37'’S, 6843'09'’W, Instituto do Meio Ambiente do Acre, 1994; MZUSP 49673 (7, 24,6 62,3) rio Acre, seringal Bom Destino, uma hora acima de Porto Acre, Porto Acre, 09³5'35''S, 67³2'28' 'W, Instituto do Meio Ambiente do Acre, 19/10/1994; MZUSP $49841(1,157,3)$ rio Acre, Xapuri, 10³9'07'’S, 68²9'50' $\mathrm{W}$, Instituto do Meio Ambiente do Acre/Universidade Federal do Acre, 06/1994; MZUSP 50140 (7, 13,4 29,9) rio Purus, Manoel Urbano, 0850’00’'S, 69¹6’06’’W, Vanzolini, P. E., 19/09/1973; MZUSP 50440 (2, 106,9 - 141,5) rio Juruá, foz do Breu, 09²4'12’’S, 7241'51'’W, Coleção Reserva Extrativista Alto Juruá, 21/06/1994; MZUSP 50441 (1, 133,8 ) rio Juruá, foz do Caipora, $09^{\circ} 23^{\prime} 45^{\prime}$ 'S, $72^{\circ} 42$ ’36' $\mathrm{W}$, Coleção Reserva Extrativista Alto Juruá, 19/07/1994; MZUSP 53017 (1,166,9) rio Juruá, foz do Tejo, 09²4'12'’S, 7242'15' W, Coleção Reserva Extrativista Alto Juruá, 15/06/1994; MZUSP 104480 (2, 131,8 - 161,3) rio Breu, afluente do rio Juruá, Marechal Thaumaturgo, 09²4'00'’S, 7242'00'’W, Amaral, B., 1998; MZUSP 104919 (1, 113,9) rio Purus, Manoel Urbano, 0848'00' 'S, 69¹5'00' 'W, Vanzolini, P. E., 19-20/09/1973; 
MCP $38018(1,129,4)$ rio Caeté, na BR-364, Sena Madureira, 0903'42’’S, 684'49' 'W, Cardoso, A. et al, 21/07/2004.

Amazonas:

MZUSP $1683(1,145,4)$ rio Juruá, 0545'51'’S, 6746’37'’W, Garbe, 1902; MZUSP 10424-33 (10, 22,0 - 44,0) rio Solimões, Fonte Boa, 02³1'27'’S, 66²05'42'’W, EPA, 06/10/1968; MZUSP 10435-36 (2, 96,9 - 131,1) rio Solimões, próximo à ilha de Barurá, 0352'41' 'S, 62 35'10' 'W, EPA, 15/10/1968; MZUSP 10437 $(1,99,8)$ rio Solimões, em frente a Jacaré, próximo de Fonte Boa, 02 31'28'’S, 6605'42'’W, EPA, 07/10/1968; MZUSP 10438 (1, 105,5) rio Solimões, Fonte Boa, 02॰31'30''S, 6605'41'’W, EPA, 06/10/1968; MZUSP 10439-40 (2, 115,3 - 138,8) Ilha

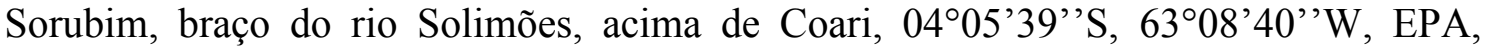
29/09/1968; MZUSP 10441-42 (2, 118,4 - 158,7) rio Juruá, 05²7'18'’S, 67²5'41'’W, Garbe, 1902; MZUSP 10443-47 (5, 139,1 - 176,5) rio Amazonas, entre Santarém e Parintins, 02³4'38',S, 56³7'30' 'W, Garbe, 1920/21; MZUSP 20066 (1, 21,3) boca do rio Içá, Santo Antonio do Içá, $03^{\circ} 05^{\prime} 45^{\prime}$ 'S, 6756’48'’W, EPA, 17/10/1968; MZUSP 20085 (2, 112,1 - 124,1) igarapé Tomé, Atí-Paraná, noroeste de Fonte Boa, 02³1'48'’S, 6605’36'’W, EPA, 13/10/1968; MZUSP 20117 (1, 48,5) rio Solimões, em frente a Jacaré, próximo a Fonte Boa, 02²2'55' 'S, 6609'46'’W, EPA, 07/10/1968; MZUSP $20515(1,137,7)$ rio Purus, boca do Pauiní, 07²42'51'’S, 66 59'33'’W, Vanzolini, P. E., 11-14/12/1974; INPA 2482 (1, 98,9) rio Javari, São Raimundo, Atalaia do Norte, 04²2'00',S, 70¹1'26' 'W, Py-Daniel, C. 19/01/1980; INPA 29326 (1, 159,0) RDS Uacari, calha do rio Juruá, boca do igarapé Xué, Carauari, 0454'01'’S, 6649'58'’W, Frederico, R. G. \& L. J. Queiroz, 27/11/2008; AMNH $221401(1,99,8)$ vicinity of mouth of rio Macaua, tributary rio Iaco, near Sena Madureira, 0903'46's, 6840’15’'W, Krukoff, B. A., 1934.

\section{Goiás:}

MZUSP 35500 (2, 229,7 - 245,2) rio Paranaíba, próximo à represa de Emborcação, 18²7'18'’S, 4758'30'’W, Gomes, O. L., 07/1980; MZUSP 40583 (1, 106,7) rio Paranã, fazenda Salobro, $8 \mathrm{~km}$ acima da balsa na GO 112, Iaciara, $14^{\circ} 05^{\prime} 49^{\prime}$ 'S, 46³7'18' 'W, de Oliveira, J. C. \& W. J. M. Costa, 15/09/1988; MZUSP 40736 (1, ) rio Paranã, acima da foz do rio Atalaia, povoado de Porto Real, Monte Alegre de Goiás, 1326'60'’S, 4705'00' 'W de Oliveira, J. C. \& W. J. M. Costa, 24-25/09/1988; MZUSP 40901 (2, 110,6 - 122,9) rio Paranã, acima da foz do rio São Domingos, fazenda Barra, São Domingos, 1337'17'’S, 4644'30'’W de Oliveira, J. C. \& W. J. M. Costa, 1619/01/1989; MZUSP 74271 (2, 73,0 - 90,1) riacho a montante dos pilares da ponte do Rubão, margem direita Serra da Mesa, Minaçu, 1331'51'’S, 48¹3'15'’W, Moraes,D. 
F., A. Akama \& O. T. Oyakawa, 01/11/1996; NUP 1128 (8, 91,8 - 174,2) reservatório Corumbá, afluente do rio Paranaíba, bacia do alto rio Paraná, Caldas Novas, divisa de Pires do Rio, 1743'37'’S, 48³2'54'’W, NUPELIA, 09/04/1999; NUP 1199 (13, 102,7 - 149,0) reservatório Corumbá, afluente do rio Paranaíba, bacia do alto rio Paraná, Caldas Novas, divisa de Pires do Rio, 1743'37''S, 48³2'54'’W, NUPELIA, 09/04/1999; NUP 1215 (21, 117,7 - 197,2) reservatório de Corumbá, afluente do rio Paranaíba, bacia do alto rio Paraná, Caldas Novas, divisa com Pires do Rio, 17²3'37'’S, 48³2'54'’W, NUPELIA, 09/04/1999; NUP 1338 (2, 106,8 - 137,1) rio Corumbá, afluente do rio Paranaíba, bacia do alto rio Paraná, Caldas Novas, divisa de Corumbaíba e Pires do Rio, 17²9'02'’S, 48²2'13'’W, NUPELIA, 10/09/1996; NUP 3809 (1, 151,5) córrego Posse, afluente do rio Paranaíba, bacia do alto rio Paraná, Nerópolis, 16²4’22'’S, 49¹3'07'’W; NUP 8778 (1, 191,5) reservatório Corumbá IV, afluente do rio Paranaíba, bacia do alto rio Paraná, Luiziania, 16¹9'59'’S, 48¹1'04' 'W, Silva, C. P., 17/12/2006; NUP 8779 (1, 125,0) reservatório Corumbá IV afluente do rio Paranaíba, bacia do alto rio Paraná Abadiânia, divisa de Silvânia, 16²'19','S, 48²9'44'’W, Silva, R. L. et al, 14/12/2008; NUP 8780 (1, 134,0) reservatório Corumbá IV, afluente do rio Paranaíba, bacia do alto rio Paraná, Luziania, 16 ${ }^{\circ} 19^{\prime} 22^{\prime}$ 'S, 48 ${ }^{\circ} 19^{\prime} 17^{\prime \prime} \mathrm{W}$, Silva, 16/12/2008; NUP8781 (2, 142,0 - 142,9) reservatório Corumbá IV, afluente do rio Paranaíba, bacia do alto rio Paraná, Alexânia, divisa com Santo Antonio do Descoberto, $16^{\circ} 01^{\prime} 07^{\prime}$ 'S, 48 $20^{\prime} 00^{\prime}$ 'W, Silva, R. L. et al, 22/04/2009; NUP 9275 (1, 146,4) córrego Brumado, afluente do rio Uru, Goiás, 1548'51'’S, 4950'36'’W, Mendonça, M. S. et al, 15/02/2009; NUP 13708 (2, 96,3 103,1) rio Corumbá, área do reservatório de Itumbiara antes do represamento, afluente do rio Paraná, bacia do alto rio Paraná, Corumbaíba, $18^{\circ} 08^{\prime} 35^{\prime}$ 'S, 48³3'32' 'W, Silva, J. E. \& I. Rocinski, 13/03/1975; NUP 13723 (1, 95,9) rio Piracanjuba, área do reservatório de Itumbiara antes do represamento, afluente do rio Paranaíba, bacia do alto rio Paraná, Itumbiara, $18^{\circ} 24^{\prime} 00^{\prime}$ S, 49¹2'11' W, Rocinski, I. \& O. Ribeiro, 27/11/1975; NUP 13826 (2, 124,6 - 154,2) rio Piracanjuba, área do reservatório de Itumbiara antes do represamento, afluente do rio Paranaíba, bacia do alto rio Paraná, Água Limpa, 1804'19'’S, 4845'54'’W, Silva, J. E. \& I. Rocinski, 29/09/1975, NUP 14144 (2, 106,5 - 221,4) rio Paranaíba, área do reservatório de Itumbiara antes do represamento, afluente do rio Paraná, bacia do alto rio Paraná, Corumbaíba, 1807'38'’S, 48³4'13',W, Silva, J. E. \& I. Rocinski, 17/03/1975; NUP 14206 (2, 137,1 - 194,7) rio Paranaíba, área do reservatório de Itumbiara antes do represamento, afluente do rio Paraná, bacia do alto rio Paraná, Anhanguera, 18 19'58' 'S, 48¹3'22'’W, Silva, J. E., 13/08/1976; NUP 14152 (2, 202,0 - 203,0) ribeirão das 
Antas, afluente do rio Paranaíba, bacia do alto rio Paraná, Itumbiara, 18²4'00'`S, 49¹2'11'’W, Silva J.E. \& Rocinski, 05-07/09/1975; NUP 14237 (2, 137,8 - 213,1) ribeirão das Antas, afluente do rio Paranaíba, bacia do alto rio Paraná, Itumbiara, 18²4'00’’S, 49¹2'11'’W, Marzulo, D., 04/02/1976; MNRJ 12599 (4, 107,3 - 139,0)

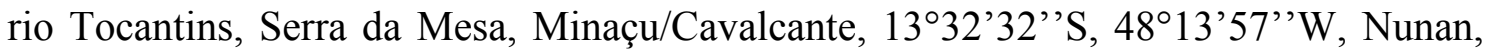
G. W. \& D. F. Moraes Jr, 20/10/1985; MNRJ 12744 (8, 110,0 - 141,3) rio Maranhão, no estreito, próximo à foz do rio Bagagem, Niquelândia, 1359'00' 'S, 48 $22^{\prime} 00^{\prime}$ ' W, Nunan, G. W. \& D. F. Moraes Jr, 13/10/1985; MNRJ 13071 (2, 48,6 - 59,3) rio Tocantins, entre futura barragem da UHE Cana Brava e ilha do Orgulho e Porto do

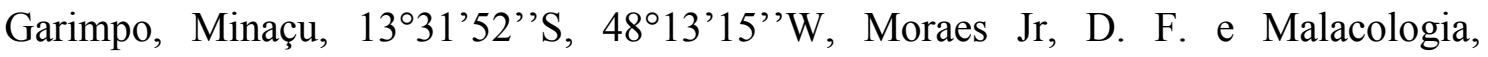
10/12/1987; MNRJ 13272 (15, 65,5 - 99,5) rio Tocantins, no local da futura barragem da UHE Serra da Mesa, Minaçu/Cavalcante, 1331'51' 'S, 48¹3'15'’W, Moraes, D. F., C. N. Ricci, O. Roppa, 07/1988; MNRJ 17617 (1, 219,0) rio Preto, corredeira, afluente da margem direita do rio Paranaíba, 1840'12'’S, 50¹4’26'’ W, Odir Sagim Jr, 31/08/1997; MNRJ 17618 (3, 200,2 - 225,5) rio Alegre, remanso, margem direita do Paranaíba, 1845'52’’W, 50³4'32'’W Prof. Odir Sagim Jr, 11/05/1997; MNRJ 18539 $(5,67,9$ - 89,1) poças formadas por riacho da margem esquerda do rio Tocantins, a

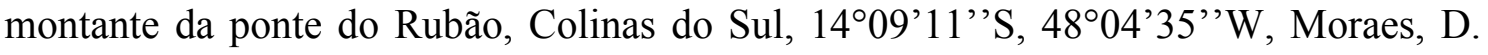
F., D. A. Habloth \& O. T. Oyakawa, 28/10/1996; MNRJ $19831(1,119,6)$ rio São Marcos, fazenda Dorvinas, afluente da margem direita do rio Paranaíba, Catalão, divisa com Divinópolis, $18^{\circ} 04^{\prime} 05^{\prime}$ 'S , 4740’26'’W, Figueiredo, C. A. F., F. A. Bockmann \& A. P. R. Pires, 23/09/1999; MNRJ 19832 (6, 145,5 - 206,6) rio São Marcos sob a ponte na GO-506, margem direita do rio Paranaíba, porto Carapina a montante do eixo, 17'54'35'’S, 4740'45' 'W, Bockmann, F. A., C. A. Figueiredo \& A. P. R. Pires, 23/09/1999; MNRJ 19833 (1, 131,6) rio São Marcos, sob a ponte da GO-506, Porto Carapina a montante do eixo, afluente da margem direita do rio Paranaíba, Catalão, 17'54'35'’S, 4740'45' 'W, Bockmann, F. A., C. A. Figueiredo \& A. P. R. Pires, 23/09/1999; MNRJ 19834 (7, 103,4 - 224,9) rio São Marcos, afluente da margem direita do rio Paranaíba, divisa entre Catalão e Divinópolis, $18^{\circ} 04^{\prime} 05^{\prime}$ 'S, 47 40'26' ' $\mathrm{W}$, Figueiredo, C. A., F. A. Bockmann, A. P. R. Pires, 23/09/1999; MNRJ 19835 (1, 122,7) rio São Marcos, fazenda Dorvinas, à jusante do eixo, afluente da margem direita do rio

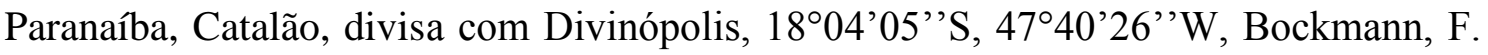
A., C. A. Figueiredo \& A. P. R. Pires, 24/09/1999; MNRJ 26044 (1, 190,0) rio Passa Três, 14²8'39'’S, 4904'33'”W, de Matos, F. J. P. \& J. K. Brondi, 11/08/1998; MNRJ 31243 (14, 122,3 - 222,9) rio Corumbá, afluente do rio Paranaíba, bacia do alto rio Paraná, região do município de Caldas Novas, 17²5'06' 'S, 48³7'07'’W, NUPELIA, 
09/1996; UERJ 0022 (3, 109,7 - 125,1) rio Paranaíba, UHE de Emborcação, 18²6'43'’S, 4759'08' 'W, Bueno, C. A., R. de Fillippo \& U. L. Gomes, 26/11/1980; MCP 14405 (1, 124,1) rio Passa Três, a dois km norte de Ural pela estrada BelémBrasília, Uruau, 14³0'21'’S, 4909'13'’W, Reis, R. E., 25/12/1990; MCP 19771 (9, 85,9 - 106,9) rio Tocantins, três km a jusante da barragem Serra da Mesa, Minaçu, 1351'50’'S, 48¹7’00’'W, Lucena C. A. S. \& J. F. P. Silva, 06/11/1996; MCP 41380 $(1,134,4)$ rio Piranhas, próximo à foz do córrego das Pedras, Piranhas, 16 $6^{\circ} 2^{\prime} 03^{\prime}$ 'S, 5149'58' 'W, Rosa, S., 11/07/2005; MCP 41407 (1, 120,3) rio Piranhas, próximo à foz do rio São Domingos, Piranhas, 16³3'06'’S, 5149'52' 'W, Rosa, S., 23/07/2006; MCP 41837 (1, 127,5) rio Piranhas, próximo à foz do rio São Domingos, Piranhas, 16³'06'’S, 5149'52''W, Equipe CPA Ltda, 16/07/2007; MCP42288 (4, 98,4 110,3) rio Claro, Montes Claros de Goiás, $15^{\circ} 57^{\prime} 20^{\prime}$ S, 51 ${ }^{\circ} 17^{\prime} 08^{\prime}$ 'W, Pereira, G. A. 05/06/2007; MCP 42351 (1, 101,0) rio Claro, Montes Claros de Goiás, 1553'13'’S, 51²4'44',W, Pereira G. A., 27/02/2007; MCP $43771(1,108,3)$ rio Piranhas, próximo à foz do rio São Domingos, Piranhas, 16³3'06'’S, 5149'52'’W, 10/07/2008; MCP $45561(1,128,4)$ rio do Peixe, Santa Isabel, $15^{\circ} 15^{\prime} 21^{\prime}$ 'S, 49²5'54' 'W, Garro F. L. T., 11/08/2008; UNT $708(2,129,8$ - 136,6) rio Passa Três, 1428’39',, 4904’33'’W, Moraes, D. F., 14/10/1998.

Maranhão:

MZUSP $4987(1,44,1)$ rio Tocantins, em poça marginal de vazante, Estreito, 06³3'41'’S, 47²6’36'’W, Exc. D.Z., 02/06/1966; MZUSP 10448 (1, 39,6) rio Tocantins, Estreito, 06³3'41'’'S, 47²6’36'’W, Exc. D. Z., 02/06/1966; MNRJ 39674 $(16,98,9$ - 129,9) rio Tocantins, resgate entre as ensecadeiras para a construção da UHE de Estreito, Estreito, 06 $33^{\circ} 42^{\prime}$ 'S, 47 $26^{\prime} 36^{\prime \prime} \mathrm{W}$, Moraes, D. F. et al,15/05/2012; UNT $3225(1,98,1)$ rio Tocantins, próximo à confluência com o rio Bananal, Imperatriz, $05^{\circ} 31^{\prime} 19^{\prime} ' \mathrm{~S}, 47^{\circ} 28^{\prime} 22^{\prime} ’ \mathrm{~W}, \mathrm{NEAMB}-\mathrm{UFT}, 28 / 04 / 2000$.

\section{Mato Grosso:}

MZUSP $10449(1,106,6)$ rio das Mortes, Xavantina, 1440'40’'S, 52²1'09' 'W, RS/RGS Xavantina-MT Exp., 01/05/1968; MZUSP 62839 (4, 124,4 - 203,2) rio Teles Pires, Pesqueiro do Dentinho, Alta Floresta, 0952'02's, 56 05'13'’ W, Machado F. A. et al, 29-30/07/1997; MZUSP 62841 (3, 148,9 - 180,8) rio Juruena, um km acima da desenbocadura do rio Arinos, Juruena, $10^{\circ} 19^{\prime} 58^{\prime}$ 'S, 58 29'37' 'W, Machado F. A. et al, 25-26/08/1997; INPA 31750 (1, 127,2) barra do Garças, abaixo do córrego Pitomba, margem esquerda, 1553'29''S, 52¹5'38' 'W, de Oliveira R. R., 20/01/2008; MNRJ

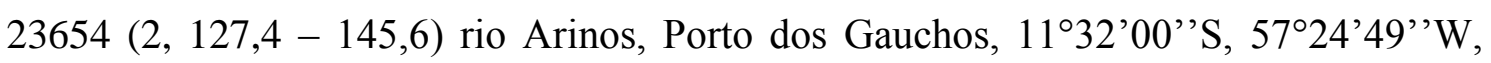
Buckup, P., A. Aranda, F. Silva, C. Figueiredo, 19/01/2002. 


\section{Mato Grosso do Sul:}

MZUSP 10476-78 (3, 151,8 - 183,2) rio Paraná, em frente a Jupiá, 2048'44' 'S, 51³7’53'’W, Exp. D.Z., 15-23/09/1962; MZUSP 10479 (1, 179,7) rio Paraná, em frente a Jupiá, 2046'12'’S, 51³6’37'’W, Exp. D.Z., 11-23/09/1964; NUP9181 (1, 71,4) montante da barragem Mimoso, Mon I, afluente do rio Pardo, bacia do alto rio Paraná, 2040’22’’S, 53³4’08’’W, Luz-Agostinho, K.D.G., 16/12/2008.

\section{Minas Gerais:}

MZUSP 1660 (1, 155,2) rio Sapucaia, Pouso Alegre, 22¹3'37' 'S, 4556'21' 'W, Dr. Pimentel, 03/1905; MZUSP 20466 (2, 121,5 - 166,9) represa de Furnas, rio Grande, Alfenas, $21^{\circ} 25^{\prime} 40^{\prime}$ 'S, 4556 52'’W, CETESB, 02-03/10/1975; MZUSP 20485 (4, 105,4 - 204,5) usina Peixoto, rio Grande, 20¹7'12'’S, 4703'50'’'W, CETESB, 18/12/1975; MZUSP $38869(18,101,0$ - 213,9) rio Paranaíba, projeto UHE Bocaina, 18¹0’00’’S, 47²7’00’’W, Lime Engenharia, 11/1987-06/1988; NUP 260 (2, 60,7 - 112,7) rio Ivaí, porto Dango, afluente do rio Paraná, bacia do alto rio Paraná, Tapira, 1955'19'’S, 4649'22'’W, NUPELIA, 15/05/1988; NUP 13682 (2, 110,5 - 111,4) rio Paranaíba, área do reservatório de Itumbiara antes do represamento, afluente do rio Paraná, bacia do alto rio Paraná, Tupaciguara, 18³6'14'’S, 4841'27'’W, Silva J. E., 02/1975; NUP 13699 (2, 114,0 - 132,9) rio Paranaíba, área do reservatório de Itumbiara antes do represamento, afluente do rio Paraná, bacia do alto Paraná, Tupaciguara, 18³6'14' 'S, 4841'27'’W, Silva, J. E. \& I. Rocinski, 30/04/1975; NUP 13747 (2, 125,7 - 146,5) ribeirão da Caridade, área do reservatório de Itumbiara antes do represamento, afluente do rio Paranaíba, bacia do alto rio Paraná, Tupaciguara, $18^{\circ} 36^{\prime} 14$ '’ $\mathrm{S}, 48^{\circ} 41^{\prime} 27^{\prime}$ ' $\mathrm{W}$, Silva, J. E., 28/01/1975; NUP 13823 (2, 106,2 - 123,2) rio Paranaíba, área do reservatório de Itumbiara antes do represamento, afluente do rio Paraná, bacia do alto rio Paraná, Taciguara, 18¹9'52'’S, 48³3’21'’W, Silva, J. E., 31/01/1975; NUP 13934 (2, 150,1 - 170,3) córrego do Vigilato, área do reservatório de Itumbiara antes do represamento, afluente do rio Paranaíba, bacia do alto rio Paraná, Tupaciguara, 18³6'14'’S, 4841'27' ’W, J. E. Silva \& I. Rocinski, 30/04/1975; NUP 14014 (2, 133,2 - 193,2) rio Paranapiba, área do reservatório de Itumbiara antes do represamento, afluente do rio Paraná, bacia do alto rio Paraná, Tupaciguara, 18¹9'44's, 48³3'42'’W, Silva, J. E. \& I. Rocinski, 27/04/1975; NUP 14039 (2, 134,5 - 162,3) rio

Paranaíba, área do reservatório de Itumbiara antes do represamento, afluente do rio Paraná, bacia do alto rio Paraná, Tupaciguara, $18^{\circ} 17^{\prime} 25^{\prime}$ 'S, $48^{\circ} 33^{\prime} 34^{\prime \prime}$ W, Silva, J. E. \& I. Rocinski, 08-10/09/1975; NUP 14188 (2, 87,8 - 190,9) rio Paranaíba, área do reservatório de Itumbiara antes do represamento, afluente do rio Paraná, bacia do alto rio Paraná, Araguari, 18³8'49' 'S, 48¹0'57' 'W, Silva, J. E. \& I. Rocinski, 12/03/1975; 
NUP $14238(2,157,7$ - 160,9) córrego do Vigilato, área do reservatório de Itumbiara antes do represamento, afluente do rio Paranaíba, bacia do alto rio Paraná, 18³6'14' 'S, 4841'27' 'W, Silva, J. E. \& I.Rocinski, 03/04/1975; NUP 14357 (2, 135,6 - 136,6) rio Paranaíba, área do reservatório de Itumbiara antes do represamento, afluente do rio Paraná, bacia do alto rio Paraná, Araguari, $18^{\circ} 38^{\prime} 49^{\prime}$ 'S, $48^{\circ} 10^{\prime} 57^{\prime}$ 'W, Silva, J. E. \& I. Rocinski, 12/03/1975; NUP 14378 (2, 164,2 - 221,2) rio das Velhas, área do reservatório de Itumbiara antes do represamento, afluente do rio Paraná, bacia do alto rio Paraná, Tupaciguara, 18³6'14'’S, 4841'27'’W, Rocinski, I., 26/07/1975; MNRJ 16991(5, 101,7 - 131,3) ribeirão dos Coelhos, afluente da margem direita do rio Grande, Perdões, $21^{\circ} 05^{\prime} 38^{\prime}$ 'S, $45^{\circ} 05^{\prime} 23^{\prime}$ 'W, Araujo, P. M. C., F. A. Bockmann \& F. Regalo,10/02/1998; MNRJ 16992(1, 133,4) rio Grande, na ponte do funil, Lavras,

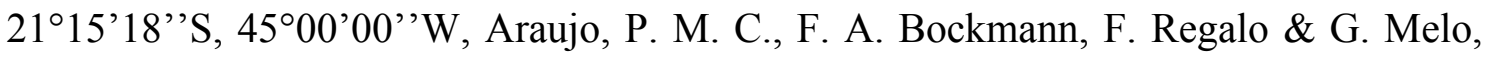
10/02/1998; MNRJ 17027 (1, 133,3) rio Grande, Itutinga, 28/11/1997 21¹7'56'’S, 44³9'24' 'W, Araujo, P. M. C., F. A. Bockmann, F. Regalo \& G. Melo; MNRJ 17038 (1, 140,9) ribeirão da Babilônia, afluente da margem direita do rio Grande, Bom

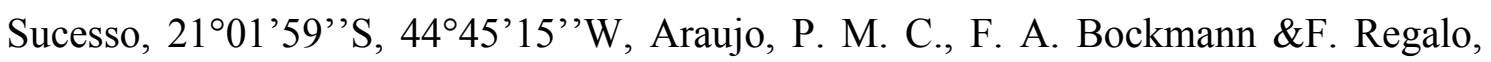
11/02/1998.

\section{Pará:}

MZUSP 106939 (2, 89,4 - 108,2) rio Paranapebas, em corredeiras a jusante do poço do Jaú, Canaã dos Carajás, 06²3'15'’S, 5002'03'’W, Loeb, M. V. \& H. R. Varella, 22/06/2010; MCP 36354 (19, 113,4 - 148,9) lago Grande, Chacoal Grande, 02²3'20'’S, 54²19'53'’W, Ribeiro, F. V., 09/10/2004; INPA 12320 (2, 99,1 - 123,3) rio Tocantins, Breu Branco, Itupiranga, $05^{\circ} 08^{\prime} 10^{\prime}$ 'S, 49 $19^{\prime} 24^{\prime}$ 'W, Equipe Ictiológica INPA, 01/01/1980; INPA 15243(5, 78,4 - 84,5) Tucurui, rio Tocantins, 03²4' 57' 'S, 4940'40’'W Equipe Ictiológica INPA, 05/02/1985; INPA 20954 (1, 106,4) rio Tocantins, Breu Branco, Tucurui, 0346’16’'S, 49³3'56'’W, Equipe Ictiológica INPA, 12/07/1982.

Paraná:

MZUSP 21079 (4, 125,9 - 188,6) rio Paraná, abaixo de Sete Quedas, 2406'41' 'S, 5419'27' 'W, CETESB, 1977-80; MZUSP 21612 (8, 139,9 - 178,5) rio Paraná, acima de Sete Quedas, Guaíra, 2401'40’’S, 54²1'14'’W, CETESB, 1977-80; NUP 256 (2, 171,7 - 210,4) foz do rio Cantu, afluente do rio Piquiri, bacia do alto rio Paraná, Campina da Lagoa, divisa de Altamira do Paraná e Guarinaçu, 2454'00’'S, 5252'00' 'W, NUPELIA, 07/1988-04/1989; NUP 257 (8, 90,7 - 192,1) rio Bandeira, na foz, afluente do rio Piquiri, bacia do alto rio Paraná, Campina da Lagoa, divisa entre Campo Bonito e Guaraniaçu, 2445'00'’S, 5416'00'’W, NUPELIA, 02-07/1987; NUP 
258 (2, 99,7 - 120,7) rio Piquiri (Apertado), afluente do rio Paraná, bacia do alto rio Paraná, Formosa do Oeste, 2417’34'’S, 5318’46' 'W, NUPELIA, 20-21/02/1987; NUP 259 (3, 104,8 - 162,6) arroio Guaçu, afluente do reservatório Itaipu, bacia do alto rio Paraná, Terra Roxa, Divisa de Marechal Candido Rondon, 24²5'00'’S, 54²0'00'’W, NUPELIA 05/05/1987; NUP 261 (1, 140,7) reservatório de Itaipu, afluente do rio Paraná, bacia do alto rio Paraná, Santa Teresinha de Itaipu, 2524'00'’S, 54²7'00'’W, NUPELIA, 05/04/1988; NUP 262 (4, 72,7 - 82,7) rio Mendes, afluente do reservatório de Itaipu, bacia do alto rio Paraná, Marechal Candido Rondon, 2429'00'’S, 54¹8'00’'W, NUPELIA, 04-08/1988; NUP 263 (7, 118,4 - 190,7) rio Paraná, bacia do alto rio Paraná, Porto Rico, $22^{\circ} 45^{\prime} 00^{\prime}$ 'S, $53^{\circ} 17^{\prime} 00^{\prime}$ 'W, NUPELIA, 12/1987-05/1988; NUP 2487 (12, 105,6 - 190,0) rio Piquiri (Iguatemi), afluente do rio Paraná, bacia do alto rio Paraná, Formosa do Oeste, 2411'53'’S, 53¹9'14' 'W, NUPELIA, 06/1987-02/1988; NUP 2503 (2, 119,6 - 130,3) reservatório de Itaipu, afluente do rio Paraná, bacia do alto rio Paraná Santa Helena, 2403'00'’S, 54¹5'00'’W, NUPELIA, 1983-1993; NUP 3119 (10, 94,4 - 195,5) reservatório de Itaipu, afluente do rio Paraná, bacia do alto rio Paraná, Foz do Iguaçu, 25³2'48' 'S, 54³5'17'’W, Okada, E. K., 22/04/2003; NUP 3868 (3, 83,1 - 91,6) rio Pirapó, afluente do rio Paranapanema, Maringá, 2319’36'S, 5150'41'’W, NUPELIA 16/09/2004; NUP $4221(9,65,2$ - 206,9) rio Goierê, afluente do rio Piquiri, bacia do alto rio Paraná, Mariluz, divisa de Umuarama, 2447'19' 'S, 50¹9'28' 'W, Deitós, C., 09/01/2005; NUP 11357 (1, 149,1) rio Bela Vista, afluente do rio Paraná, bacia do alto rio Paraná, Foz do Iguaçu, 25³0'59',S, 54³5'06'’W, NUPELIA, 20/11/2007; MNRJ 27411(1, 222,9) rio Paranapanema, à frente da fazenda Rio Claro, Ribeirão Claro, 2311'52' 'S, 4945'35' 'W, Farinaccio, C, C. R. Fermiano \& A. H. P. Borba, 28/01/2003; MNRJ 27554 (1, 205,7), rio Paranapanema, à frente da fazenda Ribeirão Claro, área do clube de pesca, propriedade Irmãos, Ribeirão Claro, 2311'52' 'S, 4945'35' 'W, Farinaccio, C. \& C. R. Fermiano, 16/12/2003.

São Paulo:

MZUSP 326 (1, 222,9) rio Piracicaba, Piracicaba, 2244'59'’S, 47³8'52', W, Von Ihering, R., 1906; MZUSP 2031 (1, 217,5) rio Piracicaba, Piracicaba, 2244’05'’S, 47³8'52'’W, Von Ihering, R., 1906; MZUSP 2039 (3, 144,5 - 189,0) rio Mogi-Guaçu, Emas, 2155'36'S, 47²2'16’'W; MZUSP 2073 (1, 198,5) rio Grande, Franca, 20³2'24'’S, 47²4'05'’W, Garbe, E., 1910; MZUSP 2925 (1, 174,4) rio Mogi-Guaçu, Emas, 21 ${ }^{\circ} 55^{\prime} 36^{\prime \prime} \mathrm{S}, 4^{\circ} 22^{\prime} 16^{\prime \prime} \mathrm{W}$ Aguirre, A., 04/1940; MZUSP 3422 (1, 151,7) rio Piracicaba, Piracicaba, $22^{\circ} 44^{\prime} 07^{\prime}$ 'S, $47^{\circ} 38^{\prime} 52^{\prime \prime}$ W, Dante, E., 1942; MZUSP 10450-75 $(26,53,8$ - 150,6) rio Paraná, ensecadeira na margem esquerda do rio Paraná, barragem 
de Jupiá, Jupiá, 2045’46’’S, 51³9’12’’W, S.D.R., 02/1967; MZUSP 10480-86 (4, 80,5 - 136,4) rio Paraná, Ilha Solteira, 20²5'46' 'S, 51²0'13'’W, Excursão MZUSP, 25-28/05/1972; MZUSP 10487-501 (15, 85,8 - 193,4) rio Paraná, Ilha Solteira, 20²5'46’'S, 51²0'13'’W, Exp. D.Z., 09/1965; MZUSP 10502 (5, 101,2 - 139,4) rio

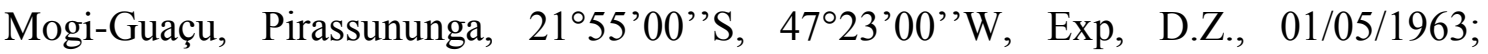
MZUSP 10511-13 (3, 109,5 - 162,1) rio Mogi-Guaçu, Emas, 2155'36'’S, 47²2'16' 'W, Dias, I.A., 26/12/1963; MZUSP 10514 (14, 118,3 - 179,7) cachoeira das Emas, Pirassununga, 21 ${ }^{\circ} 55^{\prime} 00^{\prime}$ 'S, 47²3'00'’W, Esp D.Z., 04-05/04/1962; MZUSP 10528 (2, 148,5 - 174,0) rio Mogi-Guaçu, Emas, 2155'36'’S, 47²2’16'’W, Schubart, O., 1961; MZUSP 10529 (1, 194,2) rio Piracicaba, Piracicaba, 2244'06’'S, 47³8'52'’W, Von Ihering, R. \& J. Lima, 1906; MZUSP 10530-32 (3, 178,8 - 196,8) rio Piracicaba, Piracicaba, 22 $44^{\prime} 06^{\prime}$ 'S, 47³8'52' 'W, Von Ihering, R \& J. Lima, 1906;

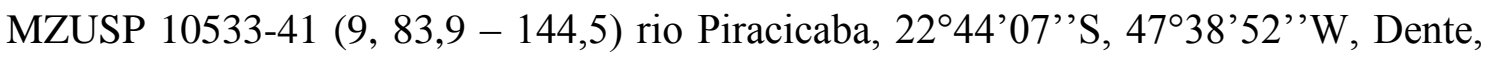
E., 1942; MZUSP 10542-55 (13, 90,9 - 129,5) represa de Americana, 2243’33'’S, 47'13'20'’W, DPA (Inst. Pesca Sec. Agr.), 23/07/1965; MZUSP 10556 (1, 135,7) rio Tietê, Barra Bonita, 22²9’29’S, 48³3’31'’W, Baggi, A.; MZUSP 10557 (1, 153,0) salto de Itapura, rio Tietê, 20³8'32'’S, 51³0'24'’W, Britski, 29/03/1966; MZUSP

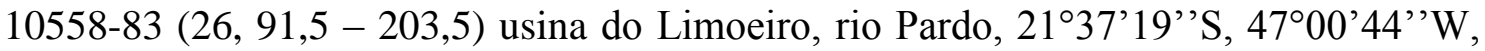
Britski, H., 13/05/1965; MZUSP 10584-85 (2, 220,7 - 226,3) rio Paranapanema, Jurumirim, 2311'00'’S, 49¹5'59'’W, D. P. A., 28/08/1963; MZUSP 20476 (6, 168,3 - 212,3) represa de Volta Grande, rio Grande, Miguelópolis, 20¹0’47' 'S, 4801'52'’W, CETESB, 06-07/11/1975; MZUSP 25679 (4, 143,7 - 171,3) rio Pardo, 2136'21'’S, 4659'51'’W, CETESB, 1978; MZUSP 42575 (1, 92,4) rio Mogi-Guaçu, Emas, 21 ${ }^{\circ} 55^{\prime} 36^{\prime \prime} \mathrm{S}, 4^{\circ} 22^{\prime} 15^{\prime \prime} \mathrm{W}$, Britski, H. A. \& Dias, I. H., 14/05/1964; MZUSP 53858 (9, 97,9 - 182,1) rio Piracicaba, represa Barra Bonita, Santa Maria da Serra, 22³4'10'’S, 4809'18'’W, Silvano R. A. M., 1995; MZSUP 53961 (8, 94,7 - 111,6) rio Piracicaba, represa de Barra Bonita, Santa Maria da Serra, 22 34'01'’S, 4809'35',W, Silvano, R. A. M., 04/1995; MZUSP 70387 (1, 221,6) rio Piracicaba, Piracicaba, 2244'07'’S, 47³8'52'’W, Carneiro, S. C., 05/1999; MZUSP 75426 (1, 155,4) rio Piracicaba, Piracicaba, 22 $44^{\prime} 07^{\prime}$ 'S, 47³8'50' 'W, Von Ihering, R. \& Lima, 1905; MZUSP 79318 (1, 95,6) rio Tietê, a jusante da barragem de Barra Bonita, Barra Bonita, 22²9'28'’S, 48³3'31'’W, Smith, W. S., 01/2001; MZUSP 84298 (1, cp?) rio

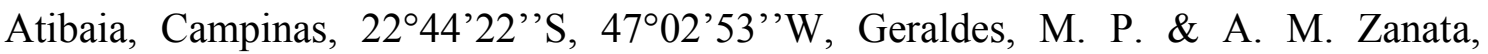
23/09/2003; MZUSP 99198 (1, 122,6) rio Mogi-Guaçu, acima da foz do rio Jaguari, municipio, 22²2'00'’S, 4656'00'’W, Kloss G. R., 16/02/1965; NUP 7018 (1, 113,5) rio Pitangueira, afluente do rio do Peixe, bacia do alto rio Paraná, Tupã, 22 03'59' 'S, 
50³4'19'’W, Biffi, A. G. \& F. A. Moraes, 02/04/2009; NUP 7043 (1, 96,4) rio Pitangueira, afluente do rio do Peixe, bacia do alto rio Paraná, Tupã, 22 03'59'’S, 50³4'19'’W, Biffi, A. G., 16/03/2009; NUP 12380 (1, 242,8) rio Tibiriçá, afluente do rio Aguapeí, bacia do alto rio Paraná, Queiroz, 2147'22'’S, 5009'02'’W, Biffi, A. G., J. L. M. Biffi, 26/08/2011; NUP 14467 (1, 229,1) rio Paranapanema, a jusante da UHE Ourinhos, afluente do rio Paraná, bacia do alto rio Paraná, Ourinhos, 2303'55's, 4952'30'’W, Wolff, L. L., 02/08/2012; NUP14478 (4, 150,2 - 189,8) rio Paranapanema, a jusante da UHE de Ourinhos afluente do rio Paraná, bacia do alto rio Paraná, Ourinhos, 2303'52'’S, 4952’26’’W, Wolf, L. L.,02/08/2012; NUP 14516 (1, 194,8) rio Paranapanema, a jusante da UHE Ourinhos, afluente do rio Paraná, bacia do alto rio Paraná, Ourinhos, $23^{\circ} 05^{\prime} 46^{\prime}$ 'S, $49^{\circ} 44^{\prime} 55^{\prime}$ 'W, Wolff, L. L., 05/08/2012; MNRJ 15595 (1, 141,3) rio Mogi-Guassu (sic), Pirassununga, 21 ${ }^{\circ} 59^{\prime} 47^{\prime}$ 'S, 47²5’33'’ W, I. Sazima, 21/02/1977; MNRJ 19469 (1, 115,2) rio Piracicaba, Piracicaba, 2244’06'’S 47³8'51',W, Sazima, 04/03/1978.

\section{Tocantins:}

MZUSP $84002(1,140,5)$ rio Manuel Alves da Natividade, em frente à cidade de

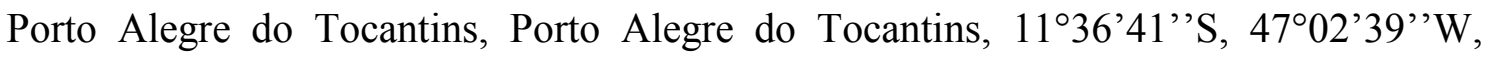
Moreira, C. M., J. C. Nolasco \& M. Avila, 26/07/2002; MCN 19060 (14, 99,8 - 150,9) Igarapé Saranzal, Palestina do Pará, 0551'16'’S, 48 21'08' 'W, Cardoso, A. R. et al, 01/10/2010; UNT 2584(1, 82,1) rio lajeadinho, próximo à UHE Lajeado, 0946’32’’S, 48²4'15','W, NEAMB-UFT, 24/03/2000; UNT 2588 (1, 86,5) rio Paranã, fazenda Traçadal, Paranã, 12³0'00'’S, 48 12'00'’W, NEAMB-UFT, 08/11/2000; UNT 2589 (4, 70,6 - 90,4) rio Tocantins, Porto Nacional, 1042’11'’S, 48²4’30'’W, NEAMB UFT, 22/03/2000; UNT 2590 (1, 70,3) rio Tocantins, fazenda Traçadal, Paranã, 12²9'00'’S, 48¹2'00'’W, NEAMB-UFT, 09/07/2000; UNT 2596 (2, 68,6 - 75,6) rio Paranã, próximo à Lagoa Verde, Paranã, 12³6'57'’S, 4752’32'’W, NEAMB-UFT, 08/07/2000; UNT 2606 (1, 105,8) rio Tocantins, Brejinho de Nazaré, 1059'46'’S, 48³2'06'”W, NEAMB-UFT, 13/01/1996; UNT 2607 (14, 39,7 - 74,9) rio Paranã, fazenda Traçadal, Paranã, 12³0'00' 'S, 48¹2'00' 'W, NEAMB-UFT, 09/05/2001; UNT 2608 (1, 78,3) rio Paranã, fazenda Traçadal, Paranã, 12॰30'00'’S, 48 $12^{\prime} 00^{\prime}$ 'W, NEAMB-UFT, 24/03/1998; UNT 2612 (1, 75,4) rio Tocantins, Porto Nacional, 1043'15' 'S, 48²5'14' 'W, NEAMB-UFT, 06/06/1996; UNT 2613 (4, 52,9 - 81,1) rio

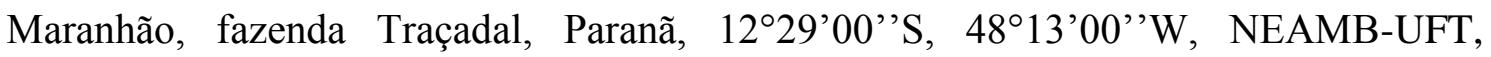
26/03/1998; UNT 2616 (1, 60,6) rio Paranã, fazenda Traçadal, Paranã, 12 30'00'’S, 48 12'00' 'W, NEAMB-UFT, 24/03/1998; UNT $2620(1,83,9)$ rio Tocantins, próximo à confluência com o rio Santa Tereza, Peixe, $11^{\circ} 47^{\prime} 27^{\prime}$ 'S, $48^{\circ} 37^{\prime} 02^{\prime}$ 'W, NEAMB-UFT, 
14/05/2000; UNT 2622 (1, 43,8) rio Tocantins, Porto Nacional, 1043'15's, 48 25'14' 'W, NEAMB-UFT, 29/01/2000; UNT $2623(1,84,0)$ rio Tocantins, próximo à

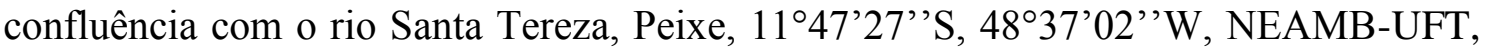
14/05/2000; UNT 2624 (18, 29,4 - 65,3) rio Paranã, fazenda Traçadal, Paranã, 12³0'00'’S, 48¹2'00'’W, NEAMB-UFT, 09/04/2001; UNT 2626 (2, 61,8 - 83,2) rio Tocantins, Porto Nacional, 1043'15'’S, 48²5'14'’W, NEAMB-UFT, 03/11/2003; UNT $2628(1,64,8)$ rio Tocantins, Porto Nacional, 1043'15',S, 48 25'14'’'W, NEAMB-UFT, 24/02/2000; UNT 2630 (1, 42,8) rio Paranã, fazenda Traçadal, Paranã, 12 ${ }^{\circ} 30^{\prime} 00^{\prime}$ 'S, 48¹2'00' 'W, NEAMB-UFT, 09/08/2000; UNT $2631(1,50,2)$ rio Paranã, fazenda Traçadal, Paranã, 12³0'00'’S, 48¹2'00' 'W, NEAMB-UFT, 09/08/2000; UNT

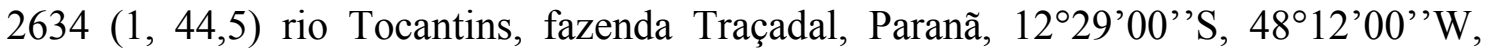
NEAMB-UFT, 10/05/2000; UNT 2635 (1, 36,7) rio Tocantins, fazenda Traçadal, Paranã, 12²9'00' 'S, 48 12'00' 'W, NEAMB-UFT, 10/05/2000; UNT 2636 (1, 74,3) rio

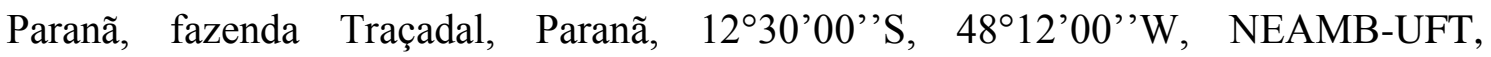
09/08/2000; UNT $2639(1,24,6)$ rio Tocantins, próximo à confluência com o rio Freio, Tupiratins, 08¹9'00'’S, 4808'00'’W, NEAMB-UFT, 15/01/2001; UNT 2642 (1, 47,9)

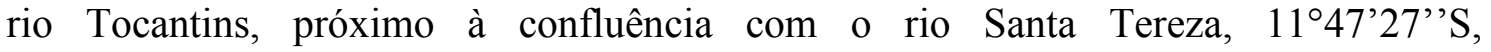
48³7'02'’W, NEAMB-UFT, 14/05/2000; UNT 2645 (2, 39,2 - 40,7) rio Paranã, fazenda Traçadal, Paranã, 12³0'00'’S, 48¹2'00' 'W, NEAMB-UFT, 11/07/2000; UNT $2646(1,26,7)$ rio Tocantins, próximo à confluência com o rio Tranqueira, Tupirama, 0845'00'’S, 48 08'00'’W, NEAMB-UFT, 17/01/2005; UNT 2677 (1, 80,0) rio Tocantins, fazenda Traçadal, Paranã, 12²9'00's, 48¹2'00'’W, NEAMB-UFT, 27/03/1998; UNT 2678 (1, 99,7) rio Paranã, fazenda Tarçadal, Paranã, 12 30’00’’S, 4812'00'’W, NEAMB-UFT, 27/03/1998; UNT $2683(1,114,2)$ rio Tocantins, fazenda Traçadal, Paranã, 12²9'00'’S, 48¹2’00’’W, NEAMB-UFT, 10/05/2000; UNT 2686 $(1,100,7)$ rio Areias, próximo à confluência com o rio Tocantins, Porto Nacional, 1051'00'’S, 48²4'00'’W, NEAMB, 09/09/1999; UNT 2687 (1, 96,8) rio Tocantins, fazenda Traçadal, Paranã, $12^{\circ} 29^{\prime} 00^{\prime}$ 'S, 48 ${ }^{\circ} 12^{\prime} 00^{\prime}$ 'W, NEAMB-UFT, 10/05/2000; UNT $2688(1,93,9)$ rio Tocantins, lago abaixo UHE Lajeado, Lajeado, 0945'02'’S, 48²1'56' 'W, NEAMB-UFT, 29/05/1999; UNT 2689 (1, 88,3) rio Maranhão, fazenda Traçadal, Paranã, 12²9'00' 'S, 48¹3'00'’W, NEAMB-UFT, 08/05/2001; UNT 2691(3, 45,9 - 85,3) rio Paranã, fazenda Traçadal, Paranã, 12 30'00'’S, 48 $12^{\prime} 00^{\prime}$ 'W, NEAMB-UFT, 04/07/2001; UNT 2697 (3, 42,7 - 79,7) rio Tocantins, próximo à

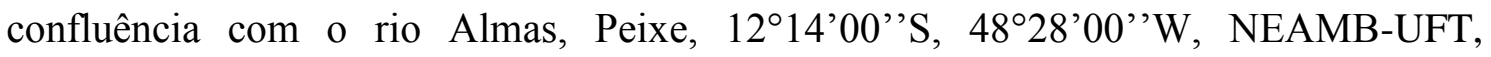
11/07/2000; UNT $2698(1,57,1)$ rio Tocantins, próximo à confluência com o rio

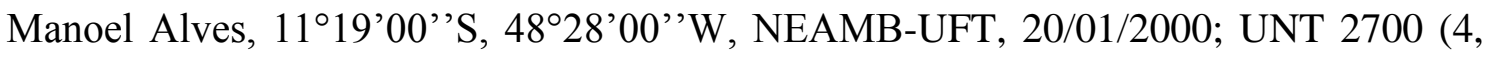


48,0 - 54,5) rio Tocantins abaixo da UHE de Lajeado, Lajeado, 0945'02'’S, 48²1'56' 'W, NEAMB-UFT, 28/02/2000; UNT 2701 (2, 70,0 - 73,6) rio Tocantins, praia Porto Real, Porto Nacional, 1042'11'’S, 48²4'30'’W, NEAMB-UFT, 05/02/1996; UNT 2704 (1, 68,2) rio Paranã, fazenda Traçadal, Paranã, 12³0’00’’S, 48¹2'00'’W, NEAMB-UFT, 06/06/2001; UNT $2705(1,80,8)$ rio Areias, próximo à confluência com o rio Tocantins, Porto Nacional, 1051'00'’S, 48²4'00'’W, NEAMB, 10/09/1999; UNT 2707 (3, 39,1 - 50,9) rio Tocantins, fazenda Traçadal, Paranã, 12²9'00'’S, 48 12'00'’W, NEAMB-UFT, 10/09/1999; UNT 2712 (1, 52,8) rio

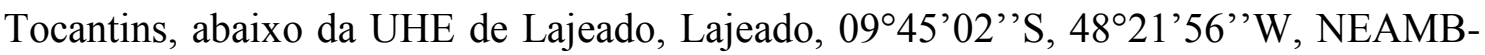
UFT, 25/08/2000; UNT 2714 (1, 73,1) rio Tocantins, fazenda Traçadal, Paranã, 12²9'00'S , 48 12'00'’W, NEAMB-UFT, 05/06/2001; UNT 3276 (1, 108,8) escada de peixe da UHE Lajeado, Lajeado, 0945'00''S, 48²1'00'’W, NEAMB-UFT, 10/12/2004; UNT $3688(1,81,6)$ rio Tocantins, UHE Peixe Angical, Peixe, $12^{\circ} 15^{\prime} 00^{\prime}$ 'S, $48^{\circ} 23^{\prime} 00^{\prime \prime} \mathrm{W}$, Soares, A. B. et al, 24/05/2005; UNT 4523 (5, 26,8 - 49,1) rio Tocanitns, Porto Nacional, 1043'15' 'S, 48²5'14' 'W, NEAMB-UFT, 13/05/2003; UNT $4619(1,52,9)$ rio Tocantins, fazenda Traçadal, Paranã, 12²9'00’'S, 48 $12^{\prime} 00^{\prime}$ 'W, NEAMB-UFT, 10/05/2000; UNT 5954 (28, 22,4 - 36,3) rio Tocantins, a

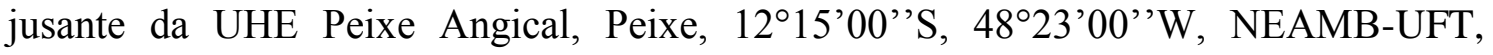
12/01/2005; UNT 5992 (1, 33,2) rio Tocantins, Porto Nacional, 1043'15'’S, 48²5'14'’W, NEAMB-UFT, 10/05/2004; UNT 6471 (2, 60,8 - 63,0) rio Tocantins, fazenda Traçadal, Paranã, 12²9'00' 'S, 48¹2'00' 'W, NEAMB-UFT, 08/02/2000; UNT $6472(1,91,8)$ rio Maranhão, fazenda Traçadal, Paranã, 12²9'00'’S, 48 13'00'’W, NEAMB-UFT, 15/10/1999; UNT 6478 (1, 74,3) rio Tocantins, fazenda Traçadal, Paranã, 12²9'00'’S, 48¹2'00'’W, NEAMB-UFT, 25/05/1999; UNT 6480 (1, 102,0)

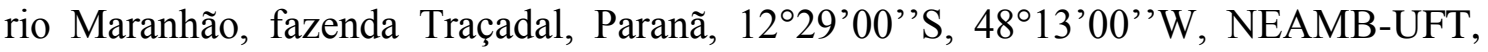
02/12/2001; UNT 6481 (1, 89,7) rio Maranhão, fazenda Traçadal, Paranã, 12²9’00’, 48¹3'00'’W, NEAMB-UFT, 15/10/1999; UNT 6483 (3, 73,6 - 85,1) rio Maranhão, fazenda Traçadal, Paranã, 12²9'00'’S, 48¹3'00'’W, NEAMB-UFT, 02/03/2000; UNT6487 $(1,55,4)$ rio Tocantins, fazenda Traçadal, Paranã, 12²9'00'’ S, 48 12 '00' 'W, NEAMB-UFT, 12/01/2000; UNT 6488 (1, 64,3) rio Tocantins, fazenda Traçadal, Paranã, 12²9'00'’S, 48¹2'00'’W, NEAMB-UFT, 22/06/1999; UNT 6490 (1, 44,2) rio

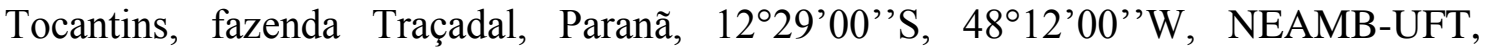
12/01/2000; UNT $6492(1,57,6)$ rio Tocantins, fazenda Traçadal, Paranã, 12²9'00’’S, 48¹2’00’’W, NEAMB-UFT, 27/07/1999 UNT 6494 (1, 87,6) rio Maranhão, fazenda Traçadal, Paranã, 12²9'00’'S, 48¹3'00’’W, NEAMB-UFT, 27/03/1999; UNT 6503 $(1,72,1)$ rio Maranhão, fazenda Traçadal, Paranã, 12²9'00'’S, 48¹3'00'’ W, NEAMB- 
UFT, 25/08/1999; UNT 6508 (1, 49,9) rio Maranhão, fazenda Traçadal, Paranã, 12²9'00'’S, 48 13'00'’W, NEAMB-UFT, 23/06/1999; UNT 6510 (1, 44,9) rio Tocantins, fazenda Traçadal, Paranã, 12²9'00'’S, 48¹2'00'’'W, NEAMB-UFT, 12/01/2000; UNT6511 $(1,23,5)$ rio Tocantins, fazenda Traçadal, Paranã, 12²9’00' 'S, 48 12'00' 'W, NEAMB-UFT, 12/01/2000; UNT 9060 (5, 105,1 - 151,4) rio Ponte Alta,

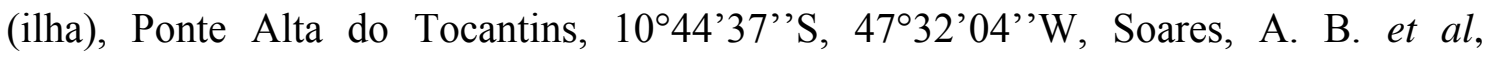
22/12/2008; UNT 9734 (55, 77,2 - 123,9) rio Maranhão, no local da futura UHE São Salvador, São Salvador, $12^{\circ} 48^{\prime} 55^{\prime}$ 'S, $48^{\circ} 14^{\prime} 45^{\prime}$ 'W, rede de espera, Soares, A. B. et al, 18/06/2008; UNT $9965(8,89,3$ - 104, 3) rio Tocantins, na draga próximo à chácara das freiras, Porto Nacional, 1043'00'’S, 48²4'00'’W, Assis, N. C., 10/02/2009; UNT 11343 (1, 152,2) lago da UHE Lajeado, na ilhota próxima à represa, Lajeado, 0946'15'’S, 48²2'09',W, Assis, N. C., 15/09/2008; UNT 12311 (1, 115,1) rio Sobrado, Aurora do Tocantins, de Paula, M. J., 13/07/2012; UNT 12503 (1, 64,7) rio Tocantins, abaixo da confluência com o rio Santa Tereza, Peixe, 11 ${ }^{\circ} 46^{\prime} 49^{\prime}$ 'S, 48³7'06'’'W, NEAMB, 04/08/2010; UNT 12526 (3, 60,8 - 84,6) rio Tocantins, na

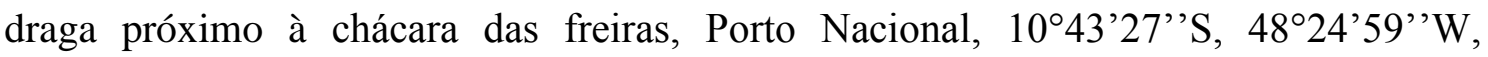
NEAMB, 15/07/2010; UNT $12544(2,57,2$ - 65,2) rio Tocantins, na draga próximo à chácara da freiras, Porto Nacional, 1043'27' 'S, 48 24'59' 'W, NEAMB, 12/08/2010; UNT $12555(1,87,6)$ rio Santa Tereza, cabeceira, Jaú do Tocantins, 1245'06’'S, 48 49'45' 'W, NEAMB, 09/08/2011; UNT $12572(1,106,6)$ rio Santa Tereza, cabeceira, Jaú do Tocantins, $12^{\circ} 45^{\prime} 06^{\prime}$ 'S 4849'45'’W, NEAMB, 04/12/2010.

Colômbia:

Meta:

ANSP 128277 (2, 100,8 - 102,2) rio Metica, ca 1,5 km E of Rajote (plancha 267), 0356'00'’N, 7303'00'’W, Saul, W. G. \& W. F. Smith-Vaniz, 19/03/1973; ANSP 131550 (2, 120,7 - 139,1) rio Metica, ca $3 \mathrm{~km}$ SE of Hacienda Mozambique, $03^{\circ} 57^{\prime} 00^{\prime}$ 'N, $73^{\circ} 02^{\prime} 00^{\prime \prime} \mathrm{W}$, Bohlke et al, 24/03/1975.

Peru:

Cuzco:

MUSM 25807 (1, 138,8) rio Camisea, bajo Urubamba, La Convención,

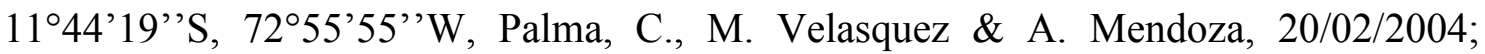
MUSM $32516(1,145,5)$ rio Picha, subcuenca rio Picha, Echarate, La Convención, $11^{\circ} 35^{\prime} 15^{\prime}$ 'S, $73^{\circ} 07^{\prime} 24^{\prime}$ 'W, DAIMI, 12/03/2008.

Huánuco: 
MZUSP $110473(1,148,2)$ rio (ou quebrada) Oro, afluente do rio Huallaga, lado direito, a montante da confluência do rio Mozón, Tingo Maria, 09¹9'22’'S, 7601'56'’W, Teixera, T. F. \& L. Chocano, 31/08/2011.

Loreto:

MZUSP 15259 (1, 52,7) rio Amazonas, isla Parlamento, Iquitos, 0344’35's, 73¹5'08' 'W, M. Villacorta C., 10/06/1980; MUSM 494 (1, 128,3) rio Napo, Iquitos, 034'48' 'S, 73¹5'07',W, Ortega, H., 25/09/1982; MUSM 6100 (1, 99,8) rio Amazonas, boca rio Napo, Ramón Castilla, 0328'37' 'S, 72 43 '42' 'W, Ortega, H. et al, 25/09/1982; MUSM 6815 (1, 112,7) rio Amazonas, ressaca Poca Playa, Ramón Castilla, 0326’57'’S, 7105'32'’W, Ortega, H., 27/09/1982; MUSM 7255 (1, 85,0) rio Pastaza, laguna Himachi, Alto Amazonas, 0449'44'’S, 76²6'01'”W, Chang, F., 14/05/1995; MUSM $15144(2,106,0$ - 122,3) rio Chambira, San Juan, 0340'59' 'S, 7346'52' 'W, Chang, F., 17/05/1987; MUSM 18186 (3, 96,9 - 112,3) rio Marañón, San Pablo de Tipishca, 04³3'19',S, 7442'10',W, Ortega, H, 05/04/2001; MUSM 18611 (1, 76,3) rio Marañón, Tigre, $04^{\circ} 29^{\prime} 29^{\prime}$ 'S, $7^{\circ} 02^{\prime} 08^{\prime}$ 'W, Ortega, H. \& E. Castro, 09/03/2001; MUSM $20602(15,32,1$ - 58,0) rio Taorana, águas abajo desmbocadura, qda. Anajo, 0319'22'’S, 77³5'08',W, Hidalgo, M., 15/05/2002; MUSM 30417 (2, 75,6 - 79,3) rio Huallaga, boca del Paranapura, Yurimaguas, Alto Amazonas,05'53'41' S, 7606’33'’W, Samanez, I. 25/04/1995; MUSM 35843 (1, 111,3) Pisqui,CCNN Charasmanã, qda. Muruinuia, Ucayali, 7³3'58'’S, 75¹4'34'’W, Olivera, 29/06/2009; MUSM $38270(1,176,9)$ rio Corrientes ACHb18E-7, Loreto, 02 45 '56' 'S, 7556'37', Quispe, R., 13/11/2008; MUSM 40512 (2, 46,4 - 93,1) río Marañón, águas abajo de la CCNN Roca Fuerte, Parinari, Loreto, 04³4'59'’S, 74²8'49'’W, Rojas, M., 30/05/2011; MUSM 40532 (2, 105,6 - 127,1) rio Marañón, águas abajo de CCNN Santa Rita de Castilla, Parinari, Loreto, 04³6'23'’S, 74²2’30'’W, Rojas, M. 30/05/2011.

Madre de Dios:

MUSM $22189(1,134,1)$ rio Purus, rio Acre, Tahuamanu,1056'40'’S, 69³4'22’’W, Ortega, H. et al, 13/08/2003.

Pasco:

MUSM $30444(1,158,0)$ rio Pichis, boca qda. Chivis, Pto. Bermudez, Oxapampa, $10^{\circ} 18^{\prime} 20^{\prime}$ 'S, 745' $50^{\prime \prime} \mathrm{W}$, Orihuela, D., 23/11/2006.

Ucayali:

MZUSP 25948 (4, 90,9 - 125,5) rio Ucayali, Masisea, 08³6'29'’S, 74¹8'18' 'W, Ortega, H., 31/05/1973; MZUSP 26160 (2, 98,8 - 115,0) rio Ucayali, Bagazan, 08²3'45',S, 74³4'58',W, Ortega, H., 29/05/1979; MZUSP 26223 (1, 128,0) rio Ucayali, Shanahan, 08¹4'08'’S, 74³2'08' 'W, Ortega, H., 24/06/1976; MUSM 127 (2, 
124,0 - 133,2) rio Ucayali, Pucallpa, 08²3'46'’S, 74³4'58'’W, Ortega, H.,14/06/1982; MUSM 849 (4, 120,9 - 131,4) rio Ucayali, Bahuanisho, Pucallpa, 08²3'38'’S, 74³4'57'’W, Ortega, H., 20/04/1983; MUSM 10436 (2, 61,5 - 69,6) rio Purus, San Marcos, Purus, 0950'00'’S, 7055'00'’W, Chang, F. \& P. de Rham, 09/09/1994; MUSM $13051(1,75,6)$ rio Sepahua, Sepahua, Atalaya, 1105’20’’S, 7300'14'’W, Ortega, H. et al, 04/06/1998; MUSM 15207 (2, 73,1 - 87,6) rio Ucayali, Independencia a $1 \mathrm{~h}$ rio arriba de Pucallpa, Coronel Portillo, 08 23'46' 'S, 74³4'56' 'W, Ortega, H., 19/01/1983; MUSM 27332 (4, 85,8 - 91,2) rio Mishchua, rio Urubamba, Atalaya, Ortega, H. et al, 17/02/2006; MUSM 27693 (1, 127,2) rio Breu,

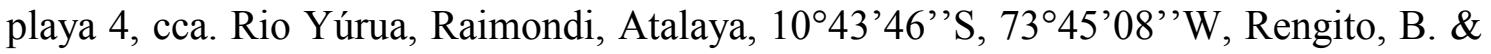
V. Chipollini, 24/03/2006; MUSM 28353 (1, 128,20) rio Santa Ana PC 84, Parque Nacional Cordillera Azul, cuenca rio Aguayatia, 08 $199^{\prime} 37^{\prime} ' \mathrm{~S}, \quad 75^{\circ} 23^{\prime} 09^{\prime}$ 'W, Hidalgo,M. \& m. Rajas, 05/12/2006; MUSM 39472 (1, 72,7) playa em El rio Purus, al lado contrario del rio Curanja, Esperanza, Purus, 09³4'21'’S, 70³3'23' 'W, Alberts, J et al, 26/07/2010; MUSM 42561 (1, 108,4) río Ucayali, margem derecha, Caco Macaya, Iparía, Coronel Portillo, 09²2'57' 'S, 74¹3'30' 'W, Correa, U., 22/09/2011; USNM $229063(1,58,2)$ temporary embayment of ilha da Marchantaria, Manaus, $03^{\circ} 07^{\prime} 10^{\prime}$ 'S, 6001'18'’W, Bayley, P., 02/03/1977; USNM $280515(1,125,4)$ rio Ucayali, main channel and side pools, approximately $10 \mathrm{~km}$ upstream Pucallpa, 08 $31^{\prime} 00 \mathrm{~S}$, $74^{\circ} 22^{\prime} 00^{\prime} ’ \mathrm{~W}$, Vari, R. P. et al, 26/08/1986.

Venezuela:

\section{Amazonas:}

ANSP159742 $(1,109,1)$ rio Orinoco, at El Burro, 06 ${ }^{\circ} 12^{\prime} 00^{\prime}{ }^{\prime} \mathrm{N}, 67^{\circ} 26^{\prime} 00^{\prime \prime} \mathrm{W}$, Aguana, L., 26/11/1985; ANSP 159743 (1, 137,3) rio Meta, ca. 20 min upstream from confluence with rio Orinoco, $06^{\circ} 15^{\prime} 00^{\prime}$ 'N, 67'37'00' W, Chernoff, B., W. Saul \& R. Royero, 27/11/1985.

\section{Apure:}

ANSP $165269(1,79,0)$ rio Matiyure, at Achaguas, 0745'00'’ $\mathrm{N}, 68^{\circ} 11^{\prime} 00^{\prime \prime} \mathrm{W}$, Schaefer, W. G. Saul, F. Provenzano \& O. Castillo, 05/11/1089; ANSP 192043 (2, 49,9 - 66,3) rio Apure, Just north San Fernando de Apure, sand/Clay beach along south bay, below route 2 bridge, $07^{\circ} 53^{\prime} 56^{\prime}$ 'N, 67²8’23W, Sabaj-Pérez, M. H., N. K. Lujan, D. C. Werneke, T. P. Carvalho \& S. V. Meza, 21/03/2010; MCNG 1459 (1, 107,9) hato El Frio, prestamo al lado del dique (donde havia un puente), $07^{\circ} 45^{\prime} 00^{\prime}{ }^{\prime} \mathrm{N}, 67^{\circ} 55^{\prime} 00^{\prime}$ ' $\mathrm{W}$; MCNG 43833 (3, 85,6 - 105,7) caño Guaritico entre los fundos Corneli Herrera y Las

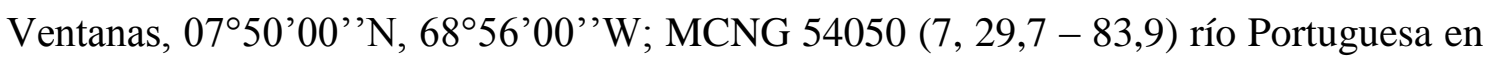
zona inundada, $08^{\circ} 51^{\prime} 35^{\prime}{ }^{\prime} \mathrm{N}, 68^{\circ} 37^{\prime} 18^{\prime}{ }^{\prime} \mathrm{W}$. 
Barinas:

MCNG $49082(1,102,3)$ caño Bravo 0800’00’’N, 6759’00’’W.

Bolivar:

ANSP $159741(1,103,5)$ rio Orinoco, rio Caura confluence, beaches, canals, laggons and islands, vicinity of Puerto Majadas, $07^{\circ} 38^{\prime} 36^{\prime}{ }^{\prime} \mathrm{N}, 64^{\circ} 50^{\prime} 00^{\prime \prime} \mathrm{W}$, Chernoff, B., L. Aguana \& J. Lundberg, 23/11/1985; ANSP 159744 (1, 93,7) cano (possibly cano Curima) feeding Caura near confluence of rio Caura, 07³7'48' $\mathrm{N}, 64^{\circ} 50^{\prime} 42^{\prime}$ ' $\mathrm{W}$, Chernoff, B., W. Saul \& R. Royero, 22/11/1985; ANSP 159745 (1, 107,3) rio Orinoco, lagoon and channel near mouth rio Caura, $07^{\circ} 38^{\prime} 42^{\prime}$ 'N, $64^{\circ} 52^{\prime} 48^{\prime}$ 'W, Chernoff, B., W. Saul , J. Lundberg \& R. Royero, 22/11/1985; MCNG 19236 (2, 73,3 - 97,8) puente Del río Oropiche, $08^{\circ} 03^{\prime} 00^{\prime}{ }^{\prime} \mathrm{N}, 63^{\circ} 40^{\prime} 00^{\prime \prime} \mathrm{W}$.

Cojedes:

MCNG 24216 (2, 91,3 - 120,1) caño Igues, via Arismendi, al sur de El Baul, $08^{\circ} 57^{\prime} 38^{\prime \prime} \mathrm{N}, 68^{\circ} 18^{\prime} 05^{\prime \prime} \mathrm{W}$.

Guarico:

MZUSP $27982(4,101,4$ - 123,1) rio Orituco, alt. da rodovia para Calabozo, 0852'00' 'N, 67¹8'00' 'W, Machado, A. et al, 27/01/1983; USNM 258535 (10, 87,0 151,3 ) rio Orituco, where crossed by road from Calabozo, $08^{\circ} 52^{\prime} 00^{\prime}{ }^{\prime} \mathrm{N}, 67^{\circ} 18^{\prime} 00^{\prime}$ 'W, Machado, A. et al, 27/01/1983.

Monaguas:

USNM $233699(1,72,0)$ caño El Jobal, upstream of caño Guarguapo and Barrancas, 08³8'38'’N, 62¹4’08'’W, Baskin, J., 11/11/1979.

\section{Galeocharax goeldii}

Bolívia:

Beni:

USNM 301901 (1, 190,0) E. B. B. Capamento Trapiche a 400m abajo del puente,

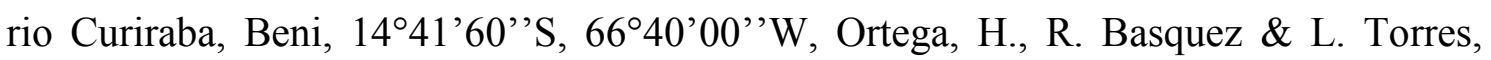
26/07/1988; USNM 305364(1, 173,9) rio Matos, below Road crossing 48 km San Borja, 14 $55^{\prime} 00^{\prime}$ 'S, 66 $17^{\circ} 00^{\prime \prime}$ W, Starnes, W. C., T. Munroe, J. Sarmiento, E. Forno \& M. Brun, 28/08/1987; USNM $305367(10,97,1$ - 213,3) rio Curiraba at $10 \mathrm{~km} \mathrm{NE}$ el pervenir, Biol. Sta., at 40 air km NE San Borja , Ballivia, Beni,1445'00'’S, $66^{\circ} 17^{\prime} 00^{\prime \prime}$ W, Starnes, W. C., T, Munroe, J. Sarmiento et al, 31/08/1987.

\section{La Paz:}

MZUSP 35951(1, 144,6) rio de La Paz, afluente do rio Beni, San Miguel de Huachi, 1546'26'’S, 67¹4'07'’W, Conv. Pscic. ORSTOM-UTB, 20/07/1982. 
Brasil:

Amazonas:

INPA 24598 (1, 109,7) Paraná do Uruá, comunidade Itapinima, Itapinima, 5²4'08'S, 6043'14'’W, Rapp Py-Daniel, L., O. M. Ribeiro \& L.M. Sousa, 22/09/2004.

Rondônia:

MZUSP 92432 (5, 20,3 - 38,6) igarapé Simão Grande, alto rio Madeira 09³2'36'’S, 65¹3'04'’W, Vilara, G. T., 12/10/2004; MZUSP 92433 (8, 19,5 - 48,2) salto Jirau , rio Madeira, 09¹9'43'’S, 6443'46'”W, Vilara, G. T., 19/10/2004; MZUSP 92434 (1, 108,0) igarapé Jatuarana, alto rio Madeira, Porto Velho, 08³8'15' 'S, 6354'31'’W, Vilara, G. T., 10/2004; MZUSP92435 (4, 28,9 - 94,6) igarapé Belmont, alto rio Madeira, 08³8'27' 'S, 6350'58'’W, Vilara, G. T., 04/2004; MZUSP92436 (24, 26,1 - 89,7) igarapé Kapiruna, alto rio Madeira, 09¹5'10'’S, 6438'31' 'W, Vilara, G. T., 10/2004; UFRO-I 722 (1, 33,5) igarapé Arara, próximo à base da ponte do Arara, Porto Velho, rede de cerco, vegetação flutuante, 1000'50'’S, 65¹9'05'’W, Röpke, C., 17/11/2008; UFRO-I 2246 (1, 54,5) foz do igarapé Kapiruna, Jaciparaná, 09¹1'33'’S, 643' 14 '’ W, rede de cerco, remanso, Barros, B., 06/04/2009; UFRO-I $2566(1,50,8)$ foz do igarapé Jatuarana, rio Madeira, Porto Velho, $08^{\circ} 49^{\prime} 49^{\prime}$ 'S, $64^{\circ} 02^{\prime} 40^{\prime \prime} \mathrm{W}$, rede de cerco, remanso, Fernandes, T., 08/05/2009; UFRO-I 5468 (2, 1 Di\&Co, 77,9 - 81,2) rio Abunã, pedral margem direita, Abunã 09 $41^{\prime} 22^{\prime}$ 'S, 65'26'31' 'W, tarrafa, calha canal lento, Silva, T., 12/01/2012; UFRO-I 6846 (1, 123,2) igarapé Jatuarana, Porto Velho, 08 $49^{\prime} 55^{\prime}$ 'S, 6402'55'’ W, malhadeira, igarapé, Eq. LIP/UNIR, 27/11/2011; UFRO-I $6854(1,121,2)$ igarapé Jatuarana I, afluente da margem esquerda do rio Madeira, Porto Velho, 08 $46^{\prime} 25^{\prime}$ 'S, $64^{\circ} 02^{\prime} 49^{\prime \prime} \mathrm{W}$, malhadeira, lago, Hungria, D., 21/03/2012; UFRO-I 9668 (1, 160,8) cachoeira de Jirau, rio Madeira, Porto Velho, 09¹8'40'’S, 64ㄴㄹ' $57^{\prime}$ 'W, malhadeira, corredeira, Eq Naturae, 07/2010; UFRO-I 9705 (1, 120,8)

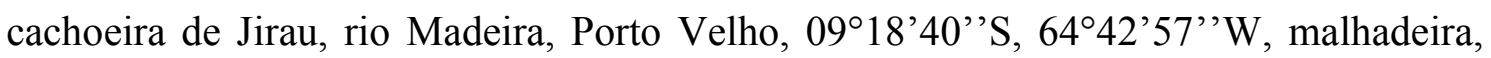
corredeira, Eq Naturae, 08/2010; UFRO-I 12941 (1, 17,3) foz do igarapé Belmont, praia do Tamanduá, Porto Velho, 08³8'38',S, 6350'48' 'W, rede de cerco, praia, Fernandes, F, 27/11/2011; UFRO-I 13077 (2, 96,9 - 147,5) rio Madeira, Porto Velho, 0848'30' 'S, 6336'53' 'W, malhadeira, canal/calha/leito, Eq. Naturae, 01/09/2010; UFRO-I 13090 (2, 101,6 - 105,7) rio Madeira, Porto Velho, 08 48'30'’S, 6336'53' 'W, malhadeira, canal/leito/calha, Eq. Naturae, 01/09/2010; UFRO-I 14233 (2, 150,3 - 153,0) ilha do Búfalo, rio Madeira, Porto Velho, $09^{\circ} 09^{\prime} 55^{\prime}$ 'S, 6423'46’'W, malhadeira, Hungria, D., 15/06/2012; UFRO-I 15986 (1, 59,3) igarapé Jatuarana, rio Madeira, Porto Velho, 08'38'23' 'S, 63 $54^{\prime} 07^{\prime}$ 'W, rede de cerco, praia, Melo, L. C. R., 04/10/2012; UFRO-I 
16104 (1, 32,3) foz do igarapé Belmont, rio Madeira, Porto Velho, 08³8'20’'S, 6350'24'’W, tarrafa, remanso, Matsuzaki, A., 05/10/2012; UFRO-I 17970 (2, 132,5 144,9) foz do rio Kapiruna, rio Madeira, Porto Velho, 09¹1'32's, 64³7’20' W, malhadeira, igarapé, Leiva, M., 11/09/2012; UFRO-I 19051 (1, 120,1) rio Madeira, a jusante da UHE de Santo Antonio, Porto Velho, 08 46'52'’s, 63 55'41' 'W, manual, calha/canal/leito, Fernandes, T, 13/09/2012; UFRO-I 19368 (1, 85,2) rio Madeira, margem esquerda, Porto Velho, 08 $47^{\prime} 08^{\prime}$ 'S, 63 ${ }^{\circ} 56^{\prime} 07^{\prime}$ 'W, malhadeira, corredeira, Santos, M. 28/09/2012; UFRO-I 20611 (1, 67,9) em frente ao igarapé Jatuarana II, Porto Velho, 08³8'19'’S, 6353'17' 'W, rede de cerco, praia, Soares, B. 28/11/2012; UFRO-I 20612 (1, 68,7) montante do igarapé Belmont, Porto Velho, 0851'42’’S, 6403'43' 'W, rede de cerco, lago, Silva, T., 27/11/2011; UFRO-I 20613 (2, 32,3 - 49,6) rio Sotério, na foz do rio Negro/ Sotério, Guajará-Mirim, $11^{\circ} 35^{\prime} 52$ ' $S, 65^{\circ} 13^{\prime} 48^{\prime}$ 'W, rede de cerco, vegetação, Barros, B., 12/01/2012; UFRO-I $20631(1,39,4)$ foz do rio Jací-Paraná, rio Madeira, Porto Velho, 09¹2'10'’S, 64²4’03'’ W, rede de cerco, praia, Eq. LIP/UNIR, 05/10/2009; UFRO-I 20632 (3, 21,4 - 29,5) foz do igarapé Belmont, 08³8'33'’S, 6350'58'’W; UFRO-I 20633 (2, 20,5 - 31,8) igarapé Arara, próximo à foz, Nova Mamoré, 1000'51' 'S, 6519'09' 'W, rede de cerco, igarapé, Eq. LIP/UNIR, 02/10/2009; UFRO-I 20634 (3, 22,8 - 29,9) rio Sotério, afluente do rio Mamoré,

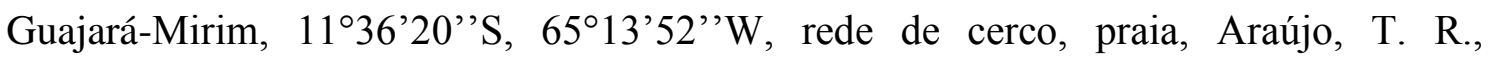
13/01/2011; UFRO-I 20635 (2, 23,1 - 24,3) foz do igarapé Jatuarana, rio Madeira, Porto Velho, $08^{\circ} 50^{\prime} 07^{\prime}$ 'S, 6402'31' W, rede de cerco, praia, Ayalla, D. M., 06/10/2009; UFRO-I 20636 (2, 81,3 - 83,6) cachoeira do Paredão, rio Madeira, 09'34'34'’S, 65'10’33'’W, tarrafa, Barros, B. S. F., 22/10/2012; UFRO-I 20639 (1, 90,9) foz do rio Karipuna, rio Madeira, Jaci-Paraná, 09¹1'34' 'S, 64³7'17' 'W, rede de cerco, Pires, T. H. S., 06/07/2009; INPA 20916 (1,151,8) rio Mamoré, a jusante de

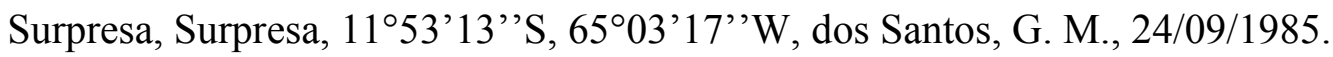

Peru:

Madre de Dios:

ANSP143577 (2, 98,3 - 114,5) alto Madre de Dios, 15km upstream from Boca Manu, 12¹9'30'’S, 7058'00’’W, Horwitz, R., 04/08/1977; MUSM 131(1, 106,9) rio Tambopata, Tambopata, 1323'49'’S, 69³0'02'’W, Ortega, H., 30/10/1982; MUSM 4931 (1, 109,4) rio Manu, Q.M. Pescador, Palcitza, Manu, 12¹7'58'’S, 7045'44'’W, Ortega, H., 30/06/1993; MUSM 7578 (1, 103,3) rio Madre de Dios, cerca boca Valencia, Tambopata, $12^{\circ} 28^{\prime} 18^{\prime}$ 'S, 68 $48^{\prime} 36^{\prime \prime} \mathrm{W}$, Chang, F. et al, 27/07/1995; MUSM 8154 (1, 105,8) rio Heath, SNPH, Refugio Juliaca, Tambopata, 1246'07' 'S, 6848’21'’W, Ortega, H., 04/06/1992; MUSM 8155 (1, 104,7) rio Heath, S. N. P. H., 
Tambopata, Ortega, H., 06/06/1992; MUSM 8790 (1, 143,4) rio Tambopata, a 20' rio abajo Malinowski, Tambopata, 1252'47'’S, 69³0'26'’W, Chang, F., 19/11/1995; MUSM 8883 (1, 139,3) rio Tambopata, Z.R.T.C., Baltimore, Qda. Gato, Tambopata, 12²0'21'’S, 6909'41'’W, Chang, F., 10/08/1995; MUSM $9180(1,115,5)$ rio Madre

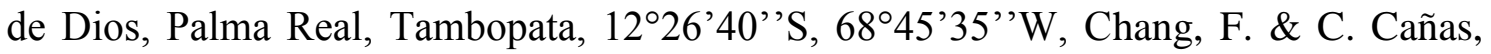
28/04/1996; MUSM 9228 (1, 132,1) rio Tambopata, Qda. La Torre, Z. R. T. C., Tambopata, 1247'10''S, 69¹6'49',W, Chang, F. \& C.Cañas, 24/09/1996; MUSM $9564(1,125,4)$ rio Las Pedras, Panguanayo,Tambopata, 12²9'17'’S, 69¹5'02'’ W, Chang, F. \& C. Cañas 13/05/1996; MUSM 19413 (1, 115,0), rio Los Amigos, playa rio abajo 100m puerto C. R. A.,Tambopata, 12³2'50'’S, 7005'34'’W, Goulding, M, R. Barthew \& C. Cañas, 23/08/2001; MUSM 36890 (1, 106,7) rio Las Piedras, playa

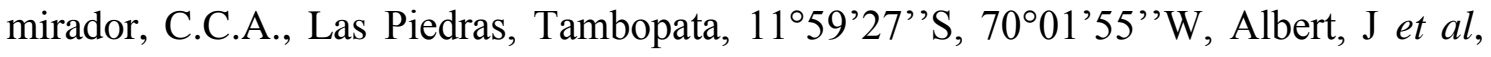
01/06/2011; MUSM 36918 (2, 105,6 - 133,0) rio Las Piedras, cachuela Trigoso, Tambopata, 1204'10',S, 6953'37' 'W, Albert, J. et al, 02/06/2011; MUSM 36958 (1, 98,7) rio Las Pedras, pequeño brazo a $1 \mathrm{~km}$ upstream cachuela Trigoso, $252 \mathrm{msnm}$, $12^{\circ} 04$ '21' 'S, 6954'20'’W, Albert, J. et al, 03/06/2011.

Material comparativo:

Cynopotamus xinguano MZUSP 94196, 97,9 mm CP, 1 di \& co Acentrocephalus stigmatus MZUSP 94216, 85,0mm CP, 1 di \& co. 